
$163 \%$

The Property of $C a, !$

W. G. FARLOW. 




\section{F V N G I \\ MECKLENBVRGENSES \\ SELECTI.}

\section{AVCTORE \\ HENRICO IVLIO TODE}

SYNODI WITTENBVRGENSIS PRAEPOSITO ET V. D. APYD

PIITZIERENSES MINISTRO. SOCIET. BEROL. AMIC.

NAT. CYR. NEC NON NAT. CVR. HALENS. SOD.

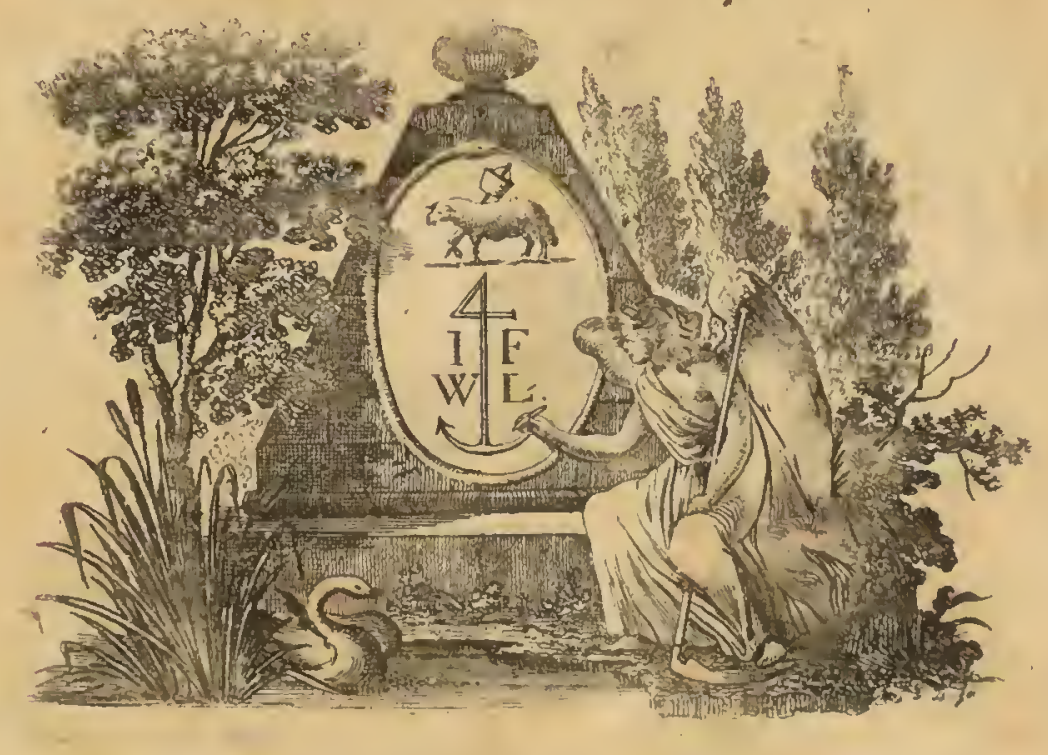

FASCICVLVS 1 .

NOVA FVNGORVM GENERA-COMPLECTENS.

TABVLIS VII. AENEIS ADIECTIS.

LVNEBVRGI $I 790$.

APVD IOH. FRIED. GVIL. LEMKE. 


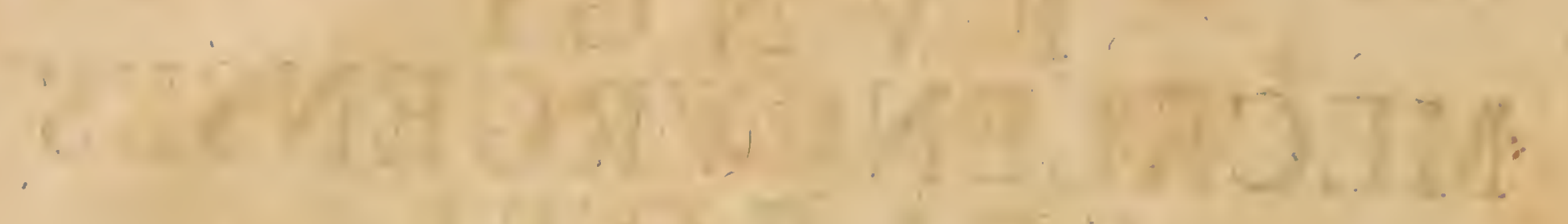

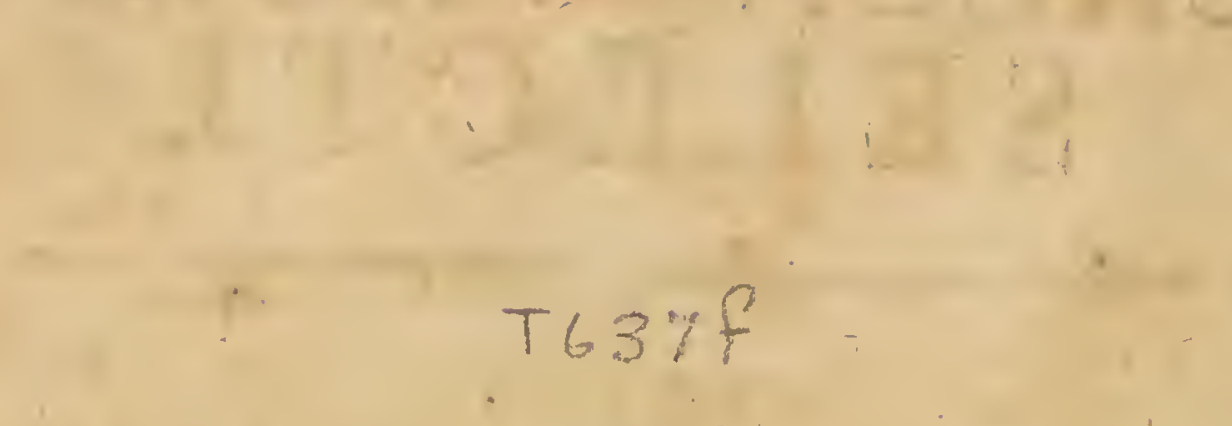




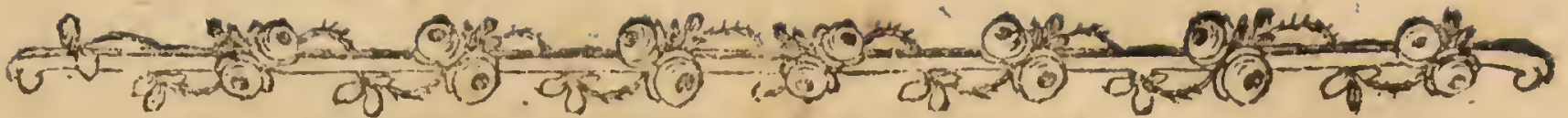

\section{$I_{\text {in }}$ Wald und Feld, auf Bergen und in Gründe}

Dich, unausfprechlich Mächtiger,

Unendlich Guter, Herrlicher,

Gott, aller Welten Gott, dich fuchen, und dich fraden.

Selbit da, noch da, dich finden, wie du bift

Und wie du wirkeft, du, defs Name heilig if,

Wohin dem eklen Stolz den Blick zu richten grauek,

Wohin fo gar der Geiz nicht fchauet,

Welch eine Seligkeit!.

O Luft, durch kein Gewiffensnagen,

Kein Ungeftüm in Herzen und im Magen,

Nicht durch Transfcendentalitäten

Und keinen Qualm der Interpreten

Geftumpft, verbittert und entweiht!

Der wunderfame Menfch blickt . cinmal; mufs,

Gedrungen durch des Schickfals Schlufy,

Nun einmal um fich blicken, um an Dingen

Vor ihm verbreitet, Wonne fich

Und feinem Geift ftets grürsre Schwingen

In ihrem Auffchlufs zu erringen.

Doch, armer Erdbewohner, fprich,

Wohin foll, zum voraus verfichert rom Gewinn

Das Auge deiner Seele dringen? 


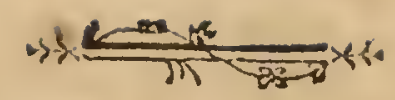

Die Welt, des Filęnds Vaterland,

Der Schauplaz aller Nichtigkeiten,

Verrïckungen und Albernheiten,

If gar $z u$ arm für unfern Frieden;

'Zu arm, des Schauens Müh uns triftig zu belohnen.

Sieh, wie ihr grofses Narrenfent

$\mathrm{Zu}$ jeder Zeit, in allen Zonen,

Ihr ftetes Werhfeln von Grimafien und Altären,

lhr Ateter Drang hin zu - ja, zu Montgolfieren!

Den Mann von feinerm Sinn und richtigerm Verftand

Nur felten lächeln macht; viel öfter ihn hienicden

Bald gähnen und bald feufzen läfst.

Heil, Heil dem Mann, den nichts fo fehr vergaligt, Als überall nach Gott zu fragen,

Um ihn den Wurm, den Halm, den Schimmel zu befragen!

Denn fonder Antwort werden fie

Fürwahr ihn nie entlaffen; aber wie,

$O$, wie wird folche ftets fein Herz durchigliihn! wie wird

Den wilden Forft, den er durchirrt,

In einen Tempel fchnell verwandelt er erblicken!

Welch froh Erftaunen, das aus weitem Aug' ihm quillt!

$\mathrm{Ha}$, welch ein fchauderndes Entzücken,

Das mit des nahen Gotts Gefühl fein Herz durchdringt!

Sieh da, mein Freund, Erwartung, die nicht triegt!

Sich da das Gegengift der fchärfften Lebensplagen!

Sieh da bey frühen, fpäten Tagen

Den Wonnequell, ảer nie verfiegt! 


\section{PRAEFATIO.}

.

um prifcus iam Hippocrates artem longam, vitam vero breuem efle, queribunda voce moneat, cum infuper prooemium longum et alte petitum, praefertim fi pufillo operi praefigatur, lectores facile faftidio afficiat: gauderem equidem, fi fufiori pracfatione opufculo huic praetexenda fuperfedere poffem. Verum enim vero cum, quod hic pertractandum mihi fumfi argumentum, ipfeque libri titulus inuidiofum quid et altius fpirans habere videantur: nae, opus, fufpicor, mihi, reipublicae botanicae ince!ebrato ciui, erit, vt Communi, ad quod trepidulus accedo, me annunciem et de inftituto meo hafce pagellas beneuole lecturis rationem reddam. Age, breuiloquentiam; quoad eius res finit, in his exponendis colamus!

Igitur quinque iam ferme luftra elapfa funt, ex quo ftirpes Mecklenburgenfes inueftigare atque colligere incepi, ab Ill. Mv R$\mathrm{R} \Lambda \mathrm{Y}$, Georgiae Auguftae decore, vt omni opera in id negotii incumberem, per litteras humanifimas excitus. Primus ita (ablit inuidia) factus fum, qui plantas hoc in Ducatu fponte rafcentes modo ad leges methodi adftricto congeflit; Floram nimirum Mecklenburgenfem concinnaturus. At enim cum, nefcio an nimium lentus feftinarem, ain de hac quantum eius fieri poffit, lautiffime dotanda nimis follicitus effem, fine vila opera mea ac impendio illa compta fatis ac ditata nuper in publicum prodiit. Ab anno inde MDCCLXXVIII fungi, quos prae caeteris regni vegetabilis ciuibus infüta caligine merios indignabundus comperi, me tota mente totisque viribus attraxerunt: primum quidem eo confilio, vt, quibus me circumfufum videbam, tenebris difcuffis, per faltus fenticofos fabrofosque viam mihi panderem; fubinde vero facie mirandum in modum varia, ita vt eximia venuftate ftirpium nimium quantum vulgo neglectorum fipretorumque attonitus ac captus. Quamobrem per annos iam duodecim integros, ftudio temporis fucceflu efferuefcente magis, quam deuigefcente, et 
diviturna propemodum opera, regionis huius fungos conquifui, comparaui, defcripti, depinxi. Ex amplinima eorumicongerie hofce tandem fegregare fafciculatimque publici inris facere, qui aut ad plane incognitos, aut faltem ad nondum rite defcriptos piatosque pertinent, operas pretium duxi.

Initium iam ab is facio, qui cum genera hucusque nota plane refpuere videantur, nouorum, fub quibus commode militent, condendorum curam mihi imporuerunt. Quodif fint, quibus in creandis einsmodi nouis generibus forte nimis largus videar, hos, fibi perfuadeant, enixe rogo, me, fi nomina noua ac inaudita crepare mihi libuifet, numerum eorum facili negotio admoduin augere potíife. Sed contra ea de induftria multa huc facientia fuppreffi et complures fungos fructura et textura perquam memorabiles etiam nunc cix $\varphi a \lambda$ ous in aduerfariis feriniisque meis reliqui, ne fcilicet entium praeter neceflitatem multiplicandorum cupidus viderer. Expleantur gloriolae iftus nominatiliae gaudio, qui hanc affectantur; aucupium eius parun fane pellicere poteft hominem in aetatis meae gradu decliuo et vanitatis illius, cui nomenclaturae formulaeque loquendi, vt caetera humana, fubiectae funt, teftem iam veteranum.

Magnorum quorundam Nominum hypothefes nouas, vel noy, antiquas, de fungorum vera generatione et natura, vt àe loco in $S_{y-}$ ftemate naturae rite illis afignando, nufpiam nẹ corroboratum, neuę refutatum iui, pacis fcilicet non ininus, quam breuitatis fudiofis.

Synonymorum, vt optimi Botanicae folidioris praefidii, omnem curam habui, quoa vero rarius fungos hic, defcriptos ftipent, nemo facile mirabitur, qui hos maxima ex parte ad rarifimos minimosque pertinere cognouerit.

Icones eorum płerumque admodum ampliatas repraefentaui, ra, tionibus grauiflmis a Cryptogainiftographo laudem meani excedente, celeberrino HEDWIG, allatis ciusque exemplo permotus.

Genera mea fecundum methodum e diuerfa feminum fede derivatam coagmentaui; alium autem locum SCLEROTIVM in SY. NOPSI fubfequente occupat, alium in libro, ad habitum generis huius et ad obferiora quaedam in eo obuia fi refpicis, fortafle aptiorem. 
Sed vt non omnia poffumus, fic non omnia videmus omnes: quare fi mihi, in naturae minimis partimque aciem eculorum haud hebetem omnino effugientibus verfanti, fubinde acciderit, vt quaedam obferuatu diona, quin neceffaria, non viderim, nemo fanus, fpero, hoc mihi vitio vertet, praefertim cum, vbi coecutire me fenf, quid? quod id modo fufpicatus fium, lectoribus animi mei fluctuationem ingenue fim confeffus. At poteram quaedam perperam videre, nubem, vt aiunt, pro Iunone amplexus? Omnino poteram; homo enim fum, fenfuum ludificationibus non minus, quam fummus $\mathrm{LIN}_{\mathrm{N}}$ NAEVS, argutiflimus HALLERVS, oculatifimus MICHELI, expofitus. Quod fi me, ab oculis caeterum laborisque, patientia fic fatis valéntem, humani quid hic illic reapfe paffum inuenerint viri cordati, aequos manfuetosque iudices fe mihi praeftituros confido; inprimis fi in iis, quae hic tracto, perueftigandis exponendisque illi ipfi defudarunt, horum proinde laborum difcrimina et aerumnas temporis aeque ac oculorum fuorum impendio probe nofcunt. Caeterorum epicrifes caffas non valde curo, haec mea qualiacunque ferae illi diei aequo animo committens, quae ingenii figmenta deftruit, naturae vero iudicia confirmat.

Quod reliquum eft, fi haec mea prima in alienam meffem falcis immiffio publica iis arrififfe refciuero, quibus placere curae mihi cordique eft, fafciculo fubfequenti Halophyta et Sphaerias, gुentes enodatione curatiori dignifimas, recenfebo. Faxit vero DEVS T. O.M. vt conamina mea in SVI, -mirabiliter magni in mirabiliter paruis, gloriam laudationemque cedant.

Scribebam haec PRITZIERI, in Comitatu Schwerinenfi, ipfis Idibus Martii MDCCXC. 


\section{SYNOPSIS METHODICA GENERVM.}

\section{Semina fungorum funt}

I. vel nuda - confpicua

I. in fuperficie integra fungi (feralis) SPERMODERMIA.

2. in parte fuperficici - fcil. eius
a. margine MESENTERICA.
b. apice ACROSPERMVM.
e. capitulo integro
$\alpha$. glabro
*) folido STILbVM.
* ) concauo ASCOPHORA.

6. hirfuto MEDVSVLA.

d. pitei fuperficic
œ. fuperna ivVBECVLARIA.
ß. inferna HELOTIVM.

II. vel tecta - (ante tempus fructefcentiae)

\section{c. volua}

a. fugaci, disrumpenda TYMPANIS. MYROTHECIVM. VOLVTELLA.

b. perfiftente, findenda HYSTERIVM.

2. cortice fatifcente VERMICVLARIA.

3. fubstantia fungi

a. ferfilis SCLEROTIVM. PYRENIVM. XYLOSTROMA.

b. Atipitati CHORDOSTYLVM.

4. Vafculo peculiari feminifero - (Fangi ciaculatorii fer Carpoboli.)
a. folido PILOBOLVS. THELEOBOLVS.
๖. veficulari SPHAEROBOLYS. ATRACTOBOLVS.

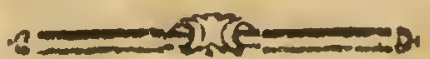




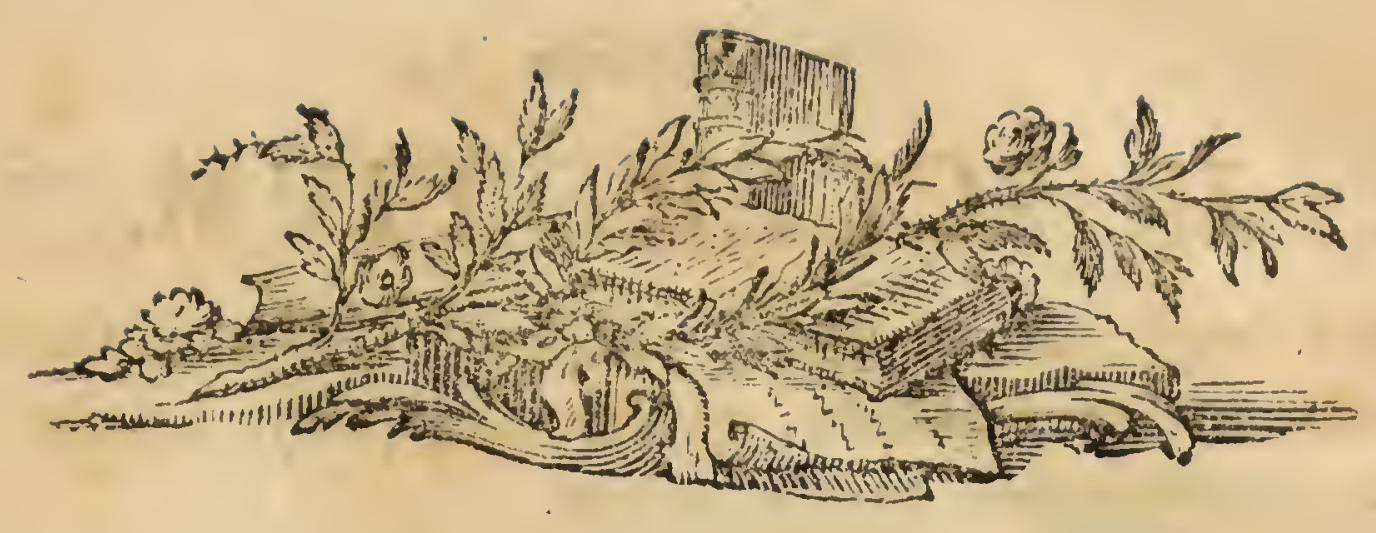

\section{SPERMODERMIA.}

$\mathrm{F}$

ungus fimpliciffimus, globofus, feffilis: fubftantia fpongiofa; polline feminali conferto corticis vicem fubeunte.

\section{SPERMODERMIA clandeftina.}

S. pulvinata, perennis; feminibus atris.

In corticis quercini putrefcentis fuperficie interna fparfim nidulantur fungilli pulvinati, feffiles, duarum vel trium linearum diametro; fubftantia fpongiofa, fucculenta, coloris e fulvo fufcefcentis; feminibus minutiffimis, rotundis, nitentibus, atris, confertis, corticem mentientibus. Majo \& Septembri inveni.

OBS. Corticem apparentem ex ipfis feminibus effe conflatum inde conftat, quod ea partira dejecta ad bafin fungorum cernuntur.

Figurae explicatio.

Tab. I. fig. I.

a. Fungi cortici arboreo infiti magnitudine naturali.

b.c. Fungus cortici exemtus, lente vitrea auctus,

b. integer,

c. ad amufim fectus: 


\section{SCLEROTIVM.}

Fungus fimpliciffimus, globofo-oblongus: fubftantia tenaci, duriufcula, centro demum fubhiante; cortice infeparabili, fuperne nunquam dehifcente; fructificatione interna, ignota.

OBS. Notis hisce genus novim a Lycoperdo fatis difpercitur.

\section{SCLEROTIVM purpureum.}

S. ovale, perpendiculare, glaberrimum, minimum, fparfum.

Oculo folummodo armato confpicuum, non nifi femel a me, in ramuli quippe quernei dejecti plaga quadam epidermidis experte deprehenfum, initio Martii. Forma ovalis; fuperficies glaberrima, nitidiufcula purpurea; fubftantia prædura; balis in cortice defixa.

OBS. Sub hoc genere militare juff fungillum non folum ob naturam rigidam, fed quoque ob germinationem ejus vernalem, utpote qux ir Sclerotiis elt characteriftica.

Figurae explicatio.

Tab. 1. fig. 2.

Fungi magnitudine aucta.

\section{SCLEROTIVM immerfum.}

S. ovale, decumbens, glabrum, aequale. a. lutefiens.

Figura plerumque ovalis, interdum rotundata, pulvinata; fubftantia alba, duriufcule valida; cortex infeparabilis, nunquam corragandus, ftraminei coloris. Longitudo fungi differt a femilineari ad linearem \& ultra. In fuperficie ramulorum emortuorum primo vere ita provenit, ut rupta epidermide cortici eorum quaff immerfus appareat.

OBS. Momorabile mith vietur, volumen fungi fenefcentis palam immisuig. ita tamen, ut tixperficies ejus nirnquam rugofa evadat.

Figurae explicatio.

Tab. I. fig. 3 .

a. Fung 


\section{SCLEROTIVM.}

a. Fungi magnitudine \& fitu naturali.

b. c. Fungus lente fpectatus,
b. a latere vifus;
c. defuper fectus.

\section{ß. album:}

Colore cutis modo alba, nonnunquam candida, a varietate a diverfum. Af non in corticibus folum ramorum putrefcentium, fed quoque radicum arentium, v.c. Crataegi Oxyacanthae, protuberat, ibi minus immerfum, quam alias, \& forma fxpiufcule globofa.

$\gamma$. clandeftinum:

In fuperficie averfa corticis frondis quercinæ putrefcentis femel inveni initio Aprilis. Figura plerumque ovato-oblonga, fubfinuata, compreffa, fæpiuscule inæquali; colore dilute paleaceo; longitudo interdum trium linearum. In rimis corticis arborei fedem fibi figit fungus rariffimis annumerandus.

Figurae explicatio.

Tab. I. fig. 4 .

a. Fungi cortici arboreo immerfi magnitudine naturali.

b. Fungus a cortice femotus.

c. Idem fecundum longitudinem diffectus:

\section{SCLEROTIVM fubterraneum.}

S. globofo-difforme, aggregatum, fubterraneum

c. mufcorum.

Radicibus mufcorum denfe adhærent fungi rotundati, coloris aurei, fuperficie tuberculofi, 2-3 lineares, formam demum admodum variam induentes; fubftantia concolore, compacta, fubfucculenta, infipida; cute membranacea, glabra. Semel inveni varietatem hanc fub initium Julii.

Figurae explicatio.

\section{Tab. I. fig. 5 .}

a. Fungi magnitudine ac fitu naturali;

b. Fungus a loco nataii remotus. 
ß. truncorum.

Proveniens fungus, femen finapis magnitudiné haud æquans, fuccrefcendo demum 3-6 linearum menfuram longitudine fuperat; tuberculofus, ut præcedens varietas, evadens, quacum omnino fere convenit, excepto magnitudine \& fubftantiz colore albo. Immenfum numerum horum fungorum, haud raro connatorum, reperi ad radicem annofæe cujusdam quercus fucciæ circumfufum, in fuperficie propemodum terræe, feu vix, ac ne vix quidem hac tectum. Menfe Augufto.

OBS. Varietas hạesse ortum, dat Agarico cuidam e numerofa familia, quam Moucerons Galli vocant, (Agaricus efculentus Murr. Syft. 14. p. 976.) \& in haç fpeciatim ad eos pertinenti, quorum eharacter peculiaris pileus fucatus eft. Agaricus itte proxime accedens ad illum, quem Schaefferus pinxit tab. 59, fubltantiam integram fungi noftri tam avide confumit \& in fuccum ac fanguinem convertit, ut de hoc demum nil nifi cutis remaneat.

\section{Figurae explicatio.}

Tab. I. fig. 5. c. d.

c. Fungus magnitudine naturali.

d. Idem transverfim fectus."

\section{SCLEROTIVM Semen. $=$}

S. fphæricum, nigrefcens, corrugandum, fparfum.

Sphæria Brafficæ Dickfon pl. cryptog. p. 23, ob fynonyma, quibus adde Rell. Cantabr. n. 1057.

Sphærula magnitudine feminis finapis, fed fapo lineari fesquilinearique diametro, glaberrima, initio nivea, mox flavefcens, tum fulva, poft fufca, demum nigra, cute tum in rugulas contracta. Subftantia folida, rigidula, attamen fucculenta, alba. Primo vere, quin durante adhuc hyeme, in omnis generis plantarum foliis caulibusque, humi jacentibus, \& putredine correptis, ubique fere locornm in confpectum venit fungus, jam fparfim, jam vero denfiore agmine proveniens, firmiterque plantis ope rudimenti ftyli adhærens, rugas autem nactus fponte decidit.

Figurae explicatio.

Tab. I. fig. 6 .

a. Fungi aetate impares, magnitudine naturali.

b. c. Fungus amplificatus: 
b. vetulus,

c. per centrum fectus,

S. ellipticum, decumbens, aggregatum.

\section{SCLEROTIVM Mucor.}

a. fungorum.

In fungis putridis maculæ apparent albidæ, quæ lente perluftratæ corpora elliptica, glabra, congefta manifeftant. Color albicans in fungo fenefcente fit cinereus. Durities ejus tactu fe prodit. Augufto.

Figurae explicatio.

\section{Tab. I. fig. 7 .}

a. Fungorum congeries magnitudine nativa.

b. Fungus per lentem vifus.

$\beta$. lignorum.

Granis filigineis quoad figuram fimilis fungus tam parvus eft, ut aciem oculo: rum vulgarem facile effugiat. Color cutis fulvus, fufcelcens; fubftantia albus. Gregatim in feftucis; fruftulisque lignorum crefcit Aprili, perrarus.

\section{SCLEROTIVM radicatum. = A mivis, Jr.}

S. Sphaericum, bafi producta, radicatum, fparfum.

Terreftris, ater, fpartim proveniens fungus ad mediam usque a folo prominens, diametro ferme lineari. Pellicula lævis, riembranacea; fubitantia compacta, fubfucculenta, in centro demum dehifcens; racix fibrofa. Semel inveni, folo humido, umbrofo, Septembri.

Figurae explicatio.

Tab. I. fig 8.

2. Fungi magnitudine ac fitu naturali.

b. Fungus terra extractus.

c. Idem verticaliter fectus.

\section{SCLEROTIVM complantum. = Scomy 1 ar.}

S. pyriforme, complanatum; ftipite brevifïmo.

Prodiens fungus ovato-elongatus, laevis, fubpellucidus, albus, fuperne fenfim 
dilatatur, pyri formam obtinens, fimul flaveicit, fulvum mox, denique vero e fufco ferrugineum colorem affumit, jam plane opacus; fucceflu fimul temporis adeo comprimitur, ut demum complanatus evadat. Veri nominis cutis an adfit, adhuc dubium; faltim illa eft a carne infeparabilis. Subftantia alba, tam tenax in fungo adulto, ut cartilagineam non immerito vocaveris; attamen initio fucci eft plena. Superficies fungi exoleti corrugatur \& tum femina minutiffima, ovalia, nitidula, alba, eam quali incruftant. Stylum cylindricum, brevifimum, ochraceum, ubi capitulo jungitur, circumfluit circulus coccineus. Appropinquante vere, quin etiam medio hyeme fub nive, fungus hic, 2 lineas plerumque longus, putrefcentibus foliis, culmis caulibusque 'fparfim infidet; fed hyeme abeunte fimul difparet, poftea non inveniendus.

OBS. Specics hac ob frucificationem externam \& ftipitem admodum a reliquarum ratura abludit, ad Stilba mea, de quibus infra, fortaflis ableganda: fed obeft fubftantia dura, interne demum dehifcens.

Figurae explicatio.

Tab. I. fig. 9.

a. Fungi rtate prima, florente, provecta.

$\mathrm{b}-\mathrm{d}$. Fungus lente ampliatus,

b. junior,

c. fub tempus fructefcentix,

d. adultus, e vertice fectus.

\section{SCLEROTIVM villofum.}

S. fphaericum, villofum, aggregatum.

a. album.

Magnitudine arenulæ modicæ; color corticis melleus, villarum albidus; fubftantia alba, duriufcula, e centro perpendiculariter ad bafin usque exterebrata. In caulibus Solani tuberofi femiputridis. Aprili \& Majo, frequentiffime.

Figurae explicatio.

Tab. I. fig. 10.

a. Fungi aggregati, magnitudine naturali.

b. c. Fungus lente adanctus. 


\section{SCLEROTIVM.}

\section{b. a latere fpectatus. \\ c. ad amufim per centrum fectus.}

ß. ferrugineum.

Color villarum huic varietati amœne ferrugineus; fenefcens eundem in modum exterebrata reperitur; fed a vertice, villis non obfito, per centrum deorfum. In cxteris utraque varietas conveniunt, magnitudine puta, figura, colore, nec non Eempore locoque natalibus.

OBs. Maftam hujus fpeciei, ut plexarumque hoc genere comprehenfarum, domum hiulcare, nullum eft dubium; fed an femper in varietate utraque en, qui hic traditur, modo fiat i res forte eft altioris indaginis, Commemoro qux, vidi \& ut vidi.

Figurae explicatio.

Tab. I. fig. II.

Fungus mole auetiore.

\section{MESENTERICA.}

Expanfum gelatinofum, venofum; margine fructificante.

\section{MESENTERICA tremelloides. =inyalin... Ityyonowhum}

M. gelatinofa repens, complanata, venofa; margine tumido.

c. lutea.

Mucilago, citrino vel aureo colore, nodulo fimilis, præviis imbribus a ramis deciduis fecamentisque lignorum pullulat, mox in venas ferpentes, fili modici craffitie, diftrahenda, quarum fubfequentes ramificationes membranula gelatinola, fulphurea, interdum viridefcente, rugofa, invicem ita junguntur, ut melenteriforme expanfum confituant. Margo tum intumefcit, læete luteum colorem affumens: quare de hoc ceu fede fructificationís videtur non effe dubitandum. Ambitus fungi ellipticus Agaricorum dimidiatorum, margine finuato lobato. Diametro majori 2-3 uncias aequat. Tempore vernali pluries, fed \& auctumno ínyeni.

OBS, Planta deficata intra 12 ho:arum Spatium aura calidiore ita corripitur, ut prater bracteolas quasdam minutifrmas, conglomeratas, nullum fui refigium relinquar.

Figurae 


\section{MESENTERICA.}

Figurae explicatio.

Tab. II. fig. 12.

a. Fungus magnitudine naturali.

b. Ejus primordia.

B. caerulea:

Colore tantum glauco-cæruleo a varietate $\alpha$ difcrepat. Semel mihi obviam facta menfe Septembri, in affula femiputrida.

\section{ACROSPERMVM.}

Fungus fimplicifimus, fuberectus, apice extus fructificante.

\section{ACROSPERMVM compreffurn $=87 r$}

A. perpendiculare, ovato-elongatum, compreffum, rigidifimum.

Fungus perennans, linea aliquantulum longior, Clavariam fimulans, rigidiffmus; cute lrevi, membranacea, a carne infeparabili, olivacea, demum nigrefcente; fubftantia glutinofa, cito indurefcente, alba. Apicem verfus e rugis, feu fulcis, quibusdam circularibus, parallelis, pollen erumpit candidum, quo mox acumen integrum obtegitur. Fructefcentia peracta femina auræ afflatu avehuntur, fungo demum complanato \& longitudinaliter fulcato. Veris initio fparfim crefcit in calllibus aridis habitioribus \& firmioribus plantarum, v. ๔. Heraclei Sphondillii L.

Figurae explicatio,

Tab. II. fig. I3.

a. Fungi magnitudine \& fitu naturali.

$b-f$. Fungus eximie amplificatus.

b. Sub tempus fructefcentix.

c. Fructefcentia incipiente.

d. Eadem completa.

e. Fungus decrepitus.

f. Fungus fecundum longitudinem lectus. 


\section{ACROSPERMVM unguino'um. - Iremellic saverides}

A. perpendiculare, digitato-cespitofum, unguinofum, apice tumido:

Defcriptam pictamque dedi hanc speciem in dew Schriften der Berlin. Gefellfch. naturforfch. Fr. vol. IV. p. 64. tab. 12.

\section{ACROSPERMVM pyramidale. y'}

A. perpendiculare, ovato-acuminatum, duriffimum, folitarium.

Fungus principio candidiffimus, fubulatus, pubefcens, adultior glabrefcit, prafertim apice, fimul inferne attenuatur. Colorem jam induit pallide rofeum, apice excepto, pulvifculo utpote feminali candido tum confperfo. Cutis infeparabilis a carne folidilfima, fucculenta, colore alba \& rubella, marmoris inftar, variegata. Radix tenera, by fina, candida. Trium ferme linearum longitudinem fungus rariffimus affequitur, unam latus. Inveni in Agarico deliciofo L. exarefacto Aprili.

OBS. Lubentifime equidem ob habitum Sclerotiis annumerarem, ni pollen in apice obftares.

Figurae explicatio.

\section{Tab. II. fig. I4.}

a. Fungi aetatis diver $æ$, magnitudine nativa.

b. Fungus junior fede femotus.

c. Fungus in ftatu fructefcentix.

d. Idem differtus, volumine aucto.

\section{ACROSPERMVM licheroides. = Richem.}

A. decumbens, ftellare: laciniis rectilineis, compreffis; apicibus fub-bifidis, tumidis.

Singularis admodum planta, Lichenibus quidem foliaceis decumbentibus perquam fimilis, ab illo genere veruntamen feparat fcutellorum tuberculorumque abfentia, ut fubftantia folida, fibrufa. Provenit in omnis generis ramis ramulisque arborum ac fructicum, humi jacentibus \& pluvia crebra madefactis. Forma eju ftellaris; fuperficie fulvo-ferruginea, fubtomentofa, æquali. Laciniarum haud raro incifi apices obtuli tumefcentes, flavidi, tempore fructefcentix pulline albo inducuntur. Carnofus fatis fungus; fed caro alba, fibrofa, tenaciffima, fenfim tabefcit fragilisque fit; laciniarum vero fuperficies rugofa. Apicem verfus hae pilis brevibus 
inftructæ firmiter adhærent ramis, quos ferpendo arripiunt \& digitorum in morem nonnunquam amplectuntur. Fungus denique in centro nigrefcit ibique dehifcens tandem rumpitur. Diameter ejus 2-3 unciarum. Auctumno viget, fed raro obvenit.

Figurae explicatio:

$$
\text { Tab. II. fig. } 15 \text {. }
$$

a. Fungus adultus magnitudine naturali.

b. Fungus fenefcens eadem magnitudine.

OBS. Vereor fane, ne fungus abnormis quibusdam hue magis compaitus, quam reliquis hujus generis (pecicbus amice confociatlis videacur; fed profecto, quo me tandem cum eo vergim, nefio.

\section{STILBVM.}

Fungus ftipitatus, gelatinofus, aggregatus; capitulo diaphano, nitente, folido, perfiftente, externe fructificante.

\section{STILBVN vulgare. $\forall \mathfrak{K}_{0}$}

S. capitulo fphrrico; ttipite cylindrico, crafficafculo.

Adeo parvum, ut nudo oculo æegre agnofcatur. Album colorem mox in ochraceum mutat, in capitulo faturatiorem. Seminibus hoc albis confpergitur, minimis, rotundis. Stipes æque nitidus, ac capitulum. 'Fungus denique decumbit. In caudicibus variorum arborum femiputridis, anctumno frequentiffimus.

Figurae explicatio.

Tab. II. fig. I6.

a. Fungorum turma magnitudine naturali pictorum.

b. Fungi quidam forma admodum extenfa.

\section{STILBVM bulbofum. y 7 .}

S. capitulo fphærico, ftipite attenuato, bulbofo.

Stipes vix vifibilis, lævis, primo attenuatus, tandem vero cylindricus, debilis, fubflexuofus, definit in bulbum hemifphæricum, glabrum, grifenm, qui fenfim comprcfius denique vero complanatus fit, colore in ochraceum mutato. Capitulum 


\section{STILBVM.}

albnm pulvifculo feminali ochroleuco obducitur. Auctumno port pluvias denfas obvenit, fed rariuscule, in culmis, ftipulis foliisque putridis, fuperne tectis, unde ad fungos fubterraneos merito referendus hic nofter. Fabrica ejus tam tenella, ut microfcopio admoto illico flaccefcat. Rúdius commoti capitula decidunt. Magnitudo fesquilinearis.

Figurae explicatio.

Tai. II. fig. I\%.

a. Fungorum magnitudine naturali pictorum agmen.

b-d. Fungus admodum auctns:

b. tempore fructefcentix;

c. effœetus ;

d. emortuus

\section{STILBVM rubicundum $\forall$ Fr}

S. capitulo ovato, comprefio; ftipite attenuato.

E minimis, vix ac ne vix quidem oculo haud armato contemplabilis. Capitulum candidum, pellucidum, ovato-comprefium; pollen ejusdem coloris; ftipes lrevis, fubpellucidus, capillari-attcnuatus, rubicundus, demum lutefcens. In caudicibus fagorum, récens cæfarum, e quarum fucco extravafante, infpiflato, ita ftipes emergit, ut inferne Perichætio cinctus videatur. Aeftate haud raro obvenit.

Figurae explicatio.

Tab. II. fig. 18.

Fungi juniores, feniores, magnitudine naturam longe excedente.

\section{STILBVM minimum.}

S. capitulo ovali, comprefio, ftipite capillari.

$$
\text { a. nigripes. }
$$

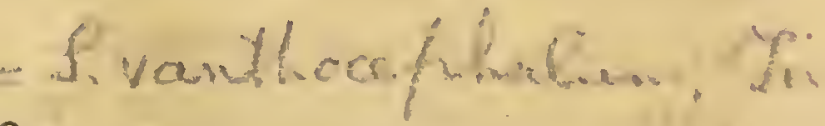

Sui generis minimus, non nifi lentis ope diftincte cognofcendus fungillus capitulo elongato-ovali, admodum nitente, paleacei coloris, oculos mox allicit. Stipes capillaris, rigidulus, grifeus, demum nigrefcens. Longe lateque agmine dénfifimo perrepit ligna humida putrefcentia; præcipue vero ramulis quercinis, putredine correptis, inhabitat. Martio, Aprili fatis frequens.

Figurae 


\section{Figuirae explicatio.}

Tab. II. fig. 19.

Fungi admodnm ampliati in fitu naturali.

B. flavipes. $=$ \&. Luteum, Fo.

A varietata priori differt capitulo non ita elongato; aureo, \& ftipite luteo, qui cum pellucidus fit, de latere vifus albus apparet. Lignarius æque; fed multo rarior. In trunco cenfpicatus fum fubputido fagi, Julio.

\section{STILBVM turbinatum. \& $7 x$.}

S. capitulo turbinato; ftipite cylindrico, ad capitulum contrakto.

Fungus delicatiffimus, lineam circiter longus, ocula nudo vix commode vilibilis. Capitulum, pyri inverfi, apice compreffi, forma, ochraceum, fi foli obvertitur, fuperne fulvum colorem prodit. Fruetefcentix tempore polline feminali albo confpergitur. Stipes gelatinofus, debilis," fuperne albus, pulverulentus; inferne glaber, fubpellucidus, dilute ochraceus. Inveni Martio in libro putrefente caudicis faginei.

Figurae explicatio.

Tab. II. fig. 20.

a. Fungi magnitudine \& fitu naturali.

b. Fungus adolefcens \& fructificans, uterque magnitudine impenfe aucta.

\section{STILBVM pubidum. $\forall$ Im}

S. capitulo ovato; ftipite inferne incraffato, pubido.

Admodum parvum delicatulumque, ut præcedens fpecies. Capitulum exacte - vale e guttula limpidiffima intra 24 horarum fpatium condenfatur \& pelluciditatem amittit, colorem tum candidum affumens a polline, mox integram ejus fuperficiem occupante. Stipes candidus, capillaris, tenuiffmus, lrevis, a medio ad bafin ùsque duplo craffior. Superficies integra ftyli incraffati filamentis byflinis, longiusculis, rigidiusculis, divifis, fquarrofis, candidis, hirta. Reperi in foliis pints fylveftris putridis poft pluvias tonitrua comitantes, Augulto.

Figurae explicatio.

Tab. II. fig. $2 \mathrm{I}$.

a. Fungi magnitudine ac fitu naturali. 
b. c. arbitrarie auctus
b. ante ftatum fructefcentix;
c. hoc in ftatu.

\section{A SCOPHORA.}

Fungus erectus, fipitatus: capitulo globofo-oblongo, inflato, opaco, elaftico, externe fructificante; ftipite fetaceo.

\section{*) Liberae. \\ I. ASCOPHORA Mucedo.}

A. libera, aggregata: capitulo fphærico ad ftipitem rumpendo; ftipite fetaceo, longo.

Nudis oculis fpectatus fungus Mucori Mucedini L. quam fimillimus apparet; aft enim vero valde ab illo difierre microfcopii ufus curiofior illico docet. Capitulum, initio guttula aquea, pellucida, poftquam ftipitem nactum eft, diaphanum effe definit cavamque fit, colorem jam fufcum, mox atrefcentem monftrans. Superficies ejus pulvifculo longe minutiflimo, albido-grifeo, quafi afflata tum videtur, polline fcilicet feminali delicatiffimo. Rumpitur vero hoc capitulum femina explodens, vi quadam elaftica, ad infertionem ftyli eo pacto, ut cutis quaquavorfum ab illo fecedentis margo aperturam perexignam, circularem in capituli bafi efficiat. Quod cum a fripite liberatum coliabafcat, ab hoc ita exipitur, ut nutans in fuperficiei internæ vertice fuffulciatur. Ruptura pedetentim tam dilatatur, ut capitulum denique formam hemifphæricam, feu cupulæ inverfx, induat. Stipitis femper pellucid̦i, trilinearis, color primum albus, poltea e cinereo nigrefcens. Obvenit in panibus fimilagineis mucefcentibus.

\section{Figurae explicatio.}

Tab. II. fig. 22.

a. Fungillorum agmen magnitudine nativa pictorum.

$b-h$. Fungus quam maxime auctus:

b. junior, capitulo pellucido;

c. idem, eapitulo nigrefcente; 

d. adultus, in ftatu fructefcentix;
e. fenefcens, capitulo ad ftylum rupto;
f. Capitulum ftipitis apice titubans, diffectum;
g. idem hians ad extremum;
h. idem e vertice fectum, tempore fruetefcentia:

\section{ASCOPHORA fragilis.}

A. libera, conférta: capitulo fphrerico, in medio diffiliente; ftipite fetaceo, breviusculo.

\section{An Mucor IV. a. Gled. Method. p. I62?}

Globuli arenulze magnitudine, albidi, conferti, initio feffiles, poftmodum ftipite ejusdem coioris, brevi, pellucido inftructi. Capitula a polline feminali candefcentia, leviter tacta diffiliunt. In carnibus elixis repofitis, præcipue in apice linguarum bubularum ante 3,4 . dies coctarum.

OBS. Dubius fungum huc voco, naturam licet Afcophorarum omnino prodat; fragilitas cnim ab illa quödammodo abhorrere videtur.

Figurae explicatio.

Tab. III. fig. 23.

a. Fungorum cefpes magnitudine naturali pictorum.

b. Fungi lente ampliati.

\section{ASCOPHORA Stilbum. =Flydrophora equina,}

A. libera, fparfa: capitulo ovato, nitido; ftipite fetaceo, brevifimo.

Ad minimos, qui unquam fe mibi obtulerunt, fungos pertinet, non nifi lentis ope fub afpectum veniens. Capitulum ante fructefcentia ftatum candidum, nitidiffimum. Stylus hoc brevior, ejusdem vero coloris. Semina non vidi; nec diffecare tantillæ molis fungum mihi poffibile fuit: quare plura de eo commemorare nequeo, pari jure fortafle Stilbis annumerando. In fimo equino non plane recenti, cxtus intusve, auctumno.

Figurae explicatio.

Fungus, uti fub lente apparet.

Tab. III. fig. 24 . 


\section{ASCOPHORA ovalis. = inela insectourn}

A. libera, fparfa: capitulo ovali, demum corrugando \& multifariam fubrumpendo; ftipite fesaceo, longiusculo.

Afcidium ovatum (mihi) in den Schriften der Berl. Gefellfch. naturf. Freunde, 7oi. 1II. p. 247. tab. 4. fig. 4-6.

Defuriptionem amplam de fungo hoc peramono \& rariori 1. c. jam dedi, quam hic repetere non lubet. Ad ea, qux ibi funt dicta, follummodo ad jiciam, ad indolcm ejus pertinere, quod apices ramorum, lignorumque occupare amet. Capitulum poft ftylum progerminat, guttulx aqua limpidiffime fimile; fed in formam mox abit ovalen \& priusquam a femine niveo confpergitur, argenti inftar nitet. Stipes attenuatus in balin deltoideam terminatur. Cutis capituli admodum tenax \& membranofa non femper, modo faltim vilibili, rumpitur; contrahitur autem femper polt fructefcentiam plus minus in varias rugas. Fungillus exinde nullam ferme mutationem externam fubire videtur; aflervo enim ejus exempla quædam jam decennalia, fed adhuc incorrupta. Septembri \& menfibus proxime fequentibus poft pluvias frequentiores.

OBS. Evitanda d $\mu \varphi_{1}, B 0 \lambda$ bses caufa nomen generis Afcidium cum Afcophora commutavi, cum in regno animali, ut poltea vidi, Afcidia nomer genericum confrituat.

\section{ASCOPHORA cylindrica. sovula ins ectersum.}

A. libera, gregaria: capitulo cylindrico, corrugando; ftipite fetaceo, breviufculo. Afcidium cylindricum (nihi) in den Schriftca der Berlin. Gefellfch. naturf. Freunde, Vol III. p. 248. toh. 4. fig. 7-9.

Ad ea, quæe 1. c. de hac fpecie commemoravi, non habeo quod addam.

$$
\begin{aligned}
& \text { **) Aggregatae. } \\
& \text { 6. ASCOPHORA lombiflora. status fradosh. wel thas wh. }
\end{aligned}
$$

A. aggregata, limbifiora: receptaculi communis convexi, demum depreffi, margine frnctificante: capitulis globolis, nutantibus, deciduis; ftipitibus capillaribus, laxis.

In fuperficie adverfa foliorum Rubi idaei fparfim prodeunt tubercula convexa, feminis papaveris magnitudine, fulvi flavefcentis coloris; fubftantia fubmolli, fuperficie æquali. Deprefia fenfim facta Pezizam imitantur. E rargine eorum confertim erumpunt globuli lutei, Ptipitati, penduli \& decidui, Floret Junio.

Figurae 


\title{
Figurae explicatio.
}

Tab. III. fig. 25 .

A. Placentulæ fungiferæe magnitudine naturali. b-f. Fungus farciculatus admodum auctus:

b. proveniens;

c. fub initium fruetefcentix;

d. in ipfo fructefcentix ftatu.

e. Ichnographia fungi in hoc ftatu defuper feeti.

f. Capitulum ftipitatum.

\section{ASCOPHORA difcifor $a_{0}=$ Phragmidium.}

A. aggregata, difciflora: receptaculo communi convexo; capitulis ovato-elongatis, deciduis; ftipitibus fetaceis.

\author{
a. Folida.
}

In fuperficie foliorum averfa Rofæ albæ hortenfis, quin in ipfis calycum fegmentis, gregatim prodeunt corpufcula rotunda, complanata, puncti majufculi menfura; fubftantia fubfolida, colole aureo, area granulata, margine æquali. Ex his propullulant confertim fungilli capitulis ovato-elongatis, polline ex nigro faturate fpadiceo inductis, fubnutantibus, deciduis; ftipitibus tenuiffimis, pellucidis.

OBS. Varietatem hanc indigitare videtur Gleditfclisus in epicrifi Afcidio ovato, a me deferipto, fubiuncta in den Schriften der Berlin Gefellfch. natwrf. Freunde. Vol. III. p. 250.

Figurae explicatio.

Tab. III. fig. 26.

a. Placentulæ fungiferæ magnitudine naturali.

b. Eaedem lente auctr.

c-d. Icones fungi admodum amplifirati:

c. ante tempus fructefcentix;

d. fub initium ejus;

e. in ftatu fructefcentix ipfo.

f. Capitulum folitarium fructificans, ftylo infidens, forma extenfifima. ß. byffina.

Receptaculum commune, feu placenta fungifera, in hac varietate texturam byffinam 
byfinam habet, quare tabefcit, \& denique vix fui veftigium relinquit. Capitula tam elongata, ut haud incommode cylindrica dixeris. Quoad reliqua cum varietate \& congruit. In fuperficie averfa foliorum Rubi idaci, Septembri, rarius.

Figurae explicatio.

Tab. III. fig. $2 \%$.

c. Placentulæ fungiferæ magnitudine naturali.

b. Placentula folitaria fructificans maximopere aucta.

OBs. Dubius admodum \& ferme anxius poftenam hanc fpeciem cum pracedente Afcophoris adjungo, cum ab illis nimium recedere mili videantur. Receptaculum \& capitula majuscula, ponderola, naturam fane fingularem \& ab aliis notis fungorum generibus admodum diverfam maniferto indicant. Pucciniis quidem Micheli accedunt; at in his femina fingulatim pediculo funt imtructa, quod longe aliter hic habet, capitulo nimirum feminifero fipitibus fingulis infidente. Adde quod in pucciniis corpus fructifcans fit erectum, fifulofum, fubdigitatum; fed vereor, ne vel hartum ftructura \&: Eructificatio jam fatis fit explorata.

\section{MEDVSVLA.}

Fungus globofus, ftipitatus, confertus: capitulo \& ftipite folidis; fructificatione externa, filiformi, flexili, colliquefcente.

OBS, A Sphaeriis differt ftylo, capitulique ftructura; ab Afpergillis Mich., filis feminalibus flexuofis, 'liquefcentibus, \& ftipite habitiori, breviori; Trichias Hall. facie folummodo xmulatur.

\section{MEDVSVLA labyrintbica $=$ ethyegeastes}

M. conferta, humilis, labyrinthica, lutea.

Fungus quautus quantus lineæ dimidiatæ longitudinem vix áfequens, denfo agmine progerminat. Capitulum globofum, folidum, fubftantia fibrofa, colore teftaceo, villis luteis hirtum. Stipes brevis, teres, crafius, tomentofus, farctus, capitulo concolor. Unius ubique capitelli villi denfi \& flexuofi contiguo proximorum fungulorum capillitio ita intricantur, ut tota congeries ftratum quoddam tomentofum oculo armato fiftat, fulcis labyrinthicis ubique peraratum. Liquefiunt vili hi, feu filamenta, \& liquamen hoc confluens in cruftulam poftea concrefcit refinofam, 
finofam, friabilem, aurantiam, integrum fungorum cefpitem fuparne obtegentem: quare nil obftare videtur, quominus villos hofce pro fede fruetificationis habeamus, nimirum aut ex feminibus ipfis contiguis, feu confertis, conflatos; aut hæc maflæ cuidam vifcidæ immixta continentes. Fungorum cefpites I- 2 uncias longi, 2-3 lineas lati. Inveni horum perplures in trunco Mali afciato, jam dudum fub dio jacente, poft imbres iteratos, initio Septembris.

Figurae explicatio.

Tab. III. fig. 28.

2. Cefpes fungorum magnitudine naturalis,

b. Idem amplificatus

c. defuper vifus;

d. transverfim vifus.

e. Fungus folitarius tempore fructefcentix, lente auctus.

f. Idem e vertice fectus.

\section{TVBERCVLARIA.}

Fungus pileatus, ftipitatus, gelatinofus: pileo tuberculofo-papillato, ftipiti arete appreffo, fuperficie fuperna fructificante; ftipite craffrfimo, fareto.

OBS. Non confundendum genus hoc cum Tubercularia clar. Wiggers Primit. p. 87. A Iachno Retzii Prodr. n. 1647 habitu difcrepat; cum Itemellis vero, genere huc usque vulgivago, fubfantia folum gehatinofa convenit.

\section{TVBERCVLARIA vulgaris.}

T.fparfa: ftipite ventricofo-globofo; pileo convexo, tuberculofo-rugofo, marsine fubrepando.

a. fubfeffilis.

Tremella purpurea Hoffm. Veget. cryptog. p. 29. Tab. 6. f. 2. Synonyma quoque ibi vide, quibus addenda

Spharia tremelloides Willden. Berol. I210. Timm. Megap, n. II72.

Defcriptionem fungi vulgatifimi accuratam \& amplam cel. Hoffmanmus dedit 1. c. 
1. c. Lapidibus, ut vocantur, cancrorum adfpectu quam fimillimus, capitulo plerumque acus mediocris magnitudine. Pileus vel miniatus, vel purpureus, vel rtifus, vel badius, fuperficie initio xquali; fed demum plerumque undato-tuberculofa, fulcoque uno ac altero notata; margine profunde apprefio, interdum femel incifo. Subftantia cerea, rubicunda, aqux immerfa naturam prodit gelatinofam. Semina minutifima, globofa, albida, fructefcencix tempore integram pileoli aream occupant. Stipes ventricofo-globofus, bafi acuminatus, glaber, farctus, fibrofus, externe interneque ex Cpadiceo fufcus, pileo quafi eft immerfus, ad infertionem ab hoc linea badia diftinctus. Totus ferme in cortisibus frondium ramorumque arentium abditus latet, pileo epidermidem perforante. Lxtiffime viget in ramulis refectis \& emortuis Aefculi Hippocaftani $L$. tempore hyberno \& vernali.

OBS. 1. Haud raro in fungi grandavi putrefcentis fipite intrinfecus \& extrinfecus circum ejus bafin globuli confertim generantur minimi, ovales, cinnabarinis, vertice pertufi, fuperficie glaberrima, papillata, quos intus tum inanes, fuperficie ejusdem coloris xquali, nitente; tum vero mucilagine rubra plenos inveni (Septembri) id, quod Sphærix fpeciem fragiformem manifeltat, ad Sphzriam rubram Wigg. Hols. n. 935. Willden. Bevol. n. 2209 , nifi illa ipfa elt, (orificii ellim diverfa fructura exiguum ita Sphariis diftinguendis, combinandis momentum affert) proxime accedentera. Spharia hxa dubio procul in caufa fuit, ut cel. Weigel $0 b f$. $p$. 46 fungum noitrum pro 5 phxtia compofita haberet, cum is folummedo sphxix cuidam fimplici parafiticx, 2lio. rum fungorum, quid? quod quarundam $s$ phxiarum compofitarum more, incunabula alimentumque prabeat: id, quod in Spharia Stigmate fieri jam animadvertit cel. Hoffmannus 1. c. pag. 7. in Obf. huic fubnexa; eft enim, quam detexit, Peziza pulchra coccinea, veri nominis sphxria, fed e fanilia vaftiflmi hujus generis usque adhuc non "defcripta.

2. Deprehondi femel in ligno putrefcente Pinus fylveftris $L$ fungulum fparfim crefcentem, gelatinofum, noftro fimillimum; pileo pulvinato, xquali, niveo et, quod huic fpeciei groprium, deciduo; itipite fubtereti, ochraceo, Martio,

\section{Figurae explicatio.}

Tab. IV. fig. 30 .

a. Fungorum agmen magnitudine \& fitu naturali depietorum.

b-d. Fungus ampliatus
b. cortici arborum infixus;
c. hoc erutus, oblique fpectatus;
d. ad perpendiculum fectus.

$\mathrm{C}_{2}$

B. Atipitata 


\section{B. ftipitata.}

Minor aliquantulum varietrte $\%$, a qua ftipite imprimis fatis longo \& omnimode tereti, coloris fpadicei, differt. In virgultis aridis, Alartio, fed rariuscule.

Figurae explicatio.

Tab. IV. fig. 3 r.

Fungus lente auctus.

\section{TVBERCVLARIA fafriculata.}

T. fafciculata: ftipite craffifimo, tereti; pileo complanato, granulato.

Fungus gelatinofus, corticalis, linearis vix longitudinis. Pilei minuti fuperficies cum carne coloris aurei, margine obfolete compreffo. Stipes glaber, craffiffmus, aureo, intus paleaceo colore, farctus, a capitulo patuxillum prominente palam eft difcretus. Cum granulis, feu papillis minimis in hujus fuperficie color fit dilutiffime luteus, ad album vergens, nullus dubito, quin in his fructificationis fedes fit quærenda; fed pollen ipfum non vidi. Fafciculatim e cuticula corticis prorumpunt fungi 6 ad ro coaretati \& epidermide eminente ita cinkti, ut capfula quadam inclufos crederes. - Communicavit exempla recens lecta perbenigne mecum cl. Timm, conful \& pharmacopola Malchinenfis de re botanica admodum meritus. Septembri.

Figurae explicatio.

Tab, IV. fig 32.

a. Fafeiculi fungorum magnitudine natugali.

b. Fafciculus eorum unicus, lente ampliatus.

c. Fungus foiitarius anctus.

d. Idem ex pilei meditullio recta fectus.

\section{TVBERCVLARIA volvatd.}

T. fparfa, volvata: ftipite craffifimo, conico; volva cyathiformi; pileo tuberculofo-rugofo, convexo, margine apprefio, repando.

Hiftoria fungi minimi ac rarillimi hæc eft. Primum prodit volva nigra, cupularis, mafla nivea, molli repleta, quæ intumefcendo formam hemifphæricam fenfim nacta, poftea in conicam abit, quo facto pilei leviter convexi \& tunc rqualis, coloris pallidiffme fufci, mox murini, primordia in ejus apice apparent. Boleti 
bovini L. exorumantis faciem hac atate fungus imitatur. Sed jam pileus fit pulvinatus, marsine apprefio \& revoluto; ftipite vero a conica paulatim in attenuatam, quin denique in cylindricam formam transfigurato. Circa fructefcentix tempus prior colliculis crifpari incipit, margine detorto, undulato, repando-lobato; colore reio in fufcum, poltremo fpadiceum verfo. Polline minutifimo cano ubique confperoitur. Caro fubfuccnlenta mollis, fufco-ferruginea, a cute infeparabilis. Stipes farkus, candidus, externe fubtomentofus, nonnunquam bifidus, pileo infertus, volva non firmiter inharens. Fungus femilineam vix altus \& primum admodum tener, naturam poftea futis firmam prodit. Volva perfiftens. In alburno pluviis macerato ramorum querneorum arentium confpicatus fum catervatim crefcentem, Augufto.

\section{Figurae explicatio.}

\section{Tab. IU'.' fig. ' 33 .}

2. Fungi magnitudine ac fitu naturali.

b-h. Fungus admodum auctus,

b. proveniens;

c. Atipite progerminante;

d. pileo primum comparente;

e. eodem adulto;

f. fungus in ftatu Fructefcentia;

g. fungus ftipite bifido;

h. fungus ad amuffim fectus.

\section{TVBERCVLARIA fulcata.}

T. fparfa, fulcata, integra: ftipite craffiffimo, crucibuliformi, cum pilei depreffi fuperficie inferna, integra, connato.

Fungus Aftroites Scop. Pl. Subterr. p. II7. n. 7I. t. 45. f. 2.

Non nifi in hiatibus \& fifluris truncorum falignorum longevorum hic locorum progerminat, fparfim, interdum 2 ad 3 fungis coalefcentibus. Admodum parva initio, fed denique haud raro diametro femiunciali. Stipes primus efformatur, villis albis minutifimis pubidus, fubglobofus, vertice fcilicet aliquantum in altum protracto. Pilei mox primordia in ejus apice fe produnt, bractex fimilia peltaformi, glaberrima, flavo-fulvæ. Af fenfim complanatur \& denique fit depreffus; 
margo interim dilatatur \& undulatus evadit: eo pacto crenulatus, ut incifuræ, feu fulci altius impreffi, per ftipitis fuperficiem uno eodemque tractu continuati, fungi defuper fpectati faciem quodammodo ftellarem, vel floriformem, reddant, dum a latere contemplatus columellam canaliculatam utcunque æmulatur. Effoetum \& tunc temporis haud raro umbilicato-excavatum, omnibusque villis orbatum, dentibus humanis molaribus corruptis \& cariofis quoad figuram non inepte affimilaveris. Color demum ex cereo fulvus. Bafis fungi innititur fibris byffinis in modum telz arachnaex pertextis. Sub finem Octobris \& Novembri.

Figurae explicatio.

Tab. IV. fig. 34 .

a. Fungus extuberans magnitudine naturalí.

b. Idem ut primum pileus in confpectum venit.

c. Idem, pileo adulto.

d. Idem, pileo jam aliquantulum depreffo.

d. Idem, pileo jam perfecte depreflo.

f. Idem, ftipite non nifi obfolete fulcato.

g. Idem, ftipite jam profunde fulcato.

h. Idem exoletus.

i. Fungus ad amufim fectus.

\section{HELOTIVM.}

Fungus perpendicularis, fugacifimus: Atipite capillari; pileo minuto, convexo, inferne nude fructificante?

OBS. Differt hoc genus a Lachino cel. Retzii in den Abbandl. der K. Schwed. Acad. d. WifSenfch. v. Jahr 1769. p. 254. n. 60. coll, Scand. n. 8643. habitu, vitze duratione \& fructificationis fede probabili.

\section{HELOTIVM glabrum.}

H. fugrcifimum, candidum: pileo \& ftipite glabris.

Habitus propemodum Agarici clavi L. Altitudo ftipitis fesquilinearis. Pileus minutus, fuperne convexus, inferne arcuatus, utrimque glaber, æqualis. Fungu- 
lus adeo eft delicatus, nt halita oris, cum eum propius intuearis, ftylus ftrietus, admodumque fubtilis, ftatim undulatus flaccefcat. In ramulis dejectis arborum, nec non in ftipitibus culmisve plantarum, ut in graminibus, putrefcentibus fparfim crefcit. Septembri.

Figurae explicatio.

Tab. IV. fig. 35.

a. Fungi magnitudine ac fitu naturali.

b. Fungi forma admodum extenfa.

\section{HELOTIVM birfutum.}

H. fugax, niveum: pilei fuperficie fuperna \& ftipite hirfutis.

Magnitudo ferme prioris. Pileolus ovalis, convexus, fuperne pilis albis, rigidulis hirtus; inferne glaber, fornicatus. Stipes fetaceus, attenuatus, pileo minus hirfutus. Simplici folum vice offendi fungillum longe rariffimum, fafciculatim in fragmine rami putridi, delitefcentis in cavernula radicali quercus cujusdam annofie, progerminatum.

OBS. Ex hujus fpeciei labieu verofimile mihi fit, quid! quod pene eft perfuafum, fructificationis fedem in hoc genere non $n$ ifi in area inferiori pilei effe quarendam; femina enim fungi fugaciorimi ipfa in neutra fpecie videre mibi contigit.

Figurae explicatio.

Tab. IV. fig. 36 .

2. Fungi magnitudine naturalio

b. c. Fungus amplificatus

b. a latere vifus;

c. perpendiculariter diffectus.

\section{TYMPANIS.}

Fungus cyathiformis: cupula fuperne volvata; fartura feminali ficca, conferta, in pulverem fatifcente.

OES, Differt hoc genus 1) a Lycoperdo, habitu; 2) a Peziza, cupula (emine farta; 3) a Tubulifera Cerato, Fl. dan. to osg. fo z. (T. Cremor, f. I, eft initium alius fangi) 
capfula imprinis perfifente, volmata; 4) a genere fequenti, cupulx repietura, qux hic eft ficca, feminibus nudis, conglebatis, difpergendis conftans; in Myrotheciis vero illa eft vifcido-lenta, non difpergenda; feminibus, ut in Phallo impudico $L$. liquamini huic infperfis.

\section{TYMPANIS Jaligna.}

T. feffilis, coriacea, atra, aggregata: cupula fubelongata, volva marginali difcreta; fartura feminali denfa, minuatim difpergenda.

E ligno ficco falicum denfe prorepit fungillus, globuli longe minutiflimi, atri forma; fed fuccrefcendo globularem figuram cum cylindrica fapiufcule commutat, apice femper obtufo-truncato. Dehifcit hic capfula glaberrima, nitidula, quo facto volva marginalis, feu velum quoddam, textura candida, bombacina, apparet, femina minima, granulato-conftipata, atra obtegens. Sed rumpitur paulo poft, colore jam in fufco-rubellum tranfeunte, \& femina difperguntur, quare capfulæ caffæ tum Pezizæ nigræ faciem præ fe ferunt. Figura \& altitudine fungus adultus admodum variat, fæpe bifidum, interdum digitatum, haud raro deformem \& connatum fe monftrans, apice nonnunquam prominulo. Ut de natura ejus notabili penfim inquirerem, multa exempla a cl. Timmio peramanter mihi funt mifla, vere medio lecta.

\section{Figurae explicatio.}

Tab. IV. 'fig. 37.

a. Fungi magnitudine \& fitu naturali pi\&ti.

$b-i$. Fungus admodum auctus.

b. protuberans;

c. capfula magis e ligno emergente;

d. velo fub afpectum veniente;

e. eodem perfecto;

f. eodem rupto;

g. capfula, ut poft veli interitum polline repleta in oculos incurrit;

h. capfula feminibus excuffis.

i. Fungi forma \& xtatis gradu diverfis. 


\section{$-$ \\ XI. MYROTHECIVM.}

Fungus cyathiformis: cupula fuperne volvata; repletura feminali lento-vifcida.

OBS. Differentia generis hujus novi 2 confmilibus ex Obfervat, ad proxime pracedens fade innotefcit.

\section{MYROTHECIVM roridum.}

M. [feffile, bombacinum, niveum: cupulis hemifphæricis, connatis, roridis; margine in volvam continuato; repletura feminali turgida, 'fufca.

Expanfum, feu vellus, bombacinum, niveum, lignifedum, unam ad duas unc cias longum, dum complanari incipit, cupulis femilinearis diametri denfe approximatis favi inftar mox lacunatum apparet, quæ maffa vifcida furca, cerato fimili, femina minima immixta continenti, fcatet. Quoplus cupularum compages floccofa fubfidet; eo plus facies ejus favoginea; fed ambitus illarum ex circulari tum fit elliptico-angulatus. Deftillant laticem ut videtur fubvifidum, fed pellucidum, ut aquæe puriffimæ. Semina liquamini infperfa \& huic ferme concoloria fuperficiem ejus occupant, \& forte ibidem generantur. In feftucis, ramentis affulisque querneis ac pineis, humi jacentibus \& crebro humectatis. Aprili, Majo.

OBS. Vidi varietatena, repletura feminali ex cinereo nigrefcente.!

Figurae explicatio,

Tab. V. fig. 38.

a. Fungi magnitudine \& fitu naturali.

b-f. Fungi lente ampliati

b. juniores \& adulti, rorantes;

c. grandrevi.

d. Cupula Cegregata velo integro;

e. eadem velo dehifcente;

f. eadem veli laciniis fecedentibus.

2. MYROTHECIVM inundatum.

M. feffile, bombacino-membranaceum, candidum: cupulis polymorphis, conD natis; 
natis, inundatis; margine in volvam continuato; repletura feminali modica, viridi, nigrefcente.

In fuperficie Agarici exficcati cujusdam albi, nigrefcentis, me fciente nondum diftincte defcripti, nec pieti, ad familiam vero Agarici integri L. referendi, eminent expanfa bombacina variæ figuræe ac magnitudinis, quae lacunata evadunt: cupulis nimirum excavata approximatis, initio rotundis, lenticulæ fæiffine diametro; fed poftea admodum dilatatis deformatisque. Repleturæ, feu mafl vifidx, color eft viridis; at feminibus granulatis poftmodum defuper telta nigrefcit. Cupulx frepenumero aqua hifce feminibus fuperfufa ftagnantur; cœlo licet fereno ac fudo. Textura earum denique tam condenfatur, ut membranacea ferme vocari queat. Junio, Julio.

Figurae explicatio.

\section{Tab. V. fig. 39.}

*. Fungi quidam magnitudine naturali.

b.d. Fidem amplificati

b. prima ætate;

c. tempore fructefcentix inftante;

d. tempore fructefcentiz ipfo.

\section{MYROTHECIVM ftercoreum.}

M. feffrle, membranaceum, nigrum, aggregatum: cupulæ margine in volvan fugaciffimam cotimuato? repletnra feminali turgida, albida, fufcefcente.

In ftercore canino, aeri diutius expolito, extus apparent granula longe minima, nigra, aggregata, mufcarum retrimento fimilia, quæ lente vitrea perluftrata cyathiformia agnofcuntur, Pezizis vuigaribus admodum affinia, extus tomentofa, colore caftaneo. Volvam marginalem non vidi, forte fugaciffimam. Repletura feminalis admodum tenax. 'Fungus inter rariffimos referendus vegetat Aprili.

Figurae explicatio.

Tab, V. fig. 40.

a. Fungi magnitudine \& fitu naturali.

b. c. Fungus mole adaucta pictus
b. adultus;
c. exolefcens. 


\section{MYROTHECIVM bifpidum.}

M. feffile, coriaceum hifpidum, fufcum fparfum: cupula margine in volvam continuato; repletura feminali fufcefcente, fubpellucida.

Diameter vix lineam æquat. Figura fungi, dilute fufci, initio globora, fenfim comprefia fit. Superficies externa cupulæ pilis acerofis hirta. Volva marginalis iisdem pilis, fed aliquantulum longioribus, conftat. Maffa feminalis primum fubpellucida. Fungus denique Pezizarum more conftringitur \& crifpatur. In cortice frondis aridæ Rofæ caninæ $L$. tempore pluviofo inveni eum fub finem Maji. Aeque rarus ac præcedens.

Figurae explicatio.

Tab. V. fig. 4r.

a. Fungi magnitudine ac fitu naturali.

b-d. Fungus lente ampliatus

b. volva marginali adhuc claufus;

c. tempore fructefcentix, velo recedente;

d. Cenefcens.

\section{MYROTHECIVM dubium.}

M. fefiile, parabolicum, aggregatum: cupula cortice proprio \& volva marginali deftituta; repletura feminali nigrefcente, exigua.

E ramulis dejectis Rofæ caninæ protuberat magnitudine feminis papaveris, epidermidem elevans, quæ ibi colore gaudet fature ac amœene fufco, apice vero ochroleuco mox dehifcit, quo facto liquamen feminale tenuius intus apparet. Non nifi femel obviam mihi factum, Martio.

OBS. Forte fungulus hic anomalus mera puftula eft, fucco extravafato diftenta, forfan vero rudimentum alius fungi: v. c. Sphxrix cujusdan e familia compofitarum, vifcidarum, in lucem nondum protractarum. Accedit faltem ad spheriam natantem (mihi) his zdfcribendam, de qua, Deo folpitante, tempore ac loco alio agam.

\section{Figurae explicatio.}

Tab. V. fig. 42 .

a. Fungi magnitudine ac fitu naturali.

b. c, Fungus lente auctus

1) 2

b. capfula 
b. capfula claufa;

c. hac aperta, feu rupta.

\section{XI1. VOLVTELLA.}

Fungus hypocrateriformis, ftipitatus: pilei fuperficie fuperna punctato-umbilicata, margine primum revoluto; repletura feminali fimilari, ftipite brevi, fetaceo.

OBS. Cum generibus $\mathrm{X} \& \mathrm{XI}$ admodum congruit: fed ab utroque tum ares punctata-umbilicatz, tum ftipite manifefto recedit.

\section{VOLVTELLA volvata.}

$\forall$. volvata, coriacea, fparfa; cupula hypocrateriformi; volva marginali difereta, revoluta, diffiliente; repletura unguinofa, in refinam coagulanda, comminuenda; ftipite perbrevi.

Color fungi albus, fulvefcens, demum flavofufcus. Diameter pilei linea minor. Formam hic hypocratcris cum patellae demum permntat. Volva candida, membranacea ita diffilit, ut fruftatim concidat. Repletura feminalis, cerati primo confiftentia, obdurefcit. Facies illi denique placentulæ refinofx, coloris ex fature fufco nigrefcentis. Excutitur hæc palam e cupula \& comminaitur, quod vero ghomodo frat, inter excutiendum puta, vel poftmodum, in tantulæ molis fungo difficile eft dictu; id cognitum compertumque habeo, maffam illam feminalem tandem plane difparere. Area punetata \& umbilicata tum vifibilis fit, colore ferrugineo, quaqua tecta erat, jam tincta. In ramulis exfuccis Pruni Ppinofe L, Septembri, poft dies humidas, aliquoties fe mihi obtulit.

OBS. Ex porulis, aream plinctatams redidentibus, maffam feminalem primo liquidam furlare, in aprico eft : id, quod affinitatem novi hujus generis cum Oaofpora, genere, fet, ut noninatam mallem, ortine Hedwigiano luculenter arguit.

Figurae explicatio.

Tab. V. fig. 43.

2. Fungi magnitudine \& fitu naturali delineati.

b-g. Tungus lente admota vifus.

b. Fungus 

b. Fungus junior defuper fpectatus;
c. idem in obliquum flexus;
d. idem, volva jam diffiliente;
e. idem, volva plane deftrueta;
f. idem, difco punEtato \& umbilico jam confpicuis;
g. Ichnographia fungi adulti per centrum difci defuper fecti.

\section{VOLVTELLA nuda.}

V. nuda, fugacifima, fparfa: pileo, plamo, nudo, primum revoluto, demam difciformi fimulque punctato-umbilicato; ftipite brevi, fetaceo.

Diameter pilei linearis; ftructura fungilli tam tenera, ut vita folum ephemerá gaudeat. Pileus candidus, quando margo ejus revolutus, cum difco orbiculatam, feu ómnimodo planam formam induit, punetatus primum \& umbilicatus apparet, tum vero depreflus fit, centro nonnunquam umbonato. Semina candida tam minuta funt, ut eoram infarctus, porulos pilei initio abfcondens, oculo vel armato perceptu difficilis fit. Color ftipitis niger. In culmo triticeo putrido femel vidi fungum longe rarifimum. Septembri.

OBS. Placentx feminalis comminuendx abfentiam fpeciem hane a congenere pracedente nimio pluts repellere, ecquis non videt? attamen habitus utramque arcte coniungit, cujus folius rationem, te tam perplexil hic efle habendam, equidem autumavi,

Figurae explicatio.

Tab. V. fig. 44 .

a. Fungi aliquot magnitudine fituque naturali.

b-e. Fangus lerte auctus

b. zetatis vere defuper vifus;

c. idem inferne fpectatus;

d. Fungus decrepitus transverfe contemplatus;

e. idem defuper vifus, 


\section{HYSTERIVM.}

Fungus labiato-globofus, feffilis: volva, feu capfula, labiato-findenda; fubftantia fublabiata, prominente, externe feminifera.

OBS. Novum miratuque dignum genus hoc indicavi in den. Schriften der Berlin. Gefcllfch. naturf. Freunde. Tom. V. p. 53; fed cum id temporis non nifi unicam ejus fpeciem nofem, definitionem 1. c. datam jam cum cantigatiore commutavi,

\section{HYSTERIVM quadrilabiatum.}

H. fubglobofum, fparfum: volva fungoque labiatis.

Defcriptionem figuramve vide fis 1. c. p. 54. tab. 2. fig. $I-6$.

\section{HYSTERIVM bilabiatum.}

H. ovale, fparfum: volvæ rima labiata ; fungo exlabiato, prominulo:

Priori fimile magnitudine arenula, loco natali, progerminandique modo \& tempore; fubftantia porro volvæ ttupofa, alba; fungi vero ipfius fimpliciffimi fuperficie glabra. At diffimile figura ovali; fubftantia fungi fubgelatinofa, fuperficie ejus æquali, feu labiis protuberantibus femper experte, dilute olivacea, feminibus minutiffimis albis adfperfa. E rima volvæ parum eminet. Vita fungilli breviffima. Semel modo fe mihi obvium dedit in ramufculo emortuo Pruni fpinofæ L. Martio.

Figurae explicatio.

\section{Tab. VI. fig. 45 .}

a. Fungorum agmen, magnitudine nativa pictorum.

b-g. Fungus maximopere ampliatus.

b. Fungus volva fuperne jam diffindenda;

c. idem tempore fructefcentix, rima volva diftenta, uti defuper vifus apparet;

d. idem, uti hoc tempore transvertim intuenti in oculos incurrit.

e. Fungus volva exutus;

f. idem quoad longitudinem diffectus.

g. Ichnographia fungi, volva inclufi, fructefcentix tempore ad amufim fecti. 


\section{$-$ \\ XIV. VERMICULARIA.}

Capfula globofa, feffilis, corporibus vermiformibus, liberis, feminiferis, repleta.

OBS. Fruetificationis nodo a Lycoperdo, ut a Trichia Hall. fatis tecedit, filis fcilicet feminiferis liberis.

\section{VERMICVLARIA PSendoppharia.}

V. globofa; aggregata: capfula granulata, nigra; filamentis feminiferis, liberis, nudis, albis.

Capfula fubcompreffa, tenera, non fragilis, ut in Sphæriis, nudo oculö puncti inftar apparens, filis brevibus, laxis, confertis repleta, quse feminibus minutiffimis albis circumquaque funt obducta, Filamenta hæc vermiformia tabefcendo demum labafcuntur, colore tum in aureum, vel potius aurantium, mutato. Capfula utrum demuin dehifcat, an fatifcat, dicere nequeo. In libro rami quernei putrefcentis femel obfervavi, Martio.

Figurae explicatio.

Tab. VI. fig. 46 .

a. Fungi magnitndine $\&$ fitu naturali pikti.

b-d. Fungus Iente auctus

b. a latere vifus;

c. e vertice fectus.

d. Fila vermiformia feminifera,

\section{VERMICVLARIA pubefcris.}

V. 'globofa, fparfa: capfula pubefcente, bicolore; filamentis liberis, nadis, canis.

Magnitudo capfula fubcomprefre ferme ut feminis Brafficx; fuperficies byffina, albida; textura levidenfis, colore faturate aureum Arfenici rubri imitante. Filamenta vermiformia feminifera incana, tenerrima, coaretata. Obvenit in ramulis dejectis, farmentisque aridis, tempore pluviolo, Julio.

Figurae 
Figurae explicatio.

Tab. VI. fig. 47.

2. Fungi magnitudine \& fitu naturali.

b. c. Fungus microfcopio amplificatus

b. a latere vifus;

c. ad perpendiculum fectus.

\section{VERMICVLARIA bipida.}

V. pulvinata, fparfa: capfula hifpida, nigra; fetis primordialibus volvam fugacem in vertice conftituentibus; filamentis feminiferis liberis, demerfis, albidis.

Primarn fpeciem magnitudine requat. Capfula, pomi aurantii forma, prima ætate ubique hifpida, fetis nempe in vertice ita conniventibus, ut ejusmedi volvam radiatam conftituant, qualis in Pezizis frepiuscule obfervatur. Eodem nempe modo fetæ primordiales confertæ, fungo magis magisque fe extendente, dirimúntur \& recedunt; fed tum, ut in Pezizis, capfula non aperitur, fed, mirabile dictu, claufa, feu integra, remanet: fuperne tunc glaberrima, nitidiufcula apparens, colore dilutius nigro; vertice depreffo-umbilicato, poftremum decuffatim rugofo. Fila vermiformia albida, licet libera; medullæ tamen cinereæ, mollicellæ, furfuraceæ immixta reperiuntur, id quod huic fpeciei peculiare eft. Fungillus cæaterum fatis firmus, cortice fcilicet, feu capfula lenta, membranacea inftruetus, formam quodammodo infulæ, qua utuntur principes, habet. Reperi illum in ligno putrefcente Sambuci nigræ L. Aprili, una folum vice.

OBS. Obveniunt, ut ex defcriptione palam eft, in hac fpccic, nonnulla phenomena, qux in definitionem genericam non omnino quadrare videntur; fed modus pracipuc fructificationis me perpulit, ut fungum ad Vermicularias ablegarea?.

Figurae explicatio.

Tab. VI. fig. 48. ,

2. Fuńgi magnitudine \& fitu naturali picti.

b-e. Fungus admodum amplificatus

b. volva adhuc claufa, feu integra;

c. eadem jam diffoluta.

d. Fungus obfolefcens;

e. Fungus adultus, e vertice diffectus. 


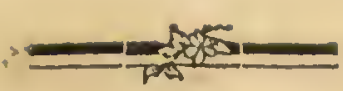

\section{PYRENIVM.}

Fungus globofus, feffilis, integerrimus: cortice, feu fubftantia, femina nuda, conglobata nuclei inftar includente.

OBS. 1. Differt hoc genus fructificatione non flamentofa 1) a Iycoperdo L. 2) a Trichis Hall. 3) a Mucore Septico L. fummo jure apud cl. Wiggerfinm, Holf. p. 112. novum genus, nomine Fuliginis' ex Hall. petito, conttituente; 4) a Mucore cruftacso, erecto, cxt. Mülleri, Abh. d. K. Schw. Acad. d. W. 1769. p. 68. t. 3. f. 2-5, eodem cum Mucore fpengiofo Leyff. Hal. 2, n. 1274.

2. Superfunt in una alterave fpecie, quas fub hoc genere confociates hic fifto, nonulla adhuc altius ximanda, qux confectari mihi quidem huc usque non licuit,

\section{PYRENIVM lignorum.}

P. globofum, fparfum: cortice bombacino; nucleo feminali fatifcente.

$$
\text { a. vulgare. }
$$

Forma globofo-compreîa, fepiuscule ovato-elongata, diametro lineæ unius in tres \& quod excurrit. Cortex candidus, bombacinus, tener, fubfidens \& in vertice præfertim fungi evanidus. Nucleus, granulis minimis conftat conglebatis, æruginis æris amœniffimo colore, quæ femina mihi videntur. Auctumno poft pluvias iteratas in virgultis emortuis ramulisque decuffis crebro confpicitur, quandoque fparfim, fæpe vero agmine denfifimo crefcens.

Figurae explicatio.

Tab. HI. fig. 29.

ล. Fungi magnitudine fituque naturali delineati.

b. Fungus lente auctus, ad perpendiculum fectus.

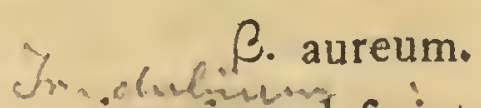

Tantum fabrica a fungo jam jam defcripto difcrepat, ut agre pro mera ejus varietate haberi poffe videatur. Figura ovalis compreffa; cortex tomentofus, diffiliens, coloris aurei; nucleus mollicellus, comminuendus, colore ex albido ad aurantium vergente. Sparfim habitat fungulus tener, perrarus, lineam longus, in ligno nudo ramorum fagineorum putrefcente. Majo. 


\section{PYRENIVM metallorum.}

P. comprefium, adfcendens, imbricatum, hirfutum: pulpa furfuraceo-lamellata: nucleo femirali globofo, d.:riore.

Fungus magnitudine femini papareris dimidiato æcquiparandus, aggregatus e metalio progerminat, forma irisio pulvinata, colore aquæe marinæ cum viridi æris mixtæ. Superficie ferme integra inferiore id ætatis adhæret natali fedi; fed temporis progreffu e complanandi marginis ambitu fere omni prodeunt cilia nivea nitida, fimulque fuperficies fuperna fungi hucusque tomentofi, fed jam hirfutuli, colore lætiffimo cæruleo, Vltramarino pißtorum fimili, exfultare incipit. Tum vero totus marginis ciliati anfractus folo avellitur eumque in modum elevatur, ut jam fungus ex feffilì erectus, vel ftrictus, fiat, quarta circiter marginis parte, ut Boletus verficolor L. fedi affixus; Agaricorum Boletorumque imbricatorum habitum hac nova directione præ fe ferens. , Subftantia ejus fpongiofa bracteolis minimis, fubtitifimis, conrolutis, friabilibus, æruginis xris colore conftat. Nucleum, quem circumdat, atro-fufcum, compactiorem, duriusculum, nec diffractu facilem, inveni. Monftravit mihi fungillam jucundiffimum, rariffmum, unicumve, quem nnquam e metallis enatum vidi, e fclopeti manualis tubo interne extuberatum Vir Generofiffimus C. zon Laffert, in Groffen-Welzin Toparcha, rerumque natura a teneris unguiculis obfervator fagaciffimus ac diligentifimus, et, qux fua eft humanitas propenfusque in me animus, quo facilizs naturam plantæe a fe detectre fcifcitarer, fclopetum ipfum benigniffime mihi commodavit. Durabilis admodum fungus hic fingularis videtar; perfiftentem ialtem jam nofco. Primum vidi menfe Augunto 2nni proxime przterlapfi.

Figurae explicatio.

Tab. VI. fig. 49.

a. Fungorum magnitudine naturali pictorum agmina.

b-e. Fungus forma extenfiore reprefentatus

b. proveniens;

c. adultus, a latere vifus.

d. Fungi imbricati defuper vif:

c. Fungus ad amuffim fectus.

OBS, Figura d, fungi adulti ferme cernui \& proní, non vero, tti natura corun eft confentaneum, ad angulum rectum a folo elevati videntur, at non in adumbratione fungo- 
rum ipforum, fed in fitu modo plagx natalis, in relatione ad eos pingentis incuria nimis obliquatx, peccatuin elt.

\section{PYRENIVM terreftre.}

P. globofum, aggregatum: pulpa gelatinofa; nucleo cereo fubrecedente. An Lycogala terreitre etc. Mich. F. G. p. 216. n. 5. t. 95. f. 5? forte fungus junior; defcriptione certe ac figura cum noftro fatis convenit.

Fungi rotundati, fæpenumero globofo-elongati, depreffi, pifi magnitudine modici, interdum multo minores, confertim e folo proveniunt nudo, fterili, fqualido. Subftantia, feu pulpa, eorum gelatinofa, indurefcendo gummata, fuperficie externa eft obfolete papillora; interne vero aequalis, utrobique coloris aurantii. Nucleus, ejusdem cum pulpa formæ ac coloris, ab hac tandem quaquaverfum, fola bali excepta, fecedit, ut quafi inflata appareat. Malchino mihi primum exempla mifit amiciffimus mihi Timmius, Junio; fed \& a me ipfo poftea lectum.

OBS. Verifinile quidem admodum eft, maffam inclufam, feu nucleum, ab includente, feu pulpa, confiftentia non folum, fed \& ftructura differre, globulum proin, de quo egimus, nil nifi concretum feminum minutiffmorum effe; at enim ne de his, qux mihi in perforutatione fungi innotuerunt, quicquam filentio prxteream, vacillantem paululum in mea fententia reliquit pulvifculus fulvus, quo fuperficiem ejus adrperfam inveni. Nibil enim obltate videtur, quo minus hic pro femine habeatur, cum 1) fungi natura primitus fit gelatinora Trenellarum, quarum quidem pars maxima ejusmodi fructificatione fuperficiali infignitur; tun quod 2) ipfe in nucleo fementem nec jam formatam, neque- hujus rudimenta dittincte obfervaverim: quare poffibilitas omnino fubeft, fubfantiarn fungi omnem omnino cfie fimilarem, gelatinofo-unguinofam puta, qux pro ratione diverfa, qua rigefcit, h. e. extrorfum plus, quam introrfum, heterogenea demum vił́ri, eadémque de cavéa inter rigefcendum perfacile intus dehifcere potest. Aecidct igicur fortaffs, He, fungilli indole penitius quondam explorata, hic e pyreniis excenturiatus aliquorfum, fub generc, inquam, a noltro plare diverfo, militatum abire jubeatur.

Figurae explicatio.

Tab. VI. ${ }^{-}$fig. 50.

a. Fungorum celpes magnitudine naturali pictorum.

b. c. Fungus lente ampliatus
b. integer.
c. medio diffectus. 


\section{XYLOSTROMA.}

Expanfum coriaceum, bilateraIe, deforme, interpolatum: fuperficie lævi, aequali; globulis feminalibus minutiffimis, intus fibrillis fungi infidentibus

\section{XYLOSTROMA giganteum.}

X. centrale, lobatum, giganteum, ochroleucum: centro fungi ex transverfo fecti comprefio-elongata; lobis radiantibus, divifis, decrefcentibus.

Fungus ampliffimus Scop. Pt. Sitbtexr. p. II6. n. 69. t. 44.

Oak-Leather Raj. Syn. p. 25 n. 2\%. tefte Lightf. Scot. p. Ioo4, qui fub Byffi candidæ fuæ varietate $\beta$ fungum noffrum defcribit.

Centralem voco fungum immanem, quod in centro femper truncorum adhuc vegetantium, præfertim in quercubus vetuftis, quarum jam fracta funt cacumina, generetur. In his trunci axem primum occupat, \& mox faciem quadammolo fariformem, feu, ut rectius dicam, cunei ancipitis, his e. duorum cuneorum vertice connatorum, affumens, direçione horizontali fimul \& verticali arborem penetrat, actione fua in modums cunei fpatium magis magisque dilatatum, quoj fuccrefcendo inveftiat, repleatque, fibi acqnirens. Idem quoque de alis, feu lobis, e centro communi radiorum inftar truncos permeantibus, pluriesque divifis, valet: hi enim ceu totidem cunei elongatî e centro transverfali trunci corticem verfús directi confiderandi funt, lignum proinde quacunque perretrant, findentes, in qquod ope htimoris cujusdam, quem continent, aciduli tanto facilius efficitur, quippe fibrarum lignearum "compagem folventis earumque corruptelam accelerantis; quo enim pertingit fungus, putridum \& plane exfuccum reddit arboris lignum. Subftantia fungr alutx, feu nebridi belle elaboratæ, admodum fimilis eft, lenta, elaftica, tactu fuavis, extus glabra, æequalis, colore ochrolenco, magis ant minnus albicante; intus fibrillis validis denfe perplexis albis contexta, quibus adhærent femina longe minutiffima, quæ fimulatque fungus dirnmpitur, nubecula inftar in altum fublata difparent. Natura gaudere videtur fere incorruptibili, ut ex fragmentis ejus, a me jam ultra feptennium farta tecta, fine ulla habitus deformatione confervatis, conjicio. Diameter minor fubftantixe centralis lineas 3 usque ad 6 aequat, Iamellarum 
vero majorum, ubi e centro egrediuntur, bilinearis craffities, hac jugiter, ut jam monuimus, antrorfum decrefcente. Longitudo perpendicularis fungi ftupefaciens, integrum fcilicet arborum truncum pedetentim pervagantis. Sæpius illam decempedalem, nonnunquam hac multo, quin duplo forte majorem comperi. Ignem exficcatus optime fovet, odorem tum aduftione fpargens haud ingratum: quare quin, curatura vel mediocri adhibita, ex-illo fomes igniarius parari poffit, minime dubito.

OBS. Maximus hic indigenorum et forte omnium omnino globi terraquei fungorum plus una de caufa valde memorabilis, mihi videtur. Nam I) quaftio hic oritur, quo demum pacto fit, ut femina ejus in cor quari arboris duriffmx penetrent, ibi germinatura? Adfupuit jam lynceus Scopoli" fimili naturx mirando'in fungorum fubteraneorum genefi, l. c. p. 119. 2) Fungers nofter, rudis vifu indigeftaque moles, admodum pro fententia corum propugnat, qui omnem veri nominis fungum non nif̌ e verz nominis femine oriri contendunt.

Figurae explicatio.

Tab. VI. fig. $5 \mathrm{r}$.

a. Fragmentum fungi in varios lobos expanfi, magnitudine naturali pictum: (adhærentibus illi ligni exefi particulis.)

b. Truncus arboris transverlim fectæ, ut diameter centralis fungi una cum lobis inde radiantibus, ita ut ligni putredo, pari paffu cum fungo procedens, tanto facilius confpici queat.

c. Particula lobi diffecti admodum aucta, quo melius fungi fruetificatio illuceat.

\section{CHORDOSTYLVM.}

Fungus ftipitatus, tenacifimns: capitulo globofo, interne fructificante, fubdeciduo; ftipite longiffimo, tenacifimo, fubramofo.

OBS. Differt a Mucore Mucedine I. feructira prafertim valiila ac firma, vita fpatio \& fi pite fere femper ramofo, vel divifo: a Byllo vero frectificationis tatione diverín ent, ut ab Usinea cl. Wiggers; ab Usnca Scopoli Subt. p. 94, in emnibus ferme differt.

\section{CHORDOSTYLVM capillare.}

C. 'erectum, fparfum: itipite capillari, glabro, integerrimo; capitulo fpharico, fatifcente. 


\section{CHORDOSTYLVM.}

Stipes capillaris admodum tenax, unciam ut plurimum longus, albidum colorem mox fpadiceo mutans, principio rectus, adultior flexuofus, tum vero reclinatus eft $\&$ denique complanatus tortilisque fit,-fulco utrimque longitudinaliter jam exaratus. Capitulum minutiffimum \& in oculos vix ineurrens, ochroleuci coloris, vertice demum nefcio quomodo ruptum, feu, fi mavis, diffiliens, pulverem fpargit dubio procul fementivum, qui utrum pulpa ipfa capituli fatifcentis, an polline, usque eo capfula inclufo, conftet, fungorum fcrutatori vel acerrimo haud facile, puto, unquam liquebit, globuli etenim maturefcentes fuccuffu quovis de ftylo deturbantur, tum vero in examen non amplius revocandi. Fungus fparfim ramis ramulisque deciduis ac emortuis increfcens haud raro per æftatem occurrit, imbribus præviis.

Figurae explicatio.

\section{Tab. VI. fig. 52 .}

a. Fungorum grex magnitudine naturali pictorur.

$b-f$. Fungus lente auctus
b. junior;
c. adultus;
d. tempore fructefcentix;
e. aetate provectus.

f. Capitulum e vertice diffectum, nempe ut femel, lente \& cultello mifere in fublidium vocatis, ftructuram tum ejus internam vidi.

\section{CHORDOSTYLVM by foides.}

C. erectum, byffinum, aggregatum: ftipite capillari, debili, ramofo, pulverulento-tuberculofo; ramis fubdivifis, patulis; capitulis terminalibus globofis, circumfciffis? majusculis, deciduis.

Infolitæe adnodum naturæ planta adeo parva \& fubtilis eft, ut oculo non armato faciie lateat. Capitulum globofum glabrum, atrofufcum, majusculum, circumfcifum, feu, fi mavis, protuberantiis longe minimis pulverulentis, rofaceocongeftis, fufcis, immerfum, ftylo infidet flexo, æque fufco, grumulis pulverulentis concoloribus, confertis, diftincto; ex quo prodeunt rami ejusdelis cum ftipite naturæ. Excuffis globulis terminalibus ut ille albefcunt \& decumbunt, grumulis 
pulverulentis tum plane difparentibus; globulis vero deturbatis ad bafin plantæa affatim confpicuis. Reperi hyeme in fuperficie \& ad.marginem chartarum fcriptoriarum complicatarum \& prope ad feneftras mufei repofitarum, q̨uæe cum vaporibus in guttas condenfatis; ut fieri folet in conclavibus calefactis, crebro maduerint, per totam hyemen hafce chartas margine \& fuperne rore fubtilifimo confperferunt humectaruntve, itaque immenfo pene fungorum jam defcriptorum numero folum luxurians \& hai to culum præbuerunt.

OBS. Fungus hic fane Byflum filamentofam valde aemulatur; fed capitulorum magnitudo \&: ponderofitas me ferme cogunt, ut pro capfulis femine repletis qualicunque modo quandolibet rumpendis habeam: a Byflis ideo, plantis fimplicifimis, feparare volui; adde quod grumulx illx pulverulentx ac evanidx ftipitis fingulare quid \& ad Lichenum naturam tendens annunciare videantur. Cxeterum cum nemine litigabo, cui fungillus nofter chordoltylum vitio creatum fortafle vifus fuerif; at redeat hac fede fua, usque dum naturx fcrusator me oculatior commodiorem ei afignaverit.

Figurae explicatio.

Tab. VII. fig. 53.

2. Fungi magnitudine \& fitu naturali pieti.

b. Fungus perquam auctus.

\section{CHORDOSTYLVM bifpidulum.}

C. repens, tenaciffimum, hifpidulum: furculo capillari decumbente, ramofo, fubradicante; ramis apice tumefcentibus \& in calycem abeuntibus; capitulis obovatis, immerfis.

In foliis putridis, prafertim fagineis, e bafi byffina ftellari figillatim protuberant furculi capillacei, flexi, initio candidi, acuminati, feticulis ejusdem coloris hirti, erecti, fed poftmodum decumbentes, colore tum in amone fpadiceum mutato. Crefcunt in longitudinem $\mathbf{I}, 2$ usque ad 5 unicartum \& plerumque fiunt ramofi, ficque totam fuperficiem foliorum deciduorum, quibus feticularum illarum ope arfte adhærent, perrepunt, apice haud raro radicante. Ramî répentes tandem adfcendunt, apicem verfus intumefcentes \& quafi inflati, in tubulumque terminati, qui calycis vicem fubit, cum ei globnlus femirralis obovatus, glaberrimus, nitidus, folidus, caftanei coloris, ad medium usque infideat, de cujus fructificatione equidem nil céti in publicum promere poffum. Fungus fenefcens in colorem fordide rubel- 
lum expallefcit, fetulas fuas tunc omnino amittens. Cæterum folia arborum putrefcentia fuper \& inter quae frequentiffimus habitat, ramis fuis vagis ita compaginat, ut difficile feparentur. Per integrum auctumnum ad brumam usque viget.

Figurae explicatio.

Tab. VII. fig. 54 .

3. Fungi magnitudine \& fitu naturali picti.

$b=f$. Fungus micrófcopio adauctus

b. progerminans;

c. adolefcens, capitulo fe calyce jam exferente;

d. adultus, capitulo ad medium usque exferto.

e. Capitulum calyci in apice tubulofo ftyli infidens;

f. idem in hoc fitu ad amuffim fectum.

\section{CHORDOSTYLVM Clavaria.}

C. erectum, tenacifimum, fimplex: ftipite capillari, glabro, flexuofo; capitulo pyriformi, coriaceo.

Stipes unciali circiter altitudine, ater, complanatur demum \& utrinque longi tudinaliter fulcatur, quod fiftulofum eum effe teftatur. Capitula cándida, aequalia, primum obovata, pyro demum admodum elongato fimilia fiunt, fimulque ftrigofa, denique vero complanąta evadunt: quare intus excavefci admodum probabile eft. Fungus, uti ex hac defcriptione elucet, naturæ dubire, quodammodo ad Clavarias fimul \& ad Afcophoras, qnin ad Acrofperma accedit; fed a prioribus capituli \& ftipitis cavitas; ab Afcophoris vero fubftantia fimilaris continua; ab Acrofpermis denique capitulum unaquaque feminiferum, (hoc enim ex ejus colore ubique eodem, omnisque nitoris experte conjicio) fegregat; nihilominus illum hic locum fuum non nifi precarium occupare, haud gravatim largior. Agedum, maneat transmigrationem fibi forfan impendentem! Semel modo hac usque fungillum. memorandum inveni, in fibra fcilicet exgrumante radicis fagineæ, Septembri.

Figurae explicatio.

Tab. VII. fig. 55 .

a. Fungi quidam magnitudine naturali.

b. c. Fungus lente auktus. 
b. Fungi xtate diverfi.

c. Capitulum fungi junioris per verticem fectum.

\section{PILOBOLVS.}

Fungus ejaculatorius, ftipitatus: ftipite capillari, fuperne ventrico. fo, hydrophoro; placenta feminifera dejicienda pileum conftituente.

\section{PILOBOLVS cryftallinus.}

P. fugax, cryftallinus, aggregatus: ftipite pellucido, rorido, lutefcente; pileo comprefio, glutinofo, atro.

Mucor obliquus Scop. Carn. 2. p. 494. n. 1643.

Pilobolus cryftallinus Tod. in dels Schriften der Berlin. Gefellfch. naturforjck. Fr. Tom. V.p. 46 . t. I.

Hydrogera cryftallina Wigg. Holf. p. I IO. n. Ixgs.

Mucor urceolatus Dicks. Pl. cryptog. p. 25. "t. 3. f.6.

Ad defcriptionem uberiorem hujus fungi 1. c. a me fuppeditatam nil hic addendum invenio, nifi me varietatem, capfula folum hydrophora, aliquantum ftrictiori, a fpecie vulgatiffima differentem, in ftercore humano femel obfervaffe.

\section{THELEOBOLVS.}

Fungus ejaculatorius, feffilis, fphæriæformis: fubftantia \& placenta feminali dejicienda folidis, gelatinofis.

\section{THELEOBOLVS ftercoreus.}

T. globofo-compreffus, croceus, confertus: fubftantia confidente; placenta, vel vafculo feminifero, papillæeformi, circumfciffo.

Magnitudo fungi femine papaveris aliquantum major. Facies primo admodum Sphæriæ flavæ: placenta mempe feminali papillæ in modum prominente. Forma hujus noftri principio ut pomi aurantii, fuperficies glabra; fed Pezizarum more bafin 
bafin verfus pilis eft inftructa, fibrarum radicalium vices obeuntibus. Quando propullulat, color ei eft pallide luteus; aft vertitur hic amplius ampliusque in croceum. Color aureus primum in vertice fungi apparet, qui mox intumefcens placentam feminibus fœtam ejusdem coloris, pulvinatam, glaberrimam, nitidam, ita protrudit, ut margini fungi in membranulam, feu volvam marginalem; terminato, hac ad mediur usque oblaqueatus, ceu cupulx cuidam infideat, unde faciem tum aequirit circumfcifam. Sad vi mox infigni elaftica ex illa thridulus projicitur, quo facto alveolus, quem mole fua expleverat, jam fuperficie nitidus fubvifciànque patet. Dilatatur vero abhinc tantopere, altitudine interea temporis femper decrefcens, ut tandem vertex fungi in planum, ut loquuntur Geometræ, horizontale transmutetur: quare demum truncatus \& Elvelis, quas Difcos Scopoli nominat, fimilis apparet, margine filicet ejus membranaceo evanefcente. Cum vero omnes hae phafes brevi admodum temporis fpatio abfolvantur, in ftatu jam jam defcripto, poftremo ut plurimum reperitur fungus, cuin Patellis cl. Wiggers tum perfacile confundendus. Cutis ejus membranofa; fubftantia albida, mollis, getatinofa. Fungus exoletus deaique rufefcit. Vafculum feminale ob nimiam minutiem cum glabritate conjunctam cuitello rite diffecare non potui, attamen folidum mihi vifum fuit. Agminibus denfifimis poft temptis pluviofum provenit fungillus, ovulorum minutorum pifcium congeriem fimulantibus; \& quod illi peculiare eft, folummodo in fuccerda; attamen femel eum in ftercore quoque humano inveni, femper vero mentibus Junio \& Julio.

OES Perfuafum eft mihi, fungos fortafle bene multos, qui Pezizarum truncatarum formam

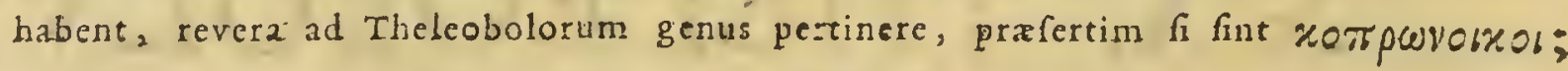
attamen huic generi minime fubjungenda eft Patella minima Wigg. Hols. p. ro\%. coll. p. III. licet fit ftercorea \& ratione formx cum fungo noftro, imprimis quándo veterafcit, adeo conveniat.

\section{Figurae explicatio.}

Tab. VII. fig. 56 .

a. Fungorum agmen magnitadine natnrali tantillum majori depictorum. - h. Fungus lente adauctus

b. proveniens;

c. adultior, vafculo feminali jam fe exferente;

d. fungus iu ftatu fructefcentix; 
e. idem, fructefcentia jam jam peracta;

f, idem hac aliquantifper jam confummata;

g. idem grand’evus;

h. idem xtatis flore ad amuffim fectus.,

\section{SPHAEROBOLVS.}

Fungus ejaculatorius feffilis, globofo-concavus: vertice radiatim findendo; veficula feminifera globofa, ejicienda.

Carpobolus Micheli.

OBS. Optimo exemplo genus hoc Michelianum a Linnaco elininatum reftituit cl. Willdenow Berol. p. 414. Sed neceffe erat, ut nomen Carpoboli nimis vagum iam cum ali. commutaretur.

\section{r) SPHAEROBOLVS fellatus.}

S. globofus, volvatus, liber: volva fugaci, albida; fungi concavi, bi-lamellati lutei, dehifcentis limbo patenti-reflexo, ftellato; veficula feminifera albefcente. Lycoperdon Carpobolus L. Sp. pl. 2. p. 1654.

OBS. I) Omitto hic nominis hujus trivialis crebram repetitionem, in Floris recentioribus haud raro obvii, cum ex fola, ad quam carum conditores ibi provocare folent, aucoritate Linnaeo-Micheliana nou fatis conftet, utram de duabus varietatibus infequentibus videtint \& inmuant.

2) Volvan fungi nuncupo integumentum ejus externum, cereum, albidum, omnes ve$r 2$ volv $x$ notas habens; fungum ipfum volva nomine infigniri noluerin: nec a fe impetrare id potuit difpex Hallerus. Hiftoriam cxterum ejus ut poft Micbeli hic repetain, nemo, credo, facile expectabit. -

\section{c. bi- Ptellatus.}

A varietate fequenti diverfus fubftantix lame!la utraque: h. e. interiore non minus, quam exteriore, ftellatim findenda, priorique una cum vafculo feminali ejaculanda.

Mich. F. G. p. 22I. n. I. t. IOI. f. I.

Hall, hifl. p. II9. n. 2175 . 


\section{SPHAEROBOLVS.}

Lycoperdon Carpobolus Bat ch. Jen. p. I53. Defcriptio concentrata, fida; aft fungus non femper 6 -fidus, fed plùies 7 -fidus, in noftra faltem regione, invenitur.

ß. uni-Atellatus.

Varietas hæc a præcedente admodum diverfa: fungi nempe lamina interiore una cum globulo feminifero minime ejaculanda; fed in loco priftino poft fructefcentiam perfiftente; margine ejus infuper non ftellatim fifo, fed obfolete folummodo incifo, vel emarginato. Nec lamina exterior tam fifla apparet, ut in varietate $u_{\text {. }}$

Mich. p. 22I. n. 2. t. IOI. f. 2.

Lycoperdon Carpobolus Fl. dan. t. 865. Figura cum natura admodum conveniens, \& quantum varietas hæc a priori diverfa fit, primo obtútu utramque comparantem edocens; fed omiffas in veficula feminali doleo venàs turgidulas, illam ubique, ut arteria coronaria cor humanum, cingentes.

OBS. 1) Spectaculum fingulare prabet obfervatori agitatio vehemens in fluido, liquenti melli fimili, fulvo-fufco, fundum fungi junioris inundante, confpicua, quando velicula feminalis primum ex eo liquore formatur \& emergit: vivere omnia, feu motu animali huc illuc feiri diceres. Idem fpectaculum offert veficula hac quando explofioni proxima vim quandam externam patitur: quare miror, Hallerum nil horum unquam vidiffe.

2) Fungum had admodim rarum lignarium effe \& a uqumno vigere, inter omnes conftat.

\section{SPHAEROBOLVS rofacens.}

S. urceolatus, nudus, immerfus, candidus: limbo rofaceo-reflexo; veficula feminifera albefcente.

a. floriformis.

Magnitudo quandoque præcedentis, interdum hoc minor; fed multum ab illo differt forna \& orificio femper aperto, limbo rofaceo-reflexo; colure candido; fuhftantia non bi-lamellata, coriacea; fitu porro non libero, cum ad limbum usque fit lignis immerfus; materia demum vifcidula, ante formationem veliculæ feminalis membranula tecta, quæ tandem in veficulam illam ipfam abit. Quibus omnibus ádde, fpeciem hanc priori longe effe rariorem \& precipue in aridis fagorum admodum 
modum juniorum radicibus, nec non interdum in cortice ramorum emortuorum Pruni fpinofa L. gregatim nidulare. Floret auctumno.

Figurae explicatio.

Tab. VII. fig. 58.

2. Fungi ligno immerfi magnitudine naturali,

b-d. Fungus per microfcopium vifus.

b. Veficula feminifera jam protuberante.

c. Fungus veficulam hanc ejaculans.

d. Fungus junior defuper fectus.

f. repandus.

Non nifi limbo repando \& bafi fubcomplanata a varietata $\alpha$ differt. Detexi florentem in radice exficcata Carpini Betuli L.

Figurae explicatio.

Tab. VII. fig. 58.

Fungus lente auctus ad perpendiculumque fectus.

\section{ATRACTOBOLVS.}

Fungus ejacnlatorius, feffilis, cupularis, operculatus: veficula feminifera fufformi, ejicienda.

\section{ATRACTOBOLVS ubiquitarius.}

A. pezizaeformis, albus, aggregatus; velicula feminifera rubicunda.

Peziza annularis Batfch. Fung. cont. I. p. 20I. t. 26. f. 139.

Admodum parvi \& abnormis fungi catervæ nudis oculis farinǽ fparfæe inftar appatent; lente vero perluttratæ cupulæ albæe agnofcuntur limbo patente, fell deflexo, upercul: plano, umbonato, ejusdem coloris tect extus, uti fuperficies cupula, granulato. Veficula feminifera fuffformis, feu elongate ovalis, glaberrima, pellucida, rubicunda, reita, laticem concolorem, feminibus procul dubio permixtum, iovet. Vi fua elaficica veficula hrec operculum cupula, quod ubi limbus deflectitur, illi quafi agglutinatum eft, trudit, (unde ei facies umbonata;) usq̧ue dum, hoc revilfo \& propulfato, e carcere quali fuo tempore fruftefcentix exfiliat, erup- 
tionem fimulac fecit, comminuenda. Mirabilis profecto hujus fungilli videtur procreatio ac habitatio; polt pluvias enim, præfertim ubi coelum tonat, denfe cadentes nbique ferme \& ubi alium nunquam fungum vigere cernas, h. e. in fuperficie adverfa, ita ut averfa, lapidum, offum, lignorum, caet. humi jacentium, præcipue in eorum rimis, fulcis ac cavernulis, aquam pluvialem aliquamdiu retinentibus, quam copiofiffme provenit: quare illi noinen ubiquitarii indidi. Cæterum ejus femina cum pluvia in terram deferri, ex iis, qux jam retuli, fole, puto, clarius eft. Augufto.

Figurae explicatio.

a. Fungi magnitudine naturali.

Tak. VII. fig. 59.

b-g. Fungus admoduni austus

b. operculo claufus;

c. hoc remoto apertus:

d. Operculum fungi.'

e. Fungus ad perpendiculum fectus.

f. Veficula feminifera;

g. eadem ex apice diffecta.

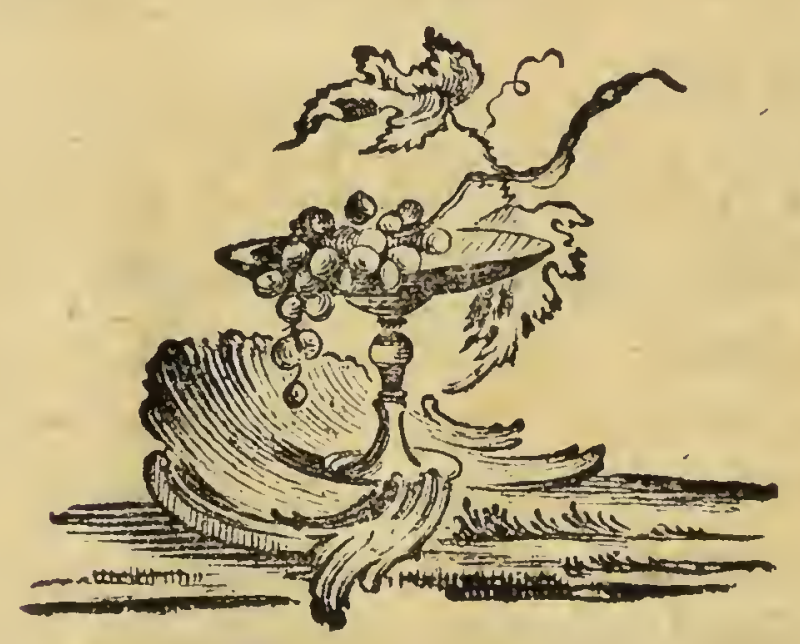




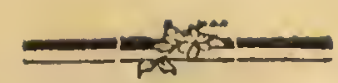

-

\section{SYNONYMA OMISSA.}

r. Ad SCLEROTIVM Semen p. 4. addendum:

Lycoperdon oleraceum Pollich. Palat. III. p. 3 I0. n. II99.

(Defcriptio fungi veterafcentis.)

2. Cum ACROSPERMO lichenoide p. 9. conferendus

Lichenis phyfodis var, prima Scop. Carn. 2. II. p. 393. n. I405. (I)

(Ergo jam huic fungus quidam lichenoidafter innotuit.).

3. ASCOPHORAE Mucedini p. I3. adjiciendus,

Mucor roridus Willden. Obff. bot. im vierten Stïck des Magazins für die Botanik. p. I8. n. 2I. f. I\%.

4. VOLVTELLAE nudae p. 29. adfcribatur

Peziza amenti Bat/ch. Fung. cont. I. p. 21r. t. 2\%. f. 148.

(Differt folummodo magnitudine \& colore.)

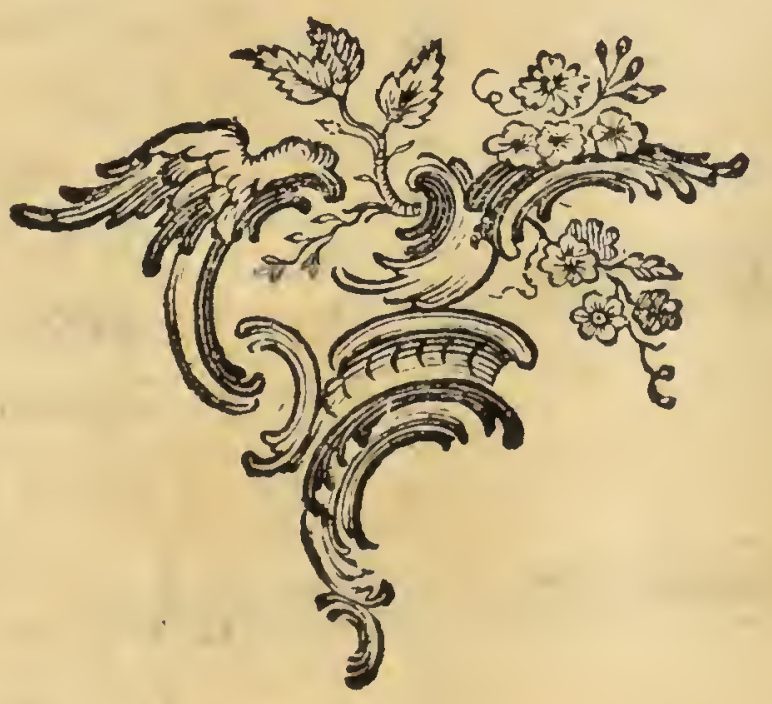




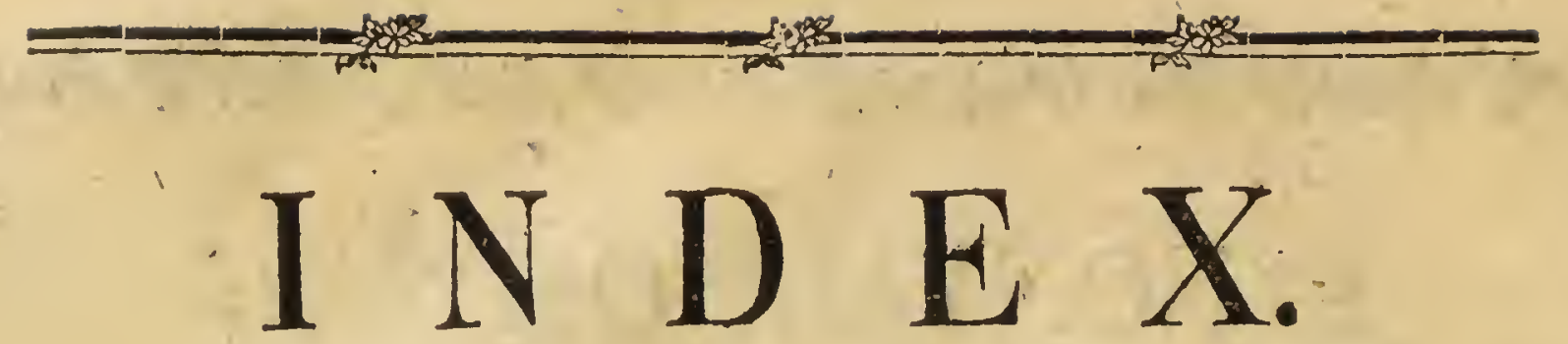

I. SPERMODERMIA গTogenfdywamm. p. I - V. STILBVM ङilanjfifmamm.

I. clandeftina.

II. SCLEROTIVM Şart [f]

I. purpureum.

2. immerfum.

c. lute $\int \mathrm{cens}$.

3. album.

$\gamma$. clandeftinum.

3. fubterraneum

a. mufcorum.

$\beta$. caudicum.

4. Semen.

5. Mucor.

6. radicatum.

7. complanatum.

8. villofum
a. album.
$\beta$. ferrugineum.

III. MESENTERICA Plattfdumamm.

I. tremelloides.
a. lutea.
ß. caerulea.

IV. ACROSPERMVM ŞOIn/4)waimm.

I. compreflum.

2. unguinofum.

3. pyramidale.

4. lichenoides.
1. vulgare.

2. bulbofum.

3. rubicundum.

4. minimum

a. nigripes.

ß. flavipes.

12

5. turbinatum.

6. pubidum.

VI. ASCOPHORA Sqlautfinumm. I3

I. Mucedo.

2. fragilis.

3. Stilbum.

4. ovalis.

5. cylindrica.

6. limbiflora

7. difciflora.

\&. Solida.

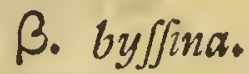

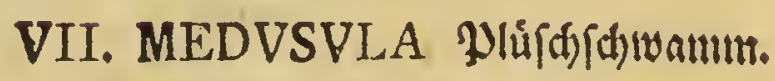

I. labyrinthica.

8

VIII. TVBERCVLARIA Rnobter: (d)w.mm.

I. vulgaris

9

a. Jubjeffilis.

ß. ftipitata.

20

2. fafciculata. 

3. volvats.
p. 20
\%. vulgare.
p. 33
4. fulcata.
$2 \mathrm{I}$
$\beta$. aureum.

IX. HELOTIVM গagelichamm.

22

2. metallorum.

1. glabrum.

3. terreftre.

2. hirfutum.

23 XVI. XYLOSTROMA Tapetenfinamim. 36

$\mathrm{X}$. TYMPANIS Dुanferiduamm.
I. faligna.

24

XI. MYROTHECIVM Balfamfanamm. 25

I. roridum.

2. inundatum:

3. ftercoreum.

4. hifpidum.

5. dubium.

XII. VOLVTELLA Sulfifivamm.
I. volvata.

2. nuda.

I. giganteum.

XVII. CHORDOSTYLVM Saiten: รึเง เomm.

I. capillare.

2. byffoides.

3. hifpidulum:

39

4. Clavaria.

40

XVIII. PILOBOLVS F̧utwerfer. $\quad$ 4I

I. cryftallinus.

29

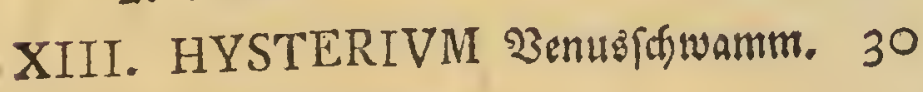

I. quadrilabiatum.

2. bilabiatum.

XIV. VERMICVLARIA ?udein: (d) wamm.

I. Pfeudofphæria.

2. pubefcens.

3. hifpida.

XV. PYRENIVM Rerniffyalnm.

r. lignorum

XIX. THELEOBOLVS Sinopftuerfer.

I. ftercoreus.

XX. SPAEROBOLVS Rugetwerfet.

I. ftellatus.

a. bi-fellatus.

ค. uni-ftellatus.

2. rofaceus.

a. floriformis.

ß. repandus.

XXI. ATRACTOBOLVS Epindelluerfer.

I. ubiquitarius. 


\section{ERRATA.}

Pag. 4. Iirs. 1. Iege ftipitum loco truncorum,

- 6. - ro. - ftipulis - culmis.

-7. - 25. - finuato-lobato - finuato lobato.

- 15. - 12. - faitem - faltim. 


\section{FVNGI \\ MECKLENBVRGENSES \\ SELECTI.}

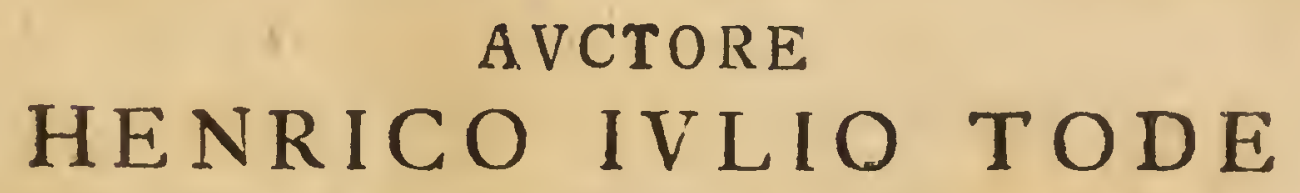

SYNODI WITTENBVRGENSIS PRAEPOSITOET V. D. APVD PRITZIERENSES MINISTRO. SOCITT, EEROL, AMIC. NAT. CVR. NIEC MON NAT.CYR, KAERS, SOD.

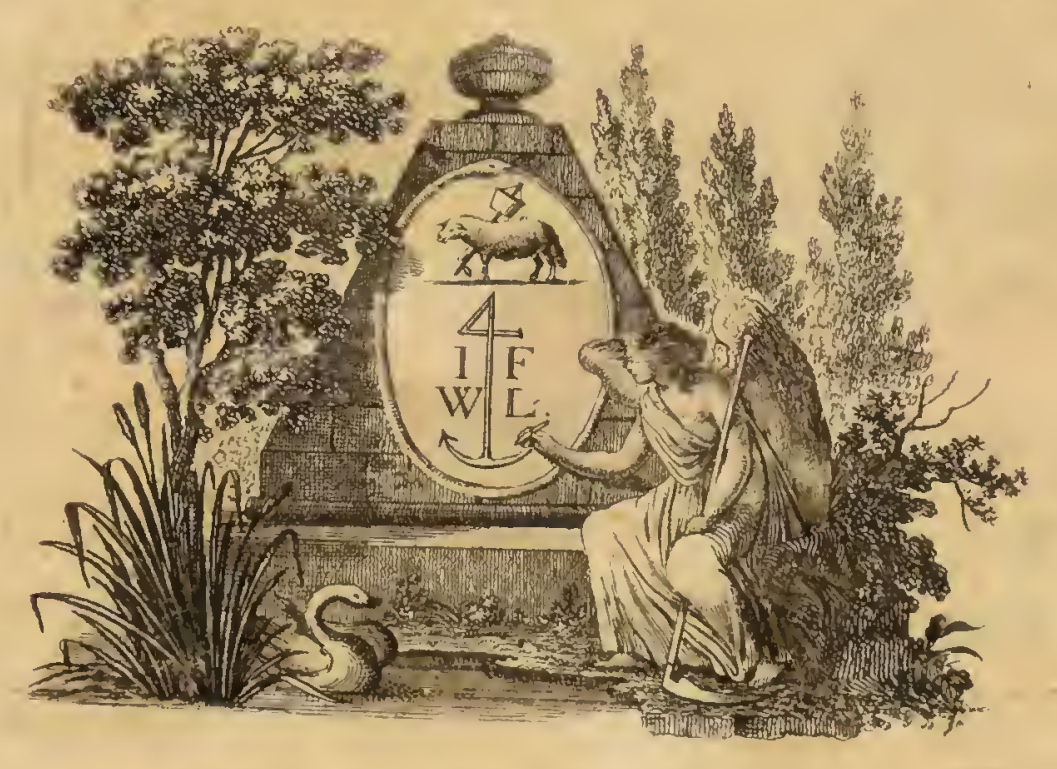

FASCICVLVS II.

GENERVM NOVORVM APPENDICEM ET SPHAERIARVM ACAVLIVM SVBORDINES III PRIORES COMPLECTENS.

TABVLIS X AENEIS ADIECTIS.

LVNEBVRGI I79I.

APVD IOH. FRIED. GVIL. LEMKE. 


\section{7\%79}

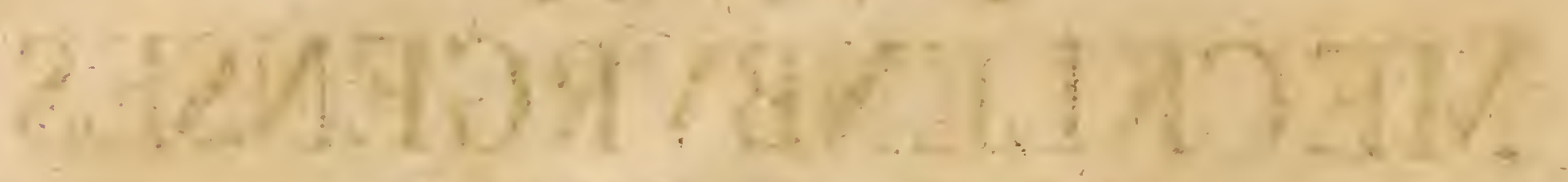

$$
\text { il 9.1.62 }
$$

$\frac{1}{10.1 .12}$

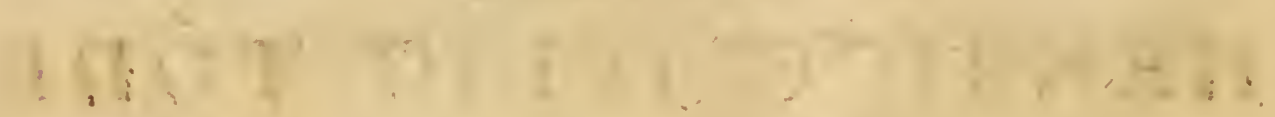

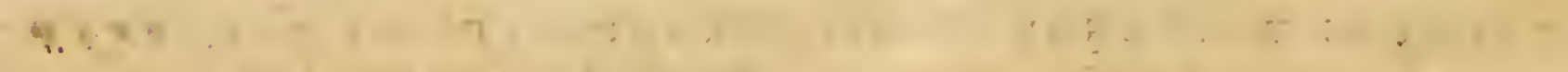

.

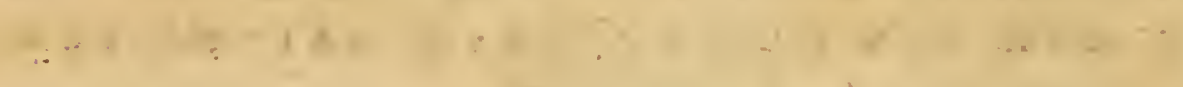

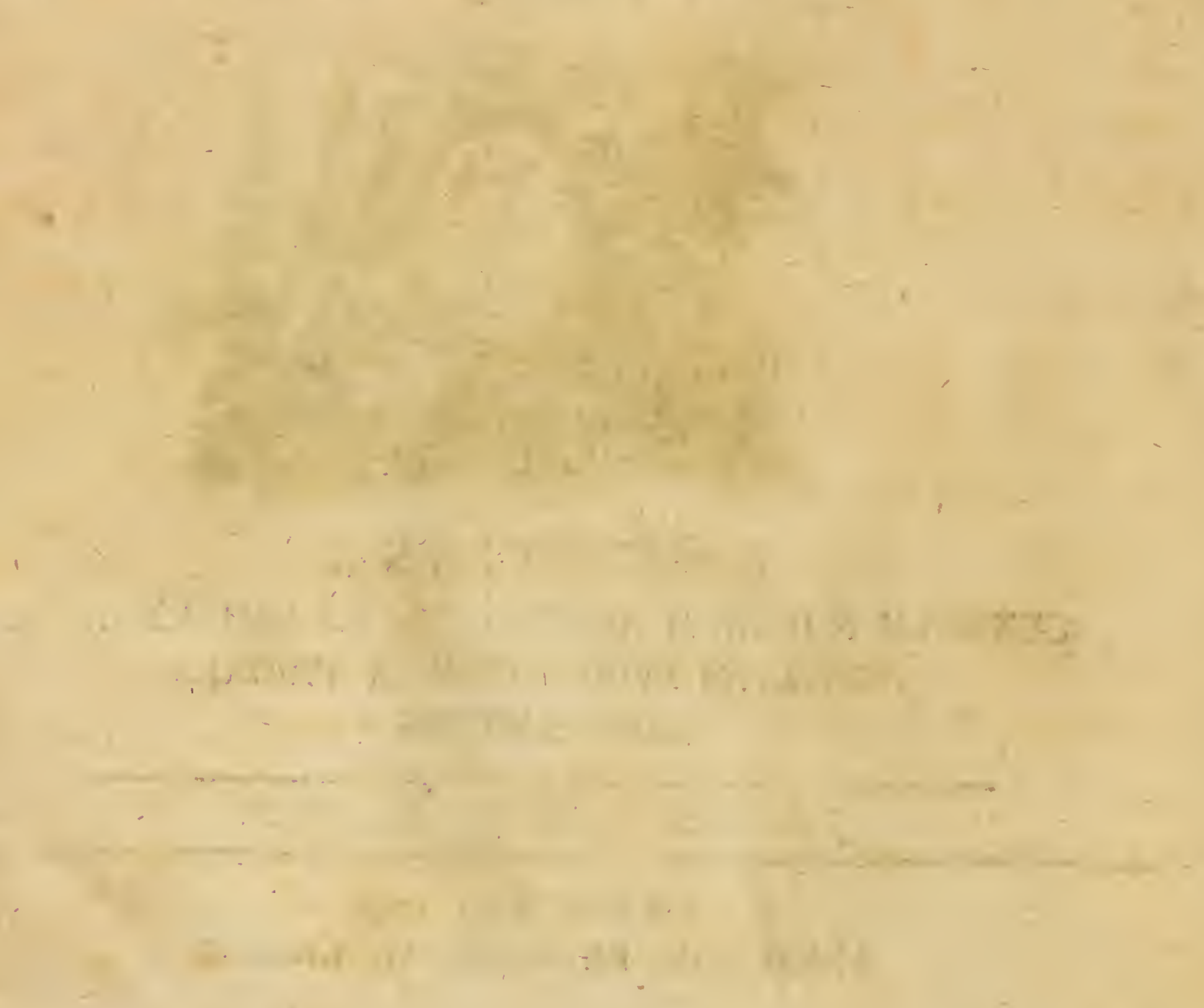




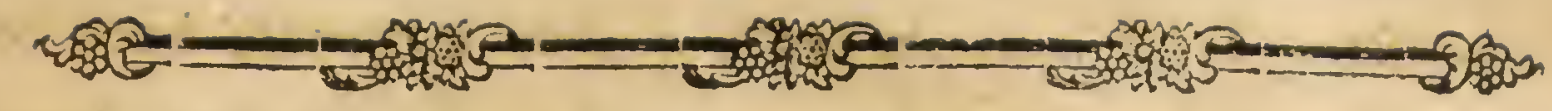

\section{PRAEFATIO.}

uandoquidem talium Virorum, quales inftituti mei judices mihi

praefertim exoptavi, comprobatum hoc fcio: iter incoptum alacriter pergo et, DEO aufpice, jam generibus fungorum vulgatis appro. pinquo. Sed priusquam, quae Fasciculo hoc novo funt pertractata, attingimus; ne officio noftro quoad ea, quae in priori funt tradita, deeffe videamur: potiora ex is, quae ibi annotanda, accuratius evolvenda ac caftiganda poftea comperi, jam breviter, age, perftringamus.

MESENTERICA tremslloides $\beta$. p. 8. interdum longe fatis lateque ferpit, Sic a me vifa ef nuperrime, fuperficiem rami abietini, carie exefi, in modum ferme Byffi fubterraneae SCOP. carn, ed, 2. 13. I45 I, late tegens.

ACROSPERMVM lichenoides, p. 9 . in praefenti nil mihi, praeter Lichenis cujusdam foliacei, decumbentis, varietas videtur; nifi forfan peculiarem generis jam dicti fpeciem in planta noftra agnosci præoptas; habitus enim vere omuis eam a genere novo propulfat.

In MEDVSVLAE labyrinthicne Tab. IIl. fig. 28. c. d. c. Cuppeditata effigie ftipes duplo falt.m craffior, contra vero brevior pubidusque 
pingi debuiffet. Fructificationis fedes quidem in genere hoc, collectis rationibus, non nifi in villo videtur quærenda: id, quod ex fpecie quoque nova, a me detecta, fatis elucescere mihi videtur; fed in cruftam refinofam certe non femper colliquescere villum illum, exempla fungilli denuo lecta domique affervata me docuere: unde colligo, ea, quae in defcriptione expanfi hujus abnormis oculis fubjecta habebam, five limacum hortenfium effluvio viscido oblita; five alia de caufa fuiffe depravata atque corrupta. Cxteroquin fungum hunc, fub dio aeris injuriae expofitum, denique plane difparere \& maculam folummodo nigram in fede fua nativa relinquere, compertum jam mihi eft \& exploratum. Plura igitur in genere hoc novo fupereffe penitius indaganda Jubentifime concedo eaque naturae fcrutatoribus, fi funt, qui veftigia noftra hic premere operae pretium ducunt, e tenebris eruenda committo,

TVBERCVLARIAM vulgarem $\beta$. pag. 18, varietatem porro falutari fupervacaneum cenfeo; ftipitem enim fpeciei e globofo-ventricofo denique, more Boletorum quorundam, cylindricum fimulque altiorem fieri, obfervationibus non dubiis jam mihi innotuit.

Nova qnaedam commemorabilisve HELOTII, feu Agarici elamellati, fpecies, in foliis Hederæ terreftris a me reperta, fructificationis modum hujus generis, dubitanter a me pag. 22 , traditum, jam extra aleam ponit; contra ea vox fugaciffma e definitione ibi obvia nunc eft eliminanda. 


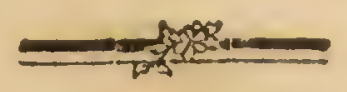

In MYROTHECIO, nec non in VOLVTELLA, definiendis, inductus tum temporis rationibus quibusdam fpcieofis, loquendi formula ufus fum minus appofita, repleturae feminalis mentionem faciens, cujus loco omnino adhibenda erat alia vulgatior, minusque vaga, Jeminum fcilicet receptaculum. Volvae vox, ibi aliasve a me pro integumento partiali fungi, vel feminum nempe, vel eorum receptaculi, fenfu Hedwigiano fumta, tum femper velum defignat; fatius autem duco, in pofterum volvae vocabulum non nif in fignificatione trita, involucrum totale fungi junioris indicante, ufurpare.

PYRENIVM lignarium a (pag. 33.) exoletum: h. e. poftquam integumentum ejus candidum, byffaceum, evanuit, cum planta, a celeb. WILLDENOW, berol. n. I2I , fub nomine Sphaeriae olivaceae defcripta, adeo congruere mihi videtur, ut parum abfit, quin pro una eademque planta utramque habere, me quafi coactum fentiam; fed. defcriptio Willdenoviana preffior in caufa eft, ut rem injudicatam relinquere malim: praefertim cum fungillus meus, cruftam illam evanescentem fi excipias, in numerum plantarum fimplicifimarum certo fit referendus.

HYSTERIO generi, quoad definitionem faltem, pag. 30 datam, una cum fpecie utraque, ibi in medium prolata, rationibus graviffimis commotus, nuncium jam remittere non haefito; obfervationibus enim follicite iteratis, ceu totidem teftibus, tandem evikus fum, $H$. quadrilabiatum re ipfa non nifi primordia alius fungi effe, Sphaeriae fcilicet cujusdam, 
jusdam, ad Cirriferarum fubordinem pertinentis, fed aut tempeftate, aut cafu alio interveniente, corruptae ac deformatae. Aft vero cum de $H$. bilabiato huc usque non nifi pauculis exemplis, eundem ramulum incolentibus, fim potitus, cumque infuper illud, ficuti loco excitato monuimus, naturae admodum tenerae fluxaeque fit; in tanto discrimine huic fungillo porro fidere, tutum confultumve minime reor. Cum vero fungorum rima transverfali conchaeque figura notabilium, huc usque vero erronum, feu acephalorum, fpecies quaedam inveniuntur, durabiles fatis, ac vulgares, quo omnis palpi, oculis forte iterum obtrudendi, formido longiffime removetur: hujusmodi dionaeos fungulos fub unum genus, cui Hyfterii nomen, immutato ejus charatere, denuo pofui, congregare mihi libuit, quorum jam fpecies tres Fasciculo hoc fecundo defcriptae inveniuntur atque depictae.

Adjeci infuper novorum generum triadem, ut pleraque a me hactenus evulgatorum, microfcopicae, fi ita loqui fas eft, fodalitatis, quae, licet, pro re nata, definitione in fingulis aeque perfecta \& completa praemunire non potuerim, hoc nop obftante, Viris ingenuis, recta via rem fecum reputantibus, nec nifi aequa poftulantibus, haud ingrata fore fpero. Ad naufeatores autem, fi qui funt, et omnivolos quod attinet, hosce omnes ac fingulọ, imprimis vero fi forfan nova Syftemata moliuntur, data hac occafione etiam atque etiam rogo, ne generibus meis novis ullam fibi moleftiam creari circulosque fuos turbari finant; quin tacito pede haec omnino tranfeant perfuafifimumque habeant, fungillos meos, ut Syfemata fua, viam certo effe inventuros. 
E Sphaeriis a me lectis eas folummodo huc evocavi; quae aut e rariorum, quin rariffimorum, numero funt; aut quarum faltem ftructura eas prae caeteris memorabiles reddit. $A b$ acaulibus incipiendo harum fubordines tres, ex mea decuriatione priores, Pulverulentas puta, Globiferias ac Styliferas, hic recenfui, reliquos cum Sphaeriis caulescentibus in Fasciculum tertium; DEO juvante, reponens,

Saepius in defcriptione Sphaeriarum noftrarum mentio fit tunicae cujusdam earum internae, e coagulo gelatinae, qua turgere plerumque cernuntur, formata: quae, cum primo a celeberr. WEIGEL obfervatam crediderim, facculi Weigeliani nomine a me fignatur; fed penfitatis denuo \& follicite collatis, quae de facculo hoc in Obfervationibus fuis botanicis paffim ftrictimque profert Vir longe eruditifimus mihique benevolentiffimus: perfuafum jam mihi eft, eum membranam potius illam candidam, nitentem, a pluribus poftmodum fcriptoribus botanicis notatam, (Tapetium candidum nobile BATSCH. cont. I. p. 137.) innuere. Loco igitur facculi WEIGELII femper dici debuiffet facculus viscofus; loco autem facculi Batfchiani, Weigelianus; feu byffinus; fed rerum figna, terminos, inquam, quos vocant technicos, haud in magno ponemus discrimine, dummodo de rebus ipfis inter nos conveniamus. De facculi caeteroquin utriusque differentia confer fis, quae pag. 8 , Obs, 2. differuntur,

Iter per Sphaeriarum regionem fenticofam obnubilamque perfequendo, raram per occultos ducere femitam calles, nimium, proh do- 
lor! fum expertus, Multa intento oculo incaffum fpectavi; compluscula per nebulam quafi confpexi; quaedam, fpero, detexi.

Procminari tandem defino; fed non nifi honore Viris, ex humatate aeque ac doctrina fua ornatiffimis, qui confilio \& re in concinnandis hisce pagellis me juvare dignati funt, gratifima in Eos mente prius perfoluto.

Vale, LECTOR BENEVOLE, et TIBI; NATVRAE, ac ejus GENITORI vive. 


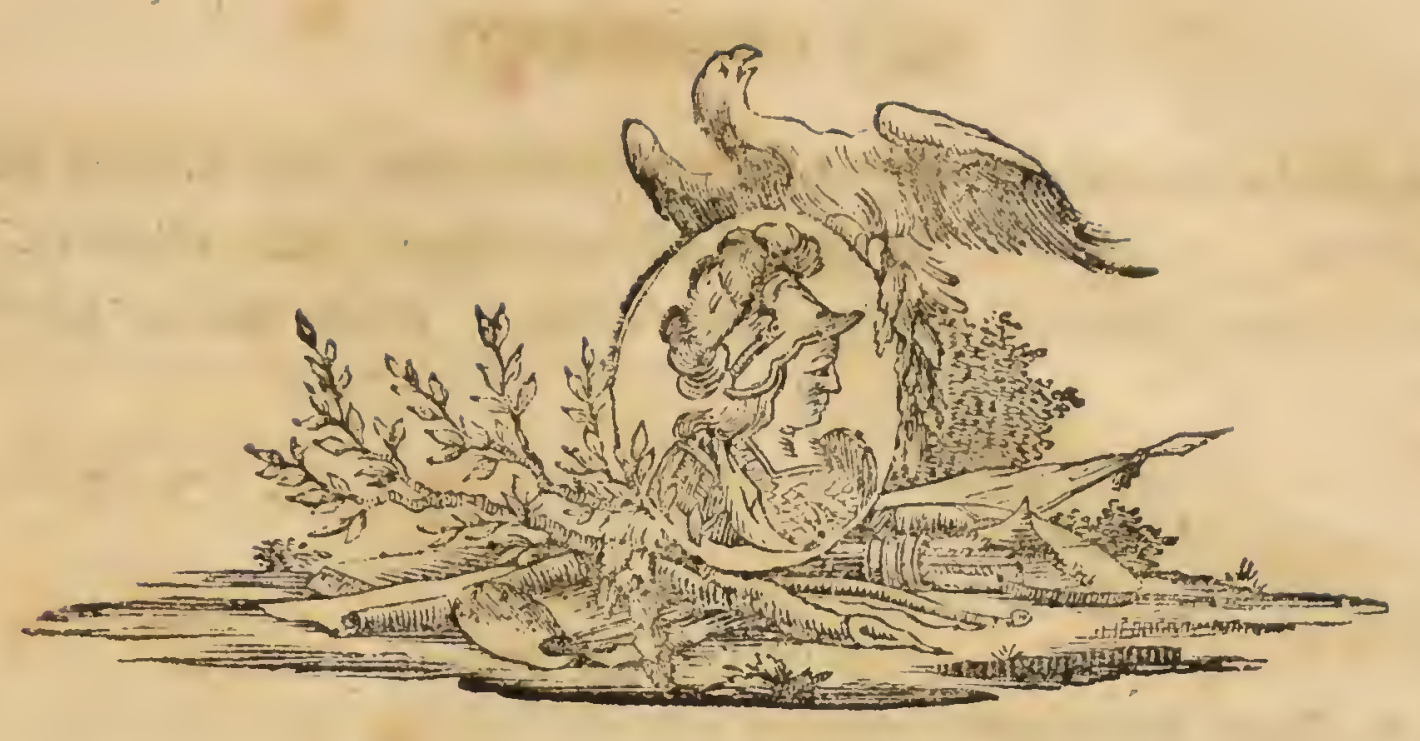

\section{EPICHYSIVM.}

Hungus feffilis, rotundato-concavus; feminibus ecaudato-globofis, diftichis, filamento ramofo, aream internam obrepenti, affixis.

\section{EPICHYSIVM argenteum.}

E. Cornu copiae forma, albidum, nitidifimum, ftercoreum; fauce obliqua in fundo umbilicata.

Subfrantia fungi membranacea; figura propemodum Cornu copiae: h. e. infundibuliformis, limbo aut elliptico, ant reniformi, patenti-reflexo; margine obfolete repando paffimque fubtilifime incifo; diametro plerumque fesquilineari. Faux, feu corpus ipfum fungi inferne attenuati, a linea perpendiculari plus minus recedit, centro fundi umbilicato. Affurgunt inde filamenta ramofa argentei coloris ac nitoris, quae fpirarum fere in modum difcum fungi anfractibus fuis ad oram usque veftíunt, \&, ut lente admota elucescit, corporibus minutiffimis, ut videtur, globofis, contiguis, aeque argenteis colore nitidisque, quae pro feminibus habeo, utrique lateri affixis, ftipantur. Superficies fungi externa laevis, 
colore ex albido virescente. Ope fibrarum quarundam, ceu totidem radicularum, ftercori bovillo, cui ad orificium usque eft immerfum, arete adhaeret. Corrugar tam demum oram monftrat totusque contrahitur. Media aeftate fparfim prodit; aft perraro.

O5S. Intertum linibo gaudict perfeete rotundo, quod cum accidit, faux now obliquatu:。

Figurae explicatio.

Tab. VIII fig. 60.

a. b. Fungi magnitudini naturali depicti.

a. Stercori immerfi;

b. hoc eruti.

$c-e$, Fungus ampliatus

c. oblique vifus;

d. perpendiculariter fectus.

e. Segmentum fungi admodum anctum, quo facilins hujus fructficatio cerni queat.

\section{XXI11. PERICONIA.}

Fungus globofus, ftipitatus; feninibus fefflibus, decutiendis, ca- . pitulum ac ftipitem ubique obducentibus.

\section{PERICONIA licbenoides.}

P. capitulo globofo, veficulari; ftipite capillari, recto, rigidiusculo.

E caulibus plantarum varii generis, humi putrescentium, poft pluvias tepidas progerminant fungilli mucoriformes, aggregati, in oculos haud armatos vix incurrentes. Veficula exacte globofa \& ftipes capillaris firmulus, rectus, fenfim palvisculo fusco obteguntur, qui fructescentia peracta primo de ftipitis parte fuprema, tum autem de reliqua ejus fuperficie, fub idem vero tempas de veficula quoque dejicitur: quo facto fungus argenti inftar nitet, cujus qnoque colorem jam monftrat. Capitulum poftea collabescendo coarctatur ad medium, feu conftringitur, 
ficque formam fphaericam cum ovali commutat, denique vero fit rugofum. Vehementius fi concutitur, decidit; ftipes tum deflettitur; fed nunquam decumbit. Reperi fungillum e crufta tenuiffima, plana, atra, quam maculam atram forte rectius dixeris, pullulantem, menfe Junio.

OBS. I.' Juniorem non vidi, quare de colore ejus, priusquam a feminibus incruftatur, ratio. nem reddere nequeo. Veficulae partem inferiorem, his nondum obductam, pellucidam \& Sanguinis draconis, ut loquuntur Pharmocopolae, amoeniffmo colore tinc. tam vidi.

2. Defcriptio hujus fungi lucem, opinor, haud parvan affundit chordofylo byfoidi noftro (Eafc. I. p. 3s. t. 7. f. S3.) Utrique nempe fungo ttylus elt plilvere deciduo confperfus, et poft fructescentiam argentei nitoris; utriusque capitulum deciduum; uterque denique ab humore calido ortum \& alimentum trahit et, ad habitum omnem fin refpicis, ad mucores refirendus. Quicquid eft, planta 1. c. defcripta ad baric nolram multo propius accedere videtur, quam ad Chordoltyla.

Figurae explicatio.

Tab. VIII fig. 6I.

a. Fungi magnitudine \& fitu naturali picti.

$\mathrm{b}-\mathrm{g}$. Fungus eximie augmentatus.

b. Fungus pulvsiculo feminali dum obtegitur.

c. Idem, hoc jam quaquaverfum confperfus.

d. Idem, hunc decutere incipiens.

e. Idem, pulvere omni excufio.

f. Idem, ut capitulo deturbato demum apparet.

g. Veficula fructificans defuper per verticem ad amufim una cum ftyli particula difiecta.

\section{HYSTERIVM.}

Fungus oblongo-acuminatus, cavus, feffilis, linea transverfali fuperne findendus, feminibus globofo-ecaudatis, discum obducentibus.

OBS. I, Rationes, quibus conpulfus chataderem hujus Gencris Fafcic, I. p. 30. Cuppeditatur immutavi, Praefatio edocet. 
2. Medium hoc genus inter Pezizas \& Lichenes; leprefos, tuberculatos puta, feu Verrucarias Wigs. Ab his \& nominatim a Lichene fcripto L. (L. hebraico \& pulicari Hoffm. Lich. I. 13. I4. 't. 3. fig. 2. e. fo) feparat praefertim conftans fungi cavitas, leminibus nunquam fatcienda, fed hic folummodo obducenda; ita ut crultae abfentia.

\section{HYSTERIVM candidum.}

H. fuiforme, papyraceum, aggregatum.

Admodum pufillum, ut greges ejus farinae fparfae grumulae videantur. Subftantia fungi ac color chartae fcriptoriae fimilis. Appropinquante fructescentiae tempore $a b$ apice uno ad alterum usque fuperne finditur \& tum area interna apparet pulvere fementivo minutiffimo obducta. Senescens rugofulus fit, labiis inflexis. In caulibus ex putredine cavis Brafficæ oleracex albæ vigentem faepius vidi, Aprili.

Figurae explicatio.

Tab. VIII fig. 62.

a. Fungorum grex magnitudine nativa depictorum.

b. Fungi lente aucti, alter junior; alter fenior.

\section{HYSTERIVM cairuleum.}

H. elongato-ovale, membranaceum, cruftaceum, fparfum.

Tantillum priori majus; figura fcaphulæ; fubftantia tenuiffima; fuperficies laevis; color dilute caeruleus. Fiffuris, feu rimulis ligni quafi infixus cernitur, qualibet cymba macula cingitur nigra, quam fi cruftam nuncupare mavis, per me licet. Semel modo exempla hujus plantæ vidi fparfim, e frufto rami quercini emortui \& cortice nudati protuberantia, Septembri. Non nifi aperta inveni; id, quod facit, ut figuræ \& cruftæ apparentis habita ratione verear, ut fungus hujus loci fit.

Figurae explicatio.

Tab. VIII fig. 63 .

a. Fungi magnitudine ac fitu naturali picti.

b. c. Fungus ampliatus

b. ligno inhaerens;

c. e ligno remotus. 


\section{HYSTERIVM nigrum.}

H. fufforme, coriaceum, obvelatum, aggregatum.

In epidermide ramulorum emortuorum Quercus obfervavi puftulas oblongas, acuminatas, quae dum fiffura longitudinali aperiuntu:, fungum detegunt inclufum, fulformem, laevem, coriaceum, concavum, nigrum, velo fusco, tomentofo, angufto, eodem tractu verticem, feu plagam fuperiorem integram, fungi'obtegentem. Sub \& fimul cum hoc velo per integram longitudinem ita finditur, ut conchae, five cymbx, figuram inde obtineat. Discus mafla quadam e murino cinerea, febacea, obductus apparet, quae exficcata femina minutiffima conglebata fiftit. Fungus a linea una ad fesquilineam longus tandem valde corrugatur \& crispatur. Obtulit fe mihi Majo menfe.

Figurae explicatio.

Tab. VIII - fig. 64 .

a. Fungorum agmen magnitudine nativa depictorum.

b-e. Fungus fub lentê vitrea vifus.

b. Fifla jam epidermide; velo jam jam findendo.

c. Velo \& capfula plane fifís.

d. Fungus decrepitus crispatus.

e. Fungus adhuc claufus extra epidermidem arboream vifus.

\section{HYDROPHORA.}

Fungus globofus, ftipitatus; capitulo aqueo; ftipite capillari, fubrecto; fructificatione ignota.

\section{HYDROPHORA minima.}

H. capitulo cryftallino; ftipite recto, integro, rigidiusculo, lutescente.

Mucor tam pufillus, ut nudo oculo plane fe fubtrahat. Sparfim gregatimque tempore aeftivo poft dies pluviofos in dejectis iisdemque exficcatis ramulis, praefertim Fagi, cortice quidem jan orbatis, fed ab incipiente putredine nondum exulceratis, lentis ope facile detegitur. Capitulum, guttula aquea limpidiffima, feta ex albido 
albido lutefcente fuffultum, formam initio ovalem mox globofa mutat. Exinde fungillus per feptimanas integras nullam mutationem vifibilem fubit; tum vero globulus contabescere incipiens, in medio magis magisque coaretatur, feu comprimitur, usquedum plane evanescat. De fruetificatione nil certi in publicum promere pofium; vidi autem capitulorum verticem fxpiffime flavedine quadam pergrata tinetum: quapropter ni fallacia forte, quam dicunt opticam, hic obtinet, feminum invifibilium fedes ibi quaerenda videtur.

OBS. Fungus hic minime ratus non confundendus eft cum Mucore microscopico noftro in den Schriften der Berlin. Gefellfch. naturforfch. Er. Tom. V. p. I6z. tab. g. f. 2. defcripto.

Figurae explicatio.

Tab. VIIII fig. 65.

a. Fungus ut primo in confpectum venit, mole perquam aucta depictus.

b. Idem, capitulo jam fuccrescente.

c. Idem, capitulo perfecto.

d. Idem, hoc contabefcere jam incipiente.

Vidi \& fpecies quasdam hac noftra majores; fed cum earum rite examinandarum ad naturamque depingendarum facultas mihi non concefia fuit, defcriptionem earum faltem aliqualem in gratiam Mycophilorum adjiciam.

\section{HYDROPHORA tenella.}

H. capitulo cryftallino, fubpendulo; ftipite erecto, grifeo, tenello:

An Mucor Afpergillus Scop. carn. 2. II. p. 464. n. I642?

Poft pluvias autumnales in ramulis caulibusque putridis obfervavi longo ac denfo agmine crescentem. Altitudo nonuullarum (3-4) linearum. Styli tenuiffimi, tenerrimi, (fimplices?) Globuli vel tantillum quaffati illico conflutint; ftipites vero una collapfi ftratum tum byfinum ftrage fua conftituunt.

\section{HYDROPHORA forcorea.}

H. capitulo fubpellucido ftipiteque erecto, procero, fimpliciffimo, fordide lutescentibus.

Lycogala petiolatum, aquofum, flavefcens Hall. hift. n. 2 I 45. 
E ftercore humano, imbre praevio enatam femel vidi, media, ni fallor, xeftate. Tota planta aquefa, colore albo paffim in foede luteum, feu ochraceum, tranfeunte. Capitula femini. Sinapis aequiparanda. Styli feta fuilla longe craffiores, erecti, fubarcuati, triunciales ferme. Aggregate crescebat, fedem natalem agmine non interiupto occupans.

OB9. Detexi nuperrime varietatem hujus fungi in ftercore canino, pluvia macerato, vegetantem \& priori ab omni parte finilem, magnitudine excepta, qua octuplo circiter minorean fe mihi praebuit.

\section{SPHAERIA.}

Mafc. Pollen fuperficiei fungi vel integræ, vel exparte, idque aut immediate, aut mediante velo, infidens.

Foem. Capfula fubrotunda, per apicem perforatum expellens mucilaginem, $\mathrm{fe}-$ minibus minutifimis, ecaudatis, repletam, inter ejaculandum diverfimodo indurefcentem.

OBS. I. Pollen illud a celeberr. Hoffmanno probe eft notztum. (Veg. cryptog. Fafc. I. Praef. \&: p. ${ }^{2}$ :) Velum ubi in fungis obvenit, pollen innatum fovet. (Hedw. Theor. generat. \& fructific. pl. cryptog. p. 136.) De varia hujus veli in variis Sphxiix fpeciebus figura ac Aructura in earum tractatione ipfa fufius, quam hic commode fieri poterat, agemus.

2. Mucilago, feminibus foeta, capfulis aridis \& vacuis mox, ut inter omnes conftat, reftauratur, fi humedantur; fed quoties cxpellitur, extemplo, quin faepifime in ipfo capfulx orificio rigefcit. Indurefcendo autem induit formam

a. Glebularum minimarum fatiscentium, feu pulveris. Spharix, quibus hic rigendi mos eft, mihi audiunt Pulverulentas.

b. Globuli folitarii, decidui, fatifcentis: Globiferae.

r. Styli, feu corniculi, decidui, fatiscentis: Styliferace-(Ceratofperma Mirb.)

d. Cirri: Cirriferace (Nacmefporae Willd.)

$\alpha$. fcabri, opaci, fatiscentis:

$\beta$. haevis, pcllucidi, folubilis,

e. Villi evanescentis, Villiferae.

Diverfus hic mucilaginis indurescendi modus adminiculo nobis egregio cte poterit, spoxriarum cum acauliun, fimplicium xque ac compofitarum; tum caulefcertium 
rigens agmen in totidem familias congruas difpescendi, fingulisque-rpeciesus-locum fuum at naturx ipfus leges afrgnandi. Accidet vero haud raro sphxriarum indagatori, ut de mucilaginis illius determinato indurescendi modo nequaquam certior fieri queat: tum equidem remper ejusmodi fpecien Pulverulentis, familix fcilicet maxime vulgari, annumerari; at uru evenire facile poterit, ut earum nonuulla ad aliam aliquando fint tranfiturx.

\section{if Acaules: \\ *) Pulverulentae. \\ I. SPHAERIA mollis.}

S. fimplex, atra, aggregata, nitidiuscula, fubpapillata.

Figura fphaerica; fed non perfecte, bafi fubdepreffa. Magnitudo puncti. Color externus ater cum aliquo nitore; internus fufcus. Orificium planum interdum cernitur pertufumque, interdum in papillam fuccrescentem elevatnm. Natura corticis mollis, cultello in modum pelliculae facile cedens. Inanes faepe capfulas; refertas vero quandoque tela araneofa candida, (Hoffm. l. c. p. 5) in hoc fungorum genere frpifime obvia, reperi. Denfiffimo agmine crescit in ramulis putridis excorticatisque Fagi. Junio.

OBS. I. Non confundenda cum Sphxria fpermoide Hoffm. cryptog. II. p. 12. t. 3.,f. 3.

2. Tela illa araneora, cujus quoque meminit Lightf. Scot. p. 806\%. n. S, valde memarabilis mihi videtur. Gignitur hxc in mucilagine Sphrias replente \& haud raro per orificium earum expellitur, quod cum accidit, figuram globuli candidi bombacini habet; fed mox complanatur \& tum in modum veli papillam obtegit, a qua, fubrequente mucilaginis fpermophorx profluvio, perforatur. At vero non femper per orificium Sphriarum expellitur, fed in his poft mucilaginis expreffonem fape fub forma tclx'araneofx, integram fungi cavitatem explentis, remanet. Rumpitur vero poftmoduin in medio \& tum ad parictes Spharix rupta filamenta recedunt, ubi confidentes facculum cadidum nitentem conltituant, a cel, Batfch'o Taperium nobile candidum appellatum; (cont. I. p. 137.) a facculo confinili, e refiduo mucilaginis ejaculatix quandoque formato, hujusque colorem rerinente, quen Weigelianum a nomine primi detectoris (OG.5. $; 6 . p .4 I$.$) poftea (emper nuncupabo, probe discernendum.$ 
Figurac explicatio.

Tab. IX fig. 66.

a. Sphrerix cohortes magnitudine naturali exhibitæ.

b. Fungus lente ampliatus.

c. Iủem ad perperdiculum fectus.

\section{SPHAERIA triftis,}

S. fimplex, aggregata, atra, immerfa, lichenoides, minima, granulata.

Vix vifibiles capfulix globofe, atix, externe obfolete granulatæ, e cruftz tenuifima tomentofa nigra, fub lente nigro-fusca, agmine denfo protuberaut, ad medium usque ligno immerfæ. Orificium planum, fell pertufum, Capfularum parietes interne partim tapetio Batfchii, feu tunica candida byflacea, veftitas inveni; partim inanes atque nudas, Obtulit fe mihi hac rariur fpecies in luperficie rami cujusdam fubputridi, cortice nudati. Majo

Figurae explicatio.

Tab. IX fig. 67.

a. Fungorum agmen, magnitudine naturali pictum.

b. c. Fungus lente auctus.
b. Ligno extractus. "
c. Ligno immerfus, e vertice per orificium fectus.

\section{SPHAERIA cimabarina.}

S. fimplex, fparfo-aggregata, rubra, ovalis, granulata.

In apice ftipitis Tremellæ purpureæ $L$. Cell Tuberculariæ vulgaris $\approx$ noftræ (Fafc. I. p. 68.) dejecto pileolo putrescentis, nec non ad bafin ejusdem fungilli enatam fparlim gregatimque vidi Sphxriam quandam minimam colore cinnabarino lætiffimo; figura globofa aliquantulum in ovalem producta; fuperficie granulata, vertice deprefio. Aperturam non vidi, nec mucilaginem capfulis contentam; quam vero ejusdem coloris effe inde colligo, quod has materia viscida rubra illitas confpexi. Septembri. 
OBS. An globuli a celeberr. Weigel in fundo Tremellx purpurer $I$. obrervat (Ouf. p. 46.) forte sphrtia hac noltra parafitica fuerunt? Non confundi caeterun debet cum Spharia rubra Wigg. bols. n. 935 .

\section{Figurae explicatio.}

Tab. IX fig. 68.

a. Fungi quidam magnitudine naturali pieti.

b-d. Fangus mole ancta cielineatus.

b. Fungi nonnulli ad batin Tubercularix vulgaris extuberantes.

c. Fungus fua fede remotus.

d. Idem ad amufin fectus.

\section{SPHAERIA by/ferda.}

S. fimplex, fparia, mammiformis, bicorticata, cruftæ filamentofæ innascens.

a. grifea.

Magnitudo femini aequiparanda Sinapis; figura capfula globi aliquantnm compreffi. Cortex exterior membranaceus, lævis, nitidus, admodum tenuis, e livido grifeus; interior craffiusculus, durior, atri coloris. Papilla ferme conica, initio claufa, poftmodum aperta Capfulas interne facculo Weigelii grifeo tomentofo veftitas \& mucilagine ejusdem cóloris repletas vidi. Singulæ, rarius geminæ, infident expanfo cuidam rotundato, figura convexa, e fibris, fẹt filamentis firmalis, laxius contexto: maffulis hisce ftuppeis confluentibus, lignumque circumquaque obducentibus. Sub finem Martii varietatem hanc pulchram aeque, ac raram, reperi in ramulo. Salicis albae putrescente.

Figurae explicatio.

Tab. IX fig. 69.

a. Fung: fparfi magnitudine ac fitu naturali,

b. c. Fungus lente vitrea auctus.

b. ffrato filamentoro exemtus;

c. per papillam, feu e vertice, fectus.

B. fufca,

A varietate $a$ differt magnitudine aliquantum minori; tum colore corticis exterioris 
terioris fufco; porro papillæ atre, in formam quandoque cylindri demum fuccrescentis; tunica demum Weigeliana, que hic non tomentofa, fed viscofa ac nigra eft. Crulta bylfacea, ex qua fparfim protiberat, continua, fusca, filamentis longiusculis, divilis, denfis, mollioribus, perplexis conftat, quæ dum exficcantur, vellus quoddam molliusculum confituunt. Capfulas nunc mafla nigra, viscida, repletas, nunc cafias, tunica folummodo jamgue defcripta interne obtectas vidi. In cortice rami quercini putridi. Majo.

\section{Figurae explicatio.}

Tab. IX fig. 70 .

a. Fungorum acervus magnitudine naturali pictorum.

b. c. Fungus lente ampliatus

b. aetate juvenili;

c. fenescens, papilla elongata.

\section{SPHAERIA mobilis.}

S. fimplex, conferta, globofa, mobilis; papilla decidua.

An Sphrria Mori Dick. Cryptog. p. 22? Defcriptio faltem admodum convenit, colore excepto.

Ad minimas fui generis referenda. Capfula exacte fphærica, Jævigata, admodum tenera, feu mollis, coloris.obfcure fusci in nigrum denique tranfeuntis $\mathrm{Pa}-$ pillam fungus fenior fxpius dejicit; eft enim infititia: quod cum fit, orificio præditus pertufo cernitur. Contiguas, quin coacervatas inveni capfulas; eft enim peculiare huic noftro, ut, cum radice nulla gaudeat, facile fe quaquaverfus moveri finat. Capfulas tum mucilagine dilute lurido, feu livido, repletas; tum tunica folum illa Weigeliana interne veftitas, tum omnino inanes vidi. Obvenit mihi in ramus lo putrido excorticato Quercus, Majo.

OBS. E colore hujlis tunicx, feu facculi, hic lateritio, admodum probabile mihi fit, capfulam ipfam prima juventute codem, feu rubro colore efle tinam; fed non nifi fuscam vidi.

Figurae explicatio.

Tab. IX fig. 7 I.

a. Fungorum greges aliquot magnitudine naturali pictorum. 
b. Acervus eorum lente auctorum.

c. Fungus ampliatus ad perpendiculum fectus.

\section{SPHAERIA porphyrogona.}

S. fimplex, aggregata, phialæformis, atra, cruftæe tenuifimæ violaceæ innata. An Spheriæ acuta Hoffim. crypt. I. p. 22. t. 5. f. 2. varietas?

In caulibus putridis Solani tuberofi paffim apparent maculæ amœne violaceæ, oblongæ, unius uncix \& quod excurrit longitudine. Ex hac crufta tenuiffima, fi mera macula crufta nomen meretur, eminent ad medium usque capfulæ læeves, atræ, minutiffmæ; papilla habitiori, procera; corpore compreffo, bafi complanata. Non nifi inanes vidi. Majo.

Figurae explicatio.

Tab. IX fig, 72 .

a. Fungi cruftre infidentes magnitudine nativa delineati.

b. c. Fungús lente vitrea augmentatus

b. in fitu naturali;

c. liber, ad perpendicuilum fectus.

\section{SPHAERIA macroftoma.}

S. fimplex, aggregato-fparfa, globofa; orificio largo, labiato.

o. nigra.

Seminis papaveris magnitudine gregatim e ligno exttiberat, colore nigrescente: externe lævis; interne non nifi vacuam confpexi. Orificium umbonatum, in formam ob!ongam criftæ, feu lobi, extenfum, nitidum, atrum, primum e igno emergit; capfala ipfa tunc temporis adhuc plane demerfa; at paufatim ad medium usque protruditur. Critta, initio integra, poftmodum in bina labia finditur; fiffura hac mucilagini erumpenti exitum dante. In ligno jpfo rami cujusdam, putredine admodum jam exefi, obfervavi Aprili menfe vegetantem.

Figurae explicatio.

a. Fungi aggregati ligno infixi.

Tab. IX fig. 76 .

b. c. 
b. c. Fungus, ut lente aucus apparet.

b. Fungi tres, erumpens, adolescens, adultus.

c. Fungus e vertice fectus.

\section{ß. fusca.}

Admodum cum varietate $\%$ congruit, fed hac eft minor \& capfule color fuscus, at osculum æque atrum nitidumque. Detexi ramuli cujusdam putrescentis, cortice exuti, fuperficiei fparim gregatimque immerfam. Majo.

$$
\gamma \text { nigro-fusca. }
$$

A varietate precedente in eo discrepat, quod capfula nigra fub microscopio nigro-fusca ac fubtomentofa appareat, osculo fpadiceo, lavi, nitido.. Color capfularum interna fuperficie idem eft, fed dilutior: non nifi inanes vidi. Obvenit 'parfin crescens in Hedere terreftris \& Lonicerae Periclymeni ftipitibus aridis Aprili \& Majo.

\section{8. libera.}

Magnitudine varietatem \& æequat. Figura fphærica; cortex exafperatus, niger, durus; osculum atrum, laeve, nitidum, fubhians. Sparfim crescit, ligno haud immerfa. Càpfulas omnes inanes inveni; vidi autem in fruftulo ligni quercini, humi jacentis.

Figurae explicatio.

$$
\text { Tab. IX fig. } 7 \% \text {. }
$$

Fungus, uti lente admota fub afpectum venito

$$
\text { E. pileata. }
$$

Cum varietate o omnino fere convenit, figura nempe fola oftioli, quae hic eft ferme ovalis, excepta; complanatur id fcilicet fuperne, lateribus ad verticem capfulæ contractis: unde cono truncato, inverfo quodammodo fimile fit. In ramulis aridis tum cortici, tum libro, immeram reperi primo vere Cortex durus \& friabilis.

\section{Figurae explicatio.}

$$
\text { Tab. IX fig. ìs. }
$$

Fungus augmentatus ligno exfculptus. 


\section{SPHAERIA roftrata.}

S. fimplex, aggregato-fparfa, globofa, longifime roftrata.

a. atra.

Capfula globola, atra, extus granulata, Ceminis Papaveris fere magnitudine; intus facculo Batfchiano candido arcte vefitam reperi, cæeterum inanem. Loco papillæ roftro prædita eft prælongo, atro, fubulato, feu ciliari, erecto, apice fubintlexo; fragili, oftiolum, ut videtur, occludente. Perforat roftrum hoc liguum, capfulre fcilicet demerfæ \& fenfim altiora petenti viam pandens, qux tandem ita elevatur, ut tota in confpectum veniat. In thipitibus Fagi cæefis ac putrescentibus fparfim habitate Julio.

Figurae explicatio.

Tab. IX fig. 79.

a. Fungi ligno partim infixi, partim ex hoc emergentes emerfique, magnitudine depicti naturcli.

$\mathrm{b}-\mathrm{d}$. Fungus lente ampliatus.
b. Roftrum fummum fungi adhuc latentis.
c. Fungus lignum fupereminens.
d. Idem perpendiculariter diflectus.

$$
\text { ß. nigro-fusca. }
$$

Tam pufilla, ut oculo non armato aegre fe cernendam præbeat. Capfulas nigro colore ad fuscum vergente, læves, nitidas, molles, mucilagine cinereo-virescente repletas vidi. Apex earum cum roftro bafi incraffato confluere videtur. Id cum in varietata o interdum quafi articulatum, feu geniculatum, appareat, in hac femper enode inveni. Sparfim vegetantem obfervavi in ramo putrido Quercus. Septembri.

OBS. Vidi varietatem granulatam, xque minutifmam, e ligno ftipitis faginei putrescentis denfo agmino protuberantem, capfulis ex parte mucilagine repletis, partin vero facculo Batchiano candido obductis. Julio.

Figurae explicatio.

Tab. X fig. 80.

Fungi quidam mole aucta pißt, tribus eorum ligno latentibus, uno verum ex hoc jam plane emergente.

9. SHHAF- 


\section{SPHAERIA comata.}

S. fimplex, aggregata, globofa, vertice capillata: capillis faftigiatis, conniventibus. Q. atra.

E ftipulis caulibusque plantarum exficcatis poft pluvias gregatim confertimque progerminant capfulx globofæe, læves, teneræ, atræ, arenulæ magnitudine, hemifphærio fuperiore capillis, fell filamentis prælongis, atris, coni truncati inverfi figuram æmulantibus, hirtæ; capillorum enin erecto-reflexorum apices ita connivent, ut culmen capillitii ferme truncatum appareat. Pondere hujus capfula intus fusca frangitur, feu in medio diffilit. Materia tenera \& leviter cohærente fusci coloris repleta eit, quæ fub cultello ita corruit, ut vix ejus veftigium remaneat. Aprili fatis frequens.

OBS. Coma hujus Sphrrix Ppecies forfan Byffi cujusdam flamentofx, tempore vernali obvix, eft. Ad bafin faltem Sphrixix cucurbitula (de qua infra fermo erit) omnino ferme finilem obfervavi, decumbentem quidem initio, fed poftea erectam, hancque plane obtegentem, At vero coma in hac noltra nunquara deficito

Figurae explicatio.

Tab. M fig. $8 \mathrm{I}$.

2. Fungorum cateria magnitudire rat.va delineatorum.

b. Fungus lente magnopere adauctus.

c. Idem, directione perpendiculari diffectus*

$\beta$. fusca.

Precedenti varietati perfecte fimilis, colore excepto, qui in hac fuscus eft, gualem nempe e mumiis præparare folent pictores. Multo rarior quoque eft; inveni autem confertim e ligno faligno plane putrido progerminantem Aprili.

\section{SPHAERIA mucida.}

S. fimplex, conferto-aggregata, globofa, tomentofa; cortice papillaque atris; tomento mucido.

$$
\text { a. cinerea. }
$$

Confertim frpiffime agmine uncialis fere menfurx provenit, magnitudine tum Sphæriæ fpermoidis Hoffm. Sed panlo major interdum obvenit, \& tum aggregata invenitur. 
invenitnr. Capfulix quandoque ad ovalem figuram tantillum accedunt. Color eft illis, uti papillæ, piceus, fuperficies lrvigato-panctata. Papilla excepta, tota Spharia villo curto, feu tomento grifeo-albido, tenerrimo, molli, te£ta elt, quo fit, ut micore quafi obducta appareat. Fibrarum quarunias ope, ceu tot radicularum, ligno affigitur. Haud admodum rara fpecies, quam tamcn nusquam defcriptam inveni. In lignis putrescentibus, Salicis pracipte, reperi, caplulis liquore atro-viriai repletis, menfe Septembri ac Octobri.

Figurae explicatio.

Tab. X fig. 82 .

a. Fungorum acervuli ad naturam delineati.

b. Fungus per lentem vifus.

c. Idem per orificium recta fectus.

B. alba.

Concordans in omnibus cum præcedente varietate; fed tomento albo obfita \& rara admodum eft. Sparfim ramo cuidam cortice orbato, \& putredine admodum corrupto, innatam vidi.' Octobri.

$\gamma$. fusca.

De hac varietate quoque valent, quæ de prima dicta funt; fed magnitudine hanc aliquantum antecedit \& in noftra tomentum fuscum \& valde delicatum eft. Capfula lineari plerumque tractu protuberant, contiguæ; haud raro nutantes cernuntur. Papilla, principio fusca, fenfim atrum colorem induit. E rimulis lignorum putridorum prógerminat Septembri.

OBS. Papillx forma a varictate \& \& $\beta$ nomihil differt, quam nec perforatam vidi: nescio igitur, an illis rite adjungatur.

\section{Figurae explicatio.}

a. Fungorum lente auctorum feries.

Tab. IX fig. 75 .

b. Fungus perpendiculariter fectus.

\section{I. SPHAERIA calva.}

S. Inplex, fparfa, atra, papillata; hemifphærio fuperiori glabro, inferiori hifpido. Diameter 
Diameter capfulæ vix dimidium linex affequitur; color piceus; figura fphæroidea, feu mali aurantii. Sphæria fuperne ad medium usque glabra, nitida; inferne fetis hifpida. Oftiolum papillæforme; capfulas inanes vidi. In ramulo dejęto, arido, obfervavi Martio.

Figurae explicatio.

\section{Tab. X fig, 83.}

a. Ramuli fragmentum, cui Sphæriæ infident magnitudine nativa piktse.

b. Sphæria, ut fub lente apparet.

c. Eadem ad amufim per papillam fecta.

\section{SPHAERIA bipida.}

S. fimplex, fparfa, pyriformis, hifpida, atra.

Capfula ovata, femilineam circiter longa, cum papilla ita confluit, ut Sphrriæe figura pyro inverfo fimilis fit. Externe fetis remotis, brevibus, ad bafin vero longioribus, obfita eft; intus mucilagine livido-virescente repletas capfulas vidi, Sparfim in ramulo quercino, cortice nudato, vegetantem reperi, Septembri.

Figurae explicatio.

Tab. X fig. 84.

a. Fungorum grex magnitudine naturali pictorum.

b. Fungus per lentem vifus.

c. Idem ad perpendiculum fectus.

\section{SPHAERIA inquinans.}

S. fimplex, aggregata, obvelato-papillata, atra, immerfa; feminum glebulis ejectis cylindricis.

Sedes ejus in cortice ramorum emortuorum Aceris Pfeudo-Platani, quos ferme integros oecupat. Figura capfulæ globofa, in papillam faftigiata; color piceus; magnitudine femine Braflicæ hand multo minor; fuperficies utraque lavis. Infixa eft alburno; corticem inbabitat, papilla ad epidermidem pertingente. Increscendo dum magis magisque extenditur capfula, endem tempore epidermis a papilla fubjscente in modum puftulæ elevatur, usque dum ab illa in mucilusinis ejuculatione una 
cum velo quodam albo, byffino, plano, puftulæque quafi agglutinato; perforatur: quod priusquam fit, hujus mucilaginis egurgitatæ portio per orificium papillare: ad latera Sphæriæ quaquaverfus defluit \& partes contiguas, v. c. ftratum corticis fuperius, atro colore tingit. Seminum glebulx, feu paftæ, quam copiofiffime ejectr, figuram exacte teretem, feu cylindri, habent, fubinde arcuati, feu lunulæ: indicio manifefto, mucilaginem feminibus fartam, dum per oftiolum ejicitur, in ipfo ejaculationis actu, ut primum aeri exponitur, rigescere \& in formam jam dictam coalescere. Floret Aprili.

OBS. 1. Nequaquam igitur femina fingula ficca, ut vulgo eceditur, e Sphribis eyomuntur: fed ipfa muciligo femina continens expellitur, illico, ut monuimus, indurescens \& fic glebulas multiformes producns, qux in pulvisculum delicatifinum fatiscunt, ar tum demum. îngula femina cernuntur.

2. Faciem primigeniam veli margine repandi nondum nosco,. cum huc usque caprulas. juveniles non viderim; dubiro vero, id ortu jam fuo efle planum,

Figurae explicatio.

\section{Tab. $X$ fig. 85.}

a. b. Fungi naturali magnitudine delineati.

a. Rami fragmentum Sphæriis fub cortice latentibus plenum.

b. Ramuli particula diffecti, quæ capfulas in cortice nidulantes ob oculos ponic.

B-f, Fungus per lentem vifus.

c. Fungus cortici rami immerfus, uti ad amuffim e vertice diffectus apparet. Corticis ftratum fuperius mucilaginis effluvio. tinctum hic exhibetur.

d. Fungus e cortice rami effractus, adhærentibus ei hujus corticis ramentis, fuperficiei Sphæriæ, initio viscidæ, agglutinatis..

e. Fungus feminum paftillis cylindricis explofis ubique cinctus.

f. Velum, fungum fub epidermidis tumore latentem obtegens.

\section{SPHAERIA fiffuela. vid.0.63.}

S. coacervata, globofa, atra: maffa glutinofo-farinacea, umboniformi, findenda, capfularum congeriem obtegente.

In epidermide rami emortui faginei confpexi Majo menfe puftulas rotundatas 
\& ovales, Tinea parifina aliquantum longiores, e quarum vertice fiffo mafia candida, viscido granulata in formam umbonis, feu lobi oblongi, recti, aflurgebat, quam vero, rima puftulæ fenfim dilatata, fupra hanc depreflam fieri, tum vero ibi eodem modo, \& fpatio, ac puftulam, findi obfervavi: Quo facto mafla illa candida, fifuræe epidernidis utrobique adhærens \& paulatim arescens, membranulx erectx, undulatæ, feu binis labiis, fit fimilis. Hians puftula prodit capfulas globofas, minimas, atras, læeres, cavas, orificio vifibili carentes, puftulæe vero cavitatem denfe replentes.

OBS. E Sphxria fpermoide materiam fatinaceam ejici, obfervavit celebert. Hoffmann. (Cryytog. II. p. ra.) Miteria ifta, dubia procul primum viscida, in nofta, ut videcur, granula, feu globulos farinaceos, invicem conglutinat: quo fit, hit mafram initio continuan, umboniformem, poftea in medio frem, velo fifo admodum finilen, conftituant, Utrum verum velum, an potius expanfum feminibus conglobatis cou. ftans? Non dubito quin prior fententia fit tenenda, Conf. infra Sphxriam ultimam.

Figurae explicatio.

Tab. X fig. 86.

a. Fungørum agmen fub epidermidis tuberculis latentium \& magnitudine nativa depictorum.

b-f. Fungus folitarius lente auctus.

b. Maffa umboniformi erumpente.

c. Eadem jam fifla.

d. Tuberculum ad perpendiculum fectum.

e. Capfula externa facie.

f. Eadem e vertice fecta.

\section{SPHAFRIA confluens.}

$S$ fimplex, confluens, atra, papillata, volva fugaci.

Ad Sphærias lineares, h. e. hineari tractu lignis infidentes, pertinet. Capfulæ sglobofe, papillatæ, atræ, nitidæe, practure, friabiles, non folum lateribus confluunt, fed quoque e fubitantia oblonga, convexa, qure cun corticis ipfarum mafia eadem ett, ceu ex bafi communi, ita protuberant, ut quondam inferne liquefactxe fuiffe videantur. Obvolutic prima æetate cernuntur volva tenerrima, mucida, nivei coloris, quæe \& fundamentuin illud, apparenter antea liquefustum, obtegit; fed 
mox ex integurento hocce papillx emicant, tum fuperiori parte capfulx pra, qua fenfim plane denudantur, denique volva penitus evanescit; remanet tamen macula candida, capfulas circumfuens in ligno. Repletas has vidi mucilagine ex livido-viridi lurida; vidi tapetium Batfchii candidum, nitidum ad parietes internas fuscas; vidi tela araneofa Hoffmanni alias plenas; vidi \& caflas. Habitat fatis frequens in lignis carie confumtis, præfertim Salicis. Martio viget infequentibusque menfibus.

\section{Figurae explicatio.}

Tab. X fig. $8 \%$.

a. Fungorum acervi nonnulli, magnitudine naturali delineati.

b-d. Fungi ampliati

b. Volva vèl omnino, vel ex parte tect:

c. Volva jam denudati.

d. Sphæria verticaliter diffecta.

\section{i6. SPHAERIA artocreas.}

S. fimplex, fparfa, atra, mammiformis; contabescenda convexo-complanata, plica annulari.

In foliis emortuis Fagi cernuntur tubercula admodum parva, fparfa, atra, retrimento Muscæ vomitoriæ perquam fimilia, quæ, fi lente admota perluftrantur, Sphærias fiftunt mammiformes, coloris picei, fuperficie laves, punctatas, papilla perforata. Senescentes dum collabescunt, forma earum ex hemifphærica plus minus fit depreffior; plica enim tum apparet in media circiter fiperficie, papillam in modum annuli cingens, \& tum fungillus artocreatis figuram quodammodo æmulatur. Cortex lentus, membranaceus. Repletas vidi capfulas pulvisculo tenerrimo, grifeo. Augufto.

OBS. Collapfam folummodo vidi hanc Sphxriam; fed dimenfio peripherix in fungo decrepito, plicx, feu rugx altioris, ratiouem fi habueris, formam primavan hemifphricam fatis manifeltat.

Figurae explicatio.

Tab. IX fig. 73 .

a. Fungi folio inidentes, magnitudine naturali picti.

b. Sphreria 
b. Sphæria contabescens, fub lente vifa.

c. Eadem ad perpendiculum fecta.

\section{SPHAERIA complanata.}

S. fimplex, aggregata, mammiformis, pulla; collabescendo complanata.

Ad minimas referenda., Caulibus plantarum humi putrescentibus agmine longo innascitur. Figura globi, in hemifphario inferiori immerfo compreffo. Superficies fcabro-tomentofa, colore nigro ad fuscum vergente, feu pullo; papilla atra, ritida. Fungus adultus, quantum e fede natali eminet, mammiformis; collapfus pott mucilaginis fpermophoræ explotionem, complanatur. Majo.

Figurae explicatio.

Tab. XI fig. 88 .

a. Fungorum coho:s magnitudine nativa pictorum.

b. Fungi quidam lente ampliati, ut forma nativa \& collapfi apparent.

c. Fungus adauctus ad perpendiculam fectus.

\section{I8. SPHAERIA epifpheria.}

S. fimplex, aggregato-fparfa, purpurea, globofa; collabescendo complanata: papilla convexo-oblonga.

Peziza granati coloris pellucentis Hoffm. crypt. I. p. 7. ObS:

Discum Sphæriæ ftigmatis Hoffm. fparfim gregatimque fupercrescit hæc noftra, tam parva, ut æegre oculis haud armatis: contemplabilis. fit. Figura ejus initio globofa, fubcompreffa in modum mali aurantii, papilla verticem occupante pulvinata, oblonga, nitidiffima, colore purpureo faturatiori, feu granati, fimili quidem admodum papillæ Sphæriæ macroftomæ, fed rima vifibili nunquam prædita. Superficies fungi amœne carmafini, pellucidi, lavis, nitida. Subftantia admodum tencra: quare mature collabitur Sphæria \& fenfim compreffa, necnon deprefia; (fic a celeberr. Hoffnann vif́a \& proinde pro Peziza habita;) tandem vero fit complanata, ambitu tum ovali, feu eliptico. Umbo quidem, papillam puta, femper figuram coloremque primitivum confervat; fed capfula color in morbofe rubrum \& ex hoc in fuscum fenfim deflectit. Fungulum, vere frequentifimum, nou nifi inanem vidi. 
OBS. I. Sedes cjus ordinaria quidem eft Sphrria ftigma devigescens; attamen eam in ramulo quoque emortuo Cratagi Oxyacantha femel reperi.

2. In fungo hoc memorabili adhuc quadam, notatu forfan dignifima, delitescere, ecquis non videt?

Figurae explicatio.

\section{Tab. XI fig. 89.}

a. Fungillorum cohors, Sphæriam ftigma, ramuli arborei fragmentum obrepentem, incolentium. (Omuia magnitudine nativa funt depicta.)

b. Alia eorum cohors Sphæriæ jam commemoratæ infidentium, ut fub lente confpiciuntur.

$c-f$. Fungus folitarius augmentatus

c. setate juvenili, nondum collapfus;

d. jam collabi incipieas;

e. omnino collapfus.

f. Fungus e vertice ad perpendiculum fectus.

\section{SPHAERIA moriformis.}

S. fimplex, aggregato-fparfa, atra, ovalis, tuberculofa.

a. vulgaris.

Satis frequens Sphæria hæc e ligno putrescente ramorum querneorum jam fparfim, jam aggregata pullutat, interdum ad linex menfuram prope accedens, frepius vero femilineæ altitudinem vix affequens. Color piceus; fubftantia dura, friabilis; figura ovalis fubelongata; fuperficies tuberculofa. Aperturam in vertice nunquam confpicatus fum, (forte mirutifimam;) punctulum autem nitidum in tuberculorum apice notavi. Cavitas Sphæriæ pulte alba repleta eft, quæ cum arescit, in telam araneofam Hoffn. transformatur. Hæc ut primum in centro rupta eft, ad parietes capfulæ retrahitur, ibique quafi confolidata hos membrana candida, nitente, feu tapetio nobili Batfch. obducit, denique, ut confuetudo ejus fert, evanescente. Tela illius fubltantia cultello fi diffecatur, cerea, feu Spermati ceti fimilis, fentitur. Ilartio ac Aprili.

ORS. A Sphxria cimabaina $(p$, 9.) noftra non folum colore \& cortice dito ac friabili, red \& pediculi rudinento, cui imnititur, fats differt. 
Figurae explicatio.

\section{Tab, XI fig. 90.}

2. Fungorun acervus magnitudine nativa pictorum.

b. Fungus lente vitrea ampliatus.

c. I.jem ad amufim fectus, uti, tela araneofa in membranam candidam jam converfa, interne ftratus cernitur.

ß. fasciculata.

A varietate præcedente in eo folum differt, quod capfulæ e bafi communi homogenea, oblonga, fub epidermide ligni latente, confertx proceantur, unde hæc pro Sphæria compolita habenda eft. Finditur quoque eundem in modum, ut in compofitis, cortici arboreo immerfis, epidermidis puftula, quo facto capfulze appreflæ e rima prominent. Puftulæ oblongæ, utrimque acuminatæ, transverfales, bilineares inveniuntur. Rariorem hanc varietatem in ramo Coryli Avellanxe emortuo confpexi, Aprili. Capfulas fubcylindricas partim tela araneofa candida repletas, partim vacuas inveni.

\section{\%. globofar.}

Figura hujus globofa mali aurantii, interdum pulvinata; magnitudo feminis Papaveris. Quoad cætera cum varietate $\alpha$ congruit. Mucilagine capfulas repletas vidi; fed colorem hujus vulgarem lividum pedetentim dilutiorem fieri \& in albidum demum tranfire, tum vero in pultem illam aibam coagulari, ex qua fenfim tela araneofa, centro dehiscens, oritur, in hac varietate obfervavi. E ligno cariofo. Salicis fparfim progerminat plantula inter rariffimas referenda, Majo.

Figurae explicatio.

Tab. XI fig. 9I.

a. Fungi quidam magnitudine naturali reprefentati\%

b. Fungus per microfcopium vifus.

\section{SPHAERIA talus.}

S. compofita, tuberculofa, monofticha, nivea; tuberculis truncatis, polymorphis; fphærulis globofis, atris.

Q3S. Munofticha mihi Sphria eft, cujus fphxrulx alix aliis non incumbunt; fed in unican modo feriem digent inveniuntur.

a. cylin- 
a. cylindrica.

De cortice variarum arborum, præfertim Alni, tubercula cylindrica, apice convexa, denfiffime pullulare cernuntur, femine Brafficæ paulo minora. Rumpitur cito apex, feu epidermidis protulerantis vertex, impulfu maffx cujusdan inclufx, candidx, fibrołæ, elafticx, quæ materia quadam, colore quidem eadem; fed fub.Atantia diverfa, initio byffina, tenella; polthrec autem laviori, compactiori, fuperfrata \& cum ifthac coalita videtur. Qua fi recte fint infpectata \& judicata, ut equidem opinor, habemus hic dubio procul velum, fphæerulas initio demerfas obtegens; fed fucceflu temporis hæ tam in altum tolluntur elaftica maffæ fibrofæ vi, ut medix demum e velo contabescente emineant. Interea tubercula, figuram fuperne truncatam affumentia, fphærulis globofis, atris, vertice perforatis, in disco fungi \& verfus ejus oram jam fparfim apparentibus, ad fimilitudinem talorum luforiorum fatis accedunt. Vidi fapenumero Majo.

\section{Figurae explicatio.}

\section{Tab. XI tig. 92.}

a. Fruftum corticis alnei, puftulis, feu tuberculis, fcabri, magnitudine nativa delineatum.

b. Particula hujus corticis, ex quo fungi quinque lente ampliati protuberant.

c. Sphæria admadum augmentata adolescens.

d. Eadem adulta, h. e. fphærulis e fubftantia fungi jam emicantibus confpicua.

e. Sphæria ad perpendiculum difeeta.

B. fulcata.

Mino priori, puftulis cylindricis brevioribus. Sphærulæe fulcatæ mihi funt iife. Sparfim ramulum quendam dejectum, aridum, ab illa obfefium vidi Martio.

Figurae explicatio.

Tab. XI fig. 93.

Sphærula, fub lente uti apparet.

$$
\gamma \cdot \text { pileata. }
$$

In varietate hac, e cortice ramorum demortuorum Aceris Pfeudo-Platani gregatim progerminante, forma tuberculorum conum truncatum refert, cujus verlici 
velum orbiculatum, prominens, demum deprefiun \& margine paffim incifum, infidet, pileum quafi efformans, e quo fphxrula emergunt comprelfæ. Senescentia modo fungi exempla vidi Aprili. Magnitudine varietati $\beta x q u a l i s$,

OBS. An Sphxria nivea Hoffm, crypt. p. I. p. 2s. t. 6. f. 3 ?

Figurae explicatio.

Fungi tres ampliati in fitu naturali.

$$
\text { Tab. XI fig. 80. }-7,4 \text { ? }
$$

\section{$\delta$. licheniformis.}

Facie externa fadmodum variat. Tubercula quidem teretia, fed altitudine varietatibus precedentibus inferiora, adde, quod forma rotundata in fungo fenescente fiat oblonga, margine tunc fubangulato. Glnbuli, nitidi magis, quam in varietate $\alpha \& \beta$, funt exferti \& non folum ad oram, fed in toto fungi disco fparfi cernuntur. Materia quadam infpiffata \& quafi cerea conftant, qua qua plus aret, eo plus in centro dehiscere incipit. Mafia quoque alba, cui funt infixi, arescit \& tum rimulis hic \& illic diftineta, feu fifia, apparet. At vero figura haud raro confpicitur ovali, utrimque acuminata; epidernide quidem, quxe Sphæriam cingit, prominente, fed mafia ipfa illius vix ac ne vix quidem ultra corticem, cui incubat, emergente. Sphrcrulx tum aut ad marginem contigure in formain rofarii, feu linex globulorum precatoriorum, difpofitx conficiuntur; ant in angulo utroque disci conftipatz commorantur. Varietatem hanc polymorpham \& forte ad Lichenes cruftaceos amandandam obfervavi in ramulis aridis Coryli Avellanæ Mlartio.

\section{Figurac explicatio.}

\section{Tab. XI fig. 95.}

a. Fungorum agmen, e ramulo ficco protuberantium, magnitudine naturali pictorum.

b-e. Furigus lente adauctus

b. adultus;

c. Fenescens;

d. Pharruiis contiguis, aream margine cingentibus.

e. Sphærulis confertis, anguhm Sphrerix utrumque occupantibus. $f-h$. Sphrerula admodum augmeritata, 
f. facie externa;

g. ad perpendiculnm fecta, cum in centro dehifcit.

h. Spharula fubtantix fungi immerfe eodemque modo fectx.

$$
\varepsilon, \text { conferta. }
$$

Sph ru'x in hac integrum discum occupant, ut nullum igitur mafie'candidx, has excipientis, veftigium appareat. Magnitudo earum eadem, ac in varietatibus pracedentibus; fubftantia ceræ fimilis; fed aliquantum durior; figura fphxrica, comprefla. Inveni Martio in cortice ramuli arborei exficcati fparfim crescentem.

\section{Figurae explicatio. \\ Tab. XI fig. 94.}

a. Fungorum hexas magnitudine nativa pictorum.

b. Fungi duo lente amp!iati.

c. Sphærula admolum aucta.

d. Eadem ad perpendiculum" difieta.

\section{I. SPHAERIA placenta.}

S. compofita, rotunda, complanata, tuberculofa, monofticha; fphærulis giobofo-acuminatis, connatis, atris.

Figura fungi placentæ rotundæ, fubconvexæ; magnitudo lineæ \& quod excurrit; fuperficies lævis; discus colliculofus; color niger in arida; nigro-fulvescens in humectata Sphæria; fubftantia fibrofa; cortex infeparabilis. Sphærulæ atræ, globofx, vertice tantillum producto, lateribus connatæ, unica ferie crescentes, nitida. Sedes fungi in epidermide ramulorum exficcatorum. Majo.

\section{Figurac explicatio.}

Tab. XII fig. 97.

a. Fungi ramulum demortuum incolentes, magnitudine naturali pieti.

b. Fungus per lentem vifus. -

c. Idem verticali directione diffectus.

d. Sphacrula adaucta.

e. Eadem, uti perfecta cernitur. 


\section{SPHAERIA natans.

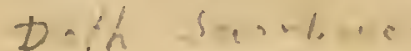

S. compolita, fubrotunda, convexo-plana, aggregata, atra, monofticha; cortice fuperne collicu?ofo, fuoftantiam viscidulam, indurescentem continente; fphacrulis aggregatis, albis.

E icortice ramorum demortuorum Sambuci nigrx denfe erumpunt tubercula rotunda \& Interdum ovalia, atra, convexa initio, demum plana, epidermidis ruptr laciniis circumcineta, disco femilineari, colliculis denfis exafperato. Diffecta folliculum fiftunt membranaceum atrum, liquore fubviscido livido, h. e. mucilagine feminifera, huic generi peculiari, repletum: quapropter primo obtutu pro Sphæria fimplici haberi facile poteft. At nantes confpicinntur immediate fub disco fungilli adolescentis fphzerulx monofichre, albidx, globofx, vertice producto acnminatx, folidre, fed fenlim cavescentes, quarum papillie, veficulie plagam fuperincumbentem trudentes, huicque forte inferta, colliculis jam jam distis ortum dant. Liquor ipfe viscidus, initio aqueus, in mafiam ceream coloris e cinereo albentis coagulat, haud raro interue dehiscentem. Aperturam in colliculis, forte ob nimiam ejus parvitatem, non vidi; adefle enim, nullus dubito. Fructificationis modum hujus Sphæriæ omnino ignoro; fingularem vero effe, ipfa fungi ftructura monet. Senescens nitet, menfibus Martio ac Aprili frequentifimus.

Figurae explicatio.

Tab. XII fig. 98.

a. Fungorum agmen ad naturam pictum.

b. Fungus aủmodum ampliatus.

c. Idem per verticem recta fectus.

d. Sphrerula adaucta.

e. Eadem ad amufim fecta.

\section{SPHAERIA deruginga.}

S. compofita, oblonga, convexa, fparfa, aqux maricx colore, monofticina; Cubltantia \& fpherulis atris.

Non confunderia cum Spharia fiarovirescente Hoffm. crypt. T. p. 10. to 2. f. 4 , ád quan fane accedit quoad figuram oblongam, piacenta fimilem, quam $\mathrm{D}_{2}$ interdum 
interdum acuminatam utrimque \& a linea una ad tres usque extenfam inveni, latitudine plus minus lineari. Convexam nonnunquam, fed \& planam vidi. Superficies tomentofa, fqualide viridis infiar aquæ marinæ. Eminent ex illa, unam modo feriem conftituentes, fphrrulæ atix, nitidæ, comprefio-acumiratæ, perforatæ \& fubftantix concolori, compacze, ad papillam usque immerfa, quas inanes inveni: Innotuit mihi fparfim in ramulo putrescente, delibrato, querno, crescens. Julio,

Figurae explicatio.

\section{Tab. XII fig. 99.}

a. Fungi nonnulli, magnitudine ac fede naturali delineati.

b. Fungus fub lente vifus.

c. Idem medio difiectus.

d. Sphærula mole perquam aucta.

e. Eadem e vertice fecta.

\section{SPHAERIA caforea.}

S. compofita, fubglobofa, aggregato-fparfa, aequalis, nigra, monoiticha; volva fusca, fugaci; fphærulis atris.

Prodit e ligno putrescente, fparfim gregatimque, figura mali aurantii, interdum ovali, diametro lineari, ad duas lineas nonnunquam extenfo. Integumento obducta cernitur, tomento nimirum angufto, byfino, tenerrimo, coloris fusci dilutioris, feu caftorei, quod cum evanuit, cortex niger, aequalis, in confpectum venit, a fubm ftantia fungi refinofa, friabili, infeparabilis; quin, ut videtur, ab ea, colore excepto, re vera non diverfus. Mafia hæc, feu corpus Sphæriæ, fi verticaliter fecatur, lobos planos, arcte obvolutos, inferne vero connatos, h. e. vafa conftrictoria, feu emulgentia, e quibus ad modum aliarum Sphxriarum conflata eft, fic fatis manifeftat, ut is certe, cui vafa hæcce, conftriftione fpontanea fphrerulas, mucilagine plenas, evacuantia, jam aliunde innotuerunt, hic ea hand difficulter recognoscat. Sphærulæ ovales, acuminatæ, oftiolo fuo fuperficiem fungi, feu, fi mavis, corticem ejus, perforant. Inanes vidi, facculo candido, vulgato, interne induEtas. Communicavit perbenevole mecum exempla recens lecta clarifi. Timm. Junio.

ODS, Involucrumne illud tenerrimum, fugax, in Epecie hac, tt in aliis, v. c. Sph. confluente \& Sph. radiante, illico defcribenda, ipfum pollen; an ejus fortanis receptaculum 


\section{SPHAERIA.}

eft ? Satagane crtertm de hac vexabili spixriarum volva fugaci Viri in ejusmodi rebus fcrutandis $\&$ - judicandis me acriores.

\section{Figurae explicatio.}

\section{Tab. XII fig. 100.}
a. Sphærix aetate impares, magnitudine nativa pietæ.
b. Sphreria mole aucta, ut rolva induta cernitur.
c. Eadem fectione verticali divifa.
d. Sphrerula adaucta, limili modo diffếta.
e. Eadem integra.

\section{SPHAERIA radians.}

S. compofita, fubglobofa, aggregato-fparfa, fubtuberculofa, atra, fubmonofticha; volva pulverulenta, fulva; fphærulis albis.

E ligno querneo, putrescente, fparfim gregatimque protuberant forma vel rotunda, vel cvali, globi fatis comprefii, five pulvinati, magnitudine Sphreriæe precedentis. Incruftati funt pulvisculo coloris e luteo, rubro fuscoque mixti, h. e. fulvo-teftacei. Sed integumentum illud pulverulentum, digitis attrectatum, facile defricatur, \& tum comparet cortex fungi ipfe infeparabilis, ater, nitidus, initio aequalis, tanden vero modice tuberculofus. Quod fi Sphreriam hanc, cultello per ejus varticem ducto, fecueris, fubjacentes videbis cortici fphærulas albas, globofas, papilla procera, in modum pyri inverfi, umbonatas ' $\&$ in unum tabulatum difpofitas, quibus tamen interdum fuccubant hic vel illic aliæ fphrerulae ejusdem coloris, globofx, papilla carentes. Maffula grifea, apparenter viscofa, utrumque earum genus repietum obfervavi. Nidulantur in ftrato quodum albido, compacto quidem, fed nec fibrofo, neque refinofo, fubftantiam Sphrerice circumdante \& cum hac connata. Pulveri carbonum illa ipfa quidem externa facie fimilis eft; ceream vero, fi, perfcinditur, fe monftrat, fuperficie fegmentorum nitente; id, quod náturam ejus refinofam, feu gummofam, arguit. Sed folemne huic Sphrerix eft, ut centro, ffeu nucleo, gandeat albo, capitulo clavæ militaris, muricatx, fimili, \& hanc ob caufam radiante quafi. Progerminat radians hocce viscus immediate e ligno, cui Sphæria ope tuberculi cujusdam affigitur; porriguntur vero cjus radii quaquaverfus in maffam carbonariam \& in ftratum albidum jam defcriptum, fphacularum fcilicet 
habitacultim; quin probabilite å ipfasmet pertingunt; duetus enim. fucco nutritio provehendo deftinati, efie videntur, qui \& in aliis Sphæriis haud raro abfervantur. Et hunc fungum munificentix Timmii mei acceptum refero.

OBS. I. Stratum in Sphatis compoficis fpharulas fovens celeberrimo Hoffmanno ( 1 . c Praf.) pollinis congeries videtur. Qund fi non fine caura dicit Vir doaifimus, id, quod volyam nuncupo, in hac faltem fpecic cum polline nil commune habere potef.

2. Accedit quiden Spharia nottra ad sph. Lycoperdoiden $\alpha$ heig. fed in hac fpharulx ant nigra, \& integumentum externum onnes veri corticis notas habet.

Figurae explicatio.

Tab. XII fig. IOI.

a. Fungi nonnulii magnitudine nativa depicti.

b. Fungus lente auctus, integumento pulverulento inftratus, cujus per plagam defrictam cortex ater confpicitur.

c. Idem ad perpendiculum una cum nodulo muricato centrali lectus.

d. Sphærula admodum ampliata.

e. Eadem e vertice, una cum ftrati, cui immerfa eft, particula, perpendiculariter diffecta.

\section{SPHAERIA lenta.}

S. compofita, lentiformis, aggregata, lenta, pulla, monofticha; fphærulis globofis. Diameter ejus duarum, vel trium linearum. Lentis figuram habet, disco gibbo, margine compreflo, fubrepando \& exficcatione undulato. Discus pullus, ad luridum vergens, lævis; in fungo vieto rugofulus, centro depreflo. Subftantia candida, lenta, fibrofa, valida; cortex infeparabilis ab illa mihi eft vifus. Prope hunc fpherularum unica feries cernitur. Globofas vidi \& coloris albidi; fed potius fphærularum primordia fuifie autumo, cum Sphæria hæc, ut omnia teftantur, ad Hypoxylorum familiam pertineat. Crescit fungus gregatim confertimque, duobus, tribus quatuorve hand raro connatis. Confpiciendum fe mihi præbuit in trunco excifr Fagi putrescente \& fimul in radicibus ejus, terra leviter tectis. Septembri.

Figurae explicatio.

Tab. XIl fig. IO2.

a. Funguli dno magritudine naturali delineati. 
b. Sphacria, uti prima aetate comparet.

c. Alia jam aủulta.

d. Sphrerix tres ejusdem aetatis, connatie.

e. Sphæria lente austa, ut ad perpendiculum difiecta cernitur.

\section{SPHAERIA Ribis.}

S. compofita, convexo-oblonga, aggregata, purpurascens, monofticha; fpharulis ovalibus, papillatis, prominulis.

E cortice ramorum demortuorum Ribis rubre protuberat, rupta eorum epidermide, qua circumfepta poftea confpicitur. Agmine non interrupto puftulæ hæ transverfales, oblongæ, lineam vix longitudine exæquantes, virgulas aridas cingunt. Fungus ipfe oblongus, modice convexus, cortice lavi, infeparabili, purpureo-badio; fubftantia ficca plantulx lanuginofa, levidenfi, e cinereo albessente. Ex hac prominent una eademque ferie, ad medium ferme, fpherulæ cortici concolores, lreves, fed absque nitore, ovales, papillatæ, quas mafia quadam albida, cerato limili, repletas inveni. Subftantice fungi non firmiter infixæe funt, quare facillime ab hac feparantur; fed evulijs ex ea portiuncula lanuginis memorata plerumque adhæret. Non nifi exempla aetate provecta vidi. Majo.

OBS. Admodum fpeciei infequenti fimilis eft; a qua tamen fpharularum figura orali potifimum differt.

Figurae explicatio.

Tab. XII fig. 103.
a. Sphxriarum agmen, naturali maguitudine pictarum.
b. Sphxria per lentem vifa
c. Eadem ad amulfim feeta.
d. Sphrcrula admodum ampliata.
e. Eadem e vertice difiecta.
f. Sphærula evulfa, cui inferne fubftantiæ lanuginof panicula adharet.

\section{SPHAERIA decidna.}

S. compofita, oblongo-convexa, aggregata, monofticha; fubftantia flaya; fpharulis globofo-papillatis, rubris, prominentibus, deciduis. 
Ad modum proxime præcedentis tex epidermide ramorum demortuortum eademque fpecie externa erumpit; at vero magnitudine hanc frepius antecellit. Subftantia a cute lavi infeparabilis eft, feu, ut rectius dicam, cutis veri nominis omnino abeft, uti in Sphæria jam nominata. Solidam fe prodit \& cerei quidpian habentem, coloris in fuperficie framinei, interne vero aurantii, in aureim expallescentis. Sphrculas vix ad medium usque immerfas excipit, confertas, globofas, obfolete punctatas, miniatas, papilla coccinea, decidua, umbonatas, qux cum confenuerint, colorem nativum cum miniato-flavescente, feu Arfenici rubri, iangnid, commutant, in papilla femper vividiori, \& ex alveolis fuis frepius excidunt. Inanes vidi menfe Martio in ramulo arido, alneo.

OBS. Eoden menfe confpexi varietatem, ut videtur, liujus sphxrix, fed tum temporis obfo: letam. Aequali modo epide:midem ramorum emortuorum in tuberctila exrendit \& tum rumpit. Figura rotunda \& oblonga, convexa, diametro a linea una ad tres extenfa:. Subftantia folida, fubfucculenta, coloris amcne ferruginci. Spharula atropurpurex, ovales, collabescendo vertice quafi truncatx \& tum nigrescentes, papilla atrum colorem induente. Bafi fua folummodo inharebant fubftantix sphxrix. In Eamulo dejecto Cratagi Oxyacanthx.

\section{Figurae explicatio.}

Tab. XIII fig. I04.

a. Fungi nonnulli ramulum inhabitantes, magnitudine \& fitu naturali depicti.

b. Fungus lente auctus.

c. Idem perpendiculari directione difiectus.

d. Sphærula ampliata.

\section{SPHAERIA atro-purpurea.}

S. compofita, rotundato-plana, fparfa, atro-purpurea, monoficha; fpherulis ovalibus, papillatis, connatis, nigris.

Inter compofitas Spherias planifimis eft affocianda. Epidermidi ramolum demortuorum innascitur \& orbiculari \& elliptico anfraetu, diametro inciali, interdum biunciali. Cortex infeparabilis, lavis, apiculis fphxerularum, nbique denfe prominentibus, fcaber, coloris pulli, feu faturate fpadiceo-nigrescentis. Subftantia fubpulverulenta, in fungo juniori fulvus, in fenescente, vero ai colorem. accedit, qui a famofiffma Pompaduria nomen traxit, fed minus latum, h. e. fpadicei quid admixtum 
admixtum habentem. Sphærulx minimx ovales, connatie, nigrx funt, red ad verticem, ut papilia, atre. Interne inanes inveni. Obfervavi fpeciem hanc admodum raram in ramis exficcatis Cratæegi Oxyacanthx Majo \& in fragmento ligni putrescentis OEtobri.

QB.S. Forte mera varietas fubfequentis rpeciei eft cenfenda; serte in hac nofta bondum omniz notatu digaz detecta mihi videntur.

Figurae explicatio.

Tab. XIII fig. I05.

a. Sphæria magnitudine nativa depiCta.

b. Eadem diflectá ad amuflim.

c. Segmentum ejus admodum ampliatum.

d. Sphærula mole valde aucta.

\section{SPHAERIA macula.}

S. compofita, polymorpha, planiffima, atra, monofticha; fphærularum globofo-papillatarum fingulis, velo fugaci tectis.

In ramulis querneis defractis aridisque poft pluvias largiores maculæ atræ, fatis magnx; b. e. nonnullarum interdum unciarum menfura, figura variæ, plerumque vero rotundatx, e fiffa ac revoluta epidermide emicare mox incipiunt, quæ, fi per lentem confpiciuntur, Sphæriam ob oculos ponunt de cortice protuberantem, planam, atram, fuperficie tomentofa, feu panno holoferico admodum fimili. Tomento huic immerfi funt glomeruli bombarini, nivei, perquam minuti, aggregati, quorum quisque, expulfus per papillam perforatam fpharularum minimarum, atri coloris, ftatim in apice oftioli, ex quo erumpebat, fublidet \& brevi poft, contabescendo complanatus, velum orbiculare fiftit, a papilla fenfim perforandum, tum autem evanescens. Perbrevi temporis intervallo hec omnia accidunt: interim vero fphzria ipfa magis complanatur, feu potius coaretatur; tomentum enim illud holofericum in cortice difparet \& e fuperficie jam glaberrima prominent, papillæ fphærularum lavium, figura fpherica fubcomprefia comparentium, quas gelatina valgari feminifera plenas, fubfantiaque folidæ, candida, immeras inceni. 


\section{SPHAERIA.}

OBS. Sphriam ftigma Hoffm. T. p. 7. t. 2. $f$. z. admodum cum noftra congruere, nemo non videt; fed anguftior longe elt lrac, ac comprefinor, quam illa \& nunquam rimis fifurisque fcifa, nec tam late ferpens, ut ramorum plagas maximas incruftet. Accedit eo, quod Sphria macula non folum cortices virgultorum fupercrescat, fed in nudo quoque ligno putrescente fedem fibi figat, Sphxrix Rigmati plane inconfuetam. Hisce tationibus commorus, aliam ab alia feparandam effe credidi. Caterum \& Hoffmannianam neu integumento fugaci holoferico, neve velo itidem fugaci fpharularura carere, cognitum \& compertum habeo.

2. Glomeruli illi bombacini delicatulique, oftiølis fpharularum paulifper incumbentes, cum complanati \& parlo polt evanescentes, velum mihi videntur, pollen fovens. Expelluntur enim manifelto jam tum e fpharulis, cum ha nucilagine, femina continente, adhuc funt repleti: quare pro hac ipfa haberi nequit. Sed unde demum venit? Nil aliud, meo quidem judicio, elt, quam tela toties dita araneofa, e mucilazine fpermatisa, in capfulis contenta, ortum trahens. Ejicitur quidem e quibusdam Sphxris tempore fructegcentix globulus candidus, feu, quod idem eff, mucilago protrufa in maffan globofam hujus coloris irrigescit; at vero ejusmodi globulus nunquam contabescit; fed figuram suam usque dum decidit, conforvat, tur vero in pulvisculum fatiscit. Conf, infra sphxriam 39 ऽqg.

Figurae explicatio.

Tab. XIII fig. 106.

2. Sphrria magnitudine nativa delineata.

b. Eadem, (mole tantillum aucta) ut verticaliter fecta comparet.

c. Segmen ampliatum Sphæriæ adolescentis, glomerulis bombacinis,-feu velis particularibus, globiofis, vixdum expulfis.

3. Segmentum æque ampliatum adultioris Sphæriæ, velis jam complanatis \& a fphzerularum mucrone transfoffis.

- Sphærula admodum aucta, cujus papilla fub velo globofo fuperincubante latet. (Tomentum Sphæriam obducens in figura non eft expreffum, ut nempe velum integrum in fitu fuo eo melius confpici queat.)

3. Sphærula adaucta, nti una cum velo contabescente ad perpendicum diffecta fe cernendam prabet.

\section{I. SPHAERIA cancellata.}

S. fubcompofita, rotundo-ovalis, convexa, aggregato-fparfa, atra, znonofticha; velo prominente; fphærulis connatis. 
E ramis falignis, dum arescunt, egerminant tubercnla, feu fparfa, feu aggregata, ferninis papaverei magnitudine, quæ epidermidem corticis arborei, quin potius lamellam illius extimam, qua teguntur, ubi ubi in formam puftulx rotındæ, vel oblongre, ita elevant extenduntque, ut ejus fibræ contextre reticuli in modum extricentur ac fenettrentur: unde cancellatæe nomine mihi venit. Simplex aeque, ac compofita invenitur: h. e. Sphærula nigra, lævis, phialæeformis, vel folitaria, vel gemina trigeminave, ad apicem usque immerfa eft fubttantix fungi parabolici, fuperne truncati, bati convexi, urnæ proinde fepulcrali, vel ollæ, exterıa fpecie fimilis; cortice infeparabili, lævi, aequali, nigro; medulla e cinereo ablescente \& apparenter ftuppea. Obtecta cernitur Sphæria velo orbiculari, candido, demum albente, fibrillis byfinis condenfatis contexto, et ültra oram urnula prominente. Videtur velum hoc, una cum papillie apice epidermidem cancellatam fupereminens, cum fubftantia fungi ipfa effe conliatum; fed probabile mihi fit, in hac Sphæria, ut in compluribus noftrae confimilibus, v. $c$ in proxime praecedente, epidermidem a papilla capfularum perforari, tum fcilicet, cum per ejus porum exploditur glomerulus ille bombacinus, feu tela araneofa, mucilaginis feminiferae progenies, hancque in eruptione aliquantifper praecedens, qui papillae eidem, qua exprimebatur, tum de more incubaris, fentim, uti monuimus, complanatur contabescens \& ab illa transfigitur. Perforatas autem effe papillas haud dubito, licet ob parvitatem eximiam porum ipfum diffincte non viderim. Medulla capfulas fovens, forte quod nimium relaxa eft, in Sphaeria humida dilucide quidem confpicitur, aft in ficca non item. Sphaerulas gelatina pervulgata impletas inveni, \& ubi plures earum fimul in uno eodemque fungo aderant, femper connatas. Sedes hujus non in ipfo ramorum cortice, fed intra lamellam, feu membranam, pellucidam mediam ac infimam epidermidis. Offendi Sphaeriam hanc concinnam raramque Majo menfe.

Figurae explicatio.

$$
\text { Tab. XIII fig. } 10 \% \text {. }
$$

a. Sphecrix, fragmini corticis faligni infidentes, magnitudine naturali pictae. b-f. Fungus quam maxime auctus.

b. Sphæria, epidermide reticulata rami faligni teêa, papilla fphrerulæ veloque emicantibus.

c. Sphæria fimplex, verticaliter fecta, quo figura ejus urnalis, feu $\mathrm{E} 2$ ollaris 
ollaris, ac ftruecura interna, ficuti veli complanati perforatique fitus, oculis commodius fubjiciarur.

đ. Sphreria compofita, eundem in modum diffecta.

e. Sphreria fimplex, velo inftructa, ut epidermidi exfculpta cernitur.

f. Eadem, diffecta quidem fubftantia una cum relo; fed fphærula incolumi.

g. Spharula nuda, mole perquam aucta.

\section{SPHAERIA infitiva.}

S. compofita, carticalis, plana, lineari-acuminata, candida, monofticha; vel s cum fubftantia fungi conudto; fphixulis papillatis, atris.

Rimas epidermidis Vitis demortux onnes omnino ita infarcit, ut quafi infititia videatur. - Cum vero cuticula hac confepta femper inveniatur, eodem jure, ac Sphæriam ftigma, tuberculofam, cæet. Hoff $m$. pro compofita habetur; licet ambitus ejus, Lichenum cruftaceorum in mortm, quam maxime fluctuet. Sphærnæ minimæ, compreflo-globof $x$, læves, nitidx, atræ, aggregatæ, papilla fuhelongata, perforata, eminent e vela candido, texturx byffinx, plana, fuperne lævi, inferne cum fubftantia ipfa fungi albida, furfuracea, tenera, connato. Corruens haec demum, feu contabescens, lateribus earum laxe adhaeret, velo tandem evanescente. Obtectas quafi vidi hac Sph xria vites compluviatas fideratasque, ad murum auftralem aedis. facræ, quæ Perlini el', plantatas, Sphærulas interdum tela, generi huic promiscua, araneofa oppletas, fæpiffime autem inanes reperi. Julio.

OBS. Non confundi debet cum Sphria byffacea Weig. obf. p. 45. t. 2. f. 9. \& Dackf. crypt. p. 22 i hujus enim fphrerulx papilla carent \& collapfx, ut obfervavi, concavescunt: h. e. pezizx faciem induunt. Adde, quod ex efidermide arborm spharia illa nunquam extuberat, fed nuda his infidet ut crufta furfuracea, neutiquam circumfepta.

Figurae explicatio.

Tab. XIII fig. Ios.

a. Sphæriæ nonnullæ magnitudine nativa pictæ.

b. Sphæriæ quædam lente auctæ.

c. Sphæria exoleta, it corruente jam fubftantià, fphærulas circumdante, fub lente apparet.

d. Segmen- 
d. Segmentum Sphæriæe agonctum, in quo Sphxrulx dux verticaliter fectx, velo adhuc fubftantize furfuracere incumbente, confpiciuntur.

e. Sphærula admodum ampliata, adhærente illi fubftantiæ contabescentis particula。

\section{SPHAERIA fuccenturiata.}

S. compolita, oblongo-pulvinata, fparfa, bicorticata, atra; fphærulis fuccenturiatis fimplicibusque.

Lignifeda, oblonga, pulvinata, lineas 2 vel 3 longa. Cortex exterior lavis, aequalis, ater, refinofus; interior fnscus, uterque anguftus \& infeparabilis. SubItantia fungi grifea, fuscescens, folida. Prefcili nitet, indicio aperto, eam e maffa gummofa, feu gelatina, efle concretam. Sphæerulas atras duplicis figuræ ac molis continet, alias nempe immerfas ad corticemque interiorem applicatas, pyriformes, quarum orificium attenuatum intra fungi corticem interiorem exterioremque dilatatur in capfulam homogeneam, globofam, fed admodum compreffam, vertice demum pertufo. Sphærulæ hæ, pro fertilibus merito habentur: capfula fcilicet fuccenturiata figuræe compreffe, jam jam defcripta, globulum illum candidum, tenerrimum, in quo velum agnosco, ad tempus faltem, manifefto includente. Adfunt vero \& aliæ fphærulæ, altius defofiæ, figuræ ovalis, capfula hac adventitia orber, quas fteriles proinde judico. Sphæria caeterum, ut complures fimilis ftructuræ, innititur tuberculo cuidam e ligno prominenti, ceu radici, fuccum nutricium fphærulis fuppeditanti. Colorem album, nativum, nunquam illud in noftra Sptæria deponit. Sphærularum fertilium capitula qui detegere cupit, cante \& verfatili manu corticem fungi atrum fenfim progrediendo abradat, neceffe eft. E rarioribus fui generis; reperi vero fparfim crescentem in ramis deciduis quercinis, quorum cortex putredine graffante jam erat abfumtus, plus una vice Majo menfe.

OBS. Splizrula fuccenturiatre, mira fane apparentia! in hac non folim fpecie; fod etiam in Spharia coronata Hoffm. crypt. I. p. 24. t. S. f. 4. s, clarifime ccrnuntus. At enim obfervantur quoque in $\mathrm{Sph}$. bullata Ejnsd. (l. r. pos. t. 2. f. s.) cujus c fuperficie Vir doâfimus fe albidum quid cthorescerc fvidific (er velum noftrum glomeratum!) teftatur. Sphrrulis nempe illa fxpius inftucta obvenit bifariis: forcumis fcilicet, ac Itcrilibus, ficuti noftra. Priores tunc collo tubulari, longiuscuto, ut ccleberr. Auقor papillas Sph, disciformis $(t, 4 . f, x)$ depinxit, funt proditx, quod 
apice in aliam quaf fphxinlam dilatatur, fubglobofam, vertice perforato; fed portmodum, h. c. polt globuli albi, byfrni, intus ex fphxrula genuina recepti, explofronem, collabesceatem, \& jam deprefia \& fubangulata forma comparentem, Sphzrulis hisce foetiferis fubjacent alix, globofx, confertx, colli, feu papilla omnino expertes, id quod in spi.. disciformi, Hoffm. a bullata Ejasd. parum discrepante, quoque obfervatur. Pertranfit vero globulus ille vexabilis, bombacinus, cavicatem utramque geminatx fphxtulx eodem modo; ficuti minoris capfule quoque parictec interdum, in tapetium Batfchianum permutatus, inyeftit.

Figurae explicatio.

Tab. XIV fig. Iog.

a. Sphrriæ dux, magnitudine naturali depictr.

b. Sphæria adaucta, ad perpendiculum diffecta, demto dextrorfum cortice exteriori nigro, ut Sphaerularum fœcundarum capfulæe fuccenturiatæ, e cortice interiori emergentes, commode confpici queant.

c. Sphaerula fœcunda, admodum ampliata ficque repraefentata, ut fegmini Sphaeriae dimidia inhaereat. In hoc vero inferne fubftantiae; fuperne, corticis interioris fungi pars cernitur, cute nigra exteriori refecta.

d. Segmentum aliud Sphaeriae, mole valde aucta, quo exhibetur fphaerula fœcunda, ad amuffim diffecta, ita ut capfula fuccenturiata, (globulum bombacinum, "e (phaerula ipfa eruetatum, jam fovens) uti cortici hæc utrique fungi eft immifia.

\section{SPHAERIA cucurbitula.}

S. compofita, convexo-plana, aggregata, monofticha; Pphaerulis ovalibus, contabescendo concavescentibus, infitis, rubris.

a. flavescens.

Ad corticales pertinet, \& in variarum arborum ramis ramulisque demortuis tempore vernali abunde, \& denfo interdum agmine, provenit, fiffa eorum epidermide, tubercula efformans linearis, vel fesquilinearis, menfurae, tum rotundata, tum praecipue oblonga, convexo-plana, feu placentiformia; cuticulae ruptae laciniis haec circumfiftentibus. Subftantia Sphaeriae ipfa cerea, ftraminei coloris, nullum genuini corticis indicium offert; ob́fervavi autem in diffecta ductus quos- 
dam, coloris dilutioris, a bafi ad fphaerulas pertingentes, h, e. fuccum alimentarium eo vehentes. Minimae hae funt, ac ovales, rubrae, laeves, pulvisculo albido confperfae, ac bafi folum fubftantiae Sphaeriae, feu receptaculo communi, confertim infixae. Arescentes vertice primum depreflae \& quafi truncatae fiunt; poftremo in formam concavam patellae contabescunt, colore jam earum ad fordide aurantium translabente. Capfulas neque duras, neque friabiles, fed lentas, repletas eadem mafla cerea, pallida Sphaeriae iplius, inveni; fed oftiolum in eis nunquam vidi.

OBS. Similitudo, inter varietatem hanc \& Sphariam deciduan (p.3I) intersedens, manifefta efo

Figurae explicatio.

Tab. XIV fig. Iro.

a. Sphaeriæ aliquot, ramulo innatae, magnitudine nativa repraefentatae.

b. Sphaeria adolescens, fub lente ut confpicitur.

c. Sphaeria adaucta, ut extrema aetate, h.e.fphaerulis concavescentibus, cernitur.

d. Sphaeria ad perpendiculum interfecata, uti fub lente apparet.

e. Sphaerula junior ac incolumis, mole sdaucta.

f. Eadem ut tabefacta \& verticaliter differta in confpectum venit.

\section{ß. nigrescens.}

In omnibus varietate o confona; fed obfoletæ fuperficies ubique, in receptaculo, puta, nec non in capfulis, pulvisculo rariori obductis, \&, hoc abfterfo, nitidis, nigrescit. Maffa lutescens arescendo interdum in centro dehiscit \& ad bafin fit cavernofa. Repletura quoque fphærularum dehiscit \& in facculum Weigeliannm, rudiori modo difpanfum, abit. In ramis deciduis Pinus filveftris, vere.

\section{SPHAERIA convergens.}

S. compofita, rofacea, aggregata; fphærulis atris, excipuliformibus, liberis, convergentibus.

Sedes hujus inter epidermidem corticemque aridum Fagi. Nulli fubftantiæ, feu maffe foventi, immerfas inveni fphærulas atras, minimas, globofas, oftiolo tubulari, procero, inftructas; fed bafi folum imprimit quæque lamellæ fubjacenti alveolum, cus immoratur. Quinæ, vel fenæ, plerumque fphærulæ unam centra- 
lem in formam circularem, feu rofaceam, circumplectuntur ficque Sphæriam conftituurt: id, quod hoc pacto efficitur, ut collis fuis, five papillis tubularibus, erectis et in commune quafi centrum conniventibus, ac cradunatis, epidermis corticis perforetur, prominentibus tunc ab hac apertura tuhulorum convergentium apicibus. Spharulas, ex exficcatione inanes, aqua vero denuo fuperfufas, mucilagine fpermatophora grifea fine mora repleri vidi. Largis denfisque agminibus protuberantem confpexi Augufto menfe.

Figurae explicatio.

Tab. XIV fig. Irr.

a. Fungi aggregati, magnitudine naturali picti.

b. Sphærularum adauctarum convergentium oscu!a, e rupta epidermide arborea exftantia.

c. Sphæria itidem valde aucta, uti ad amuffim diffecta cernitur.

d. Sphærularum ampliatarum compages, cuticula puftulæ, has defuper circumdante, refecta.

e. Veftigia augmentata alveolorum, a fphærulis lamellæ fubjacenti imprefforum, ut convexi \& quafi uftulati in hujus fuperficie averfa apparent.

\section{SPHAERIA Janguinaria $=f_{i}$ htw}

S. compofita, cruftacea, rotundato-polymorpha, glauca, limitata, monofticha; fphærulis globolis, obfolete papillatis, atris.

Lichen fanguinarius Limn. Syft. 4. p. 5250: Hoffm. lich. 29, t. 5. f. 3.

Lichen limitatus Scop. carn. 2. II, n. I370.

Sphrria nitida Weig. obf. p. 45.t. 2. f. I4. Web. fpicil n. 231. Wigg. holf. n. 932. Dich. cryst. p. 22. "Reilh. cantab. n. 1055. Timm. niegap n. II69. coll. n. 892.

Verrucaria fanguinea Will. berol. 13. 1056.

Crufta levigata, plano-convexa, coloris glauci, feu e grifeo \& viridi mixti, dilute demum fuscescentis, qure fxpiffme rotundata eft, fed figura, ut magnitudine, admodum variat et linea atra repanda circumfunditur, epidermidi Fagi aliorumque arborum fparfim innascitur. Subfantia, cortice duritisculo \& ferme car- 
tilagineo, tecta, e maffa conflata videtur ceræ, terebinthino permixtæ, fimili. Ex hac maltha emergunt, cute jam defcripta prius in puftulas minutas, convexas, aggregatas \& frpius contiguas, elevata tumque rupta, fphrerulx globofx, femilinearis in maximis diametri, atra, laves, oftiolo annulari prominulo, margine tandem fubdeflexo. I Repleta funt mucilagine coloris fanguinei, quam ad parietes in facculum Weigelianum ejusdem coloris fepe condenfatam, hunc vero tapetio infuper candido Batfchii interdum obductum obfervavi. Fruetificationem ipfarm non vidi; at fubftantize viscolx, fphrerulas circumdantis oram, orificio earum contiguam, atro femper colore confpurcatam confpexi, quod de mucilagine, dum expellitur, atrescente, teftimonium luce clarius perhibet. Subftantia, vel natura, hæc tandem valde contabescit \& maxima ex parte difparet.

OBS. Spharia mammiformis Hoffm. crypt. I. p. r3. t. 3. f. 2. cum noftra iu omnibus fere adeo congruit, ut pro ejus varietate jure optimo haberi videatur.

Figurae explicatio.

Tab. XIV fig. II2.

a. Sphxiria magnitudine nativa delineata. b-d. Sphærulæ adauctæ.

b. Sphærula ad perpendiculum diffecta, quo facculus Weigelianus \& ora fubftantix fungi, ad orificium capfulæ per mucilaginis ejaculationem inquirata, fit contemplabilis.

c. Spliærula a fede fua femota.

d. Alia jam grandrevis verticaliter difiecta, in qua faccolus Weigelianus (integumentum internum rubrum) una cum tape. tio Batfchii (integumento candido) ob oculos ponitur.

\section{SPHAERIA cespitofa.}

S. compofita, hydnoides lamellata, globofo-cefpitofa, aggregata, atra; lamellis radiatis, inferne connatis, apice fpharuliferis.

OBS. Admodum cum hac concordat Spharia brandeburgica villarfia delpho p. 105\% n. To red lamellarum apices digitati non funt in planta gallica.

Species hæc abnormis epidermidem ramorum demortuorum Sorbi aucupariæ gregatim perrumpit tuberculis rotundis, ac ellipticis, viciae ut plurimum magnitu- 
dine, atris. Qux fi lente difpiciuntur vitrea, Sphærize admirabilem fabricam oculis exhibent, lotis, feu lamellis planis, obvoluto-radiatis, praduris \& quafi refinofis, inferne connatis, apice vero, fubdilatatis \& digitatis, conftantem. Omnia fubftantiam e mucilagine obcuratam anunciant, cujus color nativus luridus jam in fuperficie atratus apparet. Spharulas quas voco, proceffus dactyloidei ejusdem fubftantix funt: quare pro Tremellx fpecie fungillus putari poteft; at enim vero cum Spharice non folum bene multa naturam lamellofam prodant; fed inter mihi notas una faltem inveniatur, itidem gclutina duritiem induente contans \& fpherulas confimiles, h. e. folidas, cylindricas, fimilares, e visceribus quafi fuis per fuperficiem globofam protrudens, cujus defcriptionem ftrictam in aliud tempus referyo, cum genere hoc annumerandam centui. Obvenit mihi hac Sphæria Majo.

OBS, Confperfam fapifrine vidi pulvisculo disute cisereo. Num fenine?

Figurae explicatio.

Tab. XIV fig. II3.

a. Spharia fex magnitudine ac fitu naturali pictze.

D. Spharia adaucta, ut, epidermide rupta quafi confepta, apparet.

c. Sphæria adauctior, demto epidermidis fifiæe cingulo.

d. Sphæriæe admodum ampliatæ \& prope bafin transverfim fectæ fegmentum inferius.

e. Lamella quam maxime aukta, nti per verticem diffecta interna fpecies in oculos incurrit.

\section{**) Globiferae. \\ 38. SPHAERIA cylindrica.}

S. fimplex, globifera, cylindrica, fparfa, nigra; globo fpermatico candido.

Exiftunt a ligno cariofo faligno fparfim Sphæriæ cylindricæ, apice obturæ, nigræ, læves, duriusculæ, vix vifibiles, repletæ maffula farinaceo-viscida, quæ ex earum orificio pertufo globuli forma ejusdem coloris expellitur, mox in paftam rigescit, ac tandem dejecta fatiscit. 
Figurae explicatio.

Tab. XV fig. II 4 .

^. Fungilli e ligno erumpentes, ut magnitudine nativa confpiciuntur.

b. Sphreria lente aukta, ligno infixa.

c. Sphrria ad perpendiculum fetta.

\section{SPHAERIA parabolica.} livido.

S. fimplex, globifera, parabolica, levis, aggregata, nigra; g!obo fpermatico

Non nifi oculo armato contemplabilis. Pullulat confertim e lignis putrescentibus humidis, figura parabolica. fuperficie levi, fuperne nigra, inferne fusca. Fabricam internam ob molis parvitatem fcicitare non potui; aft apicem perforatum fenfi. Prodire ex hoc oftiolo vidi guttulam viscidam, coloris ex lurido lividi, cito infpiffatam, tum vero arentem \& deciduam: Capfula tenella, gelatinofa, Septembri. Plantula, uti precedens, perrara.

\section{Figurae explicatio.}

Tab. XV firg. I15.

$a>d$. Spḥria admodum zucta
a. de ligno protuberans;
b. adulta, fruetificans;
c. confenescens.
d. ligno effofia.

\section{SPHAERLA conica.}

S. fimplex, globifera, conico-tomentofa, aggregata; globo fpermatico flavo, atrescente.

Admodum parva, agminatim crescens, figura in pyriformem fatis quadrante; fed in fitu naturali confpecta, h. e. bati fedi fị inhrerens, pvramidalis cernitur. Capfula nigra, cujus ftructuram intrinfecam quromin!ss explorarem, molis tennitas vetuit, tomento fubraro livido eft obfita. Guttula e poro ascendens fordide flara F 2

primum 
primum eft \& fubpellucida; fed condenfata colorem jam mutat in piceum \& globulus, antequam decidit, fit nitidiffimus. In ligno arido Coryli. Aprili.

Figurae explicatio.

Tab, XV fig. I16.

a. Funguloram acervuli magnitudine naturali depietorum.

b-e. Sphæria adaucta

b. primum comparens;

c. adulta, guttula ebulliente;

d. fenior, guttula in globulum atrum converfa.

e. Eadem Spharia, uti ligno exfculpta cernitur.

\section{I. SPHAERIA fubulata.}

S. fimplex, globifera, fubulato-granulata, aggregata, fusca; globo Spermatico flavo, atres ente.

Obviam habui in exficcati Agarici aurati (Fl. dan. t. 980) fuperficie denfo aymine luxuriantem. Statura unius fere lineæ; figura coni elongati, bafi convexa; fuperficies granulata, coloris fusci, initio dilutioris, fed pofterius faturatioris. Apicem vidi (Hypoxylorum more) pulvisculo albo confperfum; fed interiora fungilli minimi \& gracillimi rimare non valui. Guttulam explodit aureo colore nitentem, pellucidam, egreffu ipfo ovalem. (Sic a me eft depicta; fed ad modum aliorum fungorum hydrophororum formam hanc primogeniam, ovalem, polthac in globofam tranfire, nullus dubito.) Cum exempla a me lecta \& capfa papyraceæ indita, tempore quodam interjecto, reviderem, globulos omnes deturbatos in atrum pulverem jam refolutos inveni: certo igitur guttula condenfatur, colorem. mutat \& fatiscit. Capfula junior natura molliuscula gaudet, fed rigida poftmodum invenitur. Confpexi fungillum ut qui maxime rarum Septembri.

Figurae explicatio.

Tab. XV fig. 117.

a. Agmen Sphæriarum nativa magnitudine depictarum.

b. d. e. Sphæria adaucta, fungo decrepito inhærens, ut cernitur,

b. p. oveniens;

d. fructificans; 
c. nutante acumine languescens.

c. Sphreria adauctior a fede fua femota, ut tempore fructescentize confpicienda venit.

\section{SPHAERIA dubia,}

S. fimplex, glohifera, elongato-attenuata, aggregata, grifea; guttula fpermatica fubpellucida, alba, lutescente.

Fungulus lineam \& quod excurrit altus, propemodum, cylindricus, fuperne attenuatus, molliusculus, colore grifeo, tantillum in hyalinum vergente, ad apicem deorfumque flavo, cui fulvi quid admixtum eft; fuperficie lævi, attamen ad bafin tomentofa. Guttula, gelatinæ albidæe fimilis, globofa; femipellucida, flavescit. Confpicatus fum germinantem in alburno rami querni, carie infeitati, Septembri.

OBF. Ad plantulx oppido minuta delicatzque interna indaganda cultellum in fubfidium vocare mihi non licuit. quamobrem cum globuh gelatinofi nec confrfentiam, neque colorem framineum porro immutari obfervaverim; quin illum poftnodo obductum puivisculo concolore videre mihi vifus fim, vereor admodun, we de Sghrriis eximenda \&c ad Stilba ableganda fit.

Figurae explicatio.

Tab. XV fig. 118.

a. Fungillorum grex magnitudine naturali depictorum.

b. Fungorum adauctorum trias, duobus inferne connatis.

\section{SPHAERIA penetrans.}

S. fimplex, globifera, globofo acuminata, collabescendo concavescens, aggregata, nigra; globs fpermatico atro.

a. Patelia.

Minimis fui generis merito affociatur, cum puncto paulo major appareat. Crebro innascitur, menfe Septembri, caulibus plantarum putrescentibus, aggregata, quin conferta. Capfulæ nigræ, læves, nitidx, globofx, vertice acuminato, pondere mucilaginis, in guttulæ formam exprefize \& poftea in globulum, omnis nitoris expertem, coagulatæ, deprimuntur adeo, ut tandem in Patella formam exca- 
ventur; globnlis ipfis tum decidentibus. Sphæria hæc initio plane eft demerfa; at fuccrescendo fenfim e cortice, in quo nidulatur, ad hujus fupericiem tendit, eamque demum fuperat.

Figurae explicatio.

Tab. XV fig. I2I.

a. Sphæriarum grex, magnitudine nativa depictarum.

b-f. Spharia per lentem vifa.

b. extuberans;

c. adulta jamque dimidia fui parte ultra fuperficiem corticis caulini elevata;

d. corticem hunc tota quanta fupereminens; fed \& confenescendo jam depreffior facta;

e. exoleta et tum perfecte concava;

f. nondum collapfa, ut verticaliter fecta apparet:

B. compreffa.

Varietate a paulo major, corticalis xque ac lignaria, lineari plerumque tractu confertimque proveniens, capfulis ovato-compreffis, nigris, lævibus, fæpe ldeflexis. Ligno adhuc plane demerfa jam fruEtificat. Globulus fpermaticus, ater, admodum, poltquam induruit, nitet. Varietas hæece nunquam collabescit.

Figurae explicatio.

Tab. IX fig. 74 .

a. Sphrix magnitudine naturali reprefentatæ.

b. Sphæriæ adauctæ.

\subsection{SPHAERIA Peßi乞a.}

S. fimplex, globofa, hydrophora, aggregata, rubens, collabescendo concavescens.

Capfulæ perfecte globofe, lieves, fatis duræ, friabiles, primum flavæ, poftea croceo miniata, tomento brevinimo ac delicatifimo, candido, obfitæ, magnitudine feminis Milii, gregatim fipites cxfarum fagorum \& betularum, nec non lignum falicum, cavernofum incolunt. Repletas femper inveni latice limpidifimo, qui, quo 
demum pasto \& quanam fub forma protrudatur, dicere nequeo. E capfula vero hunc exturbari inde conjectatur, quod fungus adultus collabescit \& tandem in modum cupule deprefius cernitur. At vero in vertice funguli obfervatur macula rotunda, colore vividiori faturatiorique confpicua, ubi certifime, fed modo mihi quidem incognito, humor ille cryftallinus feu perfpirat; feu alio quocunque modo excernitur; porum enim capfulx nondum diftincte confoicatus fum. Sphæriæ fenescentis color dilutior ac languescens fit; in̈urgo antem denique rugofo-crenulatus apparet; fibrillis capillaribus, ad morem Pezizarum, ligno affigitur. Vifendam fe milhi prabuit alignoties aeftate ac autumno. (Julio \& OEtobri.).

Figurae explicatio.

\section{Tab. XV fig. I22.}

a. Sphariarum cohors, magaitudine naturali reprafentatarum.

b-e. Sphæria ampliata
b. junior;
c. adulta;
d. decrepita;
e. ad perpendiculum in aetatis flore perfecta.

\section{SPHAERIA Acrojpermum.}

S. fimplex, globifera, cylindrico-ventricofa, pulla, conferto-aggregata, collabescendo ftrigofa.

$$
\text { a. nigra. }
$$

Magnitudine variat, fæepius vix lineæ dimidio; interdum rero fesquilineæ aequali. E ligno putrescente quercino agmine plerumque conferto progerminat, Hydnum tum nigrum idque minutiflimum mentiens. Superficies laris, aequalis, afpectu nigra, per lentem vifa colorem faturatius fuscum prodit; forma plus minus cylindrica, in medio fungo obfolete ventricofa, cernitur, quare eodem forte jure elongato-ovalis appellatur. Aper ferme parabolicus nitorem quendam habet; fed perforatım diftincte non vidi; nec, ut Sphæria ipfa, tandem fit ftrigofus, Confperfum, exeunte Martio, vidi pulvisculo tenerrimo, candido; repletas anten capfulas"mucilagine notiffima, livida, et fubinde tapetio, jam fæpius dikto, candido Batfchii indutas inveni, Natura earum gelatinze fenfim indurantis. Superfieiem ligni, 
ligni, cui innascuntur, femper ferme atramento quafi tinetam obfervavi. Fructificationem non vidi; fed vix dubium fubett, quin Sphæriis globiferis fit adjungenda hac noftra, quam Martio ac Aprili menfibus, nec non Septembri, obviam habui.

Figurae explicatio.

Tab. XV fig. I 19.

a. Sphæriæ aggregatæ, magnitudine naturali pictæ.

b-d. Sphæria adauctior

b. adulta;

c. inveterata;

d. ad perpendiculum fecta, comparente intus tapetio candido Batfchii.

B. tricolor.

Figura in hac perfeete eft cylindrica. Globulus fubpellucidus, nitidus cum fungo quafi concretus videtur. Color illi atro-rufus, ferme fpadiceus; fed Sphariæ ipfi nigro-fuscus, quæ ad apicem cinereo pulvisculo obducta cernitur. Menfura fungilli unius lineæ; fedes rami querni, putrescendo jam excorticati. Autumno varietatem hanc interdum vidi, priori longe rariorem.

Figurae explicatio.

Tab. XV fig. 120.

a. Quaternio fungillorum, magnitudine naturali delineatorum.

b. Fungulus, mole per lentem aucta.

\section{SPHAERIA gelatino $\int a$.}

S. compofita, globifera, pulvinato-gelatinofa, lutea, monofticha; globulis fpermaticis ftramineis.

\section{a. lutea.}

Ligna in uliginofis putrescentia inhabitare amat Sphæria hæc gregatim fparfimque crescens \& magnitudine admodum, h. e. a femilinea usque ad hujus tripluin varians. Figura rotundata, fubangulata, vel ad pulvinaris, vel ad placenta fimilitudinem accedens; color framineus; fubftantia fungi molliuscula, propemodum gelatinofa, corticis (faltem cunfpicui \& feparabilis) expers. Superficies lavis, nitore omni orba, aequalis; fed mature discus Sphreriæ adolescéntis papulata fit, 
tum vero puftulis hisce ruptis extuberant papillæ, five orificia, fphærularum unico folum tabulato, fed proxime fuperficiei, fubjacentium. Figura earum globofa eft, vertice, feu papilla, in conum elongato; color flavus, in papilla vivide croceus. Excufiam ex his vidi paftam globofam, dilute citrinam, denique fatiscentem. Confpicatus fum interdum Sphreriam hanc memorabilem ac rariorem Septembri.

Figurae explicatio.

Tab. XVI fig. I23.

2. Sphæriæ gregatæ, ut oculo haud armato cernuntur.

b-f, Sphæria per lentem vitream vifa

b. adolescens;

c. eadem ad perpendiculum diffecta.

d. Sphæria adauctior fruetificans.

e. Sphærula de fede fua revulfa.

f. Eadem una cum globulo fpermatico ictu verticali diffecta.

ß. viridis.

Lignaria, ut præcedens, ejusdemque figuræe, futftantix, coloris ac magnitudinis. Comparet poft imbres autumnales fub fpecie giobuli puiflli, minutifimo tenerı: moque tomento candido (num polline?) obduEti; fed, Sphæricam formam cum pulvinata, colorem autem candidum cum ftramineo commutat: tomento nempe illo candido, feu, fi mavis, pulvere, mature evanescente, Caticula fungi (aft a pulpa infeparabilis) quafi papyracea, initio æqualis, fed in fenescente rugofula fit. Colliculatus cernitur discus, fphærularum papillis ubique punctorum, feu potius granulorum, nigrorum inftar eminentibus; attamen revera non funt nigra, fed pervirides, mucilagine ejusdem coloris repletæ. Subttantix albæ ac fucculentx fungi inmerfe funt. Fruftificationem nondum vidi. Varietatem hanc, amcenisfimis fimulque rarifimis Sphriis annumerandam, bis folummodo huc usque reperi: una vice Septembri, altera Octobri.

Figurae explicatio.

Tab. XVI fig. 124.

a-c. Sphseria magnitudine naturali depicta

a. protuberans;

b. increscens; 

c. adulta.

d f. Spharia, uti fub lente comparet,

d. junior, tomento byflino obdukta.

e. fub tempus fruetescentix.

f. eadem diffecta.

\section{***) Styliferae. \\ 47. SPHAERIA gnomon.}

S. fimp'ex, ftylifera, :ggregata, globofa, collabescendo concavescens, nigra; ftylo fpermatico procero, fubrécto.

Extucerat gregatim e cuticula foliorum deciduorum, præfertim Coryli Avellanæ, magnitudine sirciter arenulæ. Figura globi, ut:oque polo compreff, lævis, nigri, (fub lente nigro-fusci,) hemifphxrio inferiore folio immerfi. Vertex tempore fructescentix perforatur, \& per osculum hoc mucilagn, feminibus fota, fub fpecie cyiindri, fubobtufi, recti, exploditur, colore hujus nativo livido in atrum extemplo mutato. Occallet fenfim, fed priusquam hoc fit, hand raro pondere fuo curvatur. Inter et poft expulfionem liquoris viscidi capfula collabescit \& concava demum cernitur, jam fatis dura facta. Stylus fpermaticus poftquam decidit, in pulverem atrum fatiscit. Obvenit hre Sphreria, cupulam gnomonicam veterum fic fatis facie externa referens, interdum mihi Martio ac Aprili.

Figurac explicatio.

Tab. XVI fig. 125.

a. Caterræ fangilloram naturali magnitudine depietoram,

b-f. Sphiria ampliata.

b. Spharix tres protuberantes.

c. Sphria adulta, a fede fua remota.

d. Sphzeria, fruetescentia peracta.

e. Sphreria confenescens, ftylo centrali jam dejecto;

f. Spharia fruetificans verticaliter fetta. 


\section{SPHAERIA Iingam.}

S. fimplex, ftylifera, aggregata, fubovalis, pulvinata, collabescendo concavorugofa, atra; ftylo fpermatico breviusculo, decumbente.

Magnitudine Sphariam pracedenten parum antecellit, cui fummatim nimium fimilis in'enitur. E caulibus exficcatis Braficæ oleracex rubræ denfe pullulat figura ovali, nec non rotunda, pulvinata, fuperficie lævi, atra. Capfulæ, ut primo ftylum protrudunt fpermaticum, concolorem, nitisulum, jam collabescere hoc pacto incipiunt, ut fulcus plerumque in vertice fungi, dimidio fui cauli herbaceo immerfi, extemplo appareat, plus minus hians pofthac, in $\mathrm{m}$.rem labionum diftortorum. Stylus nunquam plenifitime obfirmari videtur, certe nutatem fere femper. ac decumbentem inveneris, fimulque breviuscnlum: quid? quod haud raro rudiinentum ejus folummodo apparet. Sphacria vieta, fi qux alia, multiformis deprehenditur: nunc v, c. complanatan; nune orbicularem tumida; nune vero quali labiatam; nunc demum in labia, feu plicas concentricas, fubargulatas, corrugatam cernes.

Fignrae explicatio.

Tab. XVI fig. 126.

2. Sphæriæ congninatx, magnitudine uativa depictxe.

b-e. Sphæria adaucta

b. junior \& jam fructificans, in fitu naturali;

c. adulta, e fibris canlinis evulfa.

d. Sphrrixe vario modo collapfo.

e. Sphreria poft fructescentiam ad perpendiculum diffecta.

\section{SPHAERIA tubaeformis.}

S. fimplex, ftylifera, aggregata, globefa, collabescendo cupularis, atra; fig10 fpermatico craffiusculo, connato, bicolori.

Folia decidua Fagi, Carpini \& Betula in fuperficie prona interdum fpinulis vix vifibilibus, aggregatis horrent. Quodil lente admota ejusmodi folia perlutirantur; tubercula obfervantur minutifima, hemifpharica, fulva apice findenda. Per hanc fiini:ram efiertur fpinula, feu frylus caifiuscutus, fubobtufus, lavis, aequa'is, fubrectus, fulvus, fubftantiam e grciatina obduratam prodens. Surgit tic e poro Sphre- 
riæ minimæ, globofæ, atræ, fubtilifime punctatæ, maflam afpectu ceream, albentem (e mucilagine dubio procul coagulatam) includente. Inhabitat fungillus agminatim foliorum ficcorum medullam \& fuccrescendo mole fua auctiori paginam eorum averfam in collicu?os jam dictos elevat; fed fimul Sphrria qualibet paginam folii adverfam diametrali plaga leviter fornicat. Capfula fphrica poft fructificationem cupularis, feu themifphærica, apparet, teftimonis gravifimo, ejus hemifphxrium inferius, dum per oftiolum exprimitur mucilago feminifera, motu quafi convulfivo vique maxima furfum, feu ad verticem \& concamerationem fungi fuperior $m$, rapi ibique quafi agglutinari: quo fit, ut tum hemifphæricus ille appareat. Sed explofus ex hujus orificio liquor viscidus, ut inde natus ftylus fpermaticrs, illico congelantur, colore illius nativo in fulvum, apicem verfus lutescentem; ad oftiolum autem capfula verfus nigrescentem, mutato. Cum ifthoc capfinlze poro poftea ita concretus cernitur, ut, cum in ipfo infertionis loco eodem hujus atro colore gaudeat, corpus fimplicifinum tubaforme oculis fcrutantibus objiciat. Fungum vernalem Majo legi..

OBS. Nonnuxquam Sphriam in fuperficie foliorum fupina fruetificare vidi.

Figurae explicatio.

Tab. XVI fig. I28.

2. Sphæriæ, magnitudine naturali pictæ, greges repræentantut

b-i. Sphreria ope lentis vitrex adaucta.

b. Sphæria fub puftula latens.

c. Alia, ftylo fpermatico hane jam nunc rumpente.

d. Alia, Aylo hoc jam toto quanto prominente.

e. Eadem hoc pacto liftitur, ut pultula utraque, hine inde illam operiens, una compareat.

f. Spharia fenior, pagina, feu lámella, utraque folii illam foventis ad perpendiculum diffecta.

g. Eadem, ut demto integumento fuperiore ac inferiore cernitur.

h. Sphæria nondum collabescens per verticem, una cum folii complectentis fegmento, verticaliter perfecta, quo nidus funguli, aeque ac hujus figura, incipientis fructescentia tempore, dilucide ob oculos ponuntur.

i. Sphæria, 
i. Sphæria, tempore hoc elapfo, fimilem in modum diffecta, quo ftyli fpermatici coalitio cum capfila, colorque illus, ex fulvo bafin verfus in atrum gradatim tranfiens, fit contemplabilis.

\section{SPHAERIA by trix.}

S. compofita, frylifera, ovalis, convexo-plana, aggregata, nigra, monofticha; ftylis fpermaticis proceris, fuperne fubincrafiatis, cum fphzerulis connatis.

Corticslis, oblonga, primum convexa, confenescendo verum complanata, fedem fibi fub epidermide ramorum aridorum figit, de qua extuberans cuticula rupta confepitur. Menfura ejus diametro culmi triticei aequiparanda. Mcdulla fungilli fibrofa quidem, fed laxius cohærens, coloris e cinereo rubentis, cortice tenuifimo lævi, nigro obtegitur. Sphærulæ atræ, læves, bafi comprefli, vertice autem in conum obtufum productr, in unico tractu, cuti huic contiguo, collocatre confpiciuntur. Mucilagine vulgatifima, viridi-grifea, repletas vidi. Styli nigri inde nati, proceri, rudes, fubarcuati \& apicem verfus fepiffime incraftati fimulque compreffi, cum osculo capfularum ita connati cernuntur, ut nullum hujus veftiginm fuperfit. Facile decidunt, nec apprime rigent. OEtobri gregatim crescentem reperi.

OBS. 1. Vidi rarietatem aftivam, friniman, fublantia fotifrmun nigra ab hac diverfami red fortafis \& in noftra hac deinum fit nigıa.

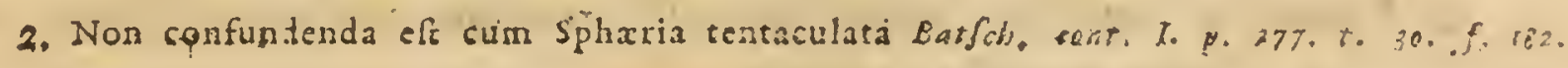

Figurae explicatio,

Tab. XVI fig, $12 \%$.

2. Fungilli magnitudine \& fitu naturali depicti.

b. Sphæria ampliata.

c. Eadem verticaliter diffecta.

d. Sphærula adaucta, ut e nido fuo extracta apparet.

e. Sphærula fructificans dimidiata.

\section{I. SPHAERIA Ceratuppermum.}

S. compofita, ftylifera, fubrotunda, pulvinato-convexa, aggregata, nigra; fphrerulis bifariis; ftylis fpermaticis fcabro-rudibus, cum iisdem connatis.

Ceratof permum nigrum minimum discoides Mich. P. G. p. 125, n. 2. t. $56 . f_{0}$. .

\%. Atrigofa 


\section{a. ferigofa.}

Sphrrire proxime pracedenti perquam fimilis; fed hac aliquantum major, bilinearis nimirum diametri, magisque cotvexa \& plerumque rotundata. Cortex niger, levis, aequalis, a fubftantia fungi infeparabilis. Hæc fibrofa, minus compacta, alba, languide demum fuscescens. Sphærulæ globofæ, nigræ, maxima ex parte focunda funt, tumque ttylum fatis longum, fuperlicie fcabrum, Arigofum \& longitudinalirer quafi fulcatum expellunt, e mucilagine livido-lurida paulatim obdurescentem, cito vero nigrescentem, quem apice pulvere albido interdum confperfum |vidi. 'At enim adfunt \& aliæ fphærulæ globofæ, concolores, aftomæ, inferiora foventis fubftantix, feu medullæ fungi, tenentes: hr; cum nunquam ftylum fpermaticum producunt, pro fterilibus jure meritoque habentur. Sacculo, feu tunica unguinofa, (mucilaginis fpermaticre relidtro coagulato, utrarumque capfularum parietes internos vidi laqueatos. Reperi fungillum, cortici Rofre caninx démortuæ gregatim innatum ejusque epidermide fiffa obfeptum, Julio.

\section{Figurae explicatio.}

\section{Tab. XVII fig. Izt.}

2. Fungilli tres magnitudine nativa reprefentati.

b. Sphæria ampliata.

c. Eadem admodum aneta, ut verticaliter difecta confpicitur.

d. Sphærula foecunda, adauctior, uti, eodem modo una cum, ftylo fpermatico perfecta, apparet.

\section{B. fareta.}

In paucis modo varietati a disconvenit. Medulla nempe Sphæriæ, fphærulas fovens, his ferme omnino farcta invenitur, quarum attamen hæ, quæ cortici funt contiguæ, ferme folæ videntur ftyligeræe efle. Styli ipfi rudes \& interdum obfolete articulati. Cortex læris, æqualis, membranacens, feparabilis. Ambitum Spharix, in ramis ramulisque varii generis putrescentibus obviæ, rotundam, fed \& ovalem interdum inveni admodumque convexam. Vernalis eft \& medio jam Martio menfe fructificantem, capfulis tum humore viscido cinereo turgidis, obfervavi.

O3S. Obtegitur varietas hac fere femper, quando cxolevit, plantula quadam mixatu digaa, byfinm arcuatan, alopecurvidem cumulante, de gua, alio rempore uberius \& furus difpucabinus. 


\section{SPHAERIA fragifera.}

S. compofita, ftylifera, plana, nigra, monofticha; ftylis fpermaticis e fingula capfula fucceffive protrufis, breviffimis, coadunatis.

In fragmine affulæ putrescentis quernæ vidi hane Sphariam, fed non integram, quare de ejus magnitudine ambitusque forma nihil pronunciare pofium. Cruftam autem vidi fuperficie fcabram, nigram, quæe vero, per lentem vitream curatius inveftigata, tuberculis minimis, fragilormibus, nigris, denfe obfita apparuit. Confat quodlibet eortm ftylis fpermaticis nunnullis, $(5-8)$ ex eodem fphrerulae poro iterato nifu exprefis, qui cum breves admodum fint, \& antequam obdurescunt, invicem leniter confuant, figuram inde fragi, feu, fi mavis, nucis pineae, utcunque obtinent. Sphaerulae ad aciculae minimae capitulum magnitudine acsedentes, ovatae, atrae, laeves, nitidae, immerfae funt fubftantiae apparenter cereae, coloris e cinereo' in glaucum vergentis. Inveftitas interne facculo Weigeliano vidi. Condonavit me peramanter exemplo hujus fungilli unico, jar defcripto, clariff. Timmins, quod autumno a fe lectum teftatur.

Figurae explicatio.

Tab. XVII fig. I3\%.
a. Segmentum ligni, cui innata eft Sphria.
b. Sphæriæ rećta præfectæ \& a ligno feparatæ fruftum.
c. Sphrrula aucta in ftatu fructificationis. (Demta mafía Sphariæe, leu medulla, cui immerfa erat illa, \& relicta modo corticis fungilli particula.)

d. Sphærula ampliata in eodem ftatu reprefentatur, difiecta directione verticali in hunc modum, ut tum corticis, medullæque Sphærix; tum vero \& ligni, cui innati eft, portiuncula ocnlis fubjiciatur.

\section{SPHAFRIA versipellis,}

S. compofita, ftyliféra, polymorpha, convexo-bicorticata, nigra, deüfta, monofticha; fphærulis biformibus; ftylis fpermaticis obfolete nodolis, fubuncinatis. Lichen-agaricus cruftaceus craffus \&c. Mich. G. P.p. 104. n. 3. t. 54. f. I. Sphæria maxima convexa nigerrima Hath, hift, p. 322, $\%$, 2192.

Spheria 
Sphæria maxima Web. ficicil. p. 286. n. 301. Dickf. crypt. p. 23. Wigg. holf. p. 84, n. 939.

Lycoperdon fraxineum Hudf. angl. 2. p. 641. n. 3.

Sphrria deufta Hoffin. crypt. I. p. 3. t. I. f. 2. Timm. Megap. p. 279. n. $1 \times 76$.

Sphreria hac vulgaris quidem admodum eft, cum frequentiffime truncis demortuis Fagorum adnata inveniatur; fed obveniunt in illa plura nondum evulgata \& uberiori defcriptione haud indigna. Verfipellis omnino nomine infigniri meretur, cum faciem fuam aetatis decurfu plus una vice mirum in modum mutet. Ineunte fcilicet vere provenit fpecie expanfi gelatinofo-tomentoli, repentis, candidi, rotundati, vel ovalis, pollicaris, bipollicaris diametri, margine repandi. Sed maculis orbicularibus aggregatis; mox diftinguitur ejus fuperficies, ceu fpeculis dèpreffis, diametro $2-4$ lineari; pulvisculo amœene glanco obductis, paulatim vero perfecte fic confluentibus, ut integer expanfi discus unicum fpeculum jam efficiat, pulvere dicto fuperftratum, margine tumido folum excepto, colorem nativum nondum mutante. Aeftate autem appropinquante fubftantia fungi gelatinofa in fibrofam lentamque, quin demum in ligneam ferme Agarici quercini L. obdurescere incipit; margo autem jam lævis fit magisque repandus, quid? quod fubinde incifo-lobatus. Interea discus magis explanatur fimulque corrugatur in centro, úbi rugæ hæ partirn in tubercula polymorpha poftmodum abeunt. Superficies inferna, qua fungus ligno fipitum adhæret, jam nigro-fusca, inaequalis \& exafperata invenitur. Subftantia iṕa fucculenta eft ac candida, inferne plerumque rubens, et punctis cum confpiciatur notata confertis, nigris, in eadem, ut videtur, ferie collocatis, fasciata quafi apparet: jamque fphærularum rudimenta ovalia, gelatinofa, dilute fusca, cernuntur. Fungus aetate eo procedens Lichenibusque coriaceis decumbentibus haud multum abfimilis factus, vel excutere, vel amittere incipit pulvisculum illum glancum, in quo pollen genuinum agnoscere parum fane abeft, quin cogamur. Nunc vero tandem Sphariae faciem induere hic nofter occipit: discus enim, huc usque planus, jam fit convexus, centro depreffo, \& fic bovillum renem 'haud male refert, cum ambitus ejus plerumque fit ellipticus, auricula fimilis, in diametrum frepe tritincialem, quin interdum quadruncialem, fuccrescendo dilatatæ; fuperficie inferiore in præenti nigra, obfolete concava, ejusque cen… in formam coni brevis, inverfi, umbonato, cujus, ceu radicula, ope ligno caudicino 
caudicino inhæret nutriturque fungus. Color fuperficiei lavis, ne margine quidem excepto, nunc eft fuscus; fed ex fusco jam in nigrum vergens. Ipramet cuticulam liftit fungi bicorticati membranaceam, tenuem, jam colliculatan puftulis confertis, quas concient fphrerulie in medullam Sphærix primum demerfie, fed impulfo inteftino ad cutem ejus propius femper tendentes, usque dum papilla fua huic infigantur. Perforant, inquam, papilla cutem fungi, feu corticem ejus interiorem, fed neutiquam, exteriorem, feu cuticulam; hanc vero in pultulas jam memoratas, denfas, hemifphrericas elevant \& diftendunt mole fua globuli byffini, quorum jam fxpiffime momini, ex orificio capfularum ante mucilaginis ipfius fementivæ explofionem exfilientes. Sed cum ejusmodi globulus de more contabescat.evanescatque, in loco, ubi jam puftula erat, pofthac vovea cupulæ forma cernitur, cujus de meditullio Sphærulæ papilla atra jam protuberat. Mucilago hæcce fub initium auttumni e capfulis expellitur inque fpeciem ftyli atri, fcabri, feu potius leviter nodoli, (conftat enim glebulis coagmentatis,) \& pedetentim obdurescentis figuratur, qui pondere fuo fæpiuscule vel arcuatus, vel uncinatus, plerumque vero decumbens, confpicitur \& in minutifimum pulverem fatiscit. Et nune confenescere incipit Sphrria, magis magisque nempe forma ejus convexa augetur, admodum jam colliculofa quoque \& angulata, fimulque durior, fit deuftaque videtur, \& in margine fepenumero apprime undulata confpicitur; fubftantia ipfa, jam plane exficcata \& friabili, adeoque tandem contabescente, ut ferme non nifi cutis de ea remaneat; lamella inferna fungi ad fpherularum bafin prorfus attracta. Sphærulæ ovales, laeves, interdum verrucis fparfis afperatæe \& lineam dimidiatam longæ, duplicis funt ordinis: focundæ nimirum \& fteriles. Priores papilla fatis eminente (fuccrescente, ad modum aliarum, ut mihi fit verifmile) funt inftuetr, \& folx globulum byffinum evomentes, colliculos illos minutiffimos, in epidermide fungi confpicuos, producunt; polteriores non nifi papillx rudimentum produnt. Epidermis demum nigra; fed cutis ipfa Sphrerix atra, refuofa, cum difiecatur, nitida cernitur \& floccis albidis congeneribus, (an globulis forfan byffinis abortivis?) intertexta. Medulla fungi tempore fruftescentix aciluc albet; fed colore jam in cinereo-fuscum aperte vergente; paulo polt vero e fusco in fpadiceum, badium, nigrescentem \& tandem in nigrum tranfit. Mucilagine livida plenas capfulas interdum vidi, interdum tapetio nobili Batfchii ttertas, alioquir inanes. 
OBS. I. Si pulvisculus ille glaucus, cui immixta quandoque filamenta tenuifrma, aranex, ftaminibus perfmilia, vidi, pollen Sphrrix non eft; ecquid eft? Si, illud antem re vera, eft; quid, quxfo, de globulis byfrnis, ex mea hypothefi polliniferis judicandum demum erit? Heu, quantis adhuc tenebris hic omnia funt circumfura?

2. Memorabile \& hoc mihi videtur, globulos hosce, crucem dixerim Botanicorum, in Spharia noftra, iuti in füblequente, intercutancos effe.

3. Defcriptio Micheliana Lichcn-Agaric ord. 11. 13. 1. p. 104. Sphxrix noftrix faciem aeftuan adumbrat, quemadmodum a, kobis Fig. 129. c. eft reprafentata.

Figurac explicatio.

Tab. XVII fig. 129.

a - e. Sphizeria magnitudine naturali depictar-

a. Recens orta, fed fpeculis pulverulentis, jam in fungo gelatinofo- pubido, confpicuis.

b. Adultior, polline discum integrum obducente, margine verum jam glabro \& detumente.

c. Aetate florens, inftante fructescentire tempore.

d. Confenescendo tuberculofo-lobata varieque crifpata.

e. Sphxrix verticaliter difiectx fruftulum.

f-h. Sphrerix anctre fegmina.

f. Fragmentum Sphæriæ fructificantis, ad amuffim præfectx.

g. b. Segmentum adauletius, Sphæriæ fiftens cuticulam cutemque, fungi futftantiam \& puncta nigra (uti fcilicet diffecti apparent ductus concolores, fuccum nutricium fphærulis advehentes) nec non fuperficiem ejus inferiorem. Præfertim hic exhibentur dimidiatæ

g. Sphærula fterilis;

h. Sphærula focunda, tempore fruetescentix papilla globum byffinnm jam penetrans.

i. Sphrerula fœecanda, lentis ope ampliata, uti ejus papilla poft fructificationem e fundo voveae, a velo globofo, fugaci, excavata, eminet. (Libera fphærula repræfentatur, corticis fungi particula folummodo huic adhærente; eo confilio nempe, ut cavernula ipfa papillæcque in hanc infertatio eo melius illuceant.) 


\section{SPHAERIA twicata.}

S. compofita, ftylo-cirrifera, fubovalis, tuberofo-bicorticata, obfolete caulescens, fusca, monofticha; tunicis, ita ut fphxrulis biformibus, connatis; velis particularibus confluentibus, fugacibusque.

Valfa tubercfa Scop. cain. 2. II.' p. 399. n. I4I5. Sed Synonyma Mick. huc non pertinent.

Sphæria tuberofa Tim. megap. p. 279. n. Ir77.

In Sphria hac non minus, quam in proxime pracedente, quxdam in cxteris fpeciepus infolitre apparentixe obveniunt. Figura ejus plerumque ovalis, raro rotunda, femper tuberofa, creberrime aequalis, fxpiuscule autem inxqualis \& obfolete angulata, vertice nonnunquam deprefio, cernitur. Magnitudo ejus interdum nuci Avellanæ fuppar eft; at haud raro menfura ferme pollicaris, quin fedecim lineis aequalis, hic obtinet. Cuticula ejus fusca, fenfim in fpadiceum \& pofthac in atro-rufum colorem vergens, a cute ipfa atra infeparabilis, admodum tenuis demumque evanescens, obtegitur tomentone dicam, an pulvere? coloris e ftramineo \& fusco mixti, itidem evanescente: quare fungus confenescens ater glaberque apparet. In bafi rudimentum caúlis prominens, fuscum confpicitur, in juniori Spheria cylindricum; in adulta vero inverfe conicum. Conftrectio interna hanc fpeciem a cateris omnibus, mihi quidem notis, nomine plus uno feparat. Primum enim fungi fubftantia tota quanta, ad effigiem ferne bulbi tunicati, concamerationibus concentricis quibusdam (4-6) magnitudine variis, h. e. alia remper $a b$ alia ampliori inclufa, invicemque comnatis conftat. In his, capacfimo, feu extimo, fornice excepto, qui fpharulas extemplo defcribendas fovet, totidem tabulata, feu receptacula capfularum abortiva, confpicies: fphacrulis fcilicet, quibus excipiendis deftinata videntur, nunquam comparentibus, feu potius nunquam cxiftentibus; fed alveolis modo earum continuis, cortici cuidam imperfecto, atro, fubnatis, comparentibus. Contabescunt quodammodo alveoli hi, feu texturx levidenfis feptulæ, \& fuccedente tempore colorem candidum cum nigro commutant, quod cum factum eft, fubftatia in mafam pulverulentam carbonariam convertitur; centrum icro fungi arescentis plerumque excavatur \& ficpe aumodum dehiscit. Ad fphaerulas autem, uno eorenque ordine, ut jam commemoravimus, immeriatcque fub cortice cellulis fuis denfifime collocatns, quod attinet, omnes omuino qui- 
dem obovatae, laeves nigraeque cernuntur; fed biformatae: fœcundae partim fcilicet, partim fteriles, quarum priores folae papilla vifibili gaudent. Evomunt hae fub fpecie globuli byffini araneofam illam, cujus jam faepius facta eft mentio, telam; congeries autem horum globulorum, confertim excretorum, contabescendo confluit in membranulam niveam, tenerrimam, intercutem: $h_{0} \cdot e$. inter corticem atrum pulpamque fungi circumcirca diffufam, at haud ita brevi port evanescentem. Spliærulæe cæterum inter fe non folum_lateribus funt connatæ; fed baî infuper a fubftantia has excipiente mordicus tenentur. Mucilagine iftas fpermatophora confueta repletas, \& frepius tapetio nobili Batchiano interne aulæatas vidi. Liquor ille feminalis e capfularum papillis, cutem fungi, alioquin aequalem, modo-vix vifibili penetrantibus, fili, feu ftyli, tenuis, nodofi atrique forma fcaturit. Nonnunquam hujusmodi ftyli fpermatici perquam elongati funt, \& tum in cirri modum crifpantur; nonnunquam contra modicx altitudinis, \& tum vel fubrectos, vel arcuatos, vel obuncos invenies; at verum maxima eorum pars cito decumbit. Textura eft illis tam tenera, ut vel leviffimo fuccufiı protinus toti corrwant, in pulvisculum refoluti: in fingula nimirum femina, atra quidem, fi nudis oculis adfpiciuntur; violacei autem faturatiffimi gratiffimique coloris, fi per lentem ea colluftrantur. Fungus minime rarus, polyfpermus, fparfim, quandoque confertim, quin fasciculatim, innascitur ftipitibus ramisque aridis Betulæ, nec non Alni, forte $\&$ aliarum arborum, Septembri menfe fructificans.

OBS. 1. En hic exemplum luculentum veli intercutanei! Fortafis ftratum illud, in quo interdum Sphriarum compofitarum capfulx demerfx latent, (Hoffm. icrypt. I. Praef. p. v.) nil, nifi ex ejusmodi velorum partialium confluxu oborrum expanfum focundans vel hujus analogum quid, eft: tum vero cum Viri acutifimi theoria fructificationis, generi huic peculiaris, hypothefis noftra de globulis byfrinis complanandis, ceu velis fcecundantibus, admodum confentanea foret.

2. Ex jam inemorati expanfi in hac fpecie ortu ac facie elucescit, maffam illam, e glokulis colliquescendo coadunatis, albis, conflatam, quam e Sphria fifivela protuberare fupra (p. 18.) annotavimus, nil, nif fimile velum, efie poffe.

3. Pulvere viridi hanc Sphriam, uti pracedentem, extremo actatis gradu fxpius coniperfam vidi, forte notabili. Conf. Hoffm. crypt. I. p. 5. obf.

Figurae 
Figurae explicatio.

Tab. XVII fig. I30.

2-e. Sphæriam naturali magnitudine depictam exhibent.

a. Sphærix tres: dux protuberantes; tertia jam adolescente.

b. Sphreria adulta, qualis in Betulis fit obviain.

c. Eadera ad amuffim diffecta, in qua concamerationum concentricarum habitus illucet.

d. Sphreria fructificans. (Exemplo, quod hic depictum exhibemus, ex Alno exficcata decerpto.)

e. Sphæriæ geminæ connatæ, (Alni antea incolæ,) corticis fungi particula devulfa: qua in plaga jam emicant globuli nivei, e capfulis emerfi, coufluendo membranam intercutem, by - $^{-}$ finam, fugacem, procreantes.

f. Segmen adauctum ejusdem Sphæriæ, plagam jam dictam, cortice ibi elifo albentem, complectens, quod eo confilio oculis hic oblique obvertitur, ut cortex fungi dúplex, necnon membrana illa nivea appofite in hos incurrat.

g. Sphærularum ampliatarum rectaque diffectarum trias, media foecunda fruetificante; utraque vero laterali fterili.

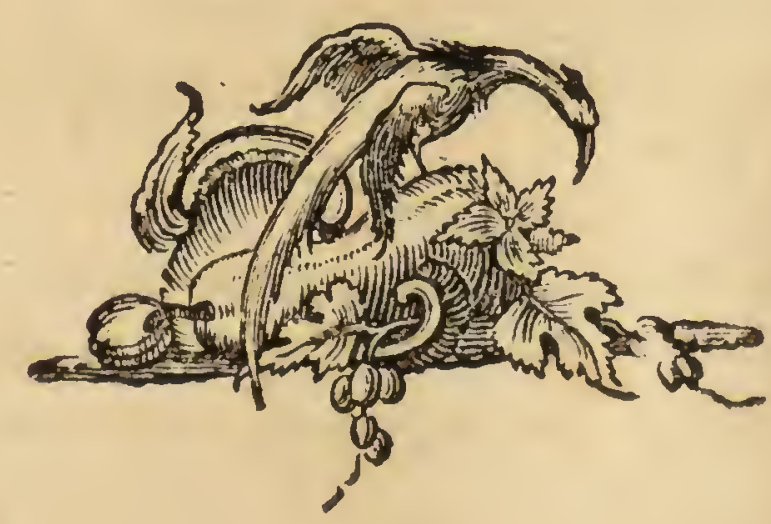




\section{ADDENDA ET EMENDANDA.}

P

ag. 8. SPHAERIA mollis. Allucinans Sphæriam hanc dixi perforatam; claufa enim eft, uti e Tab. IX fig. 66. b. c. elucet; papillæe verum folummodo nitent. Naximam alias Sphxrix globularis Batfch. cont. I. p. 27x. t. 30. f. I80. (probe mihi nota) fimilitudinem gerit; fed noftra crultam neutiquam conftituit; nec dura; neque interna ejus fuperficies atri coloris elt. Caterum Sphæriæ fimplices, claufa, molles, feu non duræ, nec friabiles, qusrum fuperficies convexa nigra; concava vero fusca cernitur, \& qua mafla plerumque inveniuntur repletæe relaxa, corruente, familiam Sphæriarum peculiarem conftituere videntur, ad quam forte et Vermicularia hifpida (Fafc. I. p. 32, t. 6. f. 48) pertinet.

Pap. 9. SPHAERIA cinnaburina. E figura verticis depreffa patet, Sphariam hanc ad collabescentes effe referendam \& forma primitus gaudere perfecte ovali. Adumbratio verum verticis depreffi $T a b$. IX. fig. 68, c. non utique ex fententia fuccefit; vereor certe, ne pertufus potius, quam depreffus multis videatur.

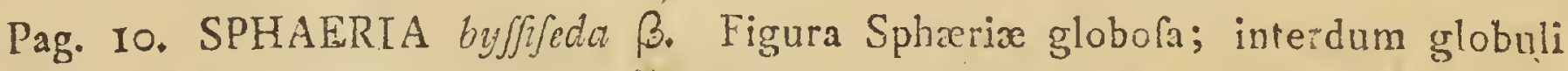
confertim, \& eo pacto nascuntur, ut ferme cruftam ex is conflatam invenias. Cólor expanfi byflacei, cui infident, ad fpadiceum valde accedit terrae colonienfis acufte, tandem vero nigrescit.

Pag. 16. SPHAERIA muciád $\gamma$. Admodum cum Spharia confluente IVillden. berol. n. 1212 concinit; fed noftra papillata elt. Segregandan autem, omnibus perpenfis, varietatem harc a duabus prioribus jam judico.

Pag. I7. SPHAERIA inquinans. Dubium adhac videri potelt, litum integumentum illud albidum, hifpidum, Sproriam externe chducens (Tab. X fig. 85. d.) pro aggregatis folummodo aiburni elif ramentis; an potins pro vera volva haberi debeat. Seminum antem paftillos, forma cylindrica explofos, pofmodum \& in 


\section{ADDENDA ET EMENDANDA.}

compluribus Sphærix fpeciebus otvios habui; fed intermistos interdum aliis globofis majuscule molis. Unde' verum ejusmodi infolens commixtura? Caligere me ad hæc ingenue confiteor.

Pag. I8. SPHAERIA fiffucla. Coacervata perneram deferipta pictaque fintitur; eft enim, ut perquilite eam iterum rimando didici, e compoftarm numero: globulis fulicet, feu fphrerulis, nt in Sphxria decidua, Ribis, cxut. fubftantix Sphrerixe concolori, ceu receptaculo communi, infixis.

Pag. 19. SPHAERIA conflicus. Non femper volva illius candida fugax effe videtur; poffideo certe exempla fexennalia, in quibus integnmentum hoc adiuc fartum tectumque apparet. De reliquo minime confundenda eft Sphxria noftra

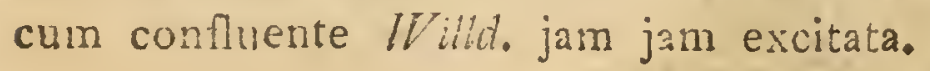

Pag. 23. SPHAERIA tolus. Figurae explicationi addatur:

f. Sphærula libera, ut mole aucta apparet.

Pag. 27. SPHAERIA natans, Semina, ut nupera obfervatione mihi innotuit, in formam globuli compacta, nigri, fed ad virorem aquae marinze vergentis coloris, propellit.

Pag. 29. SPHAERIA racians. Viscus hoc radians in fungo obfenescente fenfim difparet, in juniore, vero ac adulto eft evidentifimum. Radiantem autem nominare malui Sphreriam, quam radiatam, præcipue hac de caufa, quod nucleus ejus albus ftellae inftar exta atra fungilli irradiare quafi videatur.

Pag. 30. SPHAERIA lenta. Subftantia hujus Sphæriæ lenta quidem admodum eft; aft non fibrofa: temporis progrefiu duritiem Sclerotiorum acquirit. Jamque fcio, fphærulas adultas nigrescere, globofa forma nunquam immutata. Verum enim vero cuti Sphæriæ tam prope tum fubjacent, ut ferme concretæ cum illa videantur. Fructificatio pulverulenta, ut reliquorum Hypoxylorum.

Pag. 3I. SPHAERIA decidua. In delineatione Sphrrix hujus perfectre (Tab. XIII, fig. IO4, c.) receptaculum capfularum nimis convexum craflumque evafit; 
evafit; feu ad hoc relata fphrerularum moles nimis valde eft imminuta. Quod reliquum eft, parum abeft, quin mihi perfuadeam, Sphrriam deciduam aeque, ac, quæ proxime ad illam accedit, Sph. cucurbitulam, a plantarum conquifitoribus bene multis pro Sphæria Mori Weig. haberi; cum tamen hrec a Viro maxime perfpicaci expreffis verbis fimplex declaretur: fed fieri omnino perfacile poteft, ut qui in Sphæriam noftram incidit, ad receptaculum capfularum, fub cuticula arborea delitescens hisque fuperne denfe obfitum, non advertat.

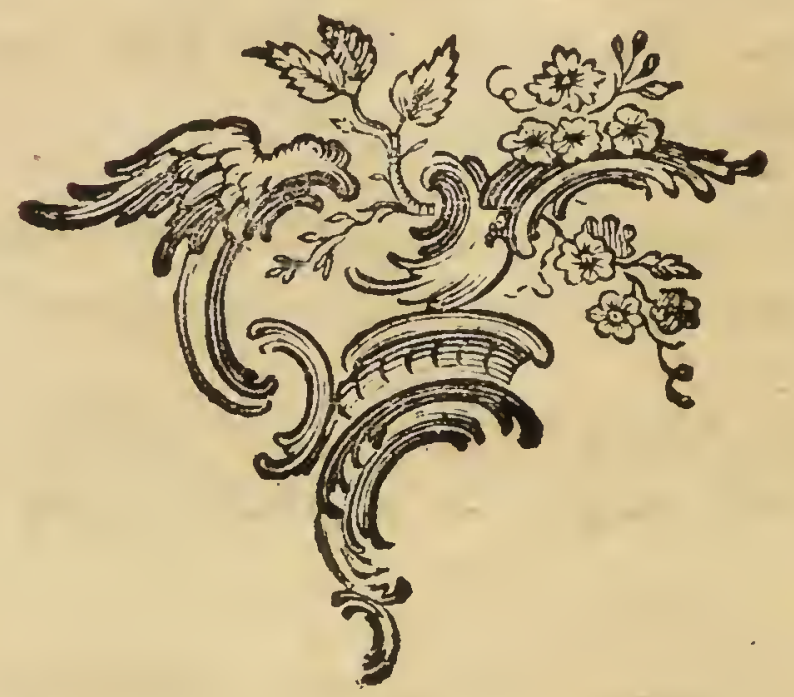




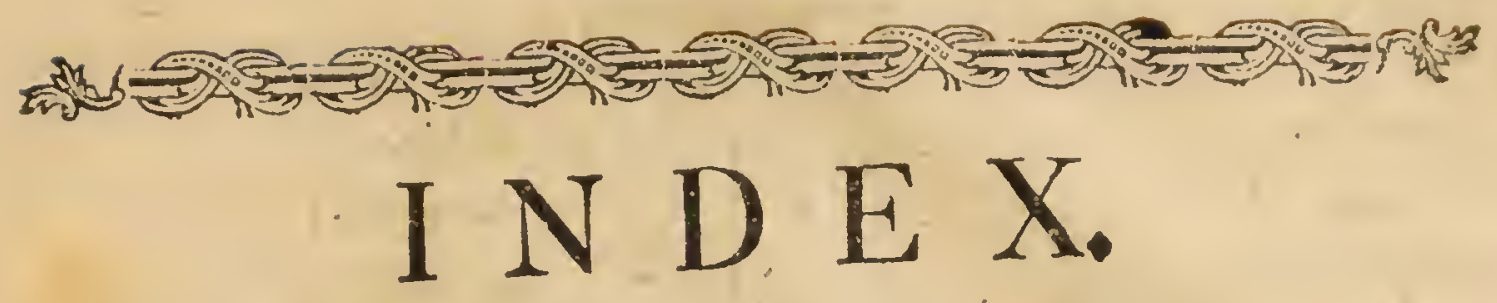

XXII. EPICHYSIVM Tridterfdramm.

8. roltrata.

r. argenteum.

a. atra.

ß. nigro-fusca.

XXIII. PERICONIA Duderidjimmel.

2

I. lichenoides.

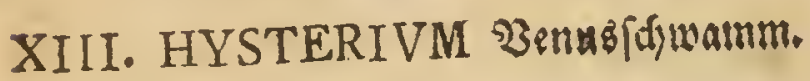

I. candidum.

2. caeruleum.

3. nigrum.

XXIV. HYDROPHORA Tropfenfulim: mel

I. minima.

2. tenella.

3. ftercorea,

XXV. SPHAERIA.

I. mollis.

2. triftis.

3. cinnabarina.

4. byffifeda
a. grifea.
ß. fusca.

5. mobilis.

6. porphyrogona.

7. macroftoma.
a. nigra.
ß. fusca.

$\gamma$. nigro-fusca.

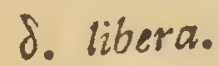

E. pileata.
13
9. comata

o. atra.

$\beta$. fusca.

I0. mucida.

a. cirrevea.

p. alba.

$\gamma \cdot$ fusca.

II. calva.

12. hifpida.

I3. inquinans.

I4. filfivela.

15. confluens

16. artocreas.

20

I7. complanata..

18. epifphaeria.

19. moriformis.

a. vuigaris.

ß. fasciculata.

23

$\gamma$. globofa.

20. talus.

a. cylindrica.

ß. fulcata.

$\gamma$. pilesta.

d. licheniformis. 23

8. confirta. 26 
21. placenta.

22. natans.

23. aeruginola.

24. cattorea.

25. radians.

26. lenta.

27. Ribis.

28. decidua.

29. atro-purpurea

30. macula.

3r. cancellata.

32. infitiva.

33. fuccenturiata:

34. cucurbitula

c. flovescens:

B. nigrescens.

35. convergens.

36. fanguinaria。

37. cefpitofa.

38. cylindrica

39. parabolica,

40. conica.

4. fubulata.
42. dubia."

p. 45

43. penetrans

u. Patella.

B. compreffa.

46

29

30

$3 I$

32

33

34

36

37

38

39

40

$4 I$

42

43

44
44. Peziza.

45. Acrofpermum

a. nigra.

$\beta$. tricolor.

46. gelatinofa

a. latec.

$\beta$. viridis.

47. gnomon.

49

50

48. Lingam.

$5 I$

49. tubaeformis.

50. hyftrix.

53

5I. Ceratofpermum

a. ftrigofa.

B. fareta.

52. fragifera.

53. verfipellis.

54. tunicata, (n) 


\section{E R R A T A.}

Pag. $V$ lin. 2 loco fpcieofis lege fpeciofis

VIII - 3-Proceminari - Procmiari; humatate - hrmanitate

$2-I_{7}-$ feffilibus - feffilibus

$6-27-$ ftorcorea - ftercorea

7 - I voci prævio fubjungatur comma.

8 - 5 loco annumerari lege annumeravi

I4 - 27 - agmino - agmine

Ibid. - penult. - tribus - duobus

15 - poft vocem globofa addatur claufa,

Ibid. - It loco $M$ lege $X$

16 - ult. - fuperiori,, ,inferiori lege fuperiore,, „inferiore

25 - II - filat lege fiat

Ibid. - I3 - qua - quo

28 - 21 poft vocem fungi inferendum eft fufca

32 - penult. loco fulvus lege fulva eft

33 - 15 poft vocem fingulis deleatur comma.

35 - 4 loco fibræ lege fibræ

Ibid. - 9 - ablescente - albescente

37 - 10 - fuscescens - fuscescens

$45-16$ - puivisculo - pulvisculo

Ibid, - 23 - globofo acuminata - globofo-acuminata

46 - antepenult. - croceo miniatre - croceo-miniatæ

31 - 13 poft orbicularem inferendum eft ora

Ibid, - antepenult: poft fulva omiffum eft comma.

35 - 25 loco innati lege innata

56 - 13.27 - glanco, giancum - glauco, glaucum.

37 - 19 delendum eft comma poft ipfa.

$59-9$ loco fpeciepus lege fpeciebus

$60-29$ - facie - facie. 



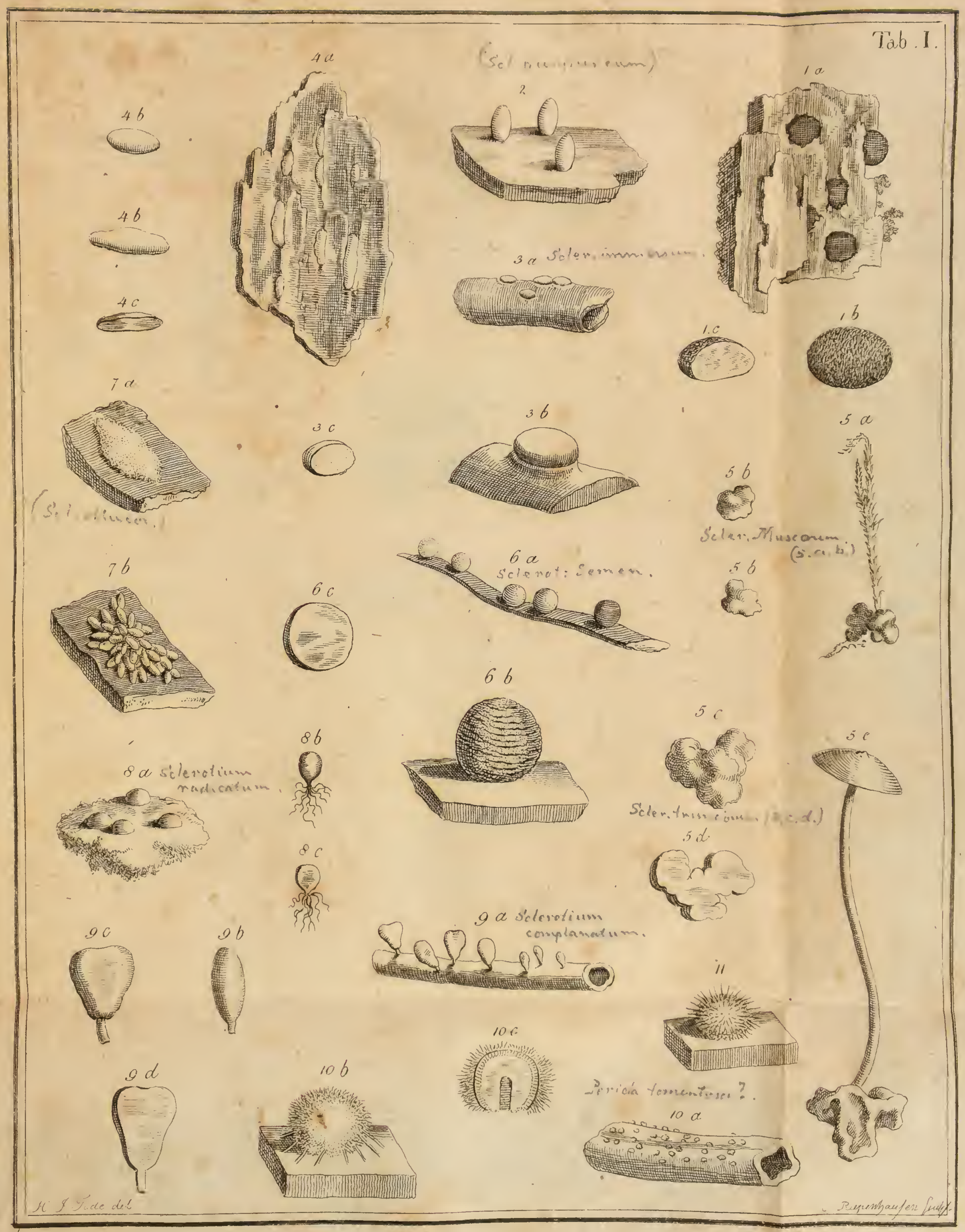


Acrospernim compt $35+6$

(1)

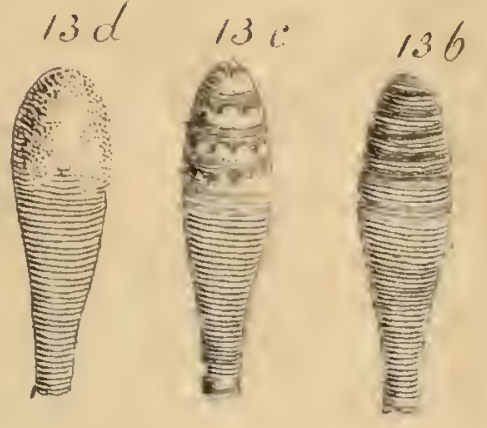

$\mathrm{C}^{210}$

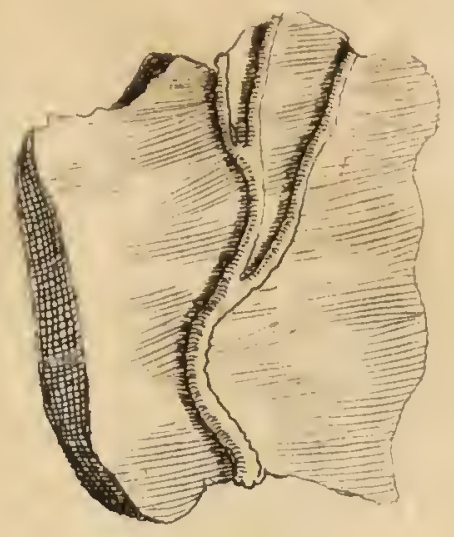

Tab.II.

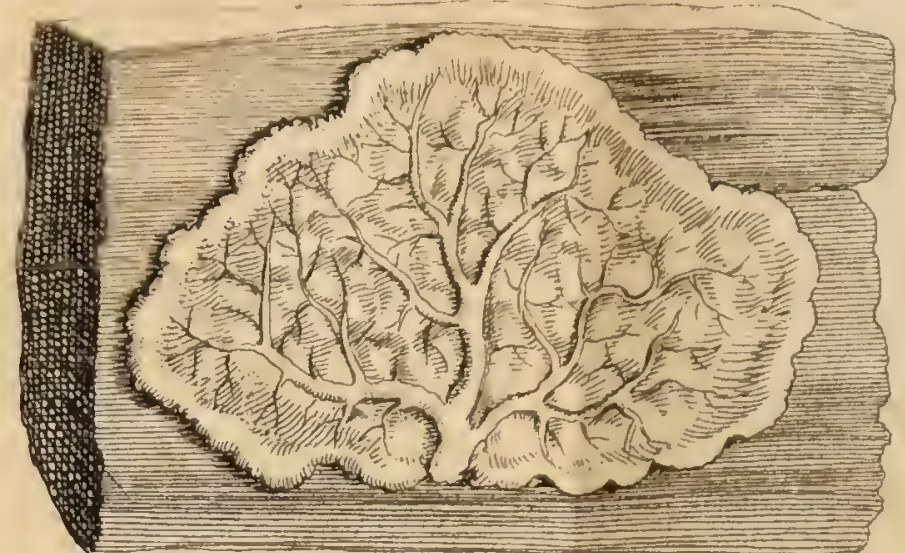

156

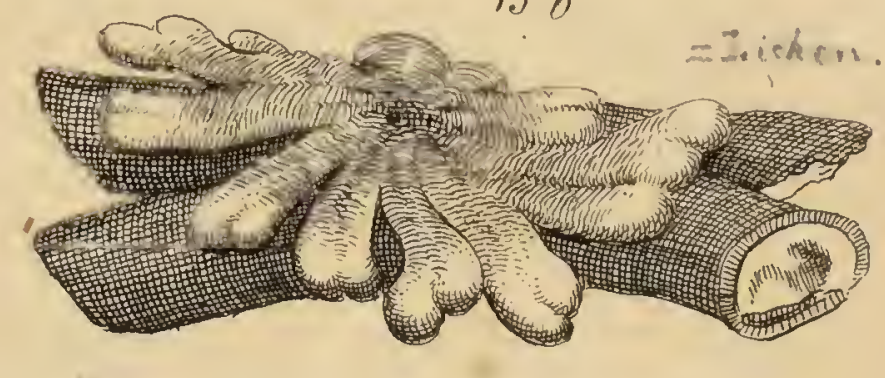

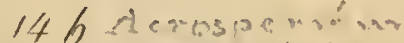

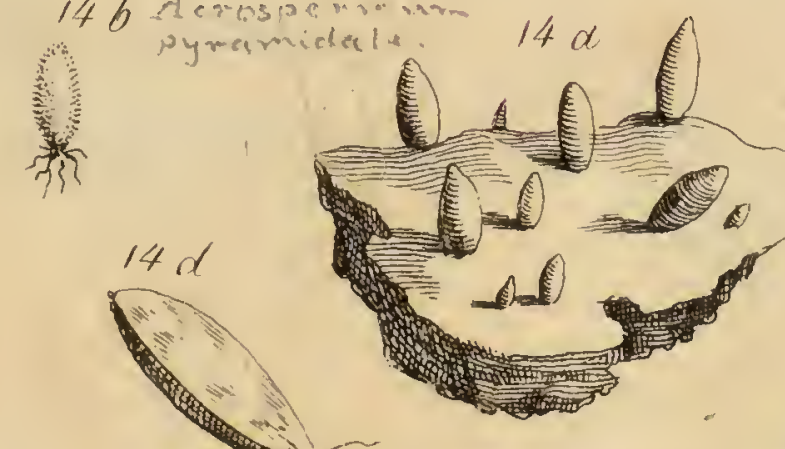

I

$20 a$

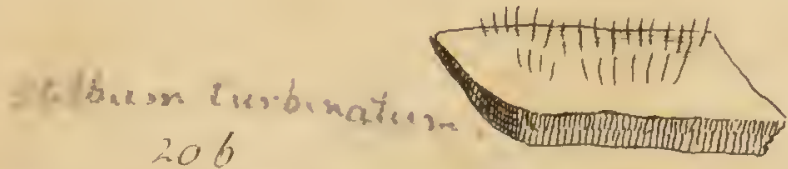
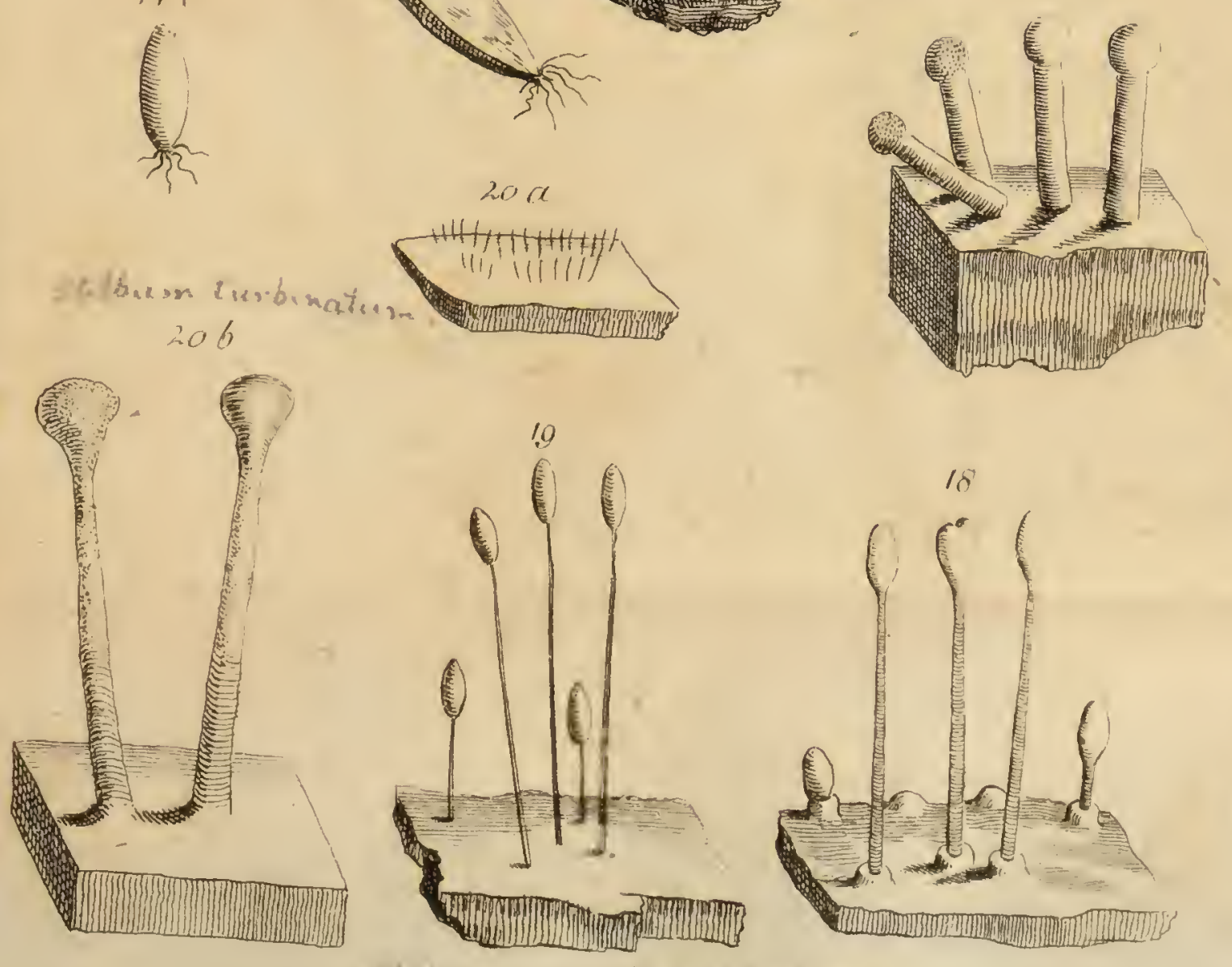

$16 a$
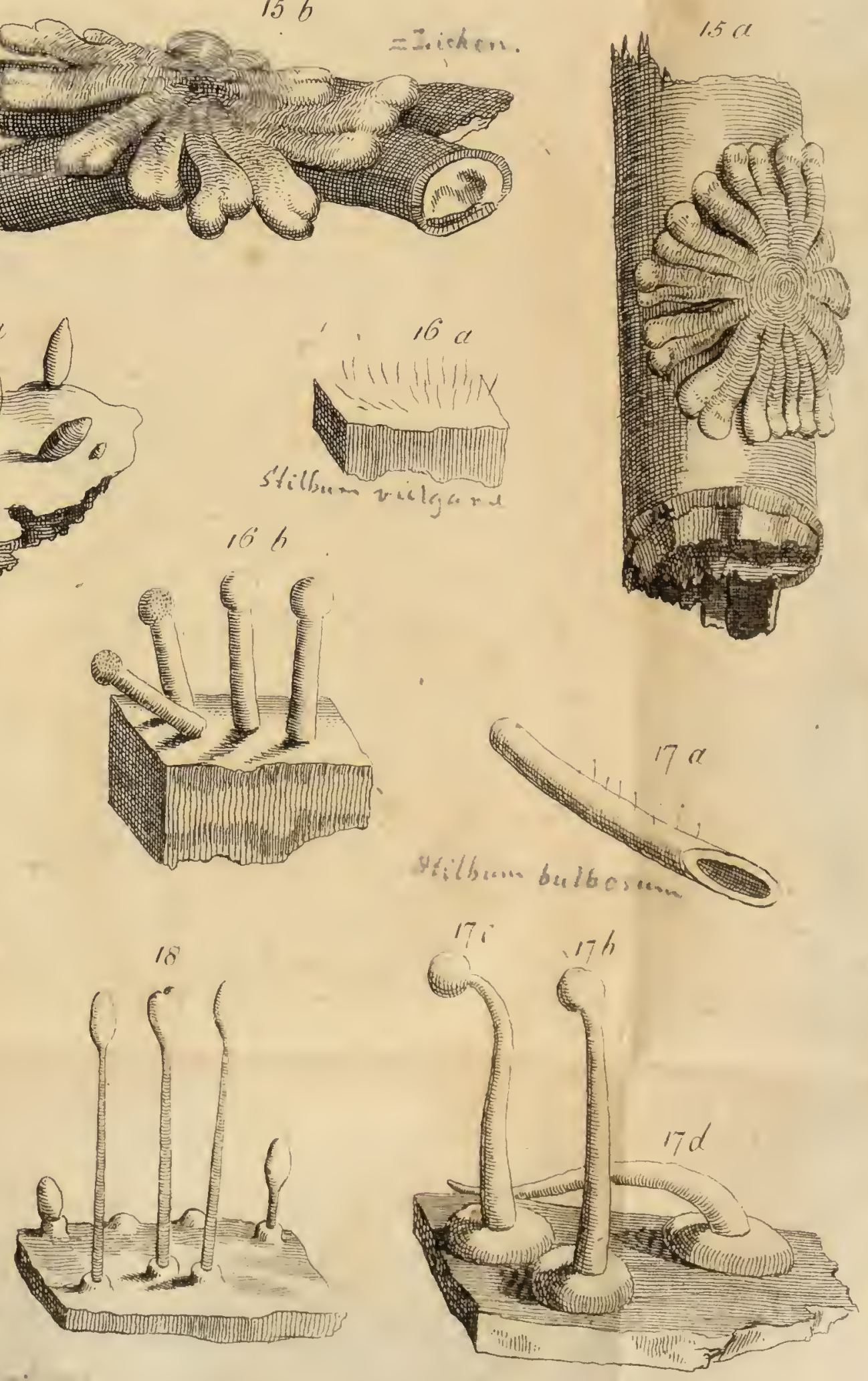



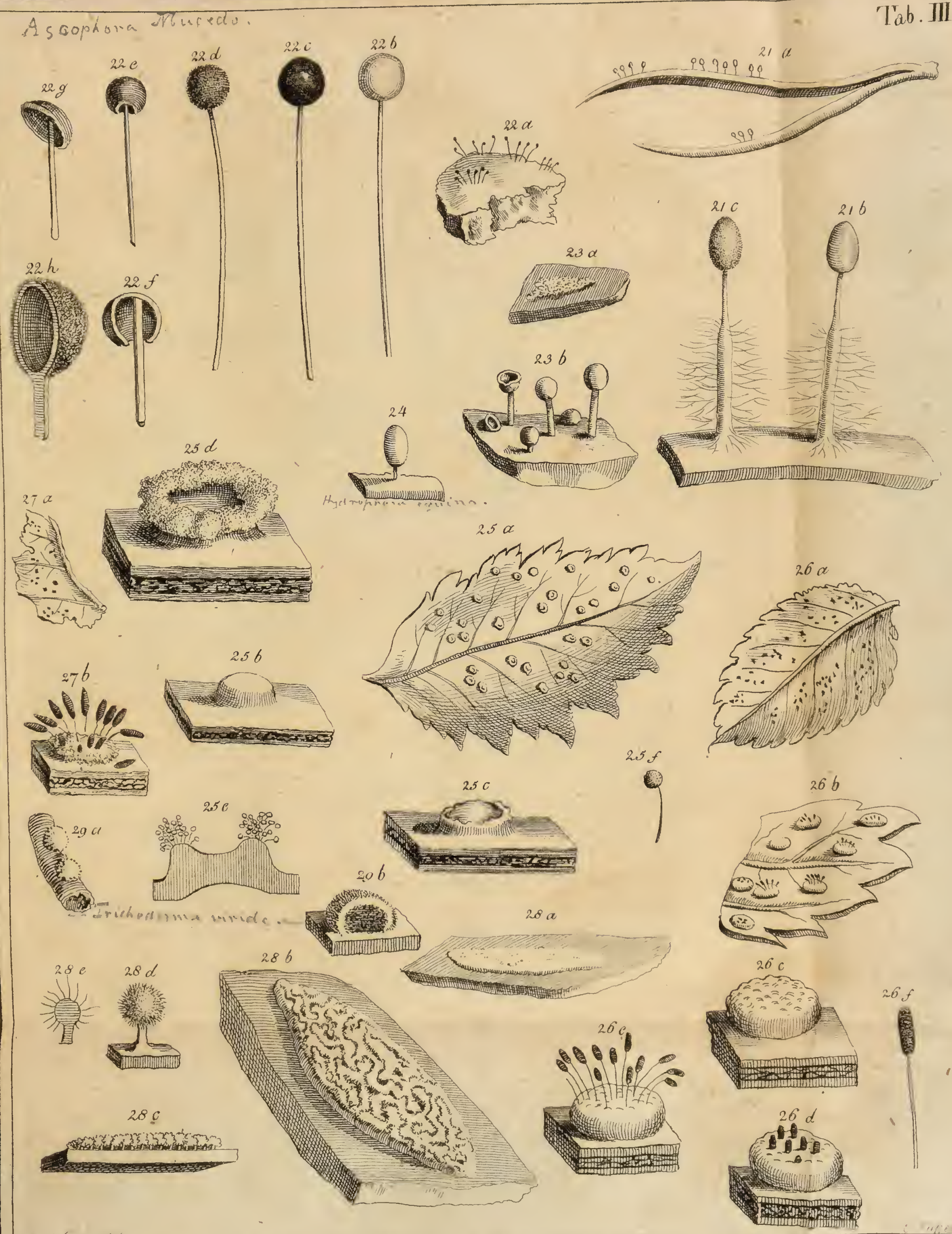





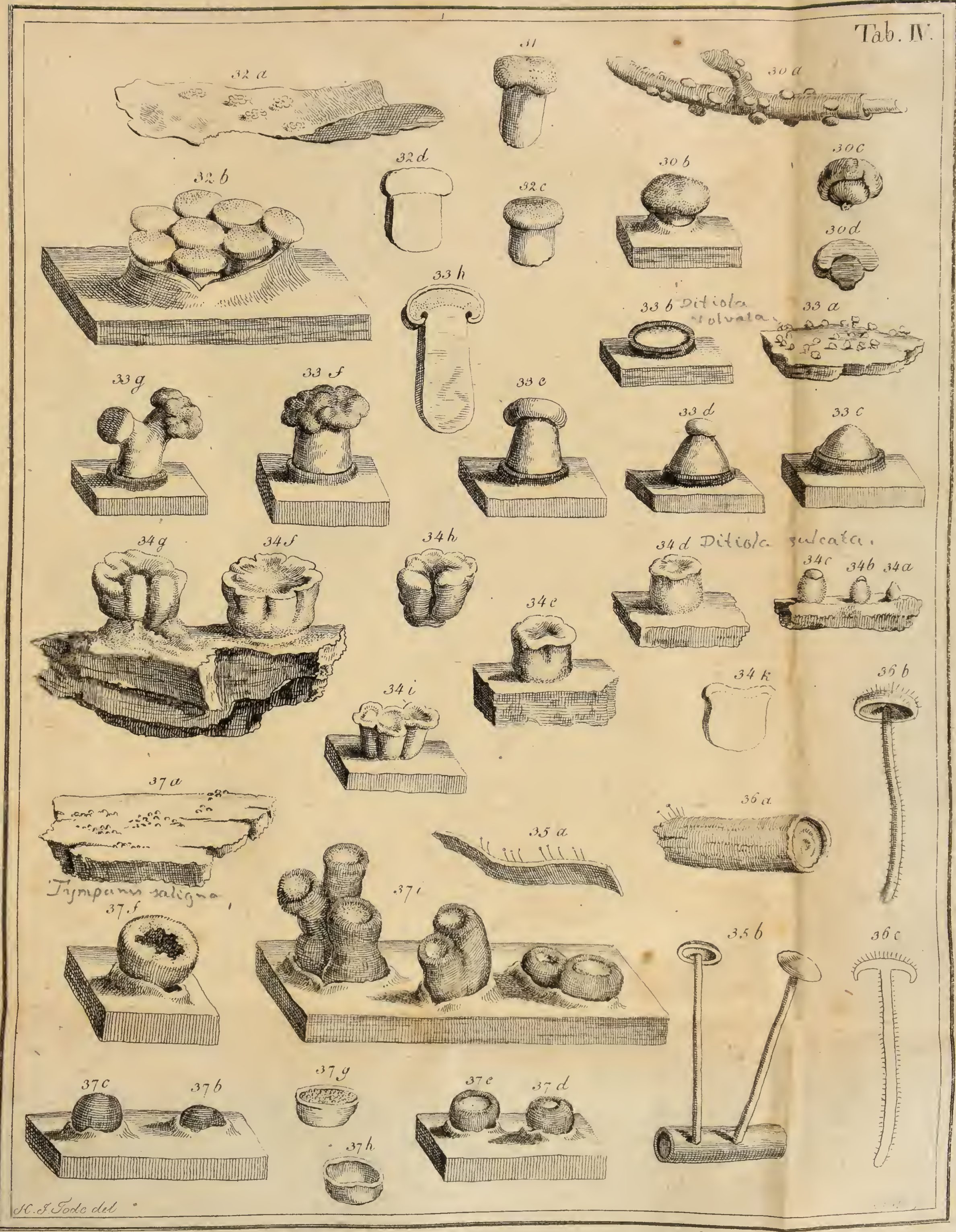





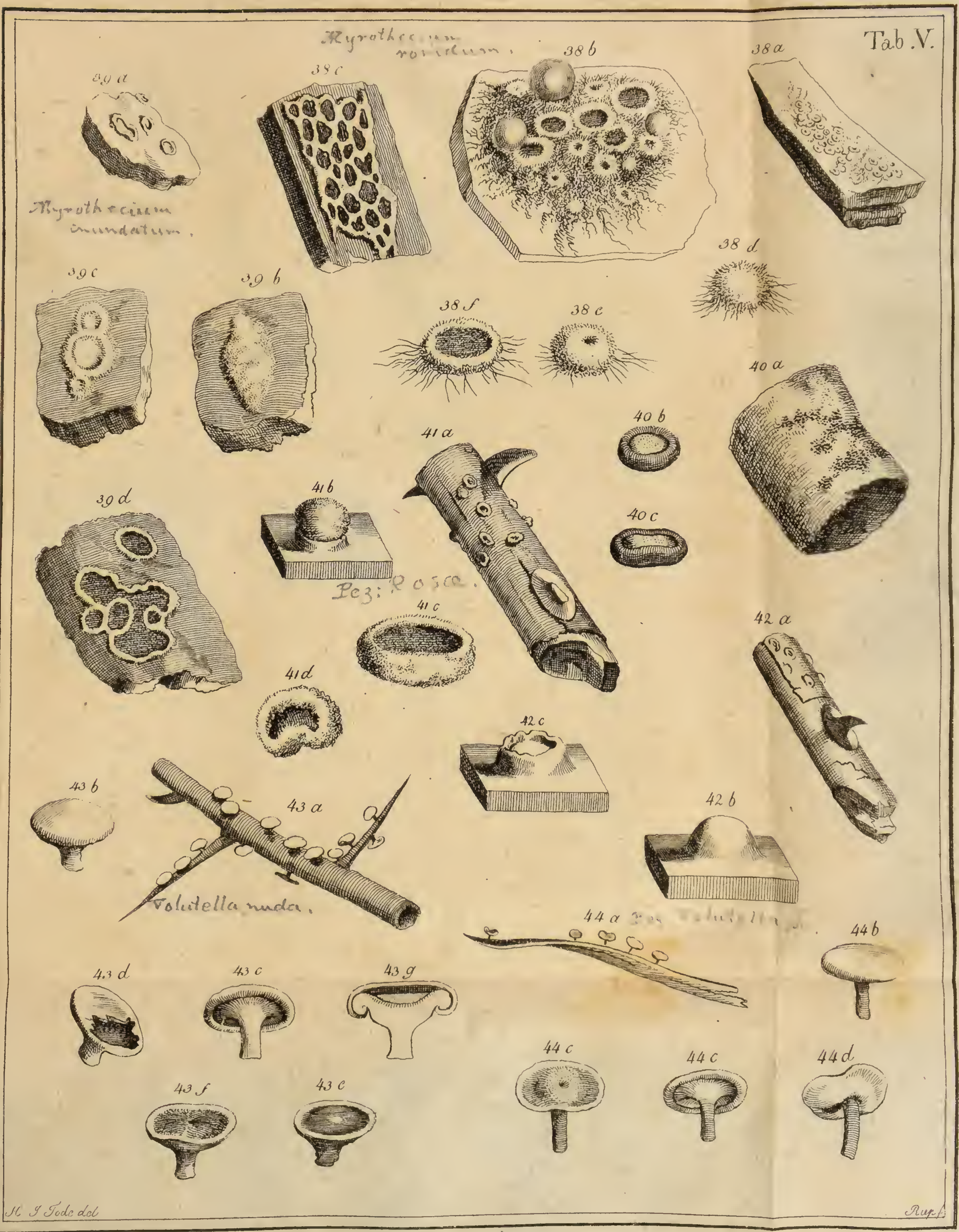




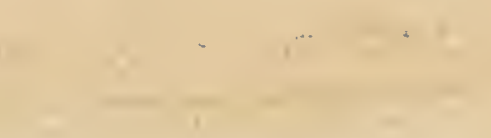

, 1

1
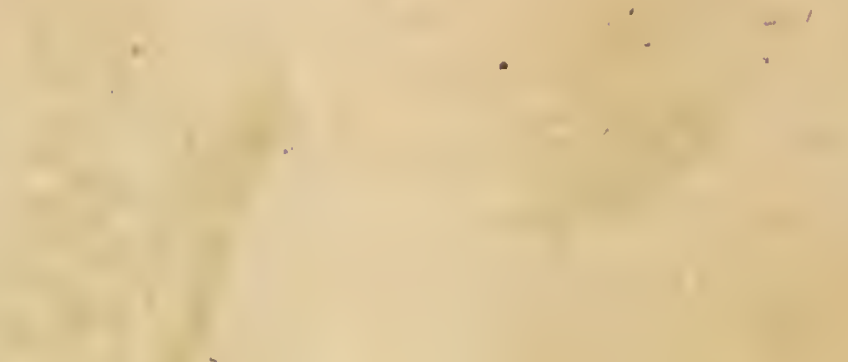

s.

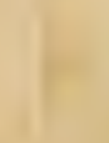

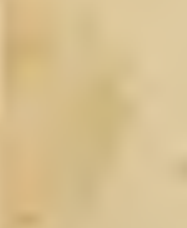

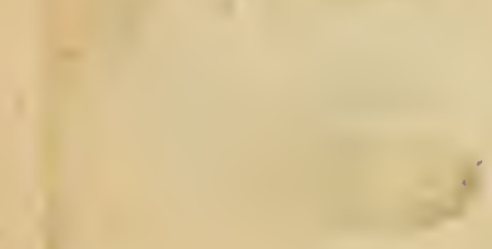

$-$

$+$
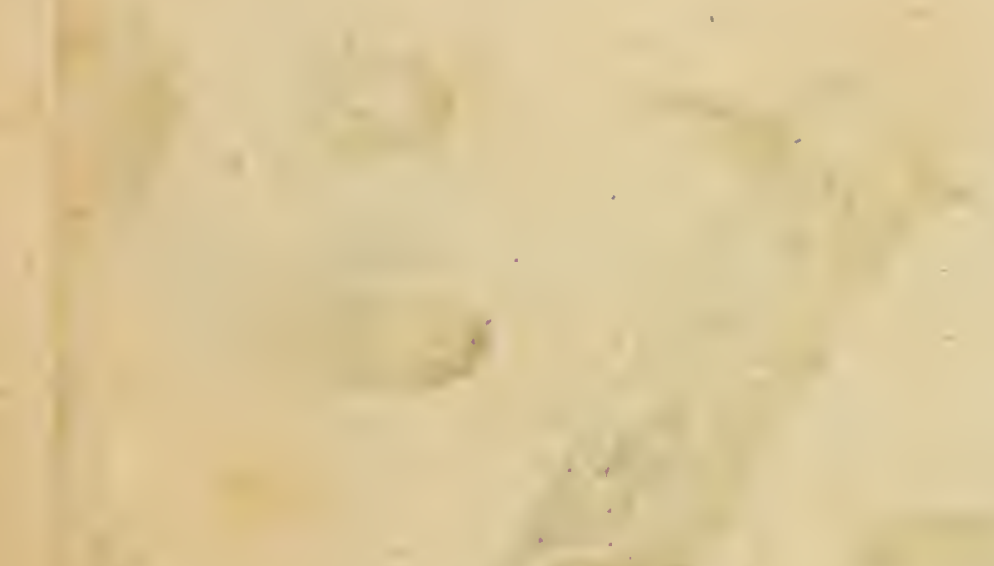

r

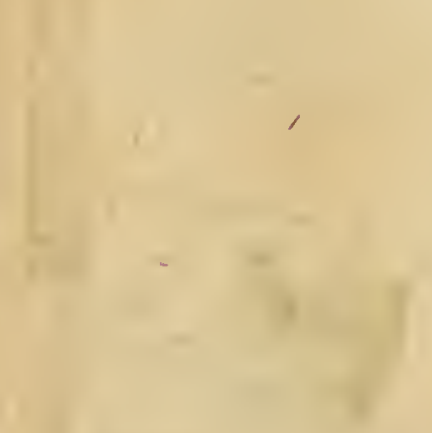
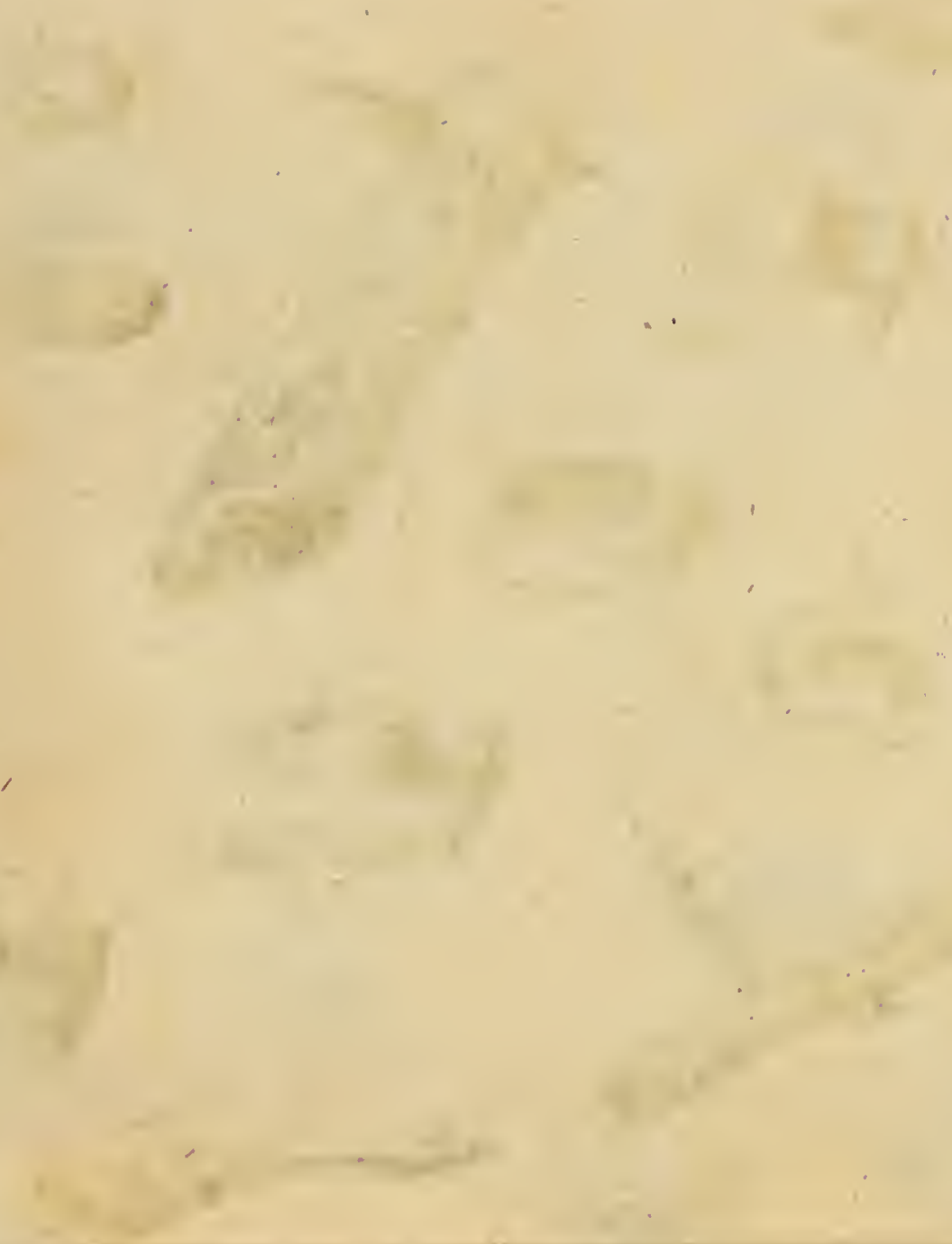


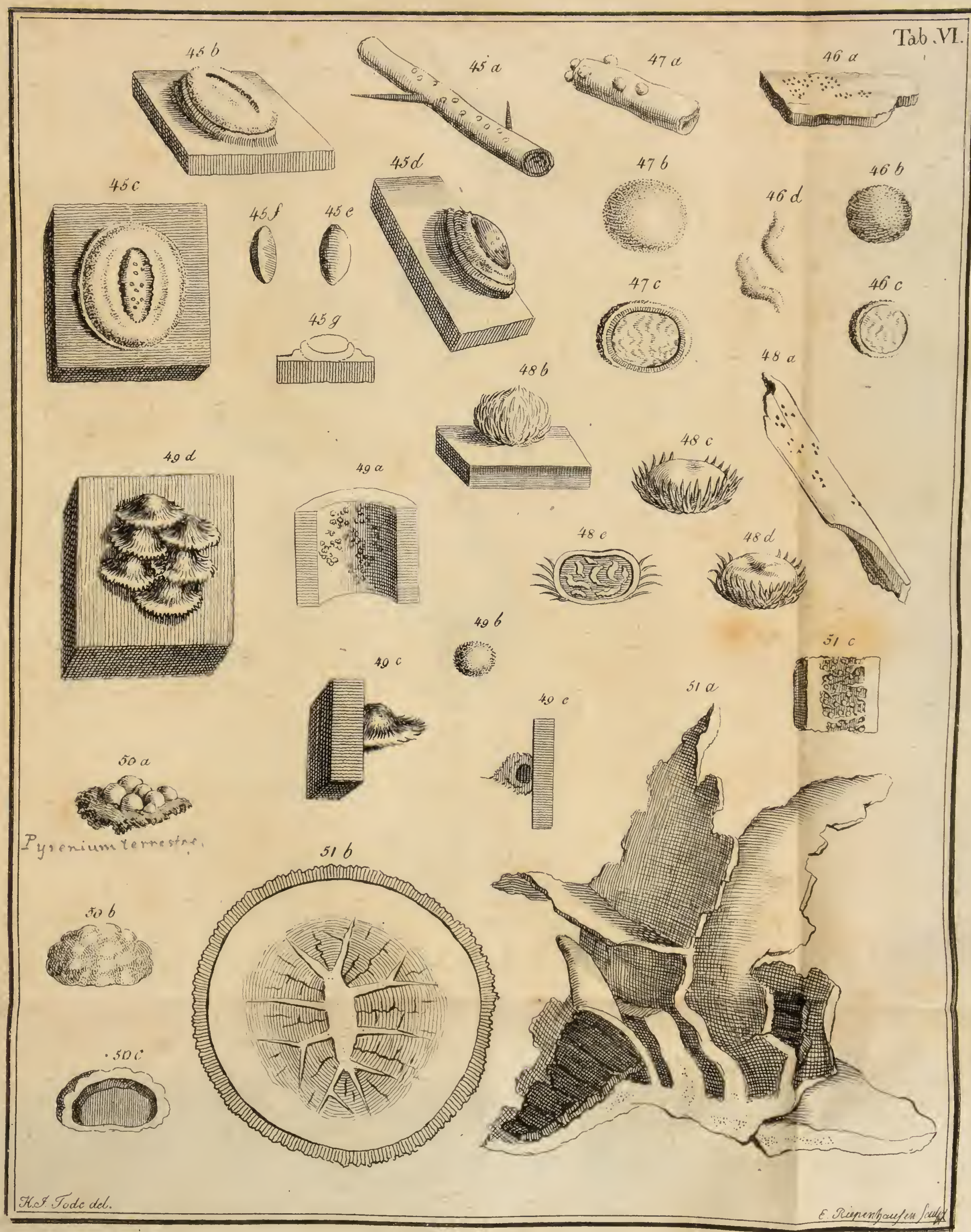



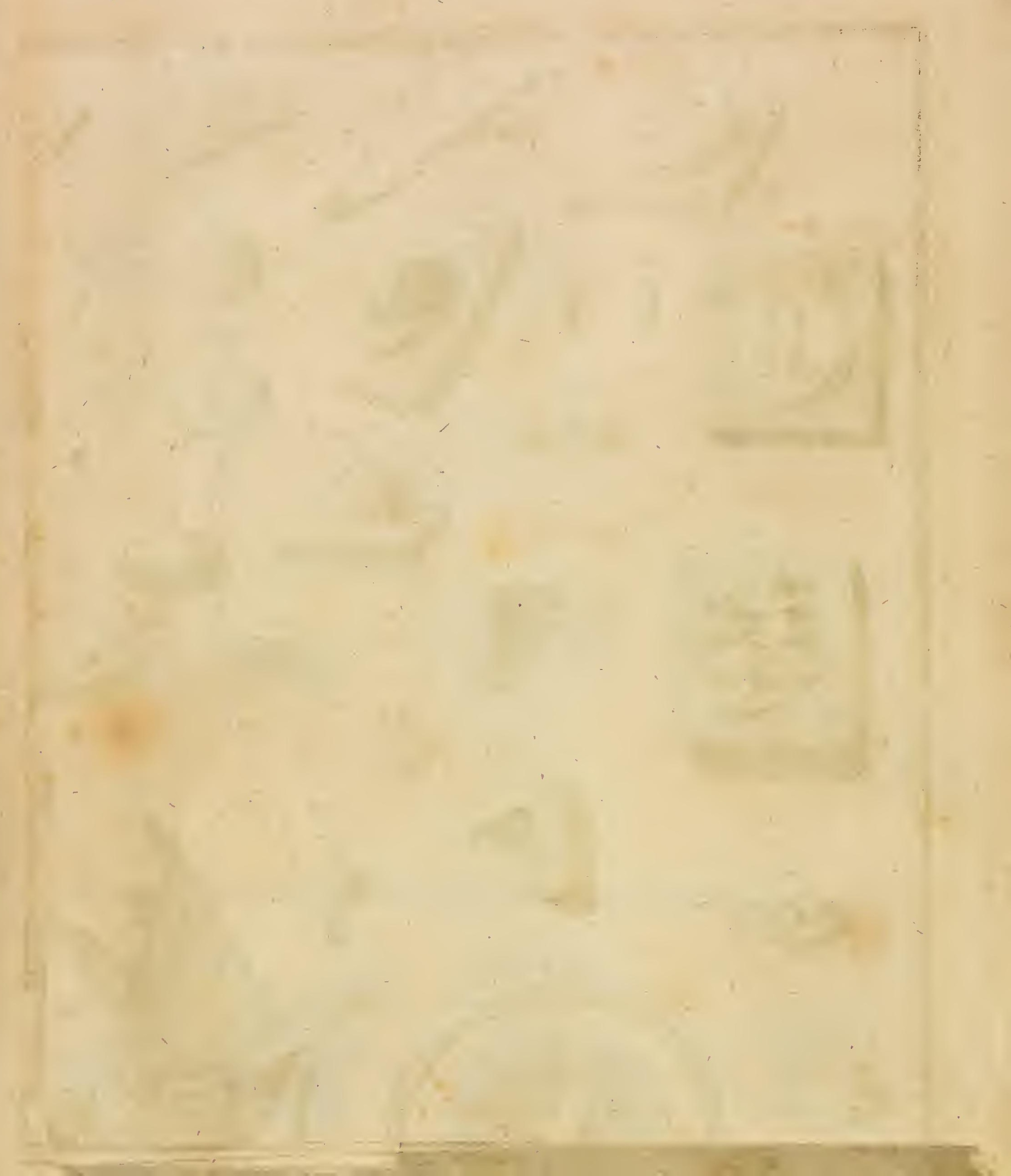

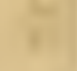




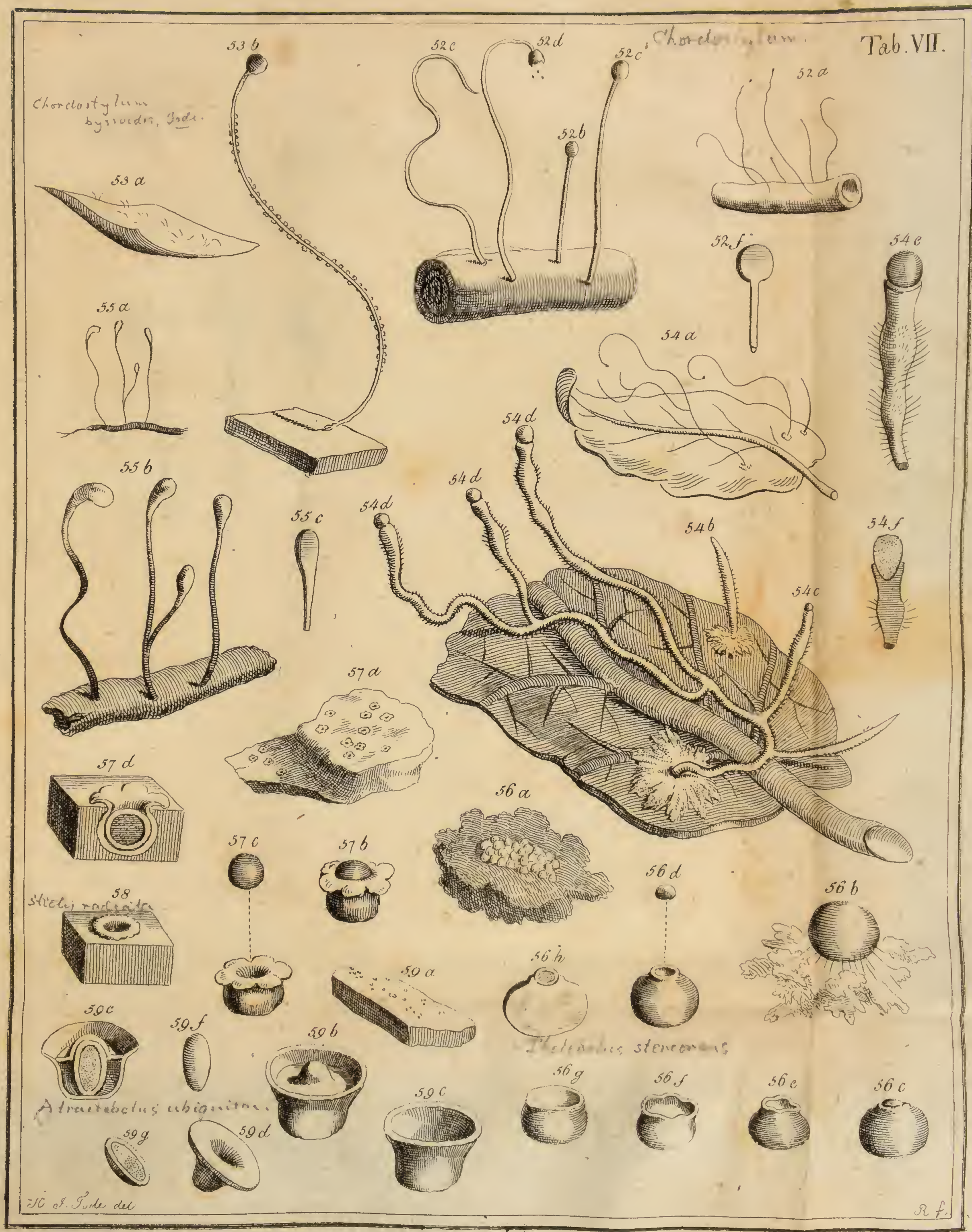





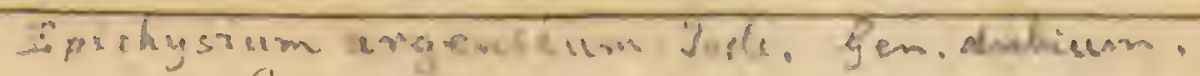

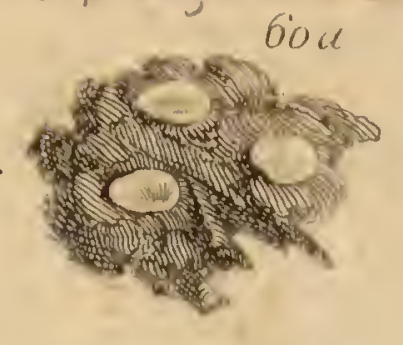

$60,6 \quad 006$

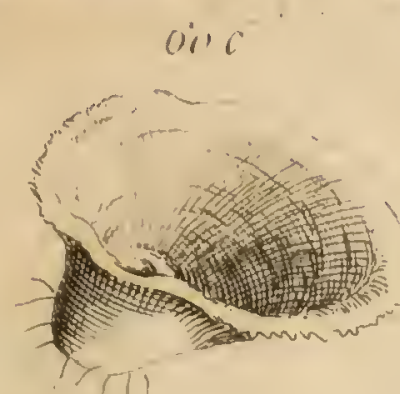

bod

6oe Tab. VIII.

2

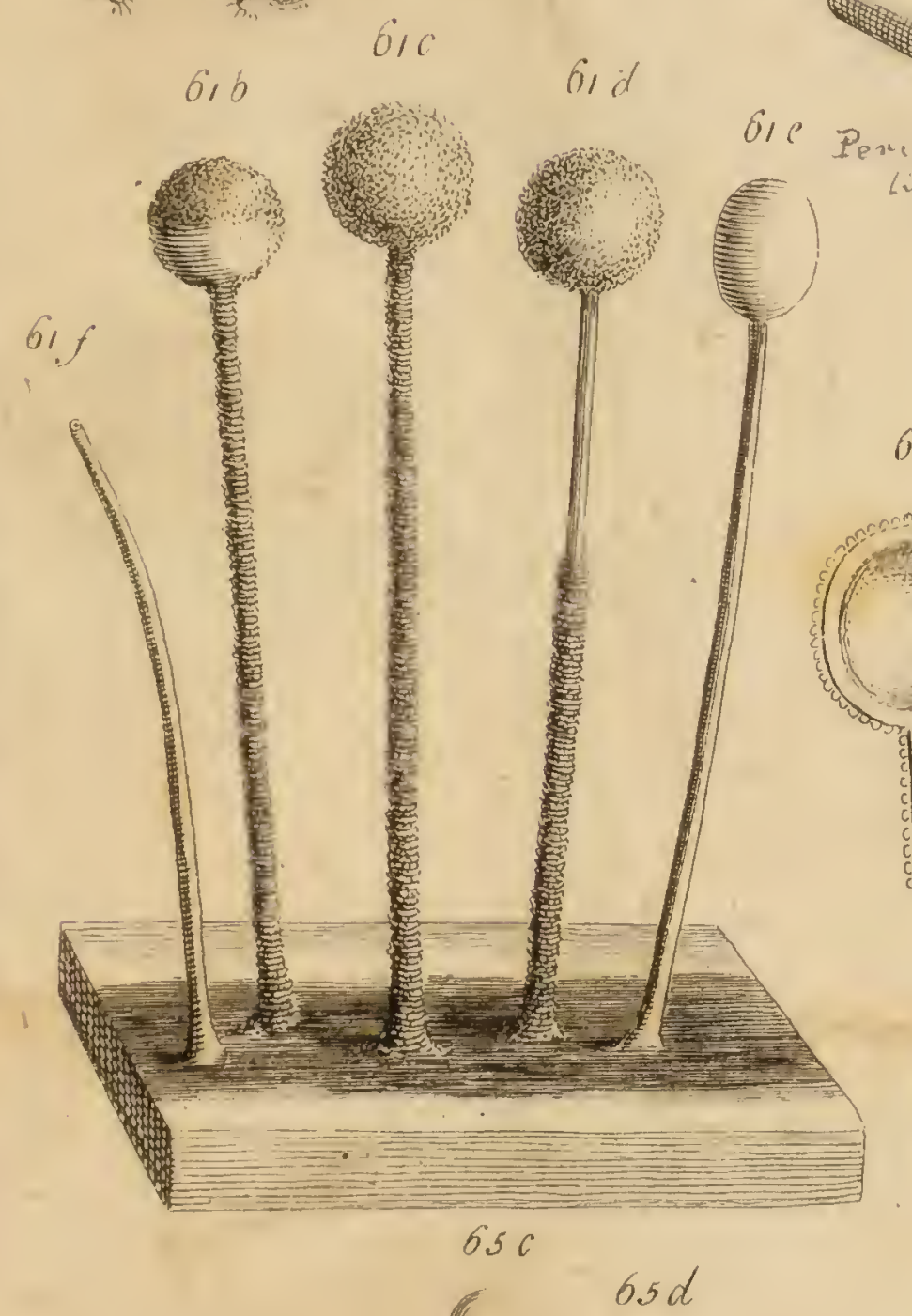

Hy trophota
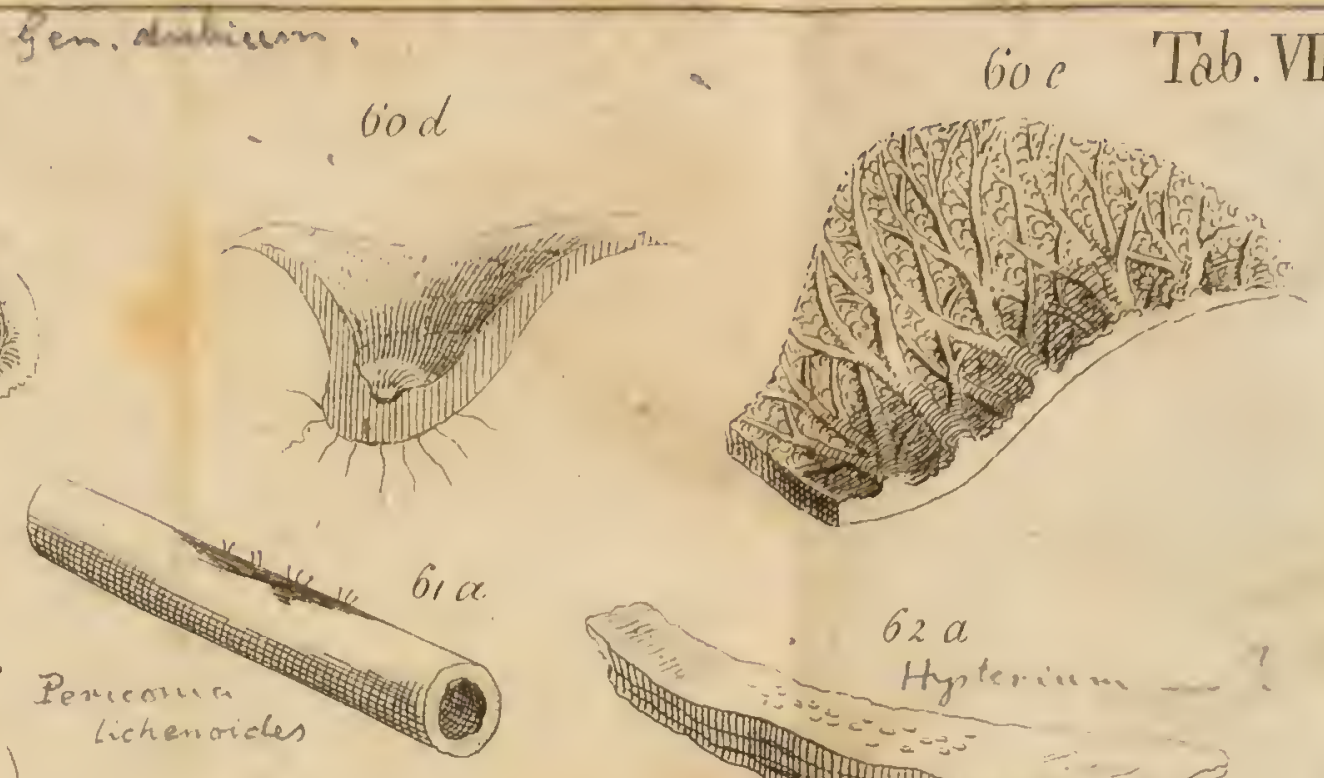

626

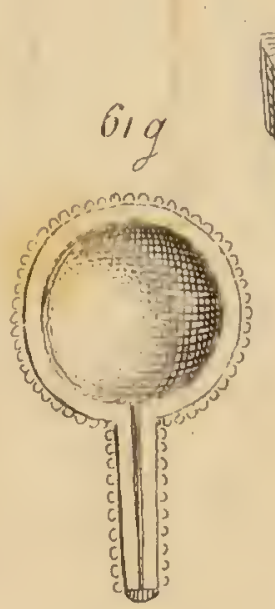

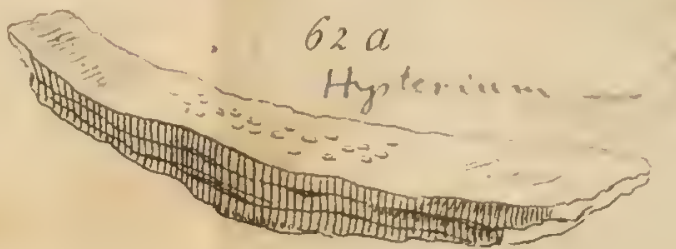

$63 a$

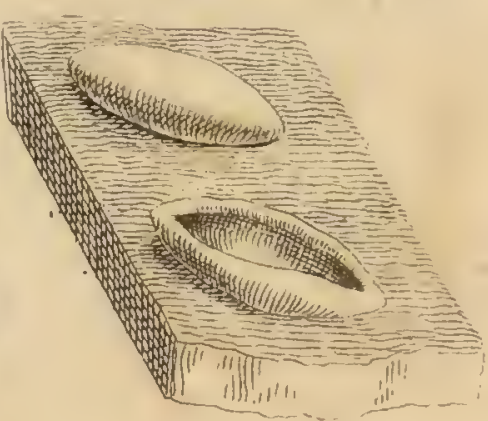

630 Hy.renom
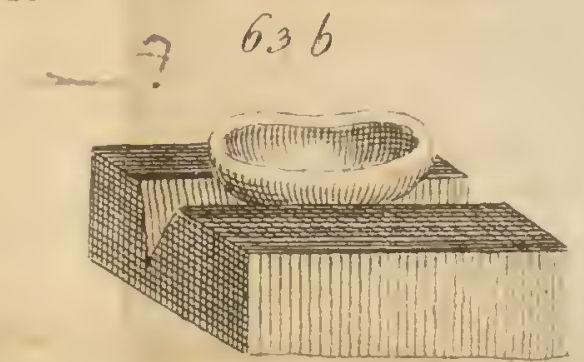

646

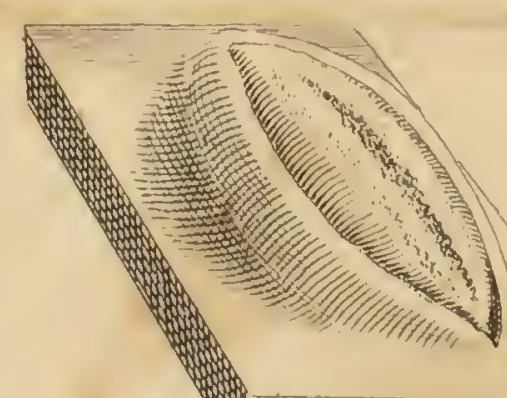

$64 a$

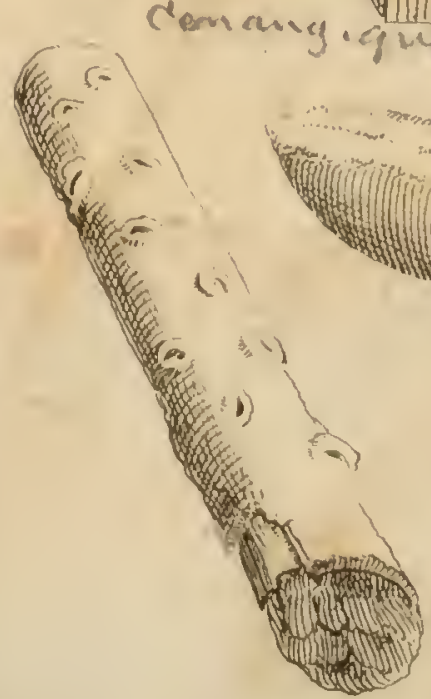

$64 d$

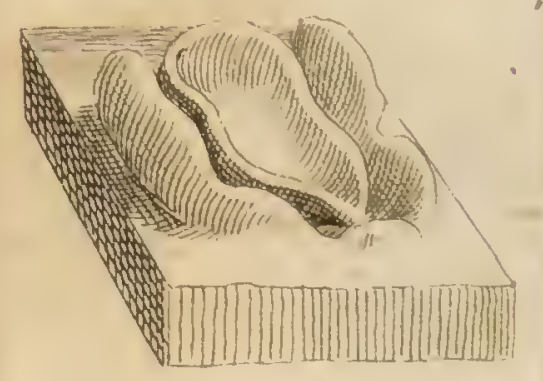

$64 r$

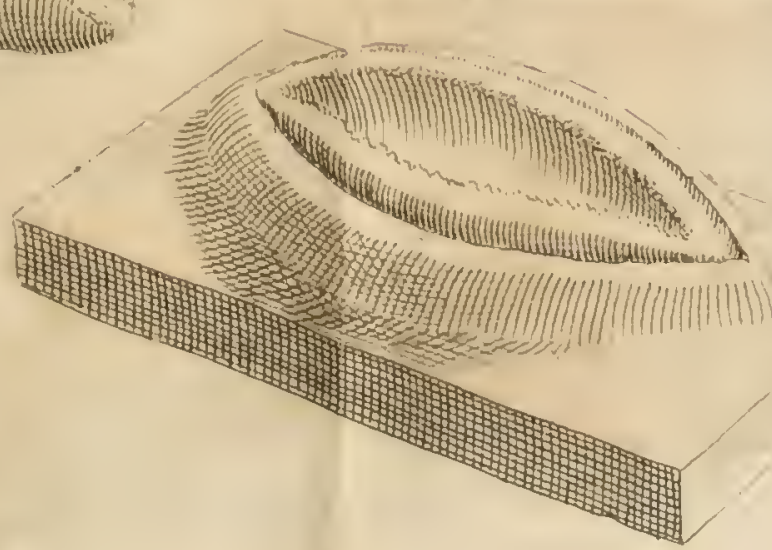





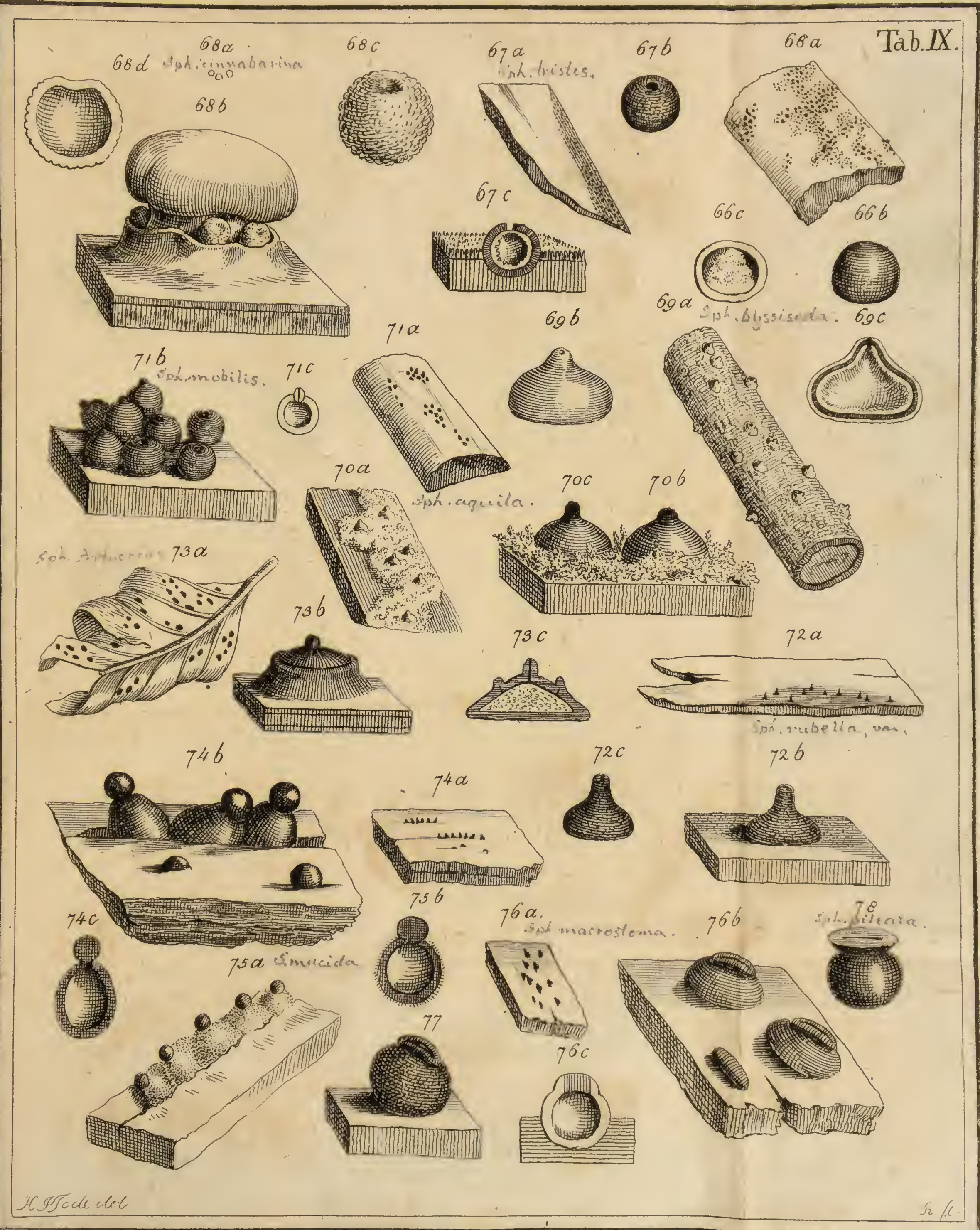




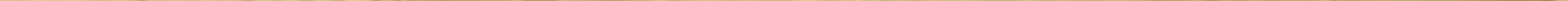




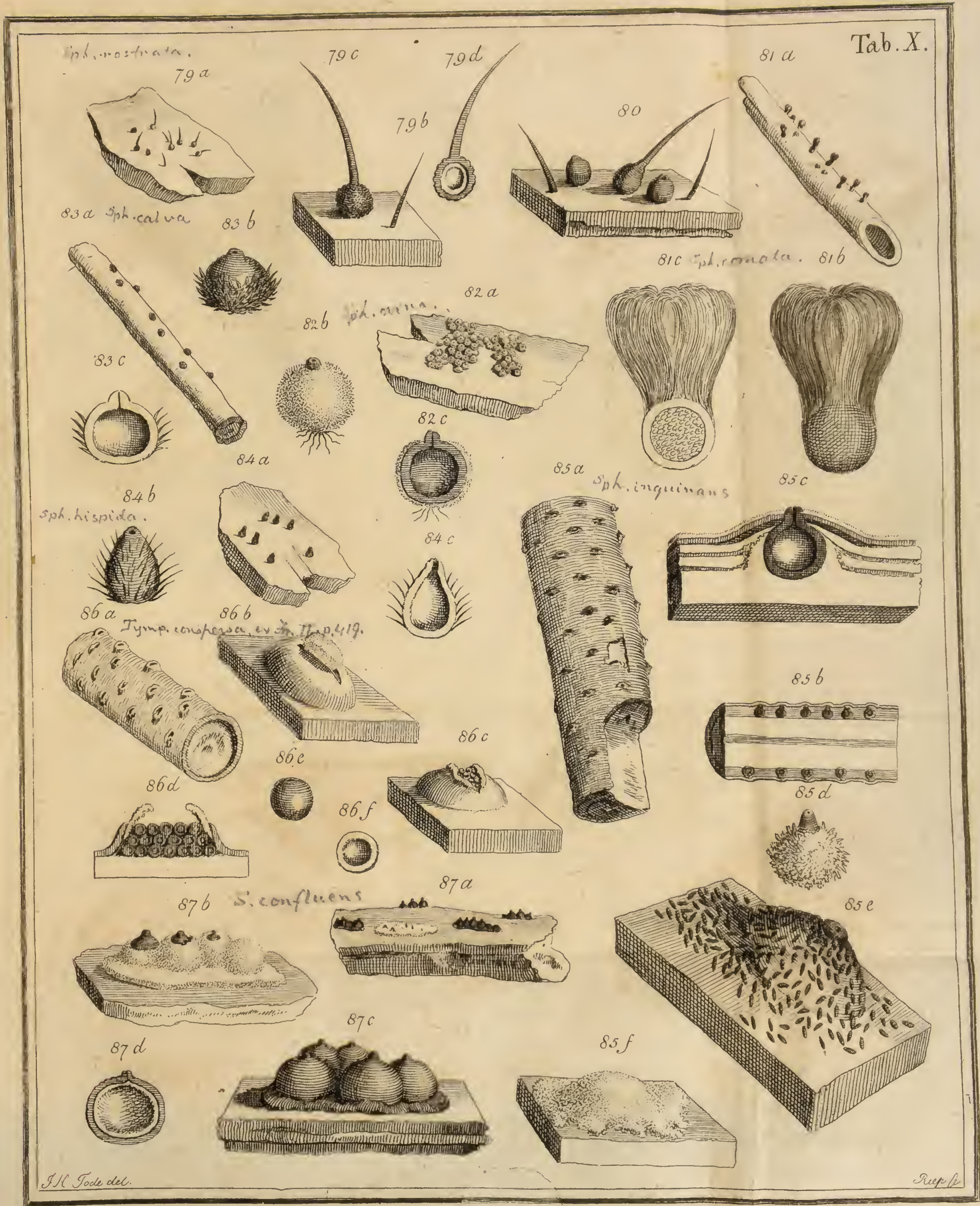




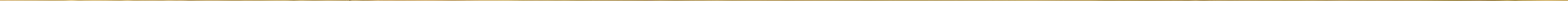




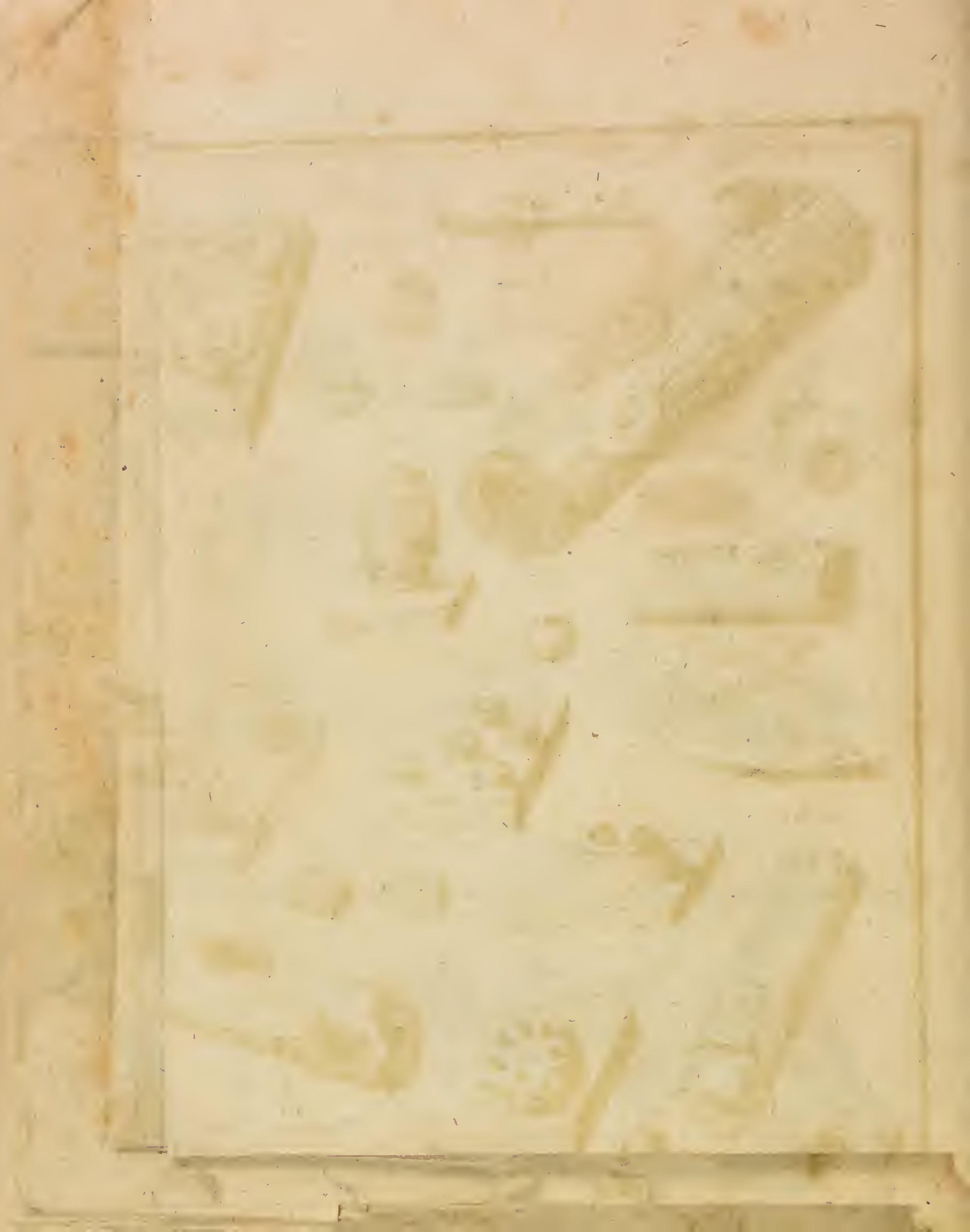




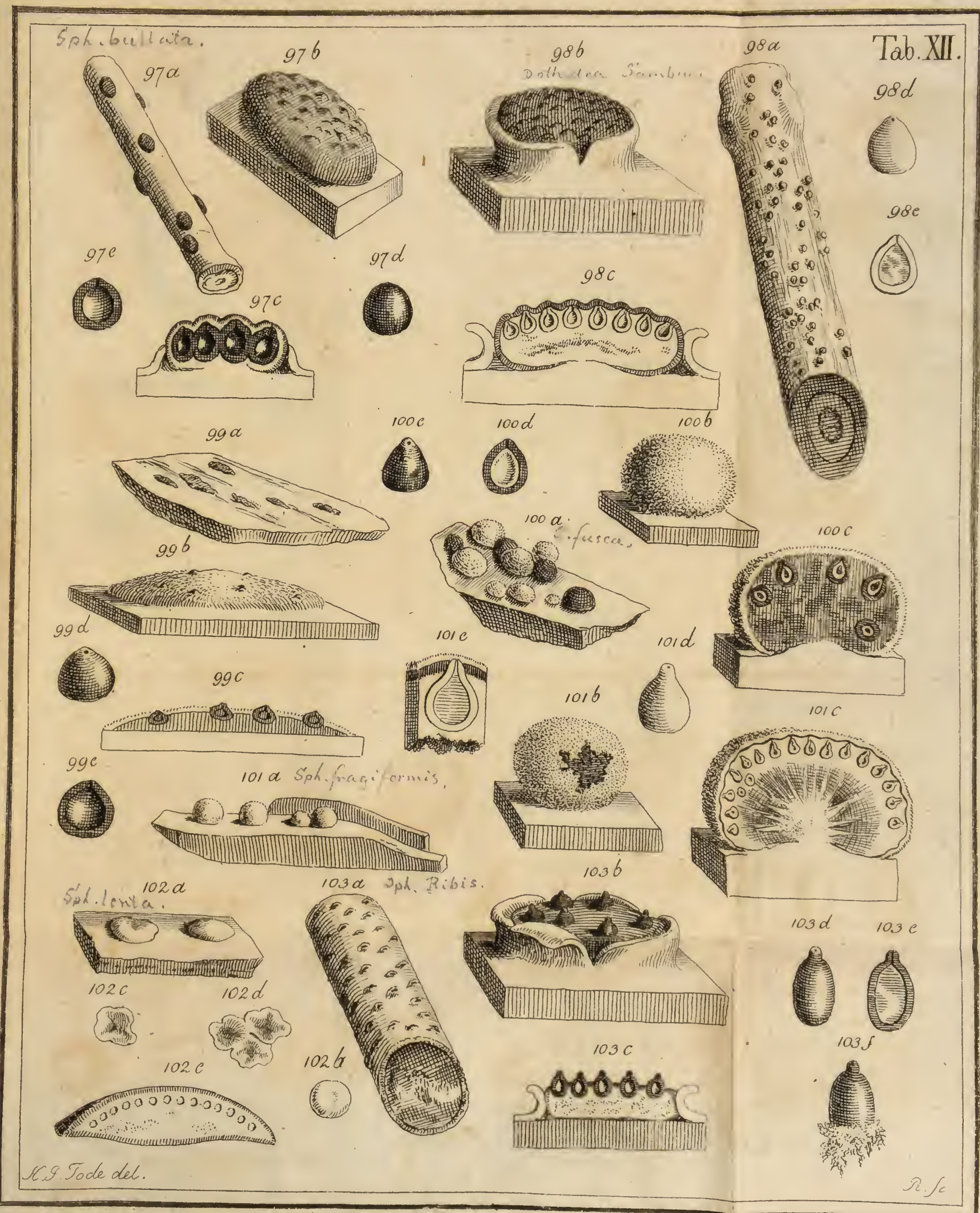





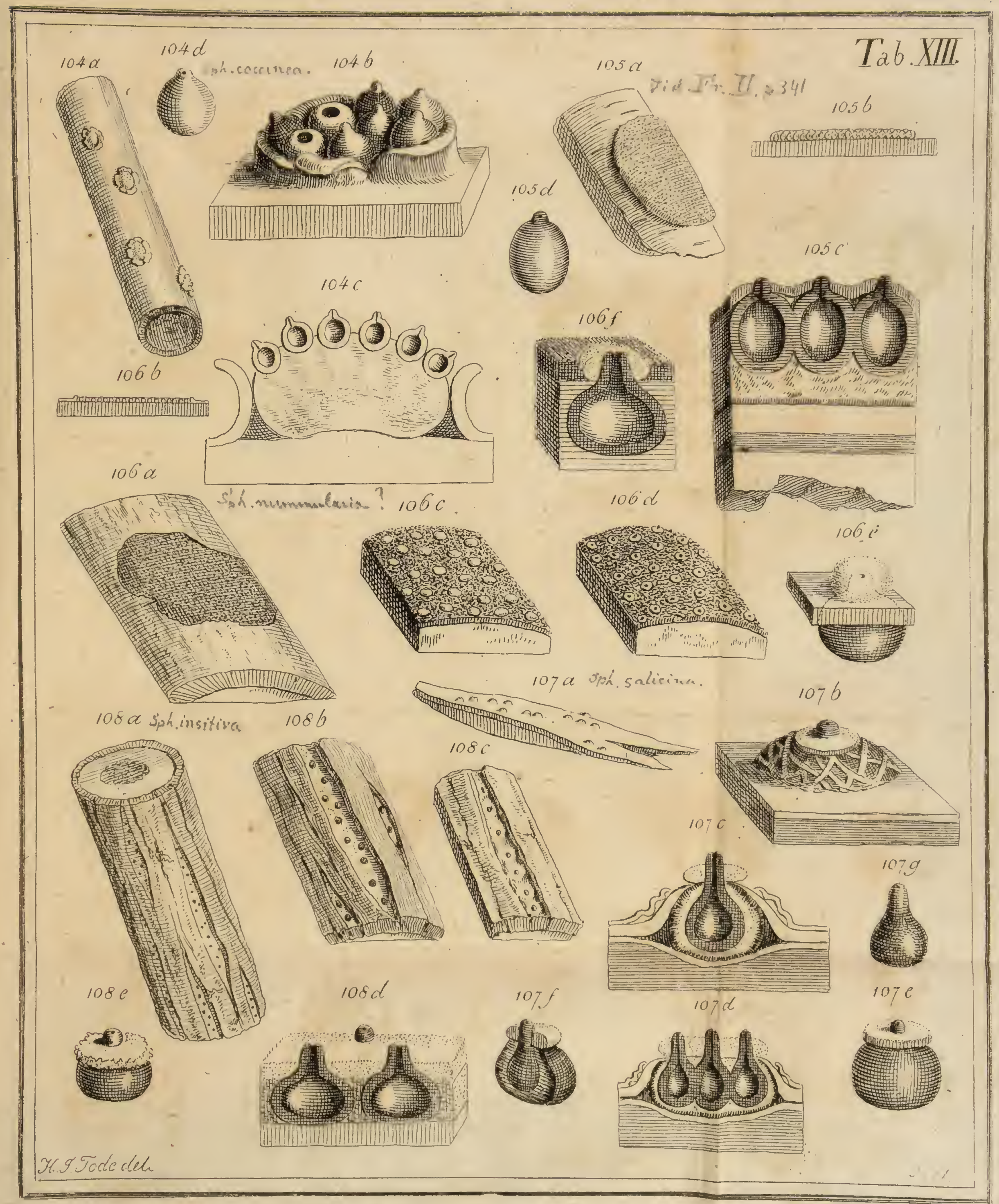




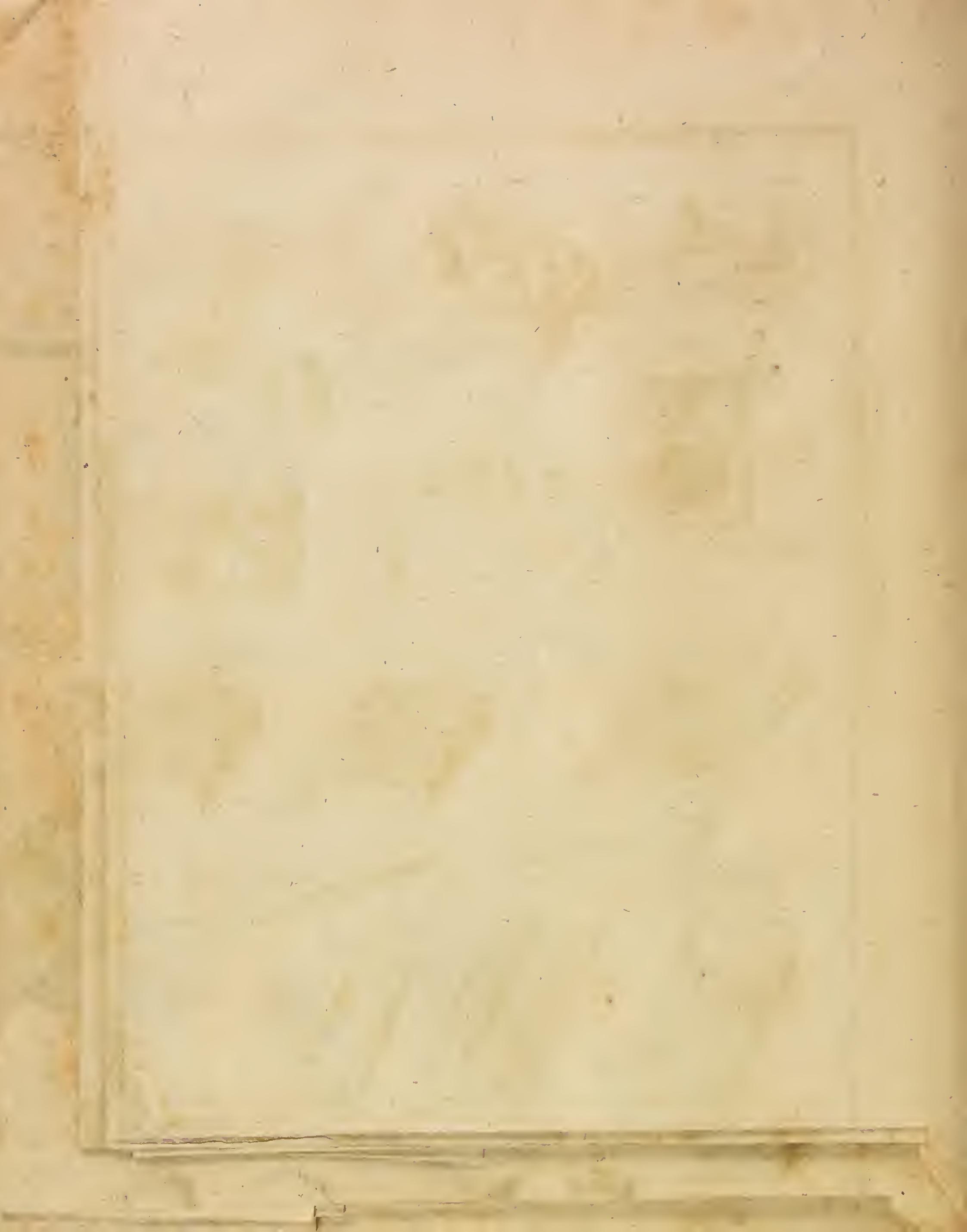




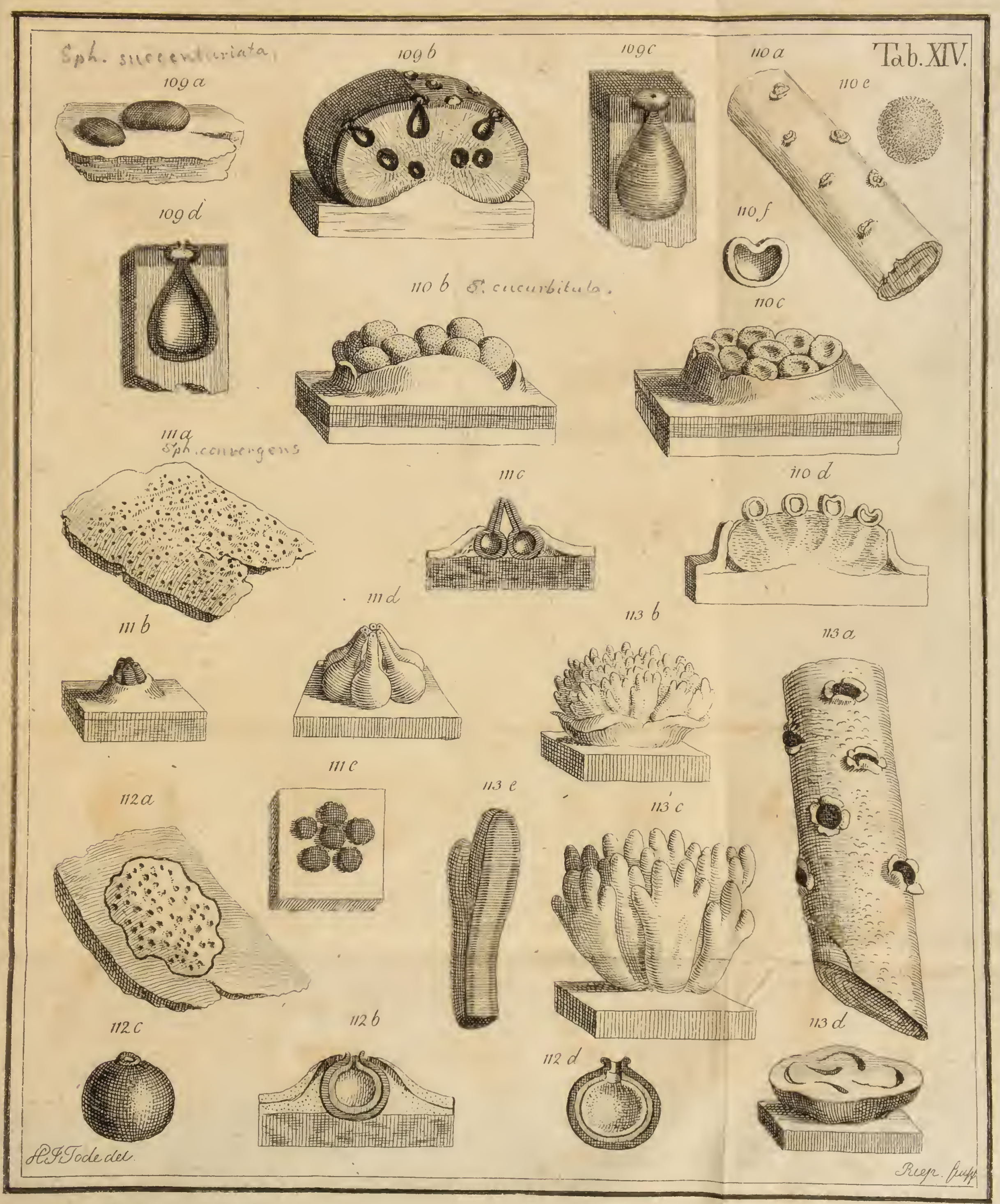





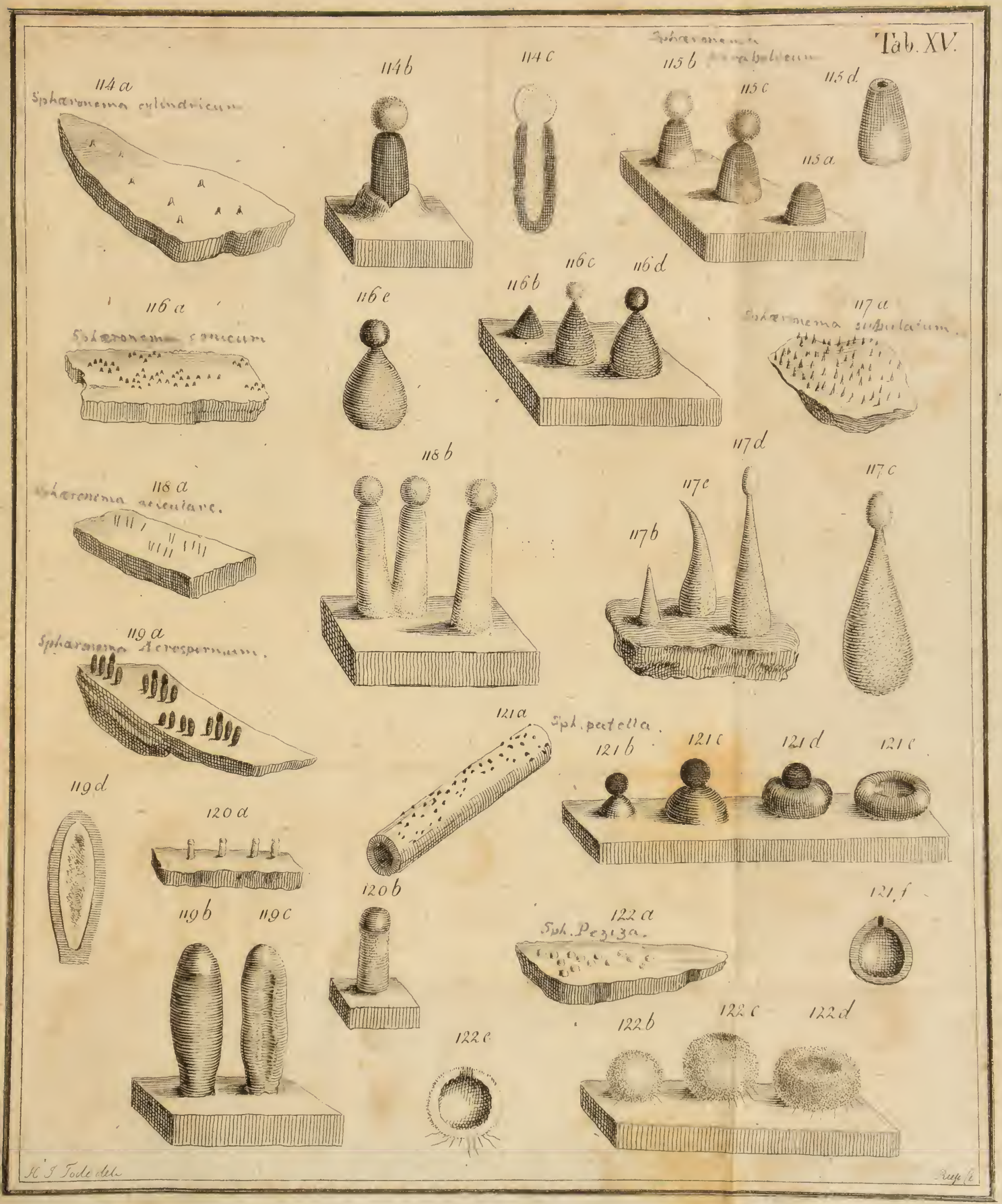



sol.gelatenesc

$123 \alpha$

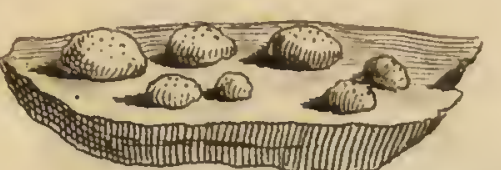

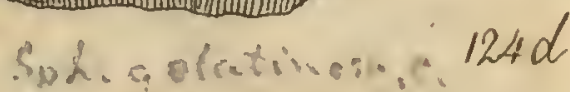

124 a $1246 \quad 124 c$

(ii) (ixiii) (iimiiii)

125 a sinc. Cun and.

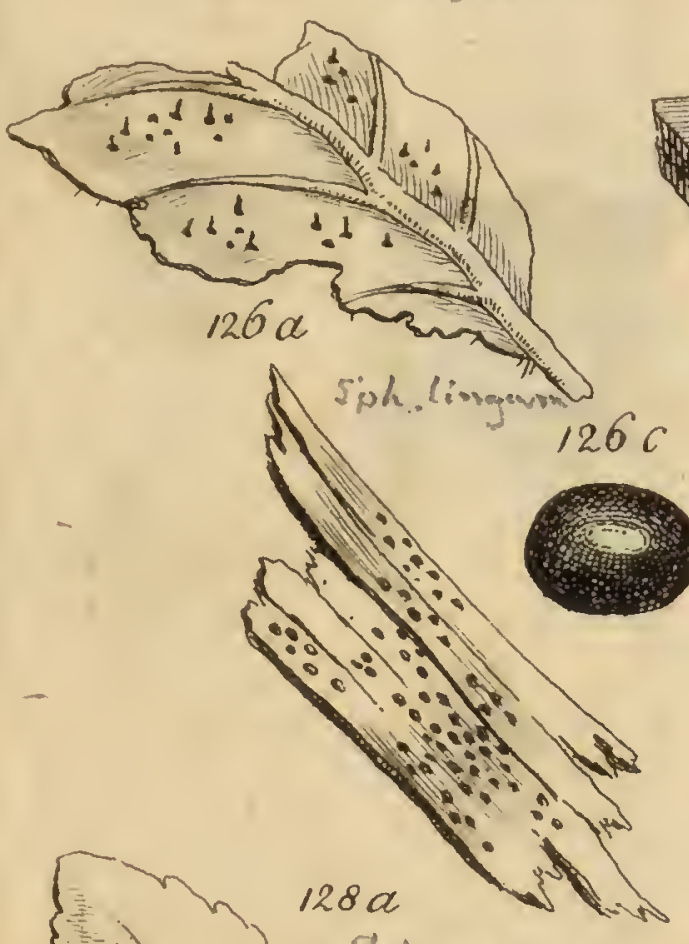

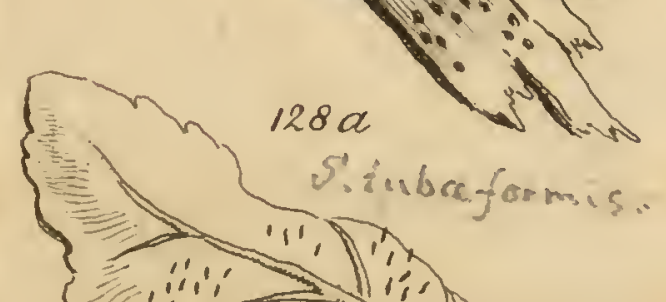
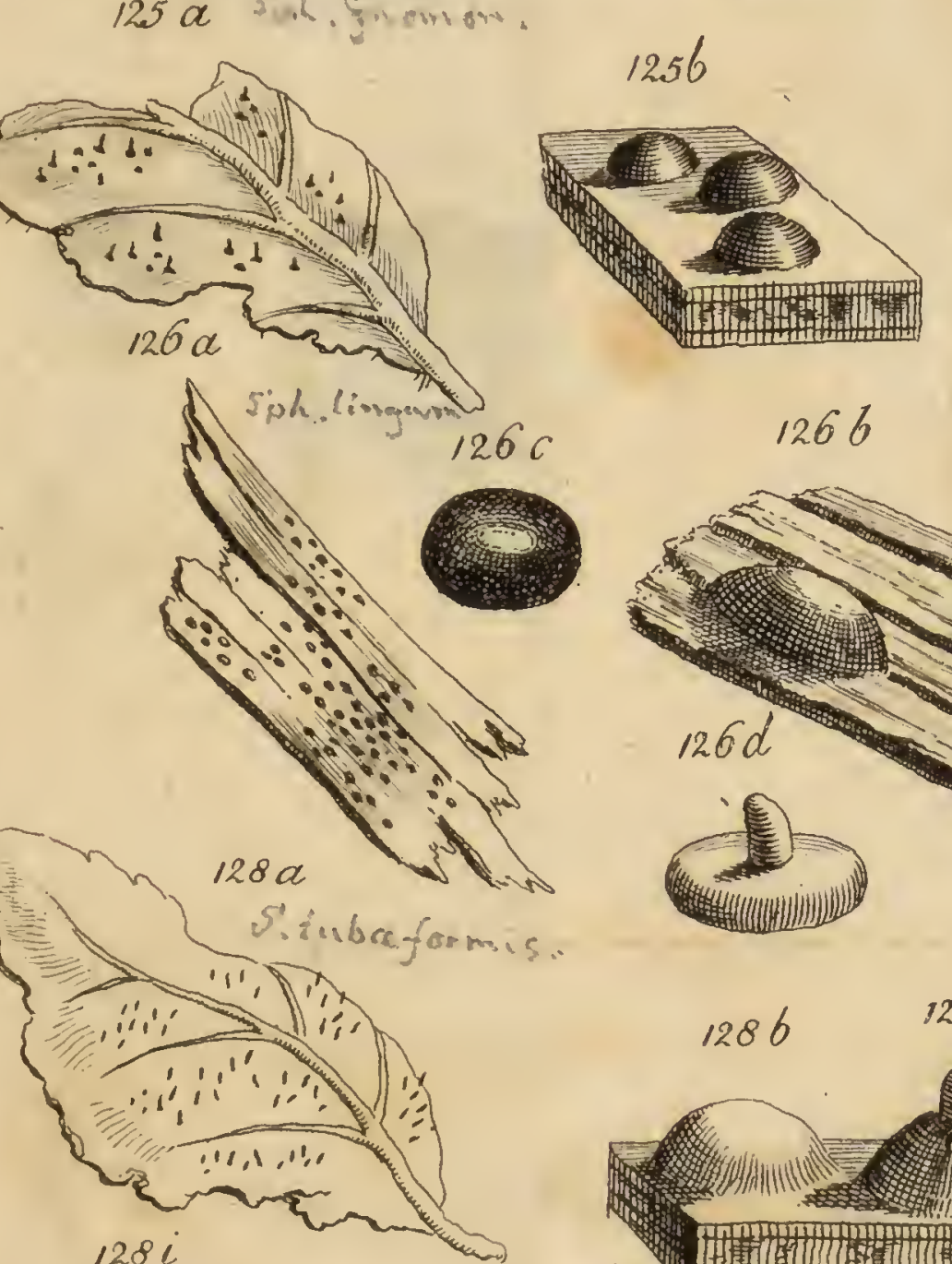

$124 c$

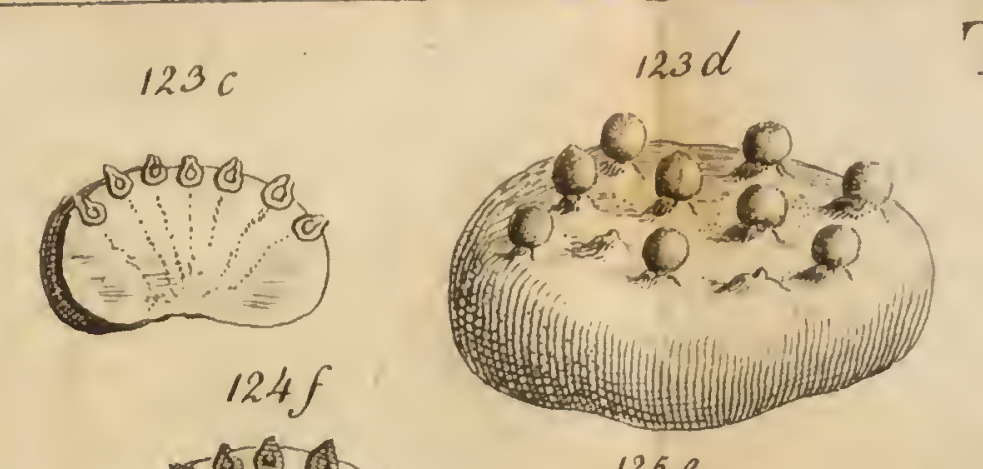

Tab.XVI.

1236
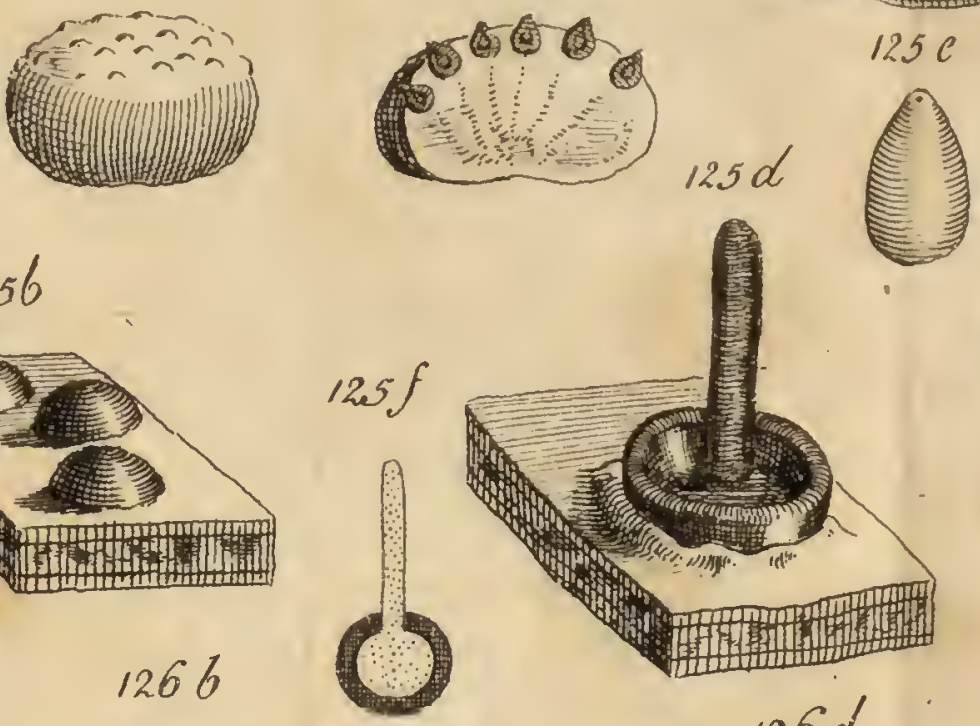

$125 c$

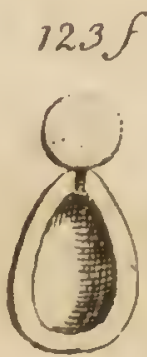

1266

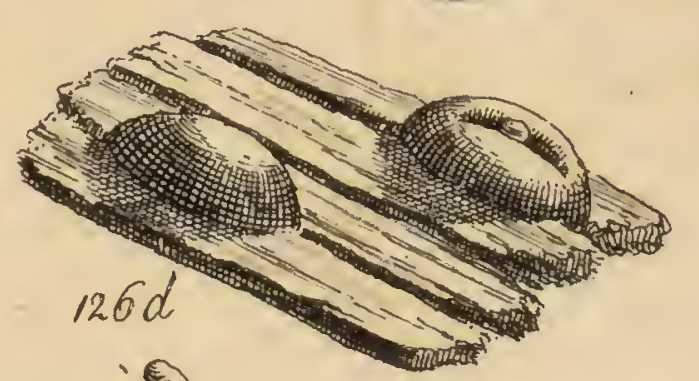

$126 e$

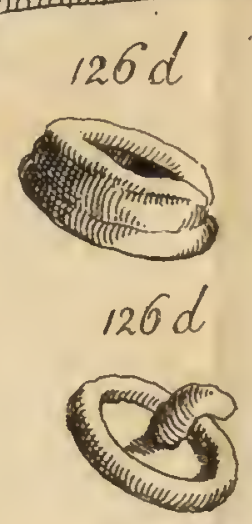

$127 d$

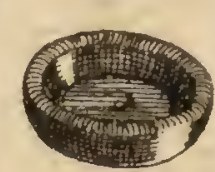

$125 c$

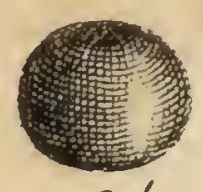

$126 d$

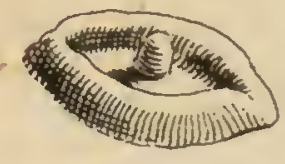

$126 d$

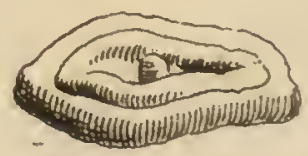

$127^{d} \quad .127 e$
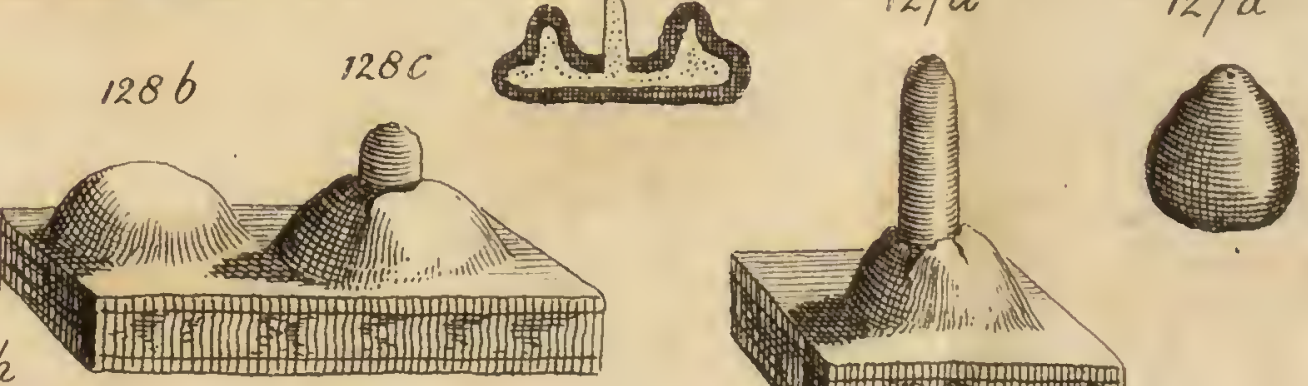

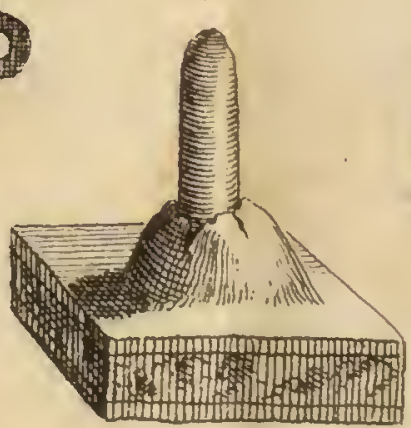
$128 h$
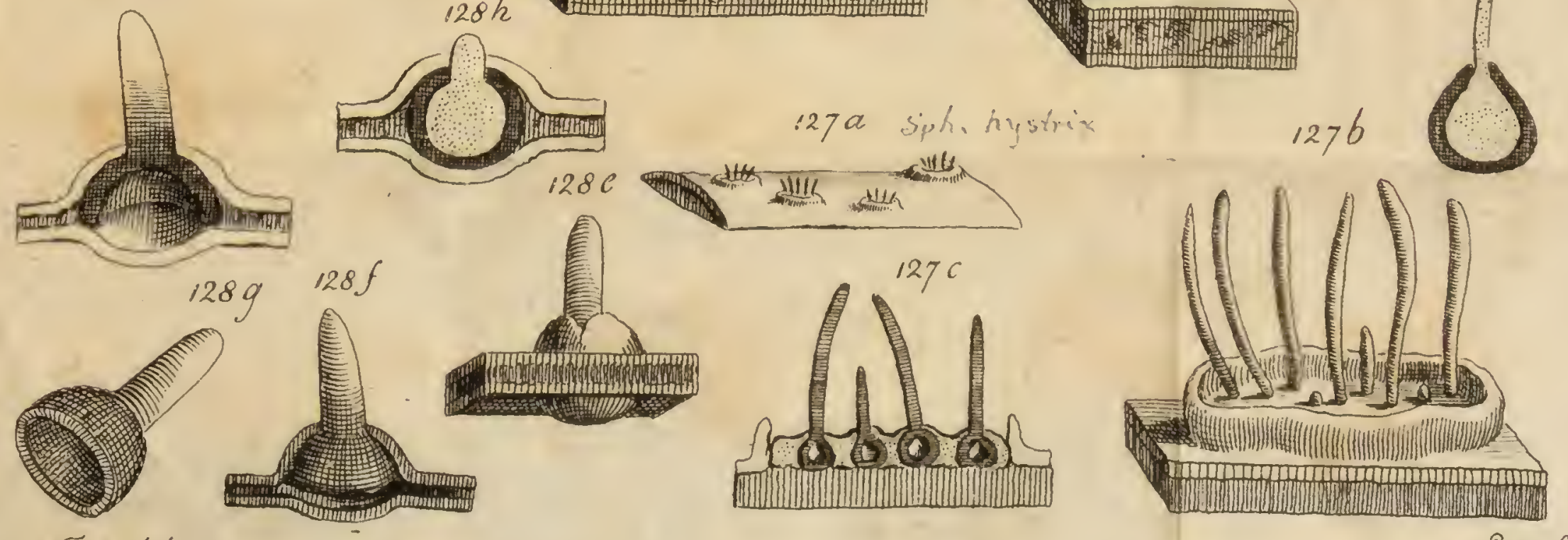


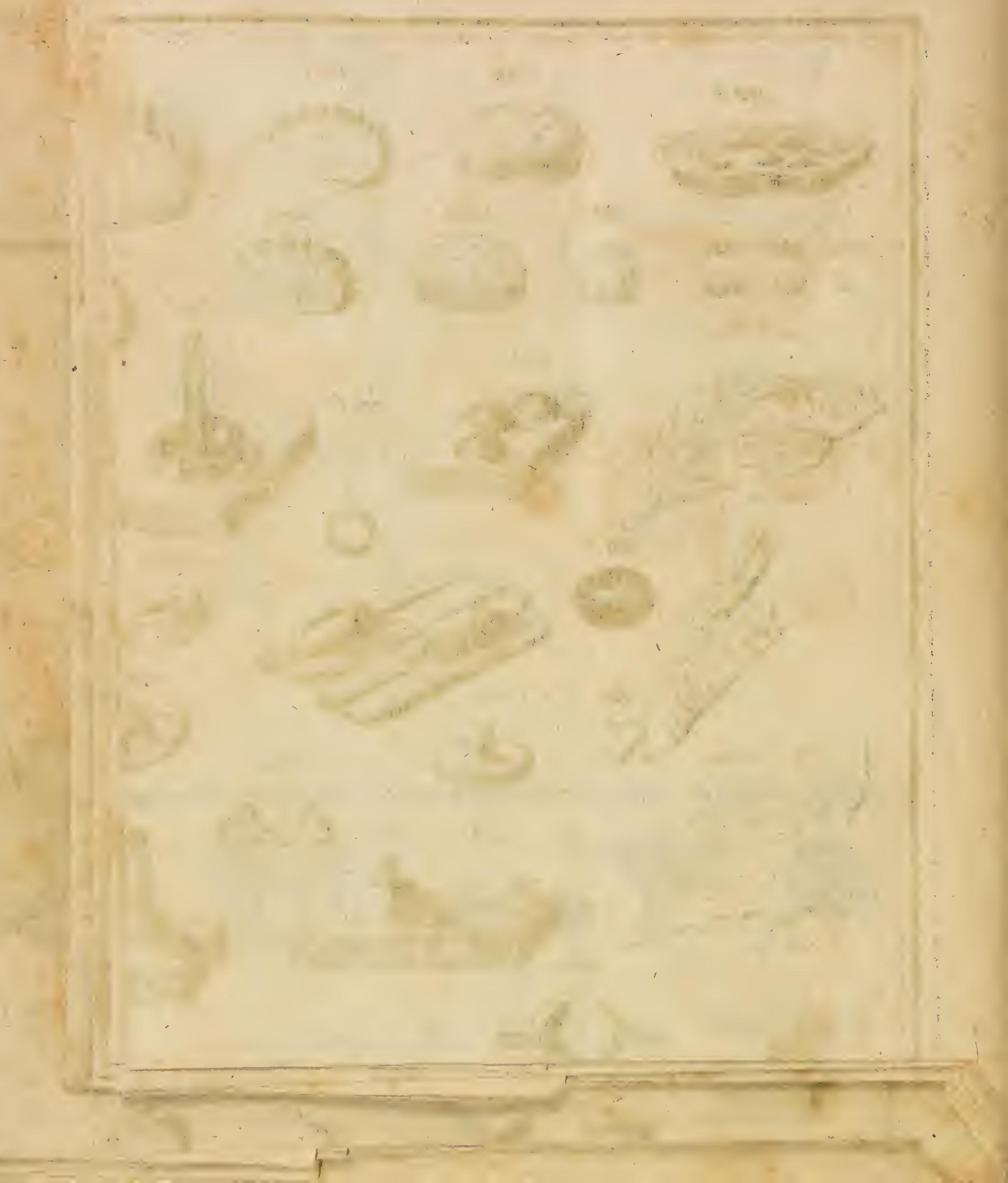


$129 a+4 L . d=u s t a$

\section{6}

$129 \mathrm{C}$

TabXVII.

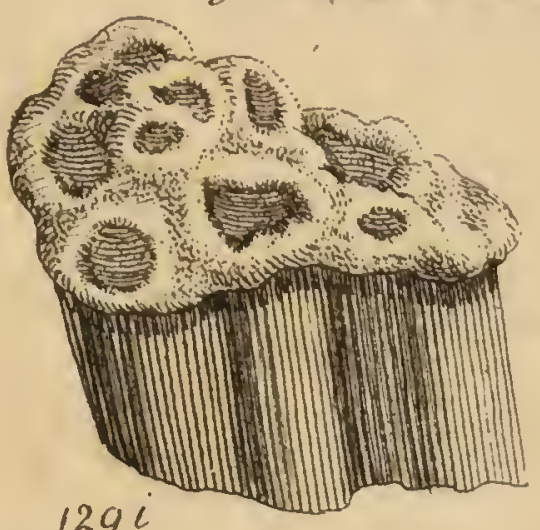

$129 i$
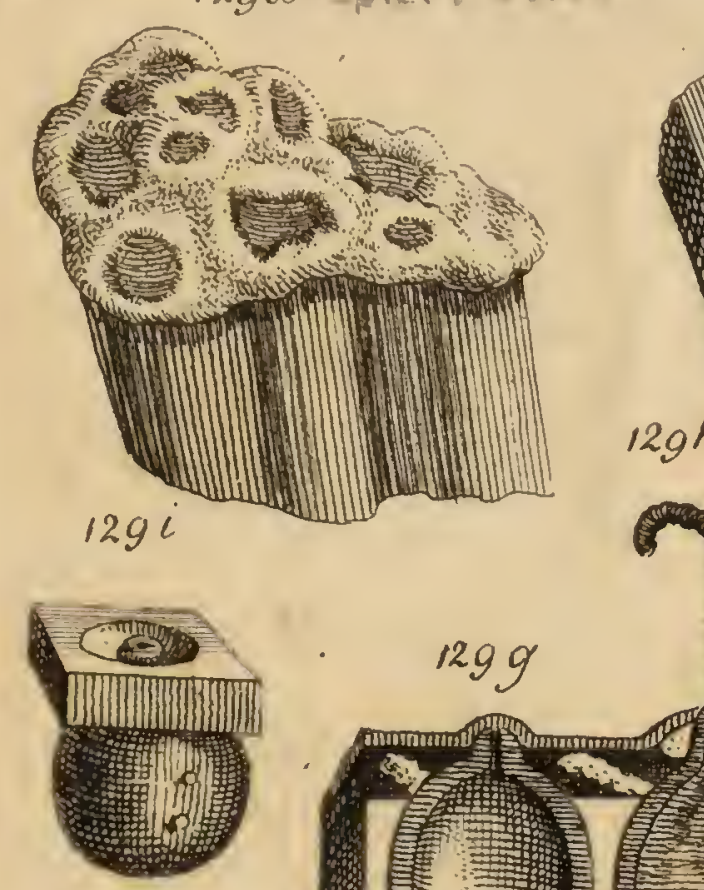

$130 \mathrm{a}$
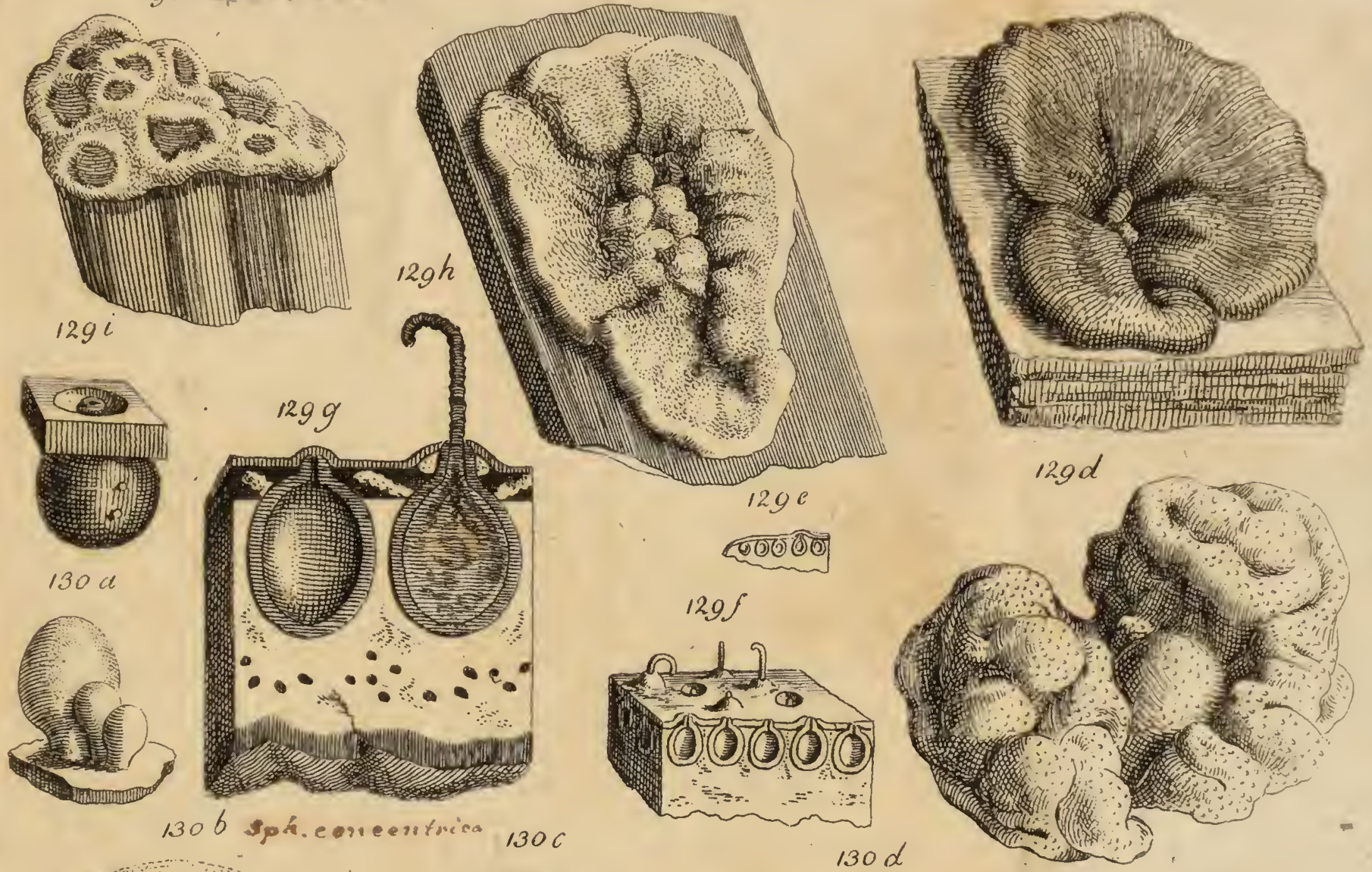

1306 sph.encentries $130 \mathrm{C}$

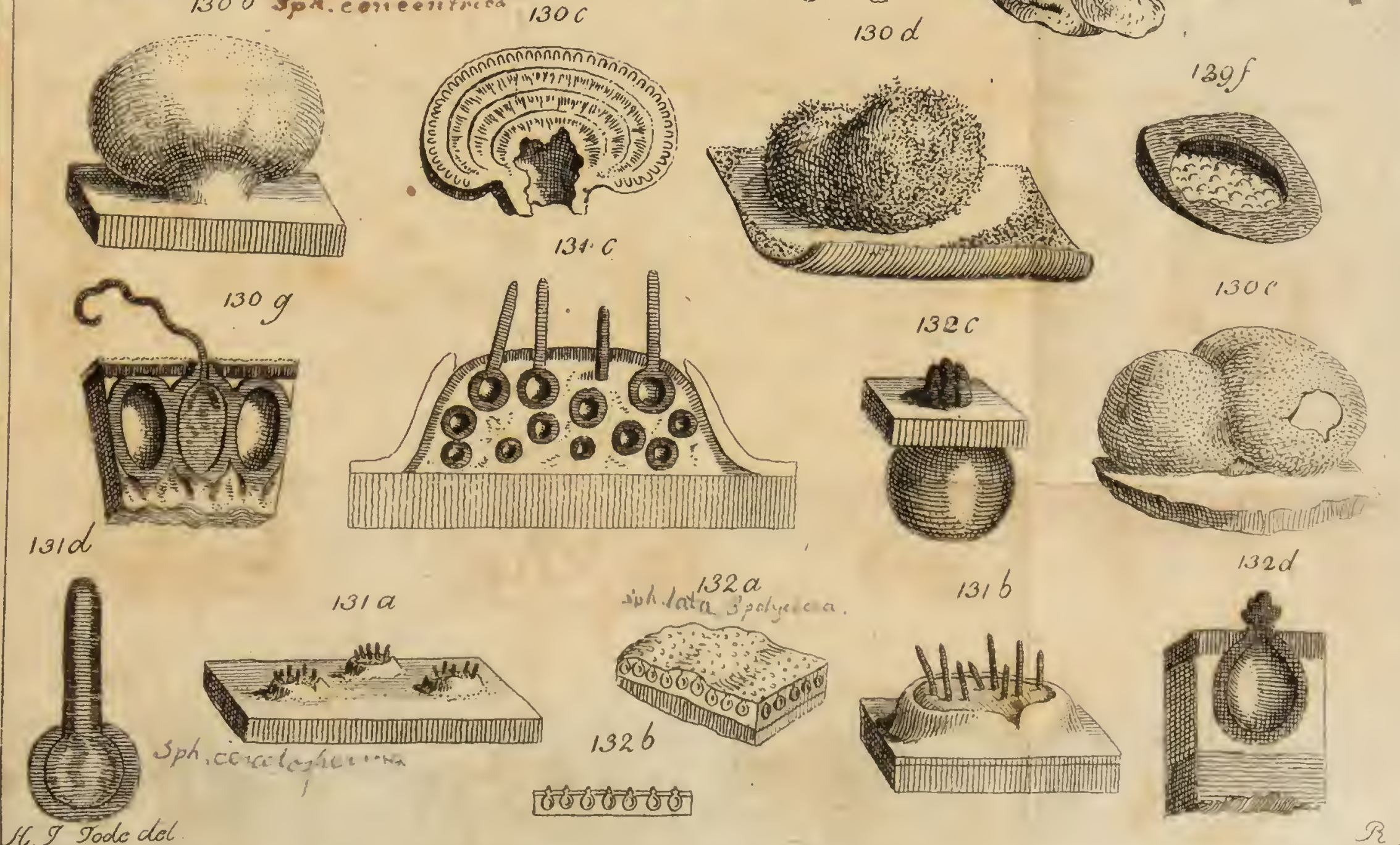




271306

t.

3

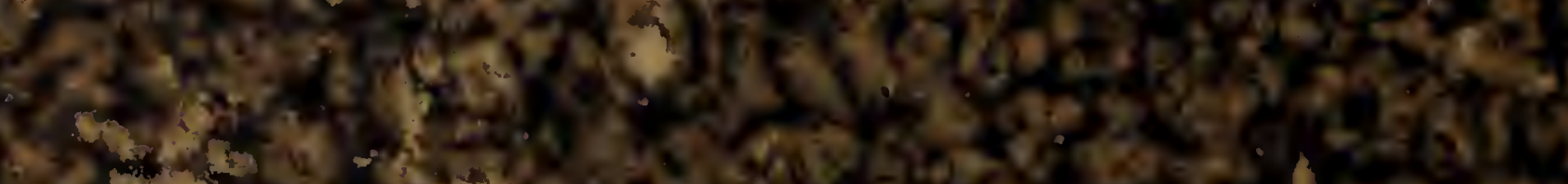

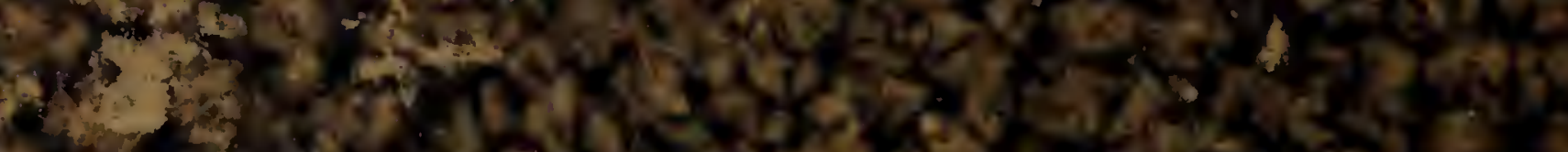

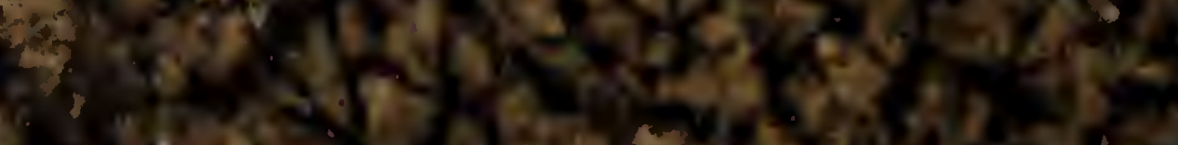

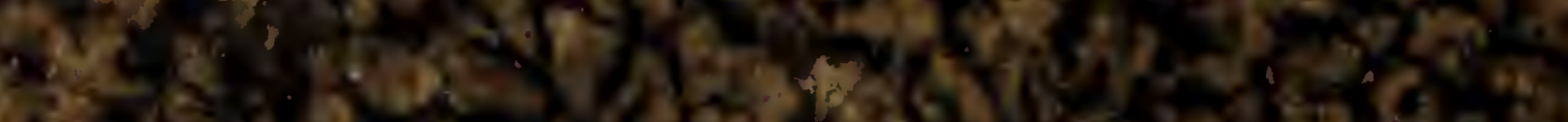

ide

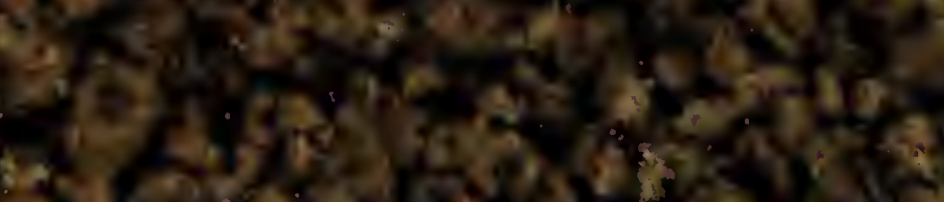

25.

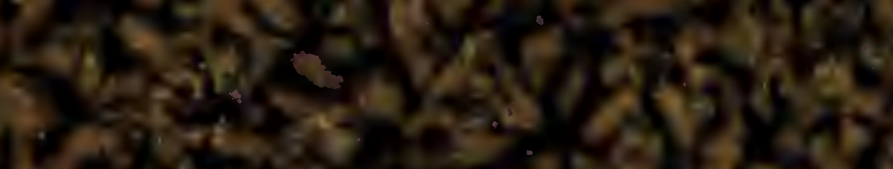

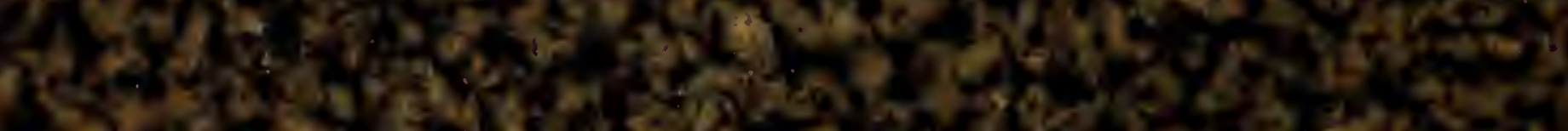

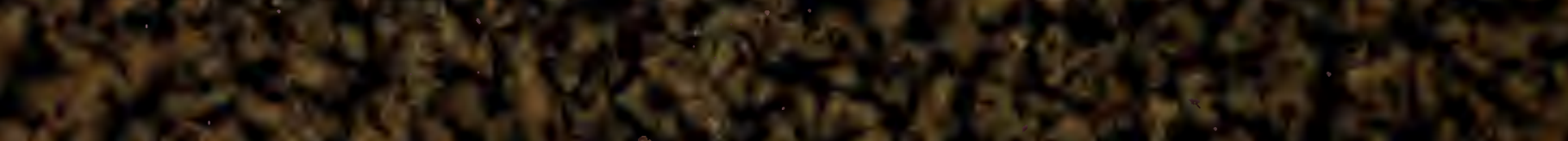

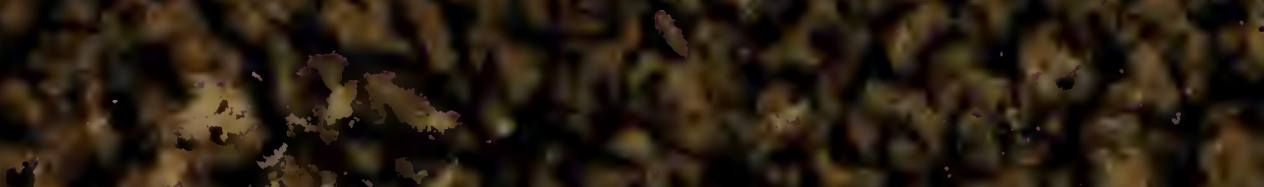

y.

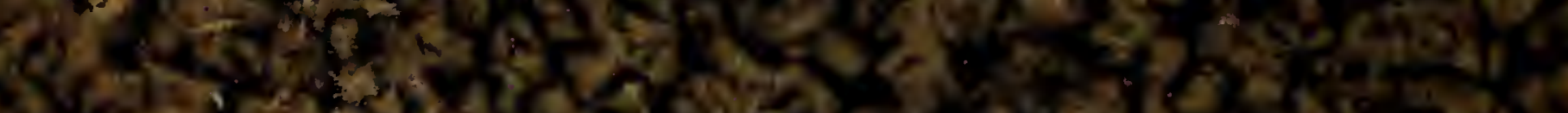

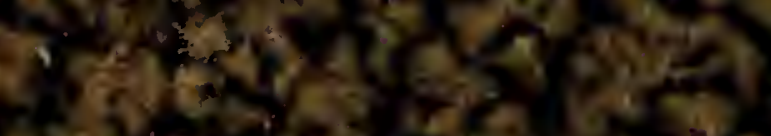

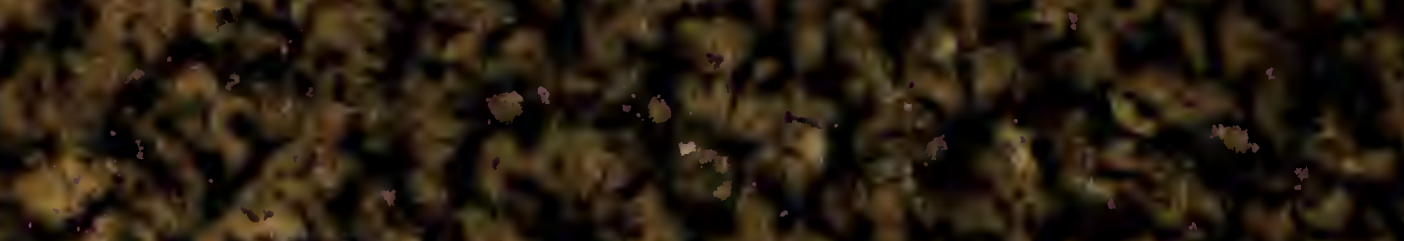

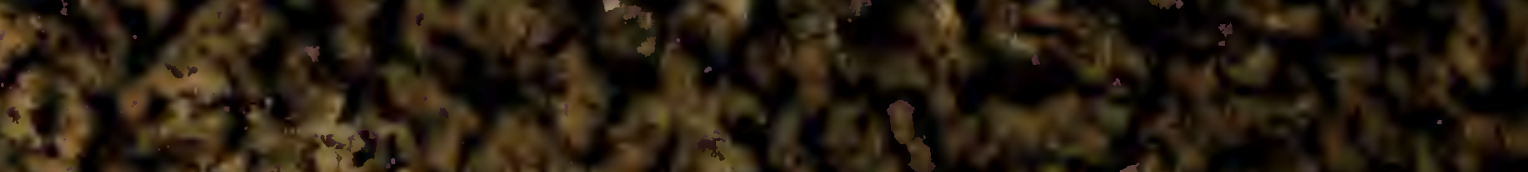

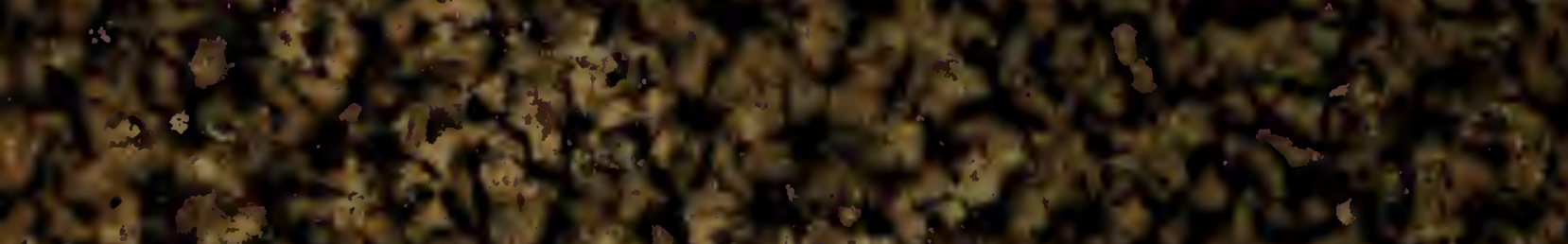

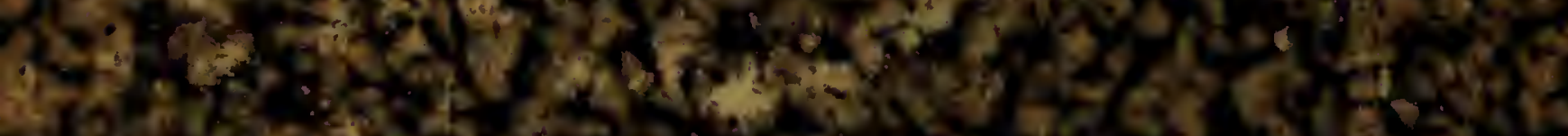

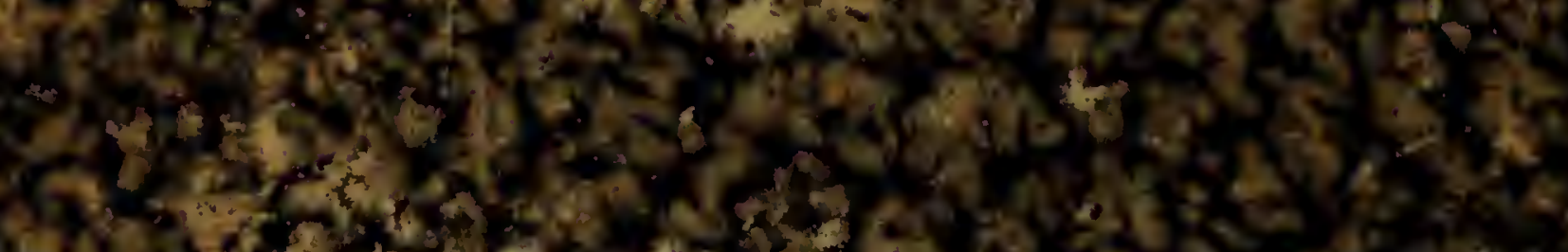

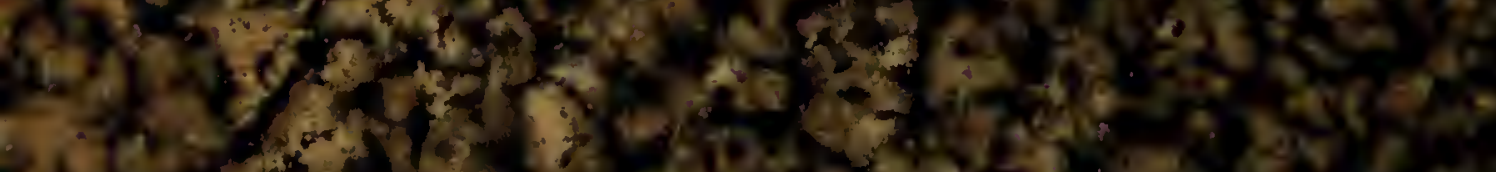

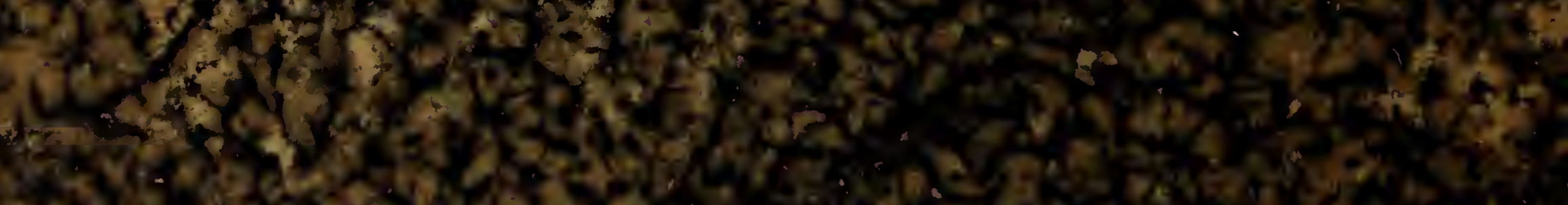

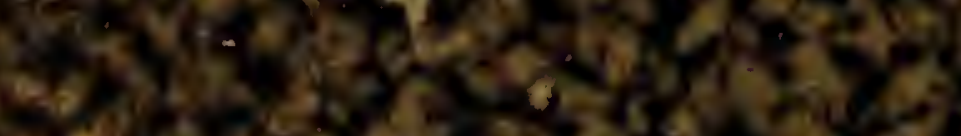

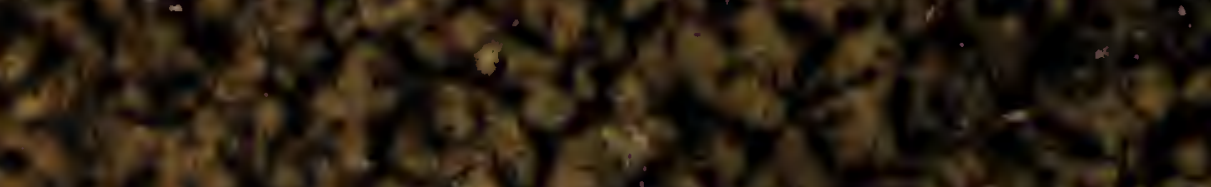

